\title{
WestVirginiaUniversity
}

THE RESEARCH REPOSITORY @ WVU

Graduate Theses, Dissertations, and Problem Reports

2008

\section{Modeling of particle trajectories of coal size and density fractions in a gasifier}

Andrew A. Slezak Jr.

West Virginia University

Follow this and additional works at: https://researchrepository.wvu.edu/etd

\section{Recommended Citation}

Slezak, Andrew A. Jr., "Modeling of particle trajectories of coal size and density fractions in a gasifier" (2008). Graduate Theses, Dissertations, and Problem Reports. 1989.

https://researchrepository.wvu.edu/etd/1989

This Thesis is protected by copyright and/or related rights. It has been brought to you by the The Research Repository @ WVU with permission from the rights-holder(s). You are free to use this Thesis in any way that is permitted by the copyright and related rights legislation that applies to your use. For other uses you must obtain permission from the rights-holder(s) directly, unless additional rights are indicated by a Creative Commons license in the record and/ or on the work itself. This Thesis has been accepted for inclusion in WVU Graduate Theses, Dissertations, and Problem Reports collection by an authorized administrator of The Research Repository @ WVU. For more information, please contact researchrepository@mail.wvu.edu. 


\title{
Modeling of Particle Trajectories of Coal Size and Density Fractions in a Gasifier
}

\author{
Andrew A. Slezak Jr. \\ Thesis submitted to the \\ College of Engineering and Mineral Resources \\ at West Virginia University \\ in partial fulfillment of the requirements \\ for the degree of \\ Master of Science \\ in \\ Mechanical Engineering \\ John Kuhlman, Ph.D., Chair \\ Eric Johnson, Ph.D. \\ Lawrence Shadle, Ph.D. \\ Chris Guenther, Ph.D. \\ Department of Mechanical and Aerospace Engineering \\ Morgantown, West Virginia \\ 2008
}

Keywords: Coal Combustion, Gasification, Entrained-flow Reactor, DPM, CFD, Coal Partitioning, Particle-wall Interactions, Coal Size/Density Fractions 


\section{Abstract \\ Modeling Particle Trajectories of Coal Size and Density Fractions in a Gasifier}

\section{Andrew A. Slezak Jr.}

A computational model of a generic commercial two-stage entrained-flow upflow coal gasifier has been used in the present work to aid the researchers of the coal partitioning project at the National Energy Technology Laboratory (NETL). Specifically, the level of variation in the predicted performance in a generic entrained-flow gasifier if both coal slurry density fractions as well as diameter fractions are properly modeled in the CFD simulation was determined.

Simulations were performed using the commercial computational fluid dynamics (CFD) software Fluent for a Pittsburgh \#8 Bailey coal to analyze fixed carbon conversion, exit gas volume fractions, and particle trajectory patterns. The computational simulation involved effects of flow turbulence, finite-rate chemistry, and solid-gas phase interactions. In order to represent the coal sample in a CFD code, two basic case setups were explored. The first used a Sauter-mean average diameter along with the overall mass average density of the 28 size/density fractions of the Bailey coal sample. Each surface injection was then treated with a uniform density and diameter distribution. The elemental composition of the parent coal was used in setting up the boundary conditions and volatile component distribution for the first case. The second case used 28 simultaneous injections on each surface, each of which assumed the average density of that particular fraction along with a uniform diameter distribution of the corresponding size class. The Ultimate and Proximate analysis of each fraction was determined and included in the setup of the particle compositions within the CFD model for the second case.

Two different devolatilization models were explored and the results were compared. Flow field characteristics such as center-plane velocity and temperature along with exit gas compositions were useful in judging the validity of the simulations as well as to compare predictions for the various chemistry models. Particle trajectory patterns were analyzed for coal feeds with varying initial diameter, density, and elemental composition.

One of the purposes of the coal partitioning project was to analyze fly ash mass flux and slag layer buildup in a commercial scale gasifier. With this in mind, different particle wall boundary conditions were explored and data was generated relating to the state of the particle when it impacts the reactor wall. Average impact velocity component normal to the wall, temperature, and char content of the impacting particle were recorded for flow fields obtained from case setups that used different injection profiles and devolatilization models.

Validation studies were performed against data taken from an experimental facility at SRI International. Results for three different experimental configurations were compared with predictions from Fluent. 


\section{Acknowledgements}

This project was a part of the DOE Gasification Technology Program, and was funded by the National Energy Technology Laboratory in Morgantown, WV, as a part of the University Research Initiative, specifically though the "Collaboratory for Multiphase Flow Research,” RDS Contracts No. 41817M2318 and 41817M2100.

I would like to thank the following people for their help during the course of this project:

John Kuhlman, Ph.D. - Provided guidance and support during the course of my graduate study at WVU. He was always patient and willing to give feedback and advice whenever I was in need of it.

Eric Johnson, Ph.D. - Committee member who gave expert advice on a subject that I am new to.

Lawrence Shadle, Ph.D. - Committee member who provided feedback and helped with analyzing results in a field that he is an expert in.

Chris Guenther, Ph.D. - Committee member who helped with editing the thesis and providing useful tips and information about computational modeling.

Esmail Monazam, Ph.D. - NETL researcher who provided encouragement and advice.

James Spenik, Ph.D. - NETL researcher who assisted me in interpreting results of CFD simulations and helped edit the thesis.

Paul Kreitzer - WVU graduate student who helped edit the final document and provided useful advice on how to write a thesis and present results in a professional format. 


\section{Table of Contents}

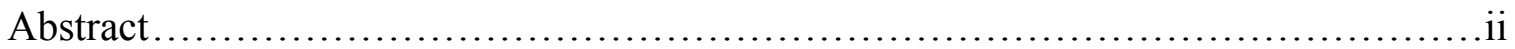

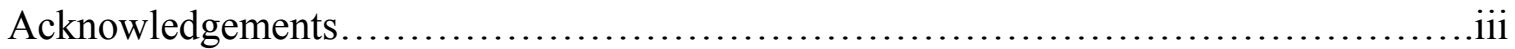

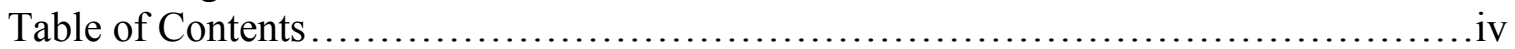

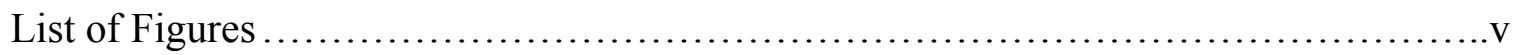

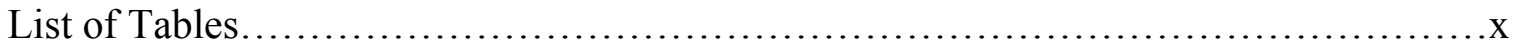

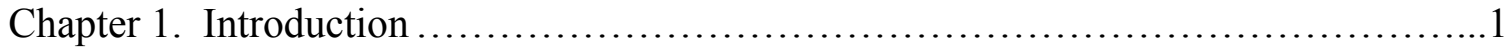

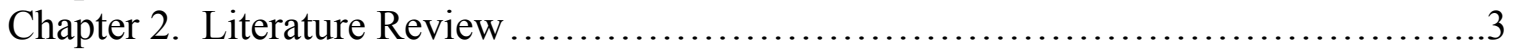

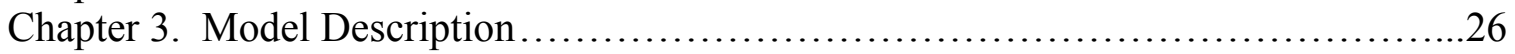

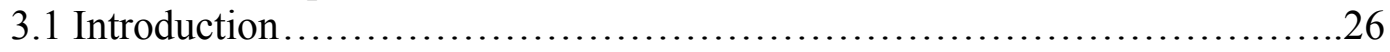

3.2 Pittsburgh \#8 Bailey Coal Properties .....................................26

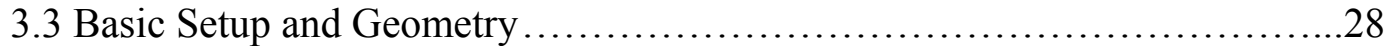

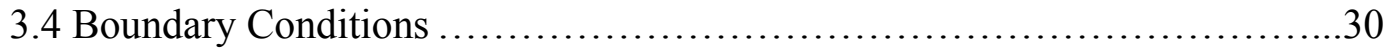

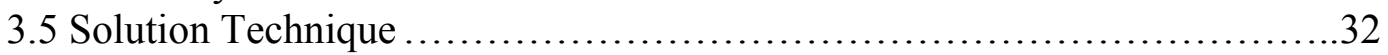

3.6 Devolatilization Models................................................ 33

3.7 Combustion and Gasification Chemistry ................................ 38

3.8. User Defined Functions .................................................. 41

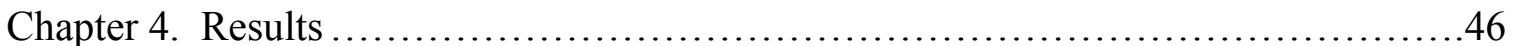

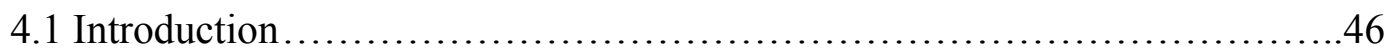

4.2 Comparison Between Single and Multiple Surface Injections ...............46

4.3 Comparison Between Devolatilization Models............................. 88

4.4 Grid Independence .................................................. 97

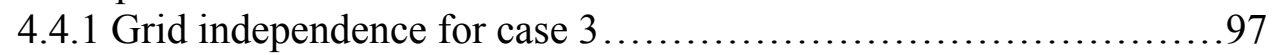

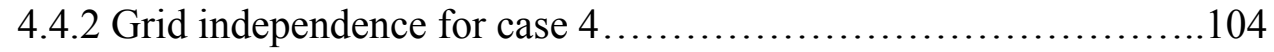

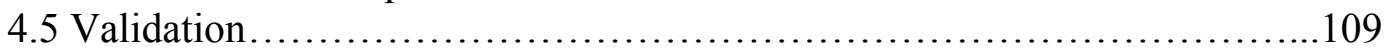

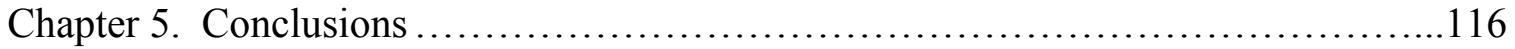

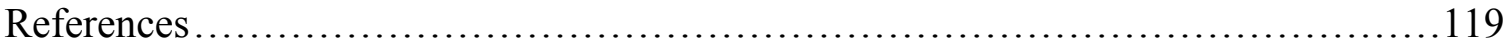

Appendix A. PC Coal Lab Output Reports........................................122

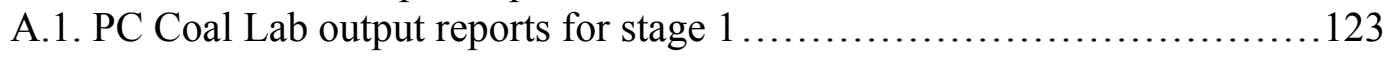

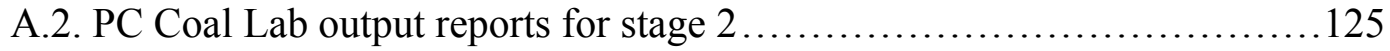

Appendix B. User Defined Function for Particle Wall Interaction ......................127

Appendix C. Particle Trajectories for Case 1, Case 2, Case 3, and Case 4 


\section{List of Figures}

Figure 2.1. Simple Gasification Chemistry......................................... 4

Figure 2.2. Schematic of the Different Reactor Types ...............................6

Figure 2.3. Typical Particle Trajectory thru a Control Volume...........................18

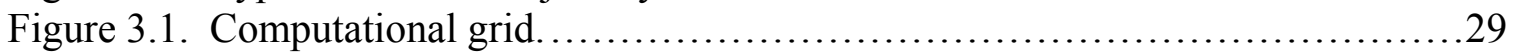

Figure 3.2. Particle temperature versus time. ...................................... 35

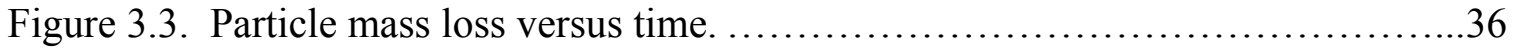

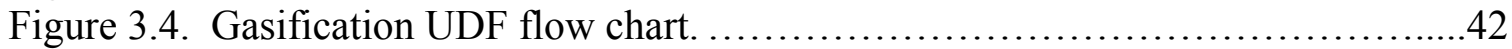

Figure 3.5. Impact angle definition.............................................. 45

Figure 4.1. Center-plane temperature contours.................................48

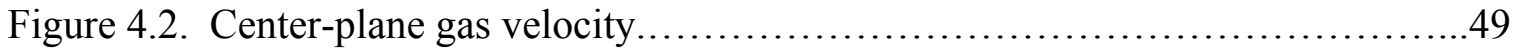

Figure 4.3. Center-plane gas contours................................................

Figure 4.4. Average gas mass fractions versus distance in stage 2 for Case $3 \ldots \ldots \ldots \ldots . .55$

Figure 4.5. Average gas mass fractions versus distance in stage 2 for Case $4 \ldots \ldots \ldots \ldots . .56$

Figure 4.6. Average particle mass loss versus distance in stage 2 (all injected). ........57

Figure 4.7. Average particle mass loss versus distance in stage 2 (stage 2 injection)....57

Figure 4.8. Average particle temperature versus distance in stage 2 (all injected)........58

Figure 4.9. Average particle temperature versus distance in stage 2 (stage 2 injection)..58

Figure 4.10. Fixed carbon conversion (all injections). ................................59

Figure 4.11. Fixed carbon conversion (stage 2 injection)..........................60

Figure 4.12. Average particle residence time (all injections). .......................60

Figure 4.13. Average particle residence time (stage 2 injection)....................61

Figure 4.14. Impact velocity normal to the wall versus axial location in second stage for density class SG1. Particles injected from both left and right

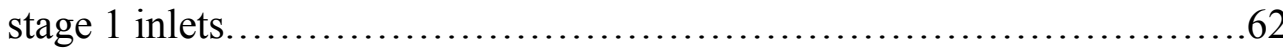

Figure 4.15. Impact velocity normal to the wall versus axial location in second stage for density class SG2. Particles injected from both left and right stage 1 inlets.

Figure 4.16. Impact velocity normal to the wall versus axial location in second stage for density class SG3. Particles injected from both left and right stage 1 inlets.

Figure 4.17. Impact velocity normal to the wall versus axial location in second stage for density class SG4. Particles injected from both left and right

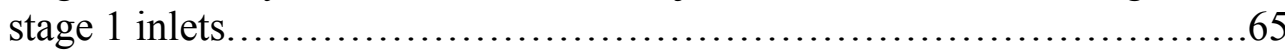

Figure 4.18. Impact velocity normal to the wall versus axial location in second stage for density class SG1. Particles injected from stage 2 inlet...........66

Figure 4.19. Impact velocity normal to the wall versus axial location in second stage for density class SG2. Particles injected from stage 2 inlet..

Figure 4.20. Impact velocity normal to the wall versus axial location in second stage for density class SG3. Particles injected from stage 2 inlet............68

Figure 4.21. Impact velocity normal to the wall versus axial location in second stage for density class SG4. Particles injected from stage 2 inlet.

Figure 4.22. Impact angle versus axial location in second stage for particles injected

from stage 1 right and left inlets .....................................70

Figure 4.23. Impact angle versus axial location in second stage for particles injected 


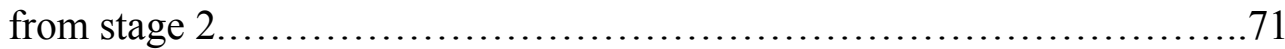

Figure 4.24. Impact temperature versus axial location in second stage for particles injected from stage 1 right and left inlets.............................72

Figure 4.25. Impact temperature versus axial location in second stage for particles

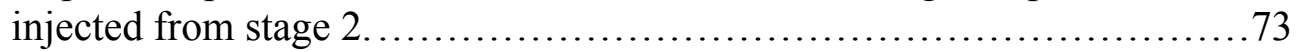

Figure 4.26. Impact char content versus axial location in second stage for particles

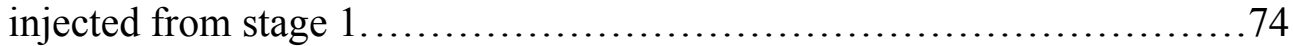

Figure 4.27. Impact char content versus axial location in second stage for particles injected from stage 2 .............................................. 75

Figure 4.28. Impact probability versus second stage distance for 28 size/density fractions. Particles injected from stage 1 and stage $2 \ldots \ldots \ldots \ldots \ldots \ldots \ldots . \ldots . \ldots . \ldots . \ldots$

Figure 4.29. Impact probability versus second stage distance for 28 size/density fractions. Particles injected from stage 2 only.

Figure 4.30. Impact probability versus second stage distance for Sauter-mean diameter and composite average density. Particles injected from stage 1

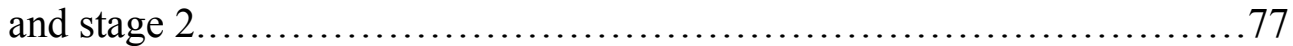

Figure 4.31. Impact probability versus second stage distance for Sauter-mean diameter and composite average density. Particles injected from stage 2

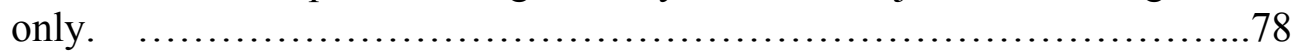

Figure 4.32. Percent of particles that escape allowing 1 impact.......................78

Figure 4.33. Contours of collision frequency for Sauter-mean diameter and composite average density. Particles impact once and then stick............80

Figure 4.34. Contours of collision frequency for Sauter-mean diameter and composite average density. Particles impact 10 times and then stick........80

Figure 4.35. Contours of collision frequency for Sauter-mean diameter and composite average density. Unlimited impacts............................81

Figure 4.36. Contours of mass flux for Sauter-mean diameter and composite average density. Particles impact once and then stick.

Figure 4.37. Contours of mass flux for Sauter-mean diameter and composite average density. Particles impact ten times and then stick.......................82

Figure 4.38. Contours of mass flux for density/size class SG1PS7. Particles impact once and then stick.

Figure 4.39. Contours of mass flux for density/size class SG1PS7. Particles impact ten times and then stick............................................ 83

Figure 4.40. Contours of mass flux for density/size class SG3PS1. Particles impact once and then stick.

Figure 4.41. Contours of mass flux for density/size class SG3PS1. Particles impact ten times and then stick.

Figure 4.42. Case 1 particle tracks for Bailey coal for first stage injection of specific gravity cut \#1 $(\mathrm{SG}=1.2)$, for particle size cuts \#7 $(50 \mu \mathrm{m})$ through \#1 $(800 \mu \mathrm{m})$

Figure 4.43. Case 4 particle tracks for Bailey coal for first stage injection of specific gravity cut \#4 ( $\mathrm{SG}=3.3)$, for particle size cuts \#7 $(50 \mu \mathrm{m})$ through \#1 $(800 \mu \mathrm{m})$.

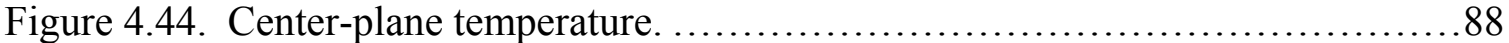

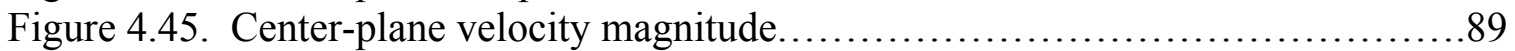


Figure 4.46. Center-plane velocity vectors. .................................... 89

Figure 4.47. Center-plane gas mole fractions. ................................. 90

Figure 4.48. Exit gas volume fractions. ......................................... 91

Figure 4.49. Average gas mass fractions versus distance in stage $2 \ldots \ldots \ldots \ldots \ldots \ldots \ldots . . . . .92$

Figure 4.50. Average particle mass loss versus distance in stage 2 (all injected) ........93

Figure 4.51. Average particle mass loss versus distance in stage 2 (stage 2 injection)...93

Figure 4.52. Average particle temperature versus distance in stage 2 (all injected)......94

Figure 4.53. Average particle temperature versus distance in stage 2

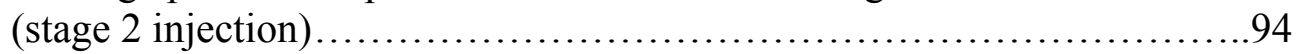

Figure 4.54. Sample particle trajectories. ..................................... 96

Figure 4.55. Computational mesh for each grid density. ...........................97

Figure 4.56. Center-plane gas mole fractions. .................................. 98

Figure 4.57. Exit gas compositions for 12,256, 20,061, 28,264, and 40,112 elements. .101

Figure 4.58. Center-plane gas temperature................................. 102

Figure 4.59. Gas and wall temperatures for 12,256, 20,061, 28,264,

and 40,112 elements................................................ 102

Figure 4.60. Normal impact velocities for 12,256 and 40,112 cells..................103

Figure 4.61. Center-plane gas mole fractions. .................................. 105

Figure 4.62. Exit gas compositions for 12,256 and 40,112 elements. ................. 106

Figure 4.63. Center-plane gas temperature................................... 107

Figure 4.64. Gas and wall temperatures for 12,256 and 40,112 elements...............107

Figure 4.65. Normal impact velocities for 12,256 and 40,112 cells.................... 108

Figure 4.66. Schematic of SRI facility. ...................................... 110

Figure 4.67. Computational model of SRI facility. ............................. 110

Figure 4.68. Wall temperature profile........................................... 111

Figure 4.69. Computed center-line gas temperature................................ 112

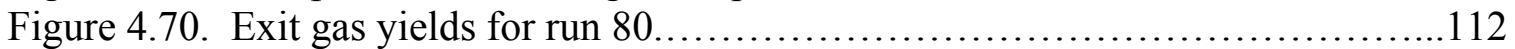

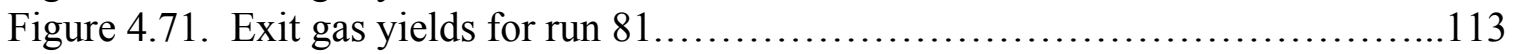

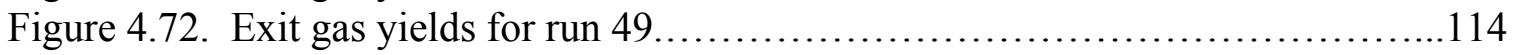

Figure C.1. Case 1 particle tracks for Bailey coal for first stage injection of specific gravity cut \#1 $(\mathrm{SG}=1.2)$, for particle size cuts \#7 $(50 \mu \mathrm{m})$ through \#1 $(800 \mu \mathrm{m})$.

Figure C.2. Case 1 particle tracks for Bailey coal for first stage injection of specific gravity cut \#2 $(\mathrm{SG}=1.4)$, for particle size cuts \#7 $(50 \mu \mathrm{m})$ through \#1 $(800 \mu \mathrm{m})$

Figure C.3. Case 1 particle tracks for Bailey coal for first stage injection of specific gravity cut \#3 $(\mathrm{SG}=2.1)$, for particle size cuts \#7 $(50 \mu \mathrm{m})$ through \#1 $(800 \mu \mathrm{m})$.

Figure C.4. Case 1 particle tracks for Bailey coal for first stage injection of specific gravity cut \#4 (SG = 3.3), for particle size cuts \#7 (50 $\mu \mathrm{m})$ through \#1 $(800 \mu \mathrm{m})$

Figure C.5. Case 1 particle tracks for Bailey coal for second stage injection of specific gravity cut \#1 $(\mathrm{SG}=1.2)$, for particle size cuts \#7 $(50 \mu \mathrm{m})$ through \#1 $(800 \mu \mathrm{m})$

Figure C.6. Case 1 particle tracks for Bailey coal for second stage injection of specific gravity cut \#2 $(\mathrm{SG}=1.4)$, for particle size cuts \#7 $(50 \mu \mathrm{m})$ 
through \#1 $(800 \mu \mathrm{m})$.

Figure C.7. Case 1 particle tracks for Bailey coal for second stage injection of specific gravity cut \#3 $(\mathrm{SG}=2.1)$, for particle size cuts \#7 $(50 \mu \mathrm{m})$ through \#1 $(800 \mu \mathrm{m})$.

Figure C.8. Case 1 particle tracks for Bailey coal for second stage injection of specific gravity cut \#4 $(\mathrm{SG}=3.3)$, for particle size cuts \#7 $(50 \mu \mathrm{m})$ through \#1 $(800 \mu \mathrm{m})$.

Figure C.9. Case 2 particle tracks for Bailey coal for first stage injection of specific gravity cut \#1 $(\mathrm{SG}=1.2)$, for particle size cuts \#7 $(50 \mu \mathrm{m})$ through \#1 $(800 \mu \mathrm{m})$.

Figure C.10. Case 2 particle tracks for Bailey coal for first stage injection of specific gravity cut \#2 $(\mathrm{SG}=1.4)$, for particle size cuts \#7 $(50 \mu \mathrm{m})$ through \#1 $(800 \mu \mathrm{m})$.

Figure C.11. Case 2 particle tracks for Bailey coal for first stage injection of specific gravity cut \#3 $(\mathrm{SG}=2.1)$, for particle size cuts \#7 $(50 \mu \mathrm{m})$ through \#1 $(800 \mu \mathrm{m})$.

Figure C.12. Case 2 particle tracks for Bailey coal for first stage injection of specific gravity cut \#4 $(\mathrm{SG}=3.3)$, for particle size cuts \#7 $(50 \mu \mathrm{m})$ through \#1 $(800 \mu \mathrm{m})$.

Figure C.13. Case 2 particle tracks for Bailey coal for second stage injection of specific gravity cut \#1 $(\mathrm{SG}=1.2)$, for particle size cuts \#7 $(50 \mu \mathrm{m})$ through \#1 $(800 \mu \mathrm{m})$.

Figure C.14. Case 2 particle tracks for Bailey coal for second stage injection of specific gravity cut \#2 $(\mathrm{SG}=1.4)$, for particle size cuts \#7 $(50 \mu \mathrm{m})$ through \#1 $(800 \mu \mathrm{m})$.

Figure C.15. Case 2 particle tracks for Bailey coal for second stage injection of specific gravity cut \#3 $(\mathrm{SG}=2.1)$, for particle size cuts \#7 $(50 \mu \mathrm{m})$ through \#1 $(800 \mu \mathrm{m})$.

Figure C.16. Case 2 particle tracks for Bailey coal for second stage injection of specific gravity cut \#4 $(\mathrm{SG}=3.3)$, for particle size cuts \#7 $(50 \mu \mathrm{m})$ through \#1 $(800 \mu \mathrm{m})$.

Figure C.17. Case 3 particle tracks for Bailey coal for first stage injection of specific gravity cut \#1 $(\mathrm{SG}=1.2)$, for particle size cuts \#7 $(50 \mu \mathrm{m})$ through \#1 $(800 \mu \mathrm{m})$.

Figure C.18. Case 3 particle tracks for Bailey coal for first stage injection of specific gravity cut \#2 $(\mathrm{SG}=1.4)$, for particle size cuts \#7 $(50 \mu \mathrm{m})$ through \#1 $(800 \mu \mathrm{m})$.

Figure C.19. Case 3 particle tracks for Bailey coal for first stage injection of specific gravity cut \#3 $(\mathrm{SG}=2.1)$, for particle size cuts \#7 $(50 \mu \mathrm{m})$ through \#1 $(800 \mu \mathrm{m})$.

Figure C.20. Case 3 particle tracks for Bailey coal for first stage injection of specific gravity cut $\# 4(\mathrm{SG}=3.3)$, for particle size cuts \#7 $(50 \mu \mathrm{m})$ through \#1 $(800 \mu \mathrm{m})$.

Figure C.21. Case 3 particle tracks for Bailey coal for second stage injection of specific gravity cut $\# 1(\mathrm{SG}=1.2)$, for particle size cuts \#7 $(50 \mu \mathrm{m})$ through \#1 $(800 \mu \mathrm{m})$. 
Figure C.22. Case 3 particle tracks for Bailey coal for second stage injection of specific gravity cut \#2 $(\mathrm{SG}=1.4)$, for particle size cuts \#7 $(50 \mu \mathrm{m})$ through \#1 $(800 \mu \mathrm{m})$.

Figure C.23. Case 3 particle tracks for Bailey coal for second stage injection of specific gravity cut \#3 $(\mathrm{SG}=2.1)$, for particle size cuts \#7 $(50 \mu \mathrm{m})$ through \#1 $(800 \mu \mathrm{m})$.

Figure C.24. Case 3 particle tracks for Bailey coal for second stage injection of specific gravity cut \#4 $(\mathrm{SG}=3.3)$, for particle size cuts \#7 $(50 \mu \mathrm{m})$ through \#1 $(800 \mu \mathrm{m})$.

Figure C.25. Case 4 particle tracks for Bailey coal for first stage injection of specific gravity cut \#1 $(\mathrm{SG}=1.2)$, for particle size cuts \#7 $(50 \mu \mathrm{m})$ through \#1 $(800 \mu \mathrm{m})$.

Figure C.26. Case 4 particle tracks for Bailey coal for first stage injection of specific gravity cut $\# 2(\mathrm{SG}=1.4)$, for particle size cuts \#7 $(50 \mu \mathrm{m})$ through \#1 $(800 \mu \mathrm{m})$.

Figure C.27. Case 4 particle tracks for Bailey coal for first stage injection of specific gravity cut \#3 $(\mathrm{SG}=2.1)$, for particle size cuts \#7 $(50 \mu \mathrm{m})$ through \#1 $(800 \mu \mathrm{m})$.

Figure C.28. Case 4 particle tracks for Bailey coal for first stage injection of specific gravity cut \#4 $(\mathrm{SG}=3.3)$, for particle size cuts \#7 $(50 \mu \mathrm{m})$ through \#1 $(800 \mu \mathrm{m})$.

Figure C.29. Case 4 particle tracks for Bailey coal for second stage injection of specific gravity cut \#1 $(\mathrm{SG}=1.2)$, for particle size cuts \#7 $(50 \mu \mathrm{m})$ through \#1 $(800 \mu \mathrm{m})$.

Figure C.30. Case 4 particle tracks for Bailey coal for second stage injection of specific gravity cut \#2 $(\mathrm{SG}=1.4)$, for particle size cuts \#7 $(50 \mu \mathrm{m})$ through \#1 $(800 \mu \mathrm{m})$.

Figure C.31. Case 4 particle tracks for Bailey coal for second stage injection of specific gravity cut \#3 $(\mathrm{SG}=2.1)$, for particle size cuts \#7 $(50 \mu \mathrm{m})$ through \#1 $(800 \mu \mathrm{m})$.

Figure C.32. Case 2 particle tracks for Bailey coal for second stage injection of specific gravity cut $\# 4(\mathrm{SG}=3.3)$, for particle size cuts \#7 $(50 \mu \mathrm{m})$ through \#1 (800 $\mu \mathrm{m})$. 


\section{List of Tables}

Table 2.1 Exit Mole Fractions from Simulations by Shi et al. [3] ......................25

Table 3.1. Ultimate and Proximate Analysis of Pitt. \#8 Bailey parent coal. .............26

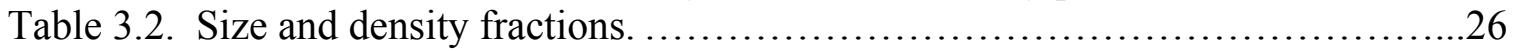

Table 3.3. Ultimate and Proximate Analysis of 28 size/density cuts.....................27

Table 3.4. Case file setup........................................................ 30

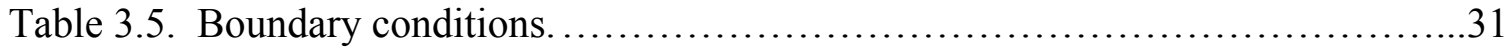

Table 3.6. Ratio of inlet gas to carbon in the fuel injection (as received). ................32

Table 3.7 Predicted secondary pyrolysis distribution from PC Coal Lab.................35

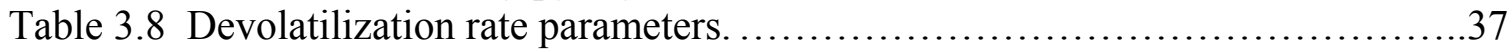

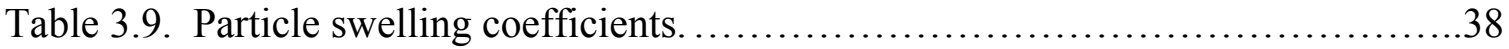

Table 3.10. Kinetic parameters.................................................... 40

Table 4.1. Definitions for particle diameter, $C_{p}, k$, and $\mu$ for cases $1-4 \ldots \ldots \ldots \ldots \ldots . \ldots 4$

Table 4.2. Average temperatures and fixed carbon conversion for cases $1-4 \ldots \ldots \ldots \ldots .50$

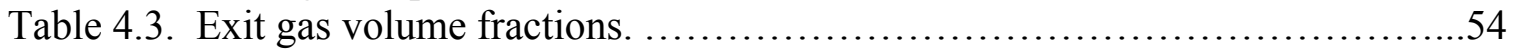

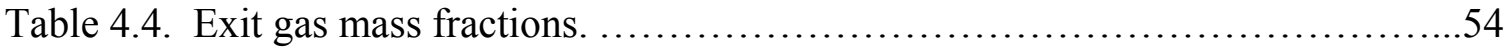

Table 4.5. Gas and wall temperature, fixed carbon conversion, and exit volume percentages........................................................ 95

Table 4.6. Operating conditions for SG2PS5 sample runs.........................111 


\section{Chapter 1. Introduction}

Coal is the United State's most abundant fossil resource [1]. The use of coal is important in providing energy and chemicals for our growing economy. Coal has been in use as a fuel for many years throughout the world, and is currently being studied to develop cost-effective ways of more efficiently and cleanly deriving energy and fuel gas from the coal. Coal gasification is a process currently under development for use in the Integrated Gasification Combined Cycle power generation plant, in order to achieve increased overall cycle efficiency.

A computational model of a generic commercial two-stage entrained-flow upflow coal gasifier was used to aid the researchers of the coal partitioning project during the course of this study. Simulations were performed using the commercial Computational Fluid Dynamics (CFD) software Fluent for a Pittsburgh \#8 Bailey coal to analyze fixed carbon conversion and exit gas volume fractions. The computational simulation involved effects of flow turbulence, finite-rate chemistry, and solid-gas phase interactions. In order to determine the variation in predicted gasifier performance with different injection profiles, several steps were taken. The composition of the Bailey coal particles, which had been partitioned into 28 size/density fractions, was incorporated into the CFD Discrete Phase Model (DPM). Coal particles were injected as discrete particle streams into the continuous phase domain and tracked in a Lagrangian frame of reference. Each particle would follow a series of laws governing inert heating, moisture release, devolatilization, and combustion and gasification. In order to represent the coal sample in a CFD code, two basic case setups were explored. The first used a Sautermean average diameter along with the overall mass average density of the 28 size/density 
fractions of the Bailey coal sample. Each surface injection was then treated with a uniform diameter distribution. The elemental composition of the parent coal was used in setting up the boundary conditions and volatile component distribution for the first case. The second case used 28 simultaneous injections on each surface, each of which assumed a density of that particular fraction along with a uniform diameter distribution of the corresponding size class. The Ultimate and Proximate analysis of each fraction was determined and included in the setup of the particle compositions within the CFD model for the second case.

Two different devolatilization models were explored and the results were compared. Flow field characteristics such as center-plane velocity and temperature along with exit gas compositions were useful in determining the validity of the simulation as well as to compare predictions for the various chemistry models.

One of the purposes of the coal partitioning project was to analyze fly ash mass flux and slag layer buildup in a commercial scale gasifier. With this in mind, postprocessing capability was developed to analyze particle-wall interactions. Different particle wall boundary conditions were explored and data was generated relating to the state of the particle when it impacts the reactor wall. Average impact velocity component normal to the wall, temperature, and char content of the impacting particle were among the various quantities of interest. 


\section{Chapter 2. Literature Review}

Coal can be thought of as consisting of four major components. These components are the volatile matter, moisture content, fixed carbon, and ash. A pulverized coal particle experiencing typical heating rates in a reactor will first release its moisture content, then undergo pyrolysis, releasing its volatile content, and then the remaining char will oxidize and combust, primarily producing carbon monoxide and carbon dioxide. The consequence of pyrolysis will result in a mixture of gases, consisting mostly of tars and hydrocarbons [2]. Extensive research is under way with the aim of predicting these gas product distributions based on the initial composition of the coal.

In the presence of hydrogen, carbon dioxide, and/or steam, the char may gasify, resulting in a mixture consisting primarily of methane, hydrogen, steam, and carbon monoxide, given that the appropriate conditions are present. The processes of moisture release, pyrolysis, and combustion/gasification is represented schematically in Figure 2.1, adapted from Shi et al. [3]. This gasification process and it's implementation is the main focus of the literature reviewed throughout this chapter. Various types of gasification systems have been researched extensively throughout the recent past. This is mostly due to increased dependence on foreign oil supply in the United States, as well as environmental concerns arising from complete combustion of coal feeds and the carbon dioxide emissions that are produced. 


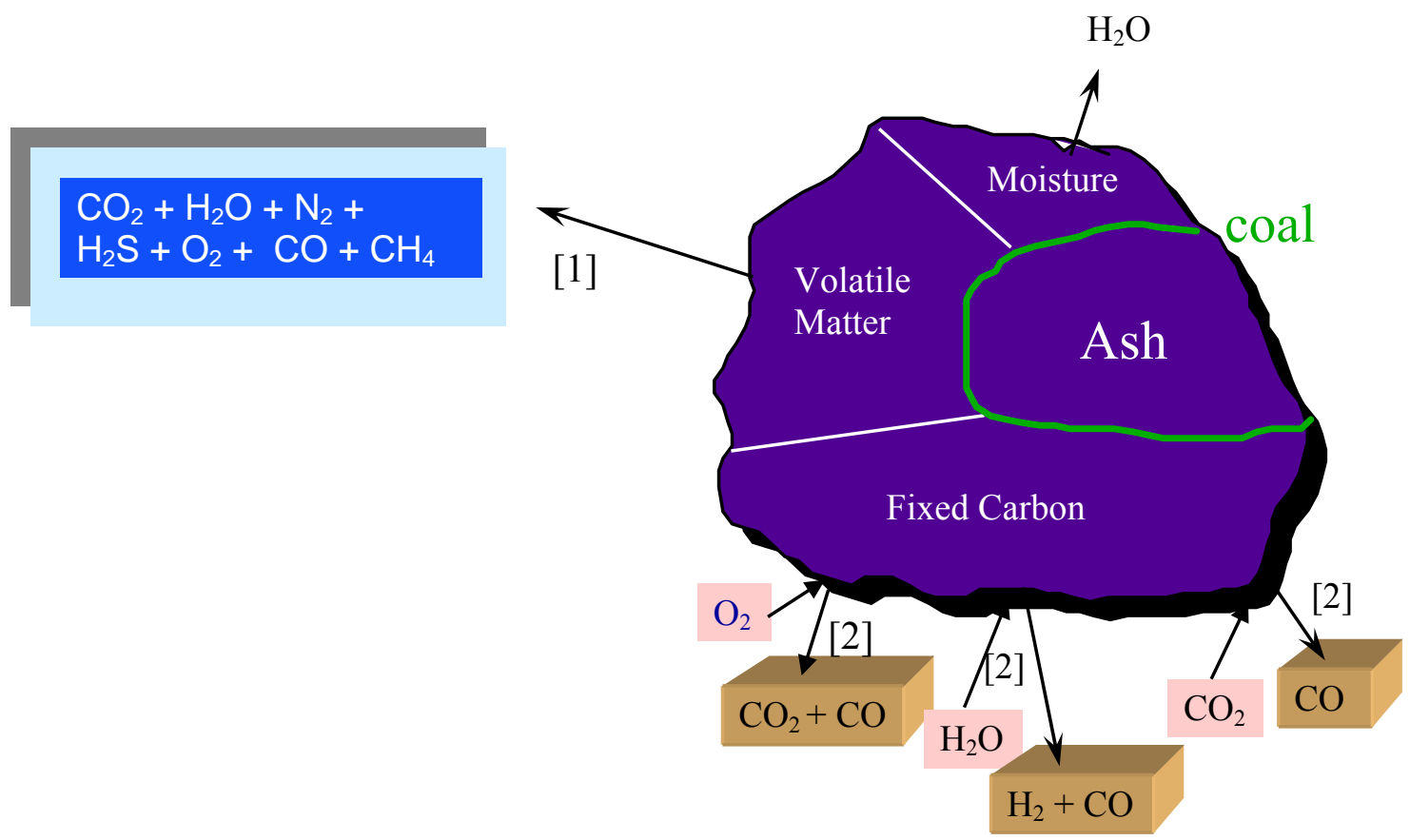

Figure 2.1. Simple Gasification Chemistry [3].

Technology is needed to develop new and efficient power plants that will utilize our own coal supply to produce energy cleanly and efficiently throughout the country, and thus reduce our dependence on imported oil. One way to utilize our coal supply cleanly is to gasify the coal to produce synthetic gases such as carbon monoxide, hydrogen, and methane while also capturing and storing carbon dioxide emissions $\left(\mathrm{CO}_{2}\right.$ sequestration). Coal gasification is an old technology dating back to the late seventeen hundreds. William Murdock (England, 1792) is purported to be the first person to gasify coal to utilize the derived gases [4]. By the mid eighteen hundreds, over fifty commercial gasification plants where in operation in the United States [4]. By 1930, over 11,000 plants were consuming approximately 12 million tons per year of coal in the United States and producing over 500 billion BTU per day of coal-derived gases (equivalent to 85,000 barrels per day of crude oil) [4]. The technology began with the moving-bed 
gasifier which operated at atmospheric pressure to react coal with air and steam. The heating value of the product gas could be increased by first blowing air over the movingbed gasifier to heat the coal, followed by steam to gasify it. This process was further improved with the addition of oil to the steam blowing cycle to increase the heating value of the coal resulting in the production of town gas (a coal-derived gas to supply lighting and/or heating) [4].

Although many different gasification processes have been developed and improved over time, every process requires one of three generic reactor types. These reactor types can be listed as moving-bed, fluidized-bed, or entrained-flow, and are represented schematically in Figure 2.2.

In moving-bed (or fixed-bed) reactors, a series of countercurrent reactions causes large coal particles to move down through the bed while reacting with gases moving up through the bed. Characteristics of moving-bed reactors include high thermal efficiency, low oxidant requirements, high methane content in the exit gas, production of tars and oils, limited ability to handle fines, and special requirements for handling caking coal [4]. The Lurgi dry ash gasifier is an example of a moving-bed type reactor design.

In fluidized-bed reactors, incoming coal particles mix well with coal particles already undergoing gasification [4]. The coal particles that break down in size during gasification get entrained with the hot gases leaving the reactor and must be separated from the gas using cyclones and barrier filters. After being cooled by incoming steam and recycle gas, the ash particles are removed from the bottom of the bed. 


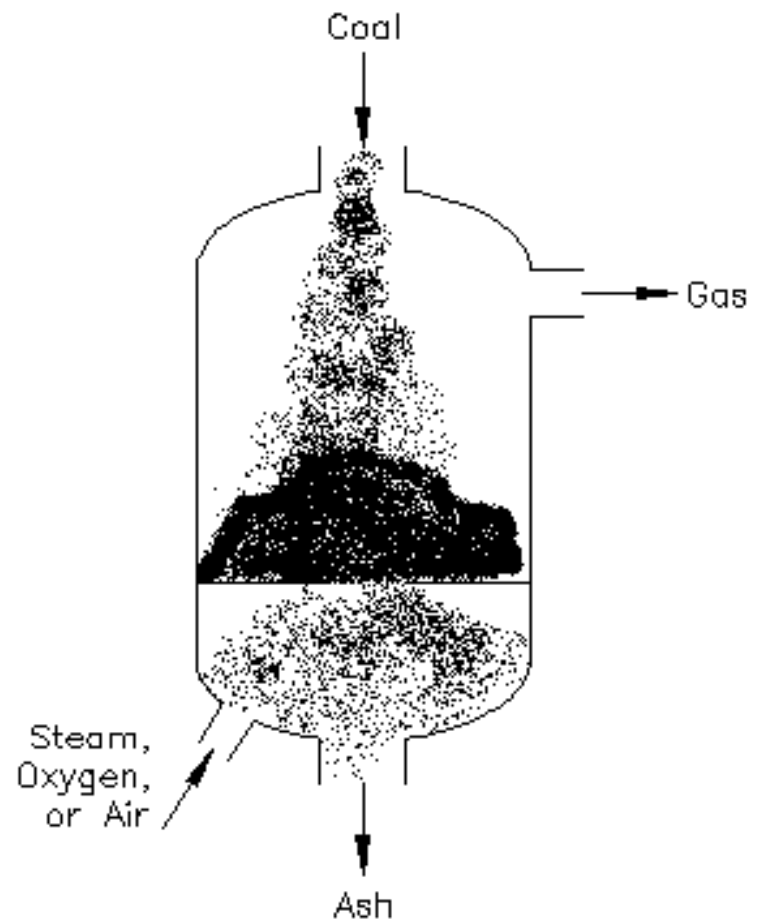

A. Moving-Bed

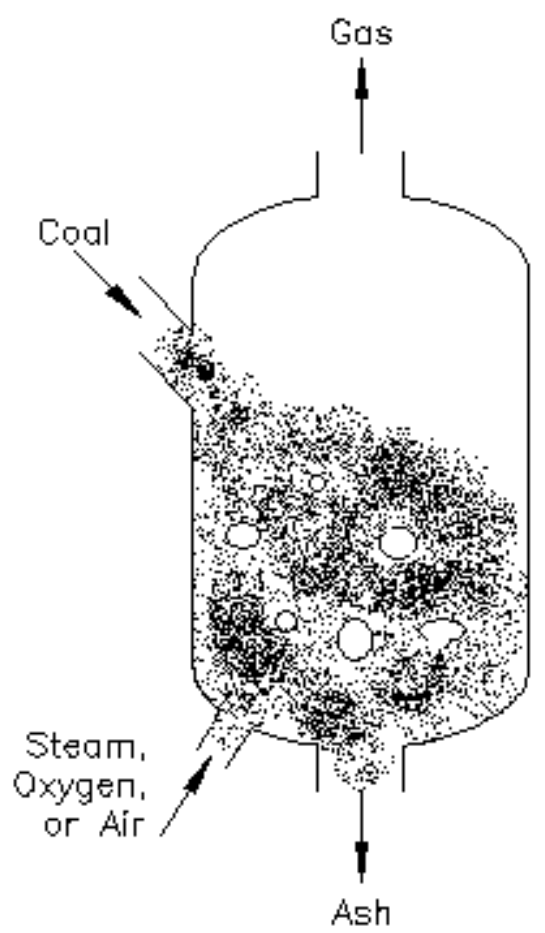

B. Fluidized-Bed

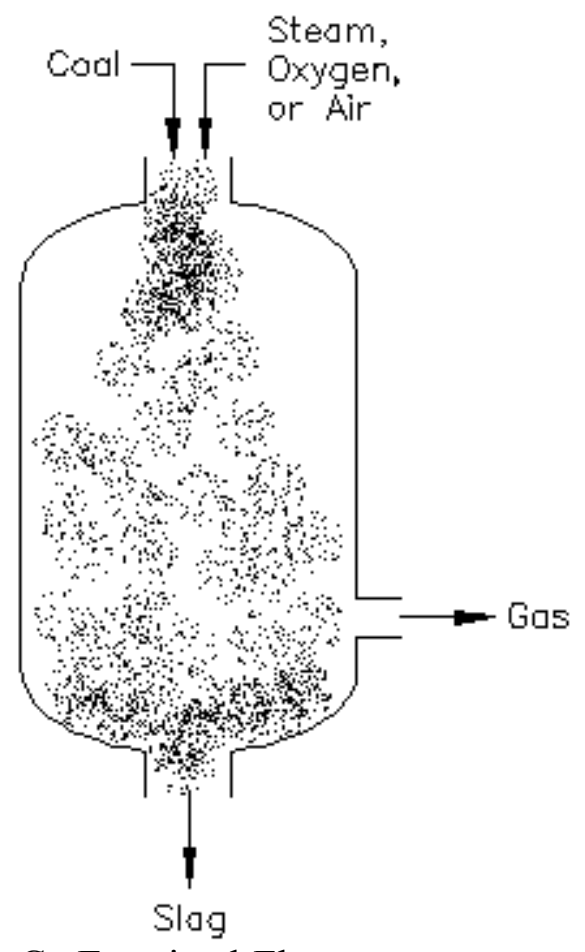

C. Entrained-Flow

Figure 2.2. Schematic of the Different Reactor Types [4]. 
Characteristics of fluidized-bed reactors include extensive char recycling, uniform and moderate temperatures along with moderate oxygen and steam requirements [4]. The High-Temperature Winkler gasification process is an example of a fluidized-bed reactor.

In entrained-flow reactors, fine coal particles react concurrently with steam and oxygen over relatively short periods of time. Due to the short residence times, high temperatures are typical in the operation of entrained-flow reactors, in order to ensure high carbon conversion. Some common characteristic of entrained-flow gasifiers include high temperature slagging operation, entrainment of molten slag in the raw gas, large oxidant requirements, large sensible heat in the raw gas, and the ability to gasify all coals effectively without regard to rank [4]. The GE gasifier is an example of an entrainedflow reactor.

The focus of this thesis will be on CFD modeling of coal gasification and combustion in entrained-flow reactors. The following review covers representative developments in CFD modeling of coal and biomass gasification. The literature reviewed provides information regarding advantages and disadvantages of some common reactor types as well as typical problems that usually occur in their operation, but focuses more heavily on previous work on the CFD modeling of entrained-flow gasifiers.

The development of molten-bath type gasifiers (a derivative of fixed-bed gasifiers) to overcome some disadvantages of conventional gas-solid reactors is discussed in reference [5]. Some advantages of molten-bath gasifiers identified include high temperature operation, which helps sustain fast reaction rates, and sulphur retainment in the slag, which helps prevent formation of gaseous pollutants. In [5], a CFD model was developed to study the flow patterns in a pilot scale molten bath gasifier. The model 
treated the feed mixture consisting of oxidizer, coal, and nitrogen as a dispersed phase of bubbles which exchange heat, mass, and momentum as they move around through the continuous phase representing the molten slag. The equations governing the continuous phase were the standard Reynolds-averaged Navier-Stokes equations for transport of mass and heat coupled with the standard k- $\varepsilon$ model for turbulence. These equations were discretized on a 3D grid containing 27,648 hexahedral cells representing the cylindrical reactor and solved with the commercial CFD software, Fluent 4 . The bubbles were tracked in a Lagrangian reference frame and the force balance was solved numerically to yield the bubble velocity and position at discrete locations throughout the continuum. The initial conditions at the nozzle injection were considered to be of the utmost importance in this study. Here, the bubble diameter, density, velocity, flow direction, and temperature had a substantial influence on the predicted flow field. The composition of the bubbles at the initial injection location contained coal grains, $\mathrm{O}_{2}$, and $\mathrm{N}_{2}$ gases [5]. The liquid slag mass composition consisted of $32 \% \mathrm{CaO}, 25 \% \mathrm{MgO}, 33 \% \mathrm{SiO}_{2}$, and $10 \% \mathrm{Al}_{2} \mathrm{O}_{3}$ [5]. During devolatilization, the main products were considered to consist mainly of $\mathrm{CH}_{4}$ and $\mathrm{CO}$, with neither tars or oils being formed [5]. Gasification was treated with an overall reaction governing the mass loss of carbonaceous material in the bubble. The model predictions for the product gas compositions obtained in [5] were found to be in good agreement with experimental results.

Ash-related problems in using woody-biomass fuels in the production of heat and electric power via fixed-bed type reactors is discussed in [6]. Some problems identified by the authors include the formation of ash deposits and slagging in furnaces as well as fouling and corrosion in boiler sections causing unscheduled shutdowns of power plants. 
In order to minimize these problems, this study aimed to improve the design of biomass gasifiers via a mathematical model. CFD simulations were performed with Fluent 6.1 to aid the development of a mathematical post-processing tool that was used to predict the formation of ash deposits in fixed-bed biomass fired combustion plants. The primary geometry of interest was for a pilot-scale low- $\mathrm{NO}_{\mathrm{x}}$ biomass grate furnace with a flame tube boiler. The CFD model was chosen to represent the furnace and flame tube portions of the plant with woody biomass as the fuel. The model developed in [6] accounts for the transport of ash-forming vapors and particles from the fuel bed to the gasifier surfaces. The ash layer build up was assumed to be a function of wall temperature, deposit porosity, and chemical composition. The model required results of a CFD combustion simulation which included the flue gas temperature, gas composition, flue gas velocity, and information concerning the flow turbulence in each cell of the combustion unit. The gas phase composition was determined through thermodynamic equilibrium calculations and combustion was simulated with the Eddy Dissipation Model in Fluent combined with a global three step reaction mechanism. Results of the CFD calculations showed that deposit formation in the primary combustion zone as well as flow-redirection zones was mainly influenced by coarse fly ash particle impaction. High wall temperatures prevented condensation of ash-forming vapors in the primary combustion zone [6]. The lower temperatures in the cooled flame tube promoted precipitation of all ash-forming vapors considered in this study. Contour plots were generated for the mass flux of the both the ash-forming vapors and ash particles to areas of interest in the furnace. Overall, it was determined that the qualitative results of this study agreed well with observations at operating combustion plants. 
The first experimental results of LCV fuel gas combustion obtained from fluidized-bed type gasification reactors were presented in [7] and [8]. Experiments were performed in [8] with the aim of assessing the feasibility of gasifying coal/biomass mixtures followed by the combustion of the derived LCV gases. To this end, two experiments were performed, one with coal and the other with coal/biomass mixture fed into the reactor. A CFD model was also developed in [7] to analyze the feasibility of utilizing biomass/coal derived gases. The results of the experiment were used to validate the numerical model. The combustor was modeled with a 2D axisymmetric geometry and meshed with 47,000 cells. The governing flow equations were discretized and solved using Fluent commercial CFD software to evaluate the temperature field, flow patterns, and species concentrations throughout the reactor. Flow field turbulence was governed by the k- $\varepsilon$ model. The chemistry model included 20 different species and the chemistryturbulence interaction was described by a presumed probability density function. The calculated gas temperature and composition at the centerline were compared with the experimental results and were found to be in good agreement. A main advantage of using biomass based fuels identified by the authors in [7] is the near-zero net $\mathrm{CO}_{2}$ addition to the atmosphere. This near-zero addition is explained through the reasoning that the biomass (in this study, straw) absorbs roughly the same amount of $\mathrm{CO}_{2}$ in growing as released when combusted. Other advantages in using biomass-based fuels identified in $[7,8]$ include the contribution to the restructuring of the agricultural sector, help in managing the waste problem, and help in the preservation of finite fossil fuel reserves.

The above studies were concerned with improving the design and operation of molten bath, fixed bed, and fluidized bed type reactors through addressing the common 
problems associated with each. CFD models were developed to aid in the visualization of ash formation on fixed-bed type reactor walls in [6]. In [5], the authors utilized CFD techniques to study the flow patterns in a molten bath gasifier. In [7] and [8], the first experimental results of using LCV derived fuel gases from fluidized-bed gasification processes were presented and analyzed with a CFD model of a gas-turbine combustor.

Now we can turn our attention to the main focus of this thesis, entrained-flow reactors. One of the main concerns in the operation of entrained-flow reactors is the buildup and removal of slag layers on refractory walls and downstream cooling sections. Other problem areas identified Bouma et al. [9] include the fate of the mineral matter in the coal, high and low temperature fouling, filter binding, and problematic fly-ash handling. To address these problems, Bouma et al. developed a CFD model to predict the temperature and composition of the gas in an oxygen-blown entrained-flow gasifier using the commercial CFD software CFX4.2. The computational results for the center axis temperature, $\mathrm{H}_{2}$, and $\mathrm{H}_{2} \mathrm{O}$ profiles generated from this model were compared with measurements taken at the Netherlands Energy Research Foundation's Atmospheric Entrained-Flow Gasification Combustion (AEFGC) simulator in an effort to validate the results. It was determined that though the CFD results differed for the $\mathrm{H}_{2} \mathrm{O}$ and temperature profiles, they still fell within the estimated experimental error. Thus, the authors concluded that the developed model could be used to help determine the appropriate operating conditions required to produce desired centerline gas compositions in the experimental test facility prior to operation.

The design and optimization of an entrained-flow biomass gasifier is presented in [10]. The authors aimed to use CFD to prove the design of a pilot plant under 
development and then use the validated model in the design of a $1 \mathrm{MW}$ plant. The fuel of interest for this study consisted of sawdust and/or cotton gin waste. Combustion was modeled via the addition of simple models for devolatilization, global gas phase reactions, and heterogeneous reactions for the gasification of the fixed carbon. For devolatilization, the authors found that at mid temperatures the pyrolysis products produced char, tar, $\mathrm{CO}_{2}, \mathrm{CO}, \mathrm{H}_{2} \mathrm{O}, \mathrm{H}_{2}, \mathrm{CH}_{4}$, and $\mathrm{C}_{\mathrm{n}} \mathrm{H}_{\mathrm{m}}$, and for temperatures above $700^{\circ}$ $\mathrm{C}$ all of the tar was cracked to $\mathrm{H}_{2}, \mathrm{CH}_{4}$, and $\mathrm{C}_{\mathrm{n}} \mathrm{H}_{\mathrm{m}}$. The product distributions of both the sawdust and cotton gin waste were determined from their initial compositions. The sawdust produced volatiles that contained significant quantities of $\mathrm{H}_{2}$ and $\mathrm{CO}$, whereas the cotton gin waste contained twice the amount of char and a significant amount of ash. Simulations were run in CFX4 using either the cotton gin waste or sawdust as the feedstock to determine the temperature field and to compare exit gas compositions. It was found that the cotton gin waste produced $11 \% \mathrm{CO}, 15 \% \mathrm{CO}_{2}, 23 \% \mathrm{H}_{2}, 0.06 \% \mathrm{CH}_{4}$, $9 \% \mathrm{H}_{2} \mathrm{O}$, and $40 \% \mathrm{~N}_{2}$ by volume at the exit whereas the results for the simulation using sawdust as the fuel showed $13 \% \mathrm{CO}, 14 \% \mathrm{CO}_{2}, 24 \% \mathrm{H}_{2}, 5 \% \mathrm{CH}_{4}, 11 \% \mathrm{H}_{2} \mathrm{O}$, and $33 \%$ $\mathrm{N}_{2}$ by volume. With detailed information about the gas composition and temperature at the outlet from the computational model, different gasifier operating conditions could be freely explored in relatively short periods of time.

In reference [11], a three dimensional model was developed to analyze the sensitivity of a hydrogen-from-coal (HYCOL) entrained-flow gasifier simulator to various coal properties, including $\mathrm{C} / \mathrm{H}$ ratio, $\mathrm{C} / \mathrm{O}$ ratio, volatile matter content, ash content, heating value, and particle size. Further sensitivity analysis for the same gasifier type was performed in [12] to identify the effects of $\mathrm{O}_{2}$ partition (ratio of the $\mathrm{O}_{2}$ supplied 
to the lower and upper burners in the reactor geometry), staged gasification, load ratio, and the $\mathrm{O}_{2} /$ coal ratio on the gasifier performance. The coal of interest in both studies was Taiheiyo Bituminite. The coal gasification model employed the Multi-Solid Progress Variables (MSVP) method with the gas phase assumed to be a steady state continuum. The coal particles were tracked in a Lagrangian reference frame with stochastic trajectories used to simulate the turbulent dispersion. The results of the sensitivity analysis in [11] showed that the heating value had a strong influence on the gasification characteristics, while the influence of particle size on the trajectory and temperature field indicated that the model could be used in further research pertaining to slag layer buildup in entrained-flow gasifiers. In [12], it was found that the carbon conversion increased as the $\mathrm{O}_{2} /$ coal ratio was increased. Overall, the experimental data obtained from a 50 ton per day HYCOL gasifier agreed well with the predicted results of the computational model.

In references [13] and [14], the chemical structure of pulverized coal flames in a entrained-flow reactor at SRI International were analyzed for Pittsburgh \#8, Illinois. \#6, and Powder River Basin coals at pressures of 1,2, and $3 \mathrm{MPa}$. This study was part of the High Pressure Coal Combustion Kinetics (HPCCK) project funded by the National Energy Technology Laboratory to understand the impact of operating conditions on coal conversion kinetics with the aim of improving power plant efficiencies. The study consisted of both experimental tests and computational simulations to characterize the chemical structure of pulverized coal flames. A main goal was to understand how the $\mathrm{O}_{2}$ in simulated near-burner flame zones is apportioned among the various fuel components, and to determine the burner operating conditions that most influence the flame structure 
[13]. The test facility used in $[13,14]$ consisted of a vertically mounted high-pressure cylindrical reactor connected to an entrainment tube that served to transport both fuel and carrier gas to the core inlet area of the reactor, while kept separate from the oxidizer that was introduced to the reactor via a annular sheath flow. The sheath flow also served to keep the coal particles away from the reactor walls, as well as to influence the combustion behavior within the reactor. CFD simulations performed with Fluent were used in this study to identify the different features of the pulverized coal flames as well as to quantitatively assign the flow and thermal fields [13]. The original intent of the CFD model was to use the predicted temperature field to assign thermal histories required for separate simulations that use detailed chemistry. In [14], the results of the CFD simulations were used to specify an equivalent reactor network for the flows. Simulations of detailed reaction mechanisms across the different reactor networks were shown to accurately predict the exit product distributions, as well as to identify the dominant conversion and $\mathrm{NO}_{\mathrm{x}}$ production mechanisms [14]. Fluent (version 5.5) was used to solve the governing flow equations coupled with the k- $\varepsilon$ turbulence model and Discrete Phase Lagrangian particle tracking to resolve the flow field and product specie distributions throughout the model reactor and to identify the coal particle trajectory patterns [13]. The test facility was represented in the computer model as a simple 2D axisymmetric geometry with appropriate boundary conditions assigned to represent the wall temperatures achieved in the actual test facility. Coal devolatilization was modeled using a single first-order reaction rate given in Eq. 2.1 [13].

$$
-\frac{d m_{p}}{d t}=k_{d v}\left(m_{p}-\left(1-f_{v 0}\right) m_{p 0}\right)
$$


Char oxidation was treated with the classical balance between an intrinsic nth-order surface reaction and film diffusion of $\mathrm{O}_{2}$ [13]. The chemical reaction mechanisms that were employed in the simulation are listed in Eqs. 2.2-2.7 below [13]:

$$
\begin{gathered}
\text { Coal } \rightarrow \text { GasVol }+ \text { Soot }+ \text { Char } \\
\text { GasVol }+\gamma_{\mathrm{O}_{2}} \mathrm{O}_{2} \rightarrow \gamma_{\mathrm{H}_{2}} \mathrm{H}_{2}+\gamma_{\mathrm{CO}} \mathrm{CO} \\
\mathrm{CO}+0.5 \mathrm{O}_{2} \rightarrow \mathrm{CO}_{2} \\
\mathrm{H}_{2}+0.5 \mathrm{O}_{2} \rightarrow \mathrm{H}_{2} \mathrm{O} \\
\mathrm{Soot}+0.5 \mathrm{O}_{2} \rightarrow 2 \mathrm{CO} \\
\text { Char }+0.5 \mathrm{O}_{2} \rightarrow \mathrm{CO}
\end{gathered}
$$

In Eq. 2.3, the GasVol specie represents the mixture of $\mathrm{CH}_{4}, \mathrm{C}_{2} \mathrm{H}_{2}, \mathrm{HCN}$, and oils that are released during pyrolysis. Soot oxidation was treated as a pseudo gas-phase reaction that produced only $\mathrm{CO}$ [13]. The computed burnout indices of gaseous fuels, soot, and char were plotted for all tests and compared to the CFD results. Reaction kinetic parameters were predicted from PC Coal Lab [2] which can be thought of as a "virtual laboratory" for analyzing the behavior of different coal types in drop tube and wire grid furnaces. It was shown that the two data sets were in close agreement after adjustments of the preexponential factors obtained from the PC Coal Lab simulations for the burning rates of gaseous fuels, soot, and char in the CFD simulations [13]. Further results obtained from the CFD simulations included axial gas velocity versus radial position, gas temperature versus radial position, and mass fractions of gaseous fuels, soot, $\mathrm{CO}$, and $\mathrm{O}_{2}$ versus radial position. Particle dispersion behavior was also analyzed and it was found that the particles tended to concentrate near the reactor walls downstream of the injector. This 
behavior heavily influenced the combustion atmosphere within the reactor due to the competing nature of the reactions with the available $\mathrm{O}_{2}$.

CFD modeling of coal entrained-flow gasification using the Discrete Phase Model has been treated by Shi et al. [3]. The Discrete Phase Model (DPM) is an application that currently is available in Fluent that allows the user to track the time evolution of individual particles using mass, energy, and force balances between each particle and the continuous gas phase written in a Lagrangian reference frame (a frame of reference that is attached to the moving particle). The force balance mentioned above equates the particle's inertia with the forces acting on the particle, and can be written (for the $\mathrm{x}$ direction in Cartesian coordinates) as [15]:

$$
\frac{d u_{p}}{d t}=F_{D}\left(u-u_{p}\right)+\frac{g_{x}\left(\rho_{p}-\rho\right)}{\rho_{p}}+F_{x}
$$

The first term on the right hand side of Eq. 2.8 represents the particle drag force per unit mass, with $\mathrm{F}_{\mathrm{D}}$ defined in Eq. 2.9.

$$
\begin{gathered}
F_{D}=\frac{18 \mu}{\rho_{p} d_{p}{ }^{2}} \frac{C_{D} \operatorname{Re}}{24} \\
\operatorname{Re}=\frac{\rho d_{p}\left|u_{p}-u\right|}{\mu}
\end{gathered}
$$

In Eq. 2.9, here $\rho$ is the fluid density, $\rho_{p}$ is the particle density, $d_{p}$ is the particle diameter, $C_{D}$ is the particle drag coefficient, $\mu$ is the molecular viscosity of the gas, and Re is the particle Reynolds number defined by Eq. 2.10 [15]. The second term on the right hand side of Eq. 2.8 represents the buoyancy force acting on the particle and the last term in Eq. 2.8 can represent any additional forces the user wishes to include. The force balance is solved using an implicit numerical integration technique to yield the particle position 
and velocity at each discrete time step. The influence of turbulence on the individual particle trajectories was determined in [3] by using the stochastic tracking model in Fluent. Stochastic tracking models the effects of random velocity fluctuations due to turbulent motion of the continuous phase on the particle trajectories. The motion of turbulent eddies can be described by the random velocity fluctuations, u', v', w', and a time scale, $\tau_{\mathrm{e}}$, described by Eq. 2.11 with the Lagrangian Integral time, $\mathrm{T}_{\mathrm{L}}$, given by Eq. $2.12[15]$

$$
\begin{aligned}
\tau_{e} & =2 T_{L} \\
T_{L} & =0.15 \frac{k}{\varepsilon}
\end{aligned}
$$

In Eq. $2.12, \mathrm{k}$ is the turbulent kinetic energy and $\varepsilon$ is the eddy dissipation rate. Fluent uses the Discrete Random Walk (DRW) model to calculate the random velocity in the continuous (gas) phase by computing the root mean square of the local velocity fluctuation multiplied by a normally distributed random number, $\zeta$, as shown in Eq. 2.13 [15].

$$
u^{\prime}=\zeta \sqrt{\bar{u}^{\prime 2}}
$$

Assuming isotropy, the root mean square of the velocity fluctuations can be obtained through Eq. 2.14 [15].

$$
\sqrt{\bar{u}^{\prime 2}}=\sqrt{\bar{v}^{\prime 2}}=\sqrt{\bar{w}^{\prime 2}}=\sqrt{\frac{2 k}{3}}
$$

Once the fluctuation is obtained, the fluid phase velocity at any point in time can be found, for example, in the x-direction, from Eq. 2.15 [15].

$$
u=\bar{u}+u^{\prime}
$$


It is noted that the particles will always experience an impact due to the presence of the continuous phase gas stream with the velocity field given by Eq. 2.15 , but that the particles conversely also influence the continuous gas phase as shown in Figure 2.3 which was adapted from reference [15].

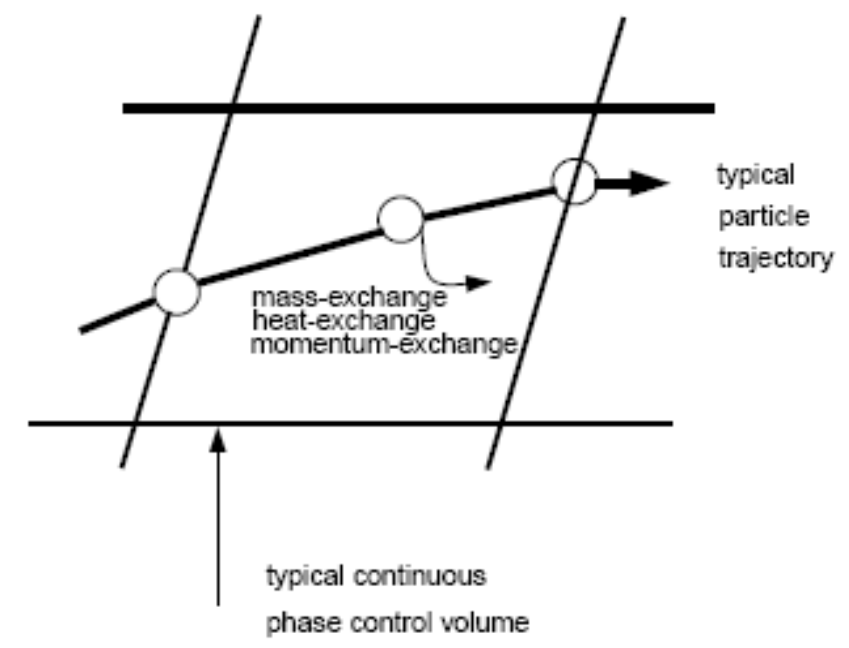

Figure 2.3. Typical Particle Trajectory thru a Control Volume [15].

In this DPM approach, the coupling between the discrete and continuous phase is accomplished via the addition of specific source terms in the governing partial differential equations for the continuous phase that will arise due to momentum, mass, and energy transfer from the individual particles. The equations representing these exchanges are listed below [3].

$$
\begin{gathered}
F=\sum\left(\frac{18 \mu C_{D} \operatorname{Re}}{\rho_{p} d_{p}{ }^{2} 24}\left(u_{p}-u\right)+F_{\text {other }}\right) \dot{m}_{p} \Delta t \\
Q=\sum\left[\bar{m} c_{p} \Delta T_{p}+\Delta m_{p}\left(-h_{f g}+h_{p y r o l}+h_{\text {reac }}+\int_{T_{\text {ref }}}^{T_{p}} c_{p, i} d T\right)\right] \frac{\dot{m}_{p, 0}}{m_{p, 0}} \\
M=\frac{\Delta m_{p}}{m_{p, 0}} \dot{m}_{p, 0}
\end{gathered}
$$


The momentum transfer is given in Eq. 2.16. The momentum of a differential fluid element is defined as the product of it's instantaneous mass and velocity at a point in a fixed frame of reference. The momentum of a particle is defined as the product of the particles instantaneous mass and velocity at the particles center in a moving frame of reference. In Eq. 2.16, the summation represents the cumulative amount of momentum transferred from the gas phase to the particles as they pass through the control volume of interest in a given time step. This exchange will appear as a sink in the continuous phase momentum equation. The heat exchange is given by Eq. 2.17. The terms within the summation in Eq. 2.17 are defined as the heat transfer due to thermal conduction and the changes in thermal energy resulting from any chemical reactions. The mass exchange is given by Eq. 2.18. From Eq. 2.18, it can be seen that the source of mass to the continuous phase is simply the change in mass of the particle as it passes through the control volume multiplied by the strength of the particle stream represented by that particle. The mass source of each individual stream that passes through each control volume in a given time step is then summed to give the total mass source to the gas phase.

Using the Discrete Phase Model places certain restrictions on the particle loading in the continuous phase, namely the volume fraction found from Eq. 2.19 must be less than $10 \%$, and the ratio of the mass flow rate of solids to that of the gas is less than or equal to one [15]. The latter is to ensure stability of the DPM calculations [3] and the former is required for ignoring particle collisions to be a valid approximation. In [3], the feedstock consisted of a mixture of water droplets and Illinois \#6 coal particles entrained 
in oxygen. The water and coal were injected using a Rosin-Rammler particle diameter distribution given by Eq. 2.20 [15].

$$
\begin{gathered}
\frac{\dot{V}_{s}}{\dot{V}_{g}}=\frac{\rho_{g} \dot{m}_{s}}{\rho_{s} \dot{m}_{g}} \\
Y_{d}=e^{-(d / d)^{n}}
\end{gathered}
$$

In Eq. 2.20, $\bar{d}$ is the mean particle diameter and $\mathrm{n}$ is the spread parameter. The RosinRammler distribution equation is based on the assumption that an exponential relationship exists between the droplet diameter, $\mathrm{d}$, and the mass fraction of droplets with diameter greater than d, $Y_{d}[15]$. The physical and chemical processing of coal slurry gasification treated in [3] and in the present study was implemented by calculating the discrete phase trajectory by using the Lagrangian DPM formulation described above. The particle force balance was integrated to obtain the trajectory of each particle as discussed previously. This process was coupled with the physical and chemical processes involving inert heating, moisture release, vaporization, devolatilization, and char combustion/gasification [3]. Each law is executed in Fluent along the particle trajectory until all of the char is combusted or until the particle leaves the computational domain. Initially, the particles are introduced into the domain and the inert heating law will immediately take effect. During inert heating, no heat/mass transfer or reaction will take place until the particle reaches a user-defined temperature (vaporization temperature). The standard equations governing the particle temperature during inert heating are given in [15] and are listed below.

$$
m_{p} c_{p} \frac{d T_{p}}{d t}=h A_{p}\left(T_{\infty}-T_{p}\right)+\varepsilon A_{p} \sigma\left(\theta_{R}{ }^{4}-T_{p}^{4}\right)
$$




$$
\begin{gathered}
N u=\frac{h d_{p}}{k_{\infty}}=2.0+0.6 \operatorname{Re}_{d}^{1 / 2} \operatorname{Pr}^{1 / 3} \\
\operatorname{Pr}=\frac{c_{p} \mu}{k_{\infty}} \\
\operatorname{Re}_{d}=\frac{\rho d_{p}\left|\vec{V}_{p}-\vec{V}\right|}{\mu}
\end{gathered}
$$

In Eq. 2.21, $\mathrm{m}_{\mathrm{p}}$ is the particle mass, $\mathrm{c}_{\mathrm{p}}$ is the particle constant-pressure specific heat, $\mathrm{A}_{\mathrm{p}}$ is the surface area of the particle, $\mathrm{T}_{\infty}$ is the local gas temperature surrounding the particle, $\mathrm{h}$ is the convective heat transfer coefficient computed using Eq. 2.21, 2.22, and 2.23, $\varepsilon$ is the particle emissivity, $\sigma$ is the Stefan-Boltzmann constant, and $\theta_{\mathrm{R}}$ is the radiation temperature.

Once the particles reach the vaporization temperature, their moisture content will be released into the continuous phase (treated as a mass source in the continuity equation) and energy will be taken away from the gas phase (treated as an energy sink in the energy equation) to supply the latent heat of vaporization [3]. The particle mass during the moisture release phase is governed by Eq. 2.25:

$$
\frac{d m_{p}}{d t}=-A_{0}
$$

where $A_{0}$ is the rate constant of moisture release [3]. The temperature of the particle during moisture release is governed Eq. 2.26, with the added term due to the increase of enthalpy during vaporization, $\mathrm{h}_{\mathrm{fg}}$.

$$
m_{p} c_{p} \frac{d T_{p}}{d t}=h A_{p}\left(T_{\infty}-T_{p}\right)+\frac{d m_{p}}{d t} h_{f g}+\varepsilon A_{p} \sigma\left(\theta_{R}{ }^{4}-T_{p}{ }^{4}\right)
$$


After the moisture has been evaporated the coal particle will begin the devolatilization phase. The volatile matter is released in this stage of the coal heating. This process will produce a mixture of gases that is highly dependant on the heating rates [1]. Shi et. al [3] assumed a mixture of $\mathrm{CH}_{4}, \mathrm{CO}_{2}, \mathrm{CO}, \mathrm{O}_{2}, \mathrm{H}_{2}, \mathrm{H}_{2} \mathrm{~S}, \mathrm{~N}_{2}$, and $\mathrm{H}_{2} \mathrm{O}$ using a phenomenological model based on experimental data. During devolatilization, the mass and temperature of the particle are governed by Eq. 2.27 and Eq. 2.28, respectively [14].

$$
\begin{gathered}
\frac{d m_{p}}{d t}=-\operatorname{Rate}\left(T_{p}\right) \\
m_{p} c_{p} \frac{d T_{p}}{d t}=h A_{p}\left(T_{\infty}-T_{p}\right)+\frac{d m_{p}}{d t} h_{p y r o l}+\varepsilon A_{p} \sigma\left(\theta_{R}{ }^{4}-T_{p}^{4}\right)
\end{gathered}
$$

In [3], the authors chose to model the rate of devolatilization using the "two-competingrates Kobayashi" model. This model is described in [16] and defined by Eq. 2.29:

$$
\frac{m_{v}(t)}{\left(1-f_{m, 0}\right) m_{p, 0}-m_{a}}=\int_{0}^{t}\left(a_{1} R_{1}+a_{2} R_{2}\right) \exp \left(-\int_{0}^{t}\left(R_{1}+R_{2}\right) d t\right) d t
$$

where $m_{v}(t)$ is the volatile yield at time t, $m_{p, 0}$ is the initial particle mass, $f_{m, 0}$ is the initial moisture mass fraction, $a_{1}$ and $a_{2}$ are yield factors, $m_{a}$ is the mass of the ash present in the particle, and $R_{1}$ and $R_{2}$ are Arrhenius reaction rates at lower and higher temperature ranges, respectively [15].

After the volatile release is complete, the char combustion and gasification laws will take effect. The surface reactions involved are char combustion, char-steam gasification, char- $\mathrm{H}_{2}$ gasification, and char- $\mathrm{CO}_{2}$ gasification. The reaction mechanisms used for gasification and combustion in [3] are listed in Eqs. 2.30-2.33.

$$
\mathrm{C}+\frac{1}{\phi} \mathrm{O}_{2} \rightarrow 2\left(1-\frac{1}{\phi}\right) \mathrm{CO}+\left(\frac{2}{\phi}-1\right) \mathrm{CO}_{2}
$$




$$
\begin{gathered}
\mathrm{C}+\mathrm{H}_{2} \mathrm{O} \rightarrow \mathrm{CO}+\mathrm{H}_{2} \\
\mathrm{C}+2 \mathrm{H}_{2} \rightarrow \mathrm{CH}_{4} \\
\mathrm{C}+\mathrm{CO}_{2} \rightarrow 2 \mathrm{CO}
\end{gathered}
$$

In Eq. 2.30, the stoichiometric coefficients for $\mathrm{O}_{2}, \mathrm{CO}$, and $\mathrm{CO}_{2}$ are a function of $\varphi$, which is a function of particle diameter and temperature as given by Eqs. 2.34-2.38 [16]. $d_{p} \leq 0.005 \mathrm{~cm}$

$$
\phi=\frac{2 Z+2}{Z+2}
$$

$0.005 \mathrm{~cm} \leq d_{p} \leq 0.1 \mathrm{~cm}$

$$
\phi=\frac{\left[(2 Z+2)-Z \frac{\left(d_{p}-0.005\right)}{0.095}\right]}{Z+2}
$$

$d_{p}>0.1 \mathrm{~cm}$

$$
\begin{gathered}
\phi=1 \\
Z=2500 \exp \left(\frac{-6249}{T_{a v g}}\right) \\
T_{a v g}=\frac{T_{p}+T_{\infty}}{2}
\end{gathered}
$$

During combustion and gasification, the particle mass and temperature are governed by Eqs. 2.39 and 2.40, respectively.

$$
\begin{gathered}
\frac{d m_{p}}{d t}=- \text { Rate } \\
m_{p} c_{p} \frac{d T_{p}}{d t}=h A_{p}\left(T_{\infty}-T_{p}\right)+\frac{d m_{p}}{d t} h_{\text {reac }}+\varepsilon A_{p} \sigma\left(\theta_{R}{ }^{4}-T_{p}{ }^{4}\right)
\end{gathered}
$$

Eq. 2.40 
The reaction rate (per unit area) employed in [3] for combustion and gasification is obtained from the unreacted shrinking-core model given by Eq. 2.41 and described in references $[17,18]$ :

$$
\text { Rate }=\frac{1}{\frac{1}{k_{\text {diff }}}+\frac{1}{k_{r} Y^{2}}+\frac{1}{k_{\text {dash }}}\left(\frac{1}{Y}-1\right)}\left(P_{i}-P_{i}^{*}\right)
$$

where $\mathrm{k}_{\text {diff }}$ is the gas film diffusion constant, $\mathrm{k}_{\mathrm{r}}$ is the Arrhenius rate constant, $\mathrm{k}_{\text {dash }}$ is the ash film diffusion constant, $\mathrm{Y}$ is the char conversion factor defined as the ratio of the unreacted core radius to the initial radius of the particle, $\mathrm{P}_{\mathrm{i}}$ is the partial pressure of reactant $i$, and $\mathrm{P}_{\mathrm{i}}{ }^{*}$ is the back reaction equilibrium pressure of reactant $\mathrm{i}[17,18]$. After the char is consumed, the particle consisting entirely of ash will again undergo inert heating until it exits the computational domain. This concludes the sequence of laws a particle will undergo along its trajectory.

In reviewing [3], only the particle surface reactions have been discussed at this point. For the gas phase reactions, the authors chose to employ simple global mechanisms, where the reaction paths taken into account are listed in Eqs. 2.42-2.48 [3].

$$
\begin{gathered}
\mathrm{CH}_{4}+2 \mathrm{O}_{2} \rightarrow \mathrm{CO}_{2}+2 \mathrm{H}_{2} \mathrm{O} \\
\mathrm{CO}+\frac{1}{2} \mathrm{O}_{2} \rightarrow \mathrm{CO}_{2} \\
\mathrm{CO}+\mathrm{H}_{2} \mathrm{O} \rightarrow \mathrm{CO}_{2}+\mathrm{H}_{2} \\
\mathrm{CO}_{2}+\mathrm{H}_{2} \rightarrow \mathrm{CO}+\mathrm{H}_{2} \mathrm{O} \\
\mathrm{H}_{2}+\frac{1}{2} \mathrm{O}_{2} \rightarrow \mathrm{H}_{2} \mathrm{O} \\
\mathrm{CH}_{4}+\mathrm{H}_{2} \mathrm{O} \rightarrow \mathrm{CO}+3 \mathrm{H}_{2}
\end{gathered}
$$




$$
\mathrm{CO}+3 \mathrm{H}_{2} \rightarrow \mathrm{CH}_{4}+\mathrm{H}_{2} \mathrm{O}
$$

In [3], the authors chose to model a generic prototype up-flow entrained-flow reactor design using the commercial CFD software Fluent. The reactor was separated into two regions, a horizontal first and vertical second stage. The first stage acts as a combustor, where coal and water entrained in oxygen are introduced through two injection locations at either end of the horizontal chamber. The hot gases produced in the first stage provide the second stage slurry injection the energy required for gasification to take place [3]. The reactor geometry was meshed with 12,256 computational cells. The char conversion was found to be $100 \%$ for the first stage and $86 \%$ for the second stage injections. The validity of this model was judged through comparisons of the predicted exit mole fractions of the syngas for some of the major species with those obtained using the less detailed Aspen Plus process simulator. Table 2.1 summarizes the results of this study, where the CFD results are shown to be in good agreement with the Aspen Plus predictions.

Table 2.1 Exit Mole Fractions from Simulations by Shi et al. [3].

\begin{tabular}{|l|l|l|}
\hline & CFD & Aspen Plus \\
\hline $\mathrm{CO}$ & 0.392 & 0.378 \\
\hline $\mathrm{H}_{2}$ & 0.237 & 0.226 \\
\hline $\mathrm{CO}_{2}$ & 0.103 & 0.090 \\
\hline $\mathrm{CH}_{4}$ & 0.015 & 0.019 \\
\hline $\mathrm{H}_{2} \mathrm{~S}$ & 0.007 & 0.007 \\
\hline $\mathrm{Ar}$ & 0.008 & 0.008 \\
\hline $\mathrm{N}_{2}$ & 0.008 & 0.008 \\
\hline $\mathrm{H}_{2} \mathrm{O}$ & 0.230 & 0.264 \\
\hline
\end{tabular}




\section{Chapter 3. Model Description}

\subsection{Introduction}

The simulations done during the course of the coal partitioning project were built on top of the original mesh and boundary conditions for the generic prototype entrainedflow up-flow gasifier provided by ANSYS and that were developed by Shi et al., $[3,16]$ in their initial studies of the application of DPM to entrained-flow gasifier simulations at the U.S. Department of Energy National Energy Technology Laboratory (NETL).

\subsection{Pittsburgh \#8 Bailey Coal Properties}

The measured ultimate and proximate analysis of the parent coal sample are summarized in Table 3.1. Table 3.2 lists the average particle specific gravities and

Table 3.1. Ultimate and proximate Analysis of Pitt. \#8 Bailey parent coal [19].

$\begin{array}{lr}\text { Fixed Carbon } & 57.69 \\ \text { Volatile Matter } & 33.52 \\ \text { Ash } & 7.79 \\ \text { Moisture } & 1.0 \\ \text { C } & 76.83 \\ \mathrm{H} & 5.49 \\ \mathrm{O} & 3.91 \\ \mathrm{~N} & 1.4 \\ \mathrm{~S} & 1.46 \\ \mathrm{HHV}, \mathrm{J} / \mathrm{kg} & 33,315,096\end{array}$

Table 3.2. Size and density fractions [19].

\begin{tabular}{lccccccc}
\hline Density Class & SG1 & & SG2 & & SG3 & & SG4 \\
Avg. Specific Gravity & 1.2 & & 1.4 & & 2.1 & & 3.3 \\
Wt. \% & 47.84 & & 47.57 & & 3.46 & & 1.12 \\
Size Class & PS1 & PS2 & PS3 & PS4 & PS5 & PS6 & PS7 \\
Avg. Diameter, $\mu$ & 800 & 512 & 318 & 181 & 128 & 90 & 50 \\
BSG1 Wt. \% & 5.31 & 10.85 & 31.15 & 13.36 & 11.57 & 10.79 & 16.97 \\
BSG2 Wt. \% & 3.91 & 9.53 & 21.66 & 9.15 & 7.38 & 6.99 & 41.39 \\
BSG3 Wt. \% & 16.15 & 11.5 & 23.38 & 10.71 & 9.12 & 8.79 & 20.4 \\
BSG4 Wt. \% & 8.69 & 5.93 & 17.5 & 8.31 & 8.65 & 13.49 & 37.43
\end{tabular}


Table 3.3. Ultimate and Proximate Analysis of 28 size/density cuts [19].

\begin{tabular}{|c|c|c|c|c|c|c|c|}
\hline SG1 & PS1 & PS2 & PS3 & PS4 & PS5 & PS6 & PS7 \\
\hline $\mathrm{FC}$ & 54.13 & 54.95 & 55.07 & 53.63 & 55.65 & 55.89 & 56.31 \\
\hline VM & 39.7 & 39.14 & 39.33 & 41.4 & 39.44 & 39.35 & 38.12 \\
\hline Ash & 4.33 & 3.96 & 3.51 & 3.03 & 3.11 & 2.75 & 3.2 \\
\hline Moisture & 1.84 & 1.95 & 2.1 & 1.94 & 1.8 & 2.01 & 2.37 \\
\hline $\mathrm{C}$ & 84 & 83.9 & 84.7 & 84.55 & 85.45 & 85.9 & 84.4 \\
\hline $\mathrm{H}$ & 6.1 & 6.01 & 6.1 & 5.95 & 6.0 & 6.09 & 6.05 \\
\hline $\mathrm{O}$ (by diff.) & 2.01 & 2.33 & 1.85 & 2.67 & 1.81 & 1.41 & 2.28 \\
\hline $\mathrm{N}$ & 1.53 & 1.62 & 1.53 & 1.58 & 1.58 & 1.57 & 1.46 \\
\hline $\mathrm{S}$ & 1.1 & 1.1 & 1.01 & 1.02 & 0.98 & 0.96 & 0.96 \\
\hline SG2 & PS1 & PS2 & PS3 & PS4 & PS5 & PS6 & PS7 \\
\hline $\mathrm{FC}$ & 48.46 & 49.4 & 49.9 & 49.8 & 49.5 & 50.8 & 54.1 \\
\hline VM & 34.15 & 34.21 & 34.43 & 34.2 & 34.7 & 33.97 & 33.1 \\
\hline Ash & 15.6 & 14.5 & 13.76 & 14.2 & 13.85 & 13.24 & 10.3 \\
\hline Moisture & 1.79 & 1.89 & 1.9 & 1.9 & 1.94 & 1.96 & 2.55 \\
\hline $\mathrm{C}$ & 73.1 & 74.6 & 74.8 & 76.0 & 75.5 & 76.0 & 77.9 \\
\hline $\mathrm{H}$ & 5.41 & 5.43 & 5.46 & 5.6 & 5.4 & 5.46 & 5.38 \\
\hline $\mathrm{O}$ (by & 3.04 & 2.37 & 2.82 & 1.1 & 2.1 & 2.0 & 2.63 \\
\hline $\mathrm{N}$ & 1.36 & 1.4 & 1.36 & 1.4 & 1.3 & 1.43 & 1.41 \\
\hline $\mathrm{S}$ & 1.75 & 1.8 & 1.91 & 1.96 & 2.0 & 1.77 & 1.28 \\
\hline SG3 & PS1 & PS2 & PS3 & PS4 & PS5 & PS6 & PS7 \\
\hline $\mathrm{FC}$ & 9.94 & 22.41 & & .0 & 19.1 & 16.2 & 15.4 \\
\hline VM & 19.2 & 18.35 & 18.76 & 17.8 & 17.9 & 17.8 & 16.33 \\
\hline Ash & 59.2 & 57.6 & 57.5 & 57.8 & 61.1 & 63.3 & 66.0 \\
\hline Moisture & 1.71 & 1.67 & 1.72 & 1.89 & 1.95 & 2.78 & 2.22 \\
\hline $\mathrm{C}$ & 36.15 & 30.4 & 32.3 & 29.25 & 29.0 & 26.9 & 28.55 \\
\hline $\mathrm{H}$ & 2.53 & 1.97 & 2.1 & 1.97 & 1.93 & 1.8 & 1.95 \\
\hline O (by diff.) & 0.61 & 8.2 & 5.81 & 8.93 & 5.6 & 4.66 & 1.53 \\
\hline $\mathrm{N}$ & 0.71 & 0.54 & 0.52 & 0.38 & 0.55 & 0.35 & 0.42 \\
\hline $\mathrm{S}$ & 7.18 & 7.97 & 8.87 & 8.34 & 8.98 & 10.0 & 8.51 \\
\hline SG4 & PS1 & PS2 & PS3 & PS4 & PS5 & PS6 & PS7 \\
\hline $\mathrm{FC}$ & 7.44 & 8.23 & 8.59 & 7.52 & 6.59 & 6.78 & 4.9 \\
\hline VM & 4.26 & 6.77 & 1.71 & 6.9 & 6.25 & 2.1 & 1.01 \\
\hline Ash & 87.7 & 84.42 & 89.0 & 85.2 & 86.54 & 90.7 & 93.6 \\
\hline Moist & & 0.58 & & 0.43 & 0.62 & 0.47 & 0.52 \\
\hline $\mathrm{C}$ & 7.44 & 8.23 & 8.59 & 7.52 & 6.59 & 6.78 & 4.9 \\
\hline $\mathrm{H}$ & 0.3 & 0.42 & 0.43 & 0.35 & 0.37 & 0.16 & 0.16 \\
\hline $\mathrm{O}$ (by & 0.0 & 0.0 & 0.0 & 0.0 & 0.0 & 0.0 & 0.0 \\
\hline $\mathrm{N}$ & 0.17 & 0.17 & 0.22 & 0.25 & 0.05 & 0.02 & 0.03 \\
\hline $\mathrm{S}$ & 34.2 & 35.48 & 36.44 & 35.7 & 40.33 & 38.7 & 36.95 \\
\hline
\end{tabular}


average particle diameters from Soundarrajan et al. [19] for each size and density class that was used as input values in the injection and material setup panels in Fluent. The ultimate and proximate analyses of the coal for each of the 28 different size/density cuts were determined by Soundarrajan et al. [19] and are listed in Table 3.3. A maceral analysis, and a mineral analysis of the ash, for each size/density cut, was also determined $[19,20]$. Particle swelling coefficients were determined by Niksa Energy Associates (NEA) for the Bailey coal and were used in the CFD model studied here.

\section{$\underline{3.3 \text { Basic Setup and Geometry }}$}

The computational grid for the entrained-flow reactor used in this study is illustrated in Figure 3.1. The geometry represents a generic entrained-flow two-stage upflow gasifier. Here, the grid is separated into two stages to model combustion and gasification separately. The first stage of the model is a combustion zone were gas and fuel are introduced from opposite locations in the lower horizontal cylindrical chamber. Then, the resulting gas mixture consisting of the species produced during devolatilization as well as char combustion flows out through the vertical second stage region were a secondary solids inlet provides a slurry of additional pulverized coal and water to facilitate gasification. The goal of the system is to gasify as much of the available carbon in the fuel as possible. The grid provided by ANSYS [3] to represent this generic reactor contains 12,256 hexahedral cells. The first stage diameter is $2 \mathrm{~m}$, with a length of $8 \mathrm{~m}$. The second stage is $1.6 \mathrm{~m}$ in diameter and is $12.2 \mathrm{~m}$ in height. The total volume of the computational domain is $45.5 \mathrm{~m}^{3}$. 


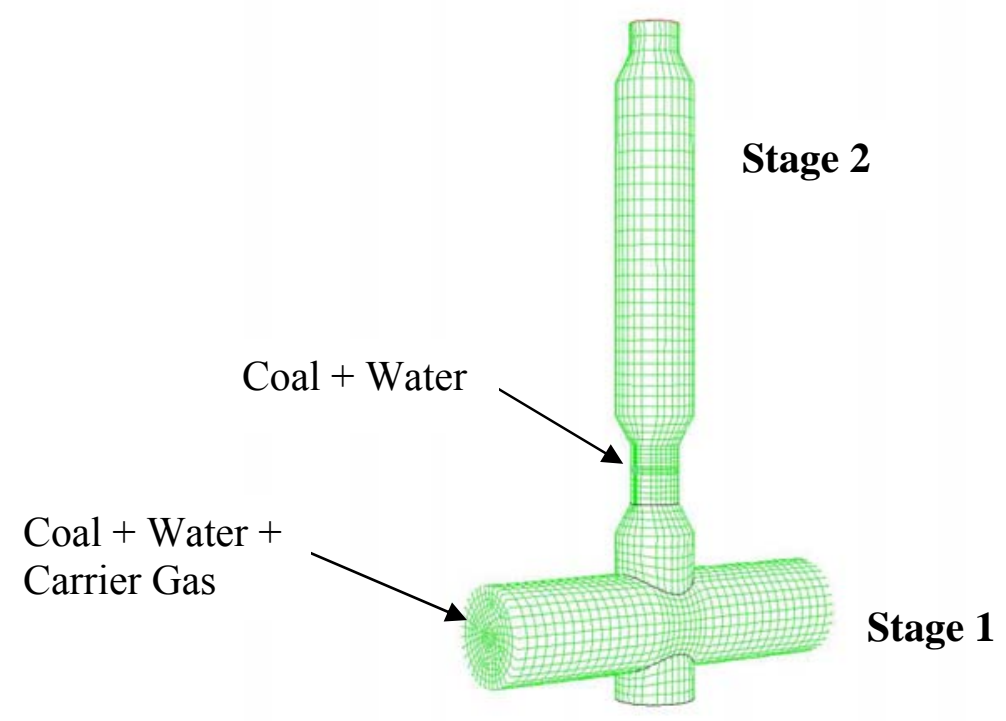

Figure 3.1. Computational grid.

The gasifier operating pressure was set to $2,840,658 \mathrm{~Pa}$ (28 atm), the discrete ordinates radiation heat transfer model has been used, and the gravity force was enabled in all simulations. The solid phase was modeled with DPM and the continuous phase was modeled using the pressure based, implicit, steady, 3D solver built into Fluent v6.3.31. The ratio of the volume of solids to gas is less than $10 \%$ [3]. The fluid mixture was modeled with specie transport equations with volumetric reactions. The finite-rate/eddy dissipation model was enabled to account for the interaction of turbulence with chemistry.

Two basic types of case setup were explored with the 3D up-flow geometry. One used a constant diameter distribution equal to the Sauter mean diameter of the Bailey parent coal, and the other used 28 partitioned injections with a constant diameter distribution for each of the separate Bailey size/density cuts. Density and diameter values for each of these 28 injections were taken from Table 3.2. The gas viscosity was assumed constant, and thermal conductivity was modeled with a user-defined power law 
for variation with temperature. Gas specific heats have been computed using two different models: the polynomial equations versus $\mathrm{T}$ that were in the original ".cas" file provided by ANSYS, and the fourth degree polynomial equations given by McBride et al. [21]. The basic setup for the CFD simulations performed during the course of the coal partitioning project is summarized in Table 3.4.

Table 3.4. Case file setup.

\begin{aligned} \hline Solver: & Pressure Based \\ Formulation: & Implicit \\ Space: & $3 \mathrm{D} \\$ Time: & Steady \\ Velocity Formulation: & Absolute \\ Gradient : & Green-Gauss Cell Based \\ Energy Equation: & Enabled \\ Radiation: & Discrete Ordinates \\ Viscous model: & Standard k- $\varepsilon \\$ Species Model: & Transport \\ Reactions: & Volumetric \\ Turbulence-Chemistry: & Finite-rate/Eddy-dissipation \end{aligned}

\section{$\underline{3.4 \text { Boundary Conditions }}$}

The mass flow rate of gas through the left and right inlets of the horizontal first stage was set to $12.274 \mathrm{~kg} / \mathrm{s}$ with an initial temperature of $440 \mathrm{~K}$. The inlet gas consisted of $1.5 \% \mathrm{Ar}, 4.1 \% \mathrm{~N}_{2}$, and $94.4 \% \mathrm{O}_{2}$. Turbulence intensity was initialized to $10 \%$ and the hydraulic diameter was set to $0.01 \mathrm{~m}$ for both inlets. For the discrete phase initial conditions, the mass flow rates for each injection (SG1PS1 to SG4PS7) were obtained from the mass fraction data determined by Soundarrajan et al. [19], and sum up to 10.936 $\mathrm{kg} / \mathrm{s}$ of coal, that is mixed with $4.531 \mathrm{~kg} / \mathrm{s}$ of liquid water, for each of the left and right stage 1 inlets and $6.169 \mathrm{~kg} / \mathrm{s}$ of coal and $2.556 \mathrm{~kg} / \mathrm{s}$ of liquid water for the second stage 
inlet. Also, particle diameters measured by PSU for each size/density cut were used to compute the constant average diameter for each size cut. The initial injection velocity vector for each particle was set normal to the injector face with a magnitude of $50 \mathrm{~m} / \mathrm{s}$; this value was also used in the study by Shi et al. [3]. The initial particle temperature was set to $450 \mathrm{~K}$. For the wall boundaries, the no slip condition was enabled. Perfectly insulated walls were assumed (zero heat flux across boundary) and the radiation boundary condition was set to opaque with a diffuse fraction of 1 . Separate wall interaction conditions for the discrete phase were explored. The most frequently used was to allow the particle to reflect against the walls without loss of momentum. Another condition allowed the particle to leave the domain after 10 impacts. Once the number of impacts for a particle reached 10, the mass flow rate of the stream represented by that particle was assigned to an array index along with the flux (mass flow rate divided by the face area of the wall element). The array indices correspond to each wall face of the gasifier wall boundary zone of interest. With this, post-processing can be used to visualize the flux of ash to the slag at different wall sections of the computational model. The boundary conditions discussed above are summarized in Table 3.5.

Table 3.5. Boundary conditions.

\begin{tabular}{l|cccccccccc} 
Inlet & $\begin{array}{c}\dot{m}_{\text {gas }} \\
\mathrm{kg} / \mathrm{s}\end{array}$ & $\begin{array}{c}\mathrm{O}_{2} \\
\%\end{array}$ & $\begin{array}{c}\mathrm{N}_{2} \\
\%\end{array}$ & $\begin{array}{c}\mathrm{Ar} \\
\%\end{array}$ & $\begin{array}{c}\dot{m}_{\text {coal }} \\
\mathrm{kg} / \mathrm{s}\end{array}$ & $\begin{array}{c}\dot{m}_{h_{2} \mathrm{O}} \\
\mathrm{kg} / \mathrm{s}\end{array}$ & $\begin{array}{c}\mathrm{T}_{\text {gas }} \\
\mathrm{K}\end{array}$ & $\begin{array}{c}\mathrm{T}_{\mathrm{p}} \\
\mathrm{K}\end{array}$ & $\begin{array}{c}\mathrm{TI} \\
\%\end{array}$ & $\begin{array}{c}\mathrm{D}_{\text {hyd }} \\
\mathrm{m}\end{array}$ \\
\hline Left & 12.27 & 94.4 & 4.1 & 1.5 & 10.94 & 4.53 & 440 & 450 & 10 & 0.01 \\
Right & 12.27 & 94.4 & 4.1 & 1.5 & 10.94 & 4.53 & 440 & 450 & 10 & 0.01 \\
Stage 2 & 0.0 & 0.0 & 0.0 & 0.0 & 6.17 & 2.56 & $\mathrm{~N} / \mathrm{A}$ & 450 & $\mathrm{~N} / \mathrm{A}$ & N/A
\end{tabular}

Table 3.6 summarizes the assumed fuel loading in terms of ratios of $\mathrm{O}_{2}$ to carbon, $\mathrm{N}_{2}$ to carbon, and $\mathrm{H}_{2} \mathrm{O}$ to carbon entering the gasifier. 
Table 3.6. Ratio of inlet gas to carbon in the fuel injection (as received).

$\begin{array}{ll}\mathrm{O}_{2} / \mathrm{C} & 1.21 \\ \mathrm{H}_{2} \mathrm{O} / \mathrm{C} & 0.65 \\ \mathrm{~N}_{2} / \mathrm{C} & 0.07\end{array}$

\section{$\underline{3.5 \text { Solution Technique }}$}

Simulations were usually started (but not always) by interpolating the velocity field from one of the solutions obtained by Shi et al., 2006 for the Illinois \#6 coal [3] and patching a temperature of $1800 \mathrm{~K}$ into the fluid stage 1 region of the model. For those simulations that did not interpolate the velocity field, the interaction of the discrete and continuous phase was turned off so that a cold flow field could first be established. The standard k- $\varepsilon$ model was enabled to model the fluid turbulence. Once a gas velocity field was obtained and a hot temperature was patched in fluid stage 1, the discrete phase was solved first to ensure that the volatile specie source terms were added into the gas phase to initiate the gas phase reactions for the subsequent continuous phase iteration. Reducing the energy equation under-relaxation factor to 0.8 was helpful in establishing a combustion atmosphere during the first few hundred gas phase iterations. After a flame had been established, the discrete phase was solved only once per 25-50 continuous phase iterations. Actual convergence of the overall solution process can be obtained by reducing the scaled residuals of the mass, momentum, energy, and species transport equations to below $10^{-6}$. Because of the discrete injections of coal particles, this is easier said than done. An alternate means to check convergence is to balance the mass and energy entering and leaving the system. If this is within a specified tolerance then the flow field can be considered converged. Also, it has been observed that the residuals tend to jump whenever a DPM update is performed. After this perturbation, the 
continuous phase iterates and these fluctuations are gradually damped out until another DPM update takes place. The level to which the residuals dampen out changes ever so slightly after a certain point in the solution process. This point cannot be considered a converged flow field in the traditional sense even though the residuals are no longer changing. This is when the alternate means mentioned above for checking convergence has been used. Other factors are important in judging the validity of a simulation. An example is the spatial distribution of the gaseous species within a steady state flow field, along with the maximum gas and wall temperatures produced. Experimental evidence should be used as a guide to judge what exit gas volume fractions and wall temperatures are realistic. The flow field of interest here is not completely symmetric due to the second stage solids injection and no experimental numbers are available for comparing exit gas volume fractions. The temperature in the first stage is expected to be significantly hotter than in the second stage due to the exothermic reactions taking place in stage 1. Gasification will require energy and thus reduce the gas temperature, so the second stage should be at a consistently lower temperature.

\subsection{Devolatilization Models}

A custom UDF was developed by Shi et al. [3] to govern the rate of mass loss during moisture release, devolatilization, combustion, and gasification for each tracked particle. In this model, the mass of the particle can be thought of as a combination of water, volatile matter, fixed carbon, and ash, as described in detail in Chapter 2. During the initial process of moisture release, the mass associated with the water will vaporize. The energy required to vaporize a given amount of water during a discrete time step is accounted for by subtracting the same energy from the continuous phase for the cell 
where the particle resides at that instant. Likewise, the mass of water released during this time step is added to the continuous phase. Once all of the moisture is gone, the particle law will next increment to the devolatilization law. During this second stage, the mass of the particle can be controlled by either of two models explored in this study. The first used the two-competing rates [22] model (Eq. 2.29) with pre-exponential factors and activation energies provided by Shi et al., [3]. The product species resulting from devolatilization when applying this model consist of $\mathrm{CO}, \mathrm{CO}_{2}, \mathrm{CH}_{4}, \mathrm{H}_{2}, \mathrm{~N}_{2}, \mathrm{O}_{2}, \mathrm{H}_{2} \mathrm{~S}$, $\mathrm{H}_{2} \mathrm{O}$, and $\mathrm{HCL}$ with the amount of each (Table 3.7) determined from a phenomenological model based on the ultimate analysis of the coal. The mass loss during devolatilization is divided into the above specie distribution and added to the computational cell as a source for each specie. The second approach used a single kinetic rate equation (Eq. 3.1) [2, 15] along with a predicted secondary pyrolysis species distribution obtained from PC Coal Lab consisting of soot, $\mathrm{CH}_{4}, \mathrm{C}_{2} \mathrm{H}_{2}, \mathrm{H}_{2}, \mathrm{CO}, \mathrm{CO}_{2}, \mathrm{H}_{2} \mathrm{O}, \mathrm{HCN}$, and $\mathrm{H}_{2} \mathrm{~S}$ [2]. The amount of each specie has been given in terms of dry ash free weight percentages from a PC Coal Lab drop tube simulation. The output reports from this simulation are provided in Appendix A, and the results are summarized in Table 3.7 for the predicted product yields. The PC Coal Lab simulation also predicts the pre-exponential factor and activation energy for the overall volatile release rate for use in Eq. 3.2.

$$
\begin{gathered}
\frac{d m_{p}}{d t}=-k\left(m_{p}-\left(1-f_{v_{0}}\right)\left(1-f_{w_{0}}\right) m_{p_{0}}\right) \\
k=A e^{-E / R T}
\end{gathered}
$$

In Eq. $3.1, \mathrm{~m}_{\mathrm{p}}$ is the current particle mass, $\mathrm{m}_{\mathrm{p} 0}$ is the initial particle mass, $\mathrm{k}$ is the Arrhenius reaction rate (Eq. 3.2) [15], $\mathrm{A}$ is the pre-exponential factor, $\mathrm{E}$ is the activation energy, $\mathrm{R}$ is the universal gas constant, $\mathrm{T}$ is the gas temperature, $\mathrm{f}_{\mathrm{v} 0}$ is the initial mass 
fraction of volatile matter in the particle, and $\mathrm{f}_{\mathrm{w} 0}$ is the initial mass fraction of moisture in the particle. The kinetic parameters used in Eq. 2.29 and Eq. 3.1 are summarized in Table 3.8.

A check was performed to verify that Fluent and PC Coal Lab produced consistent thermal and mass loss histories for particles undergoing pyrolysis in a isothermal gas stream. Particle temperature and weight loss curves are illustrated in Figures 3.2 and 3.3 for this purpose.

Table 3.7 Predicted volatile distribution (wt. \%).

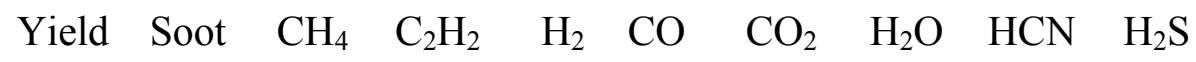

$\begin{array}{lllllllllll}\text { Fluent (ar) } & 33.5 & \text { N/A } & 22.8 & \text { N/A } & 0.29 & 7.2 & 0.0 & 0.5 & \text { N/A } & 1.8\end{array}$

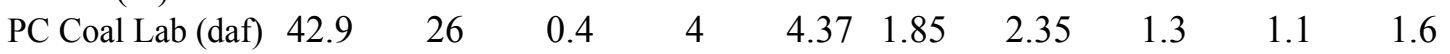

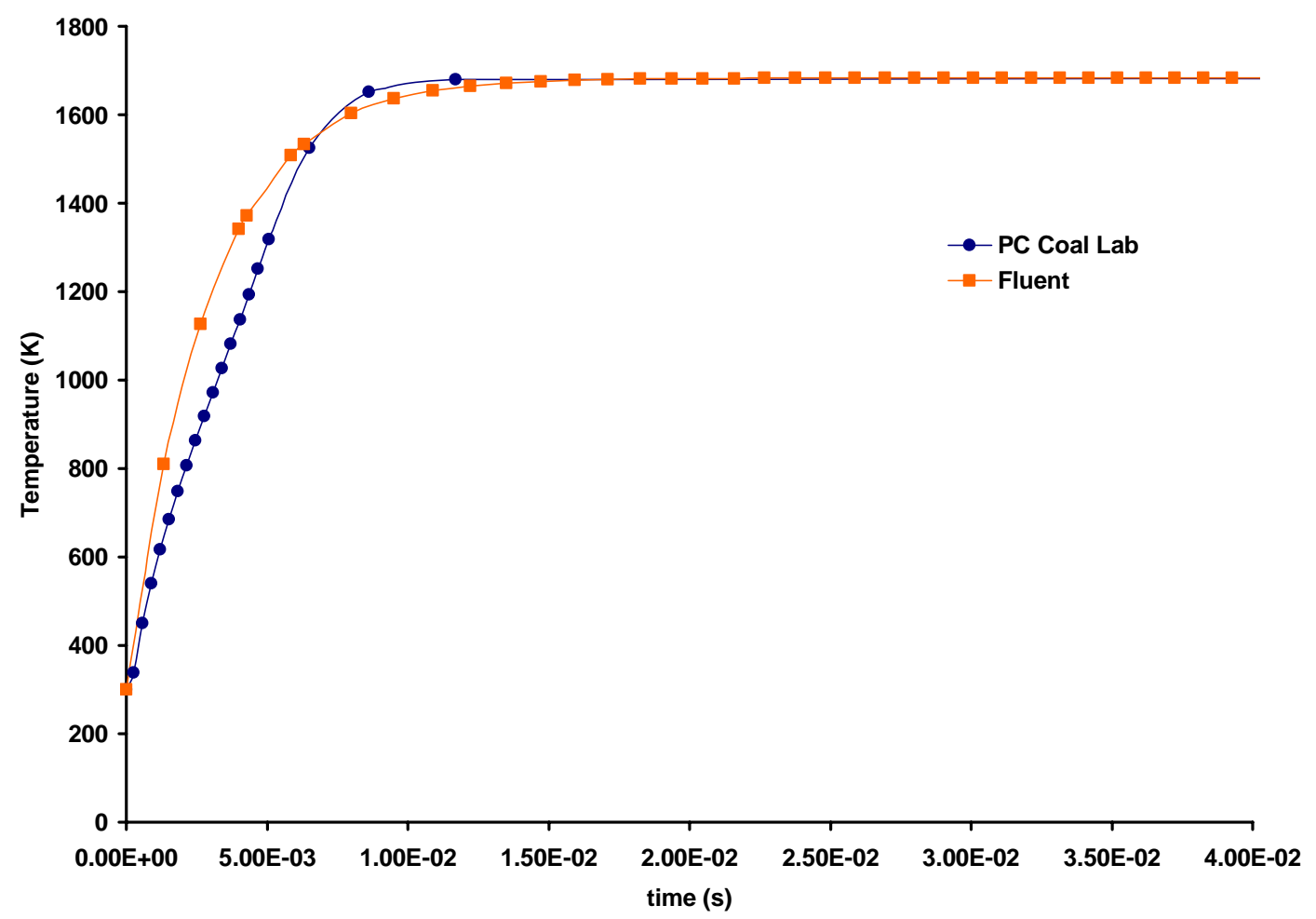

Figure 3.2. Particle temperature versus time. 


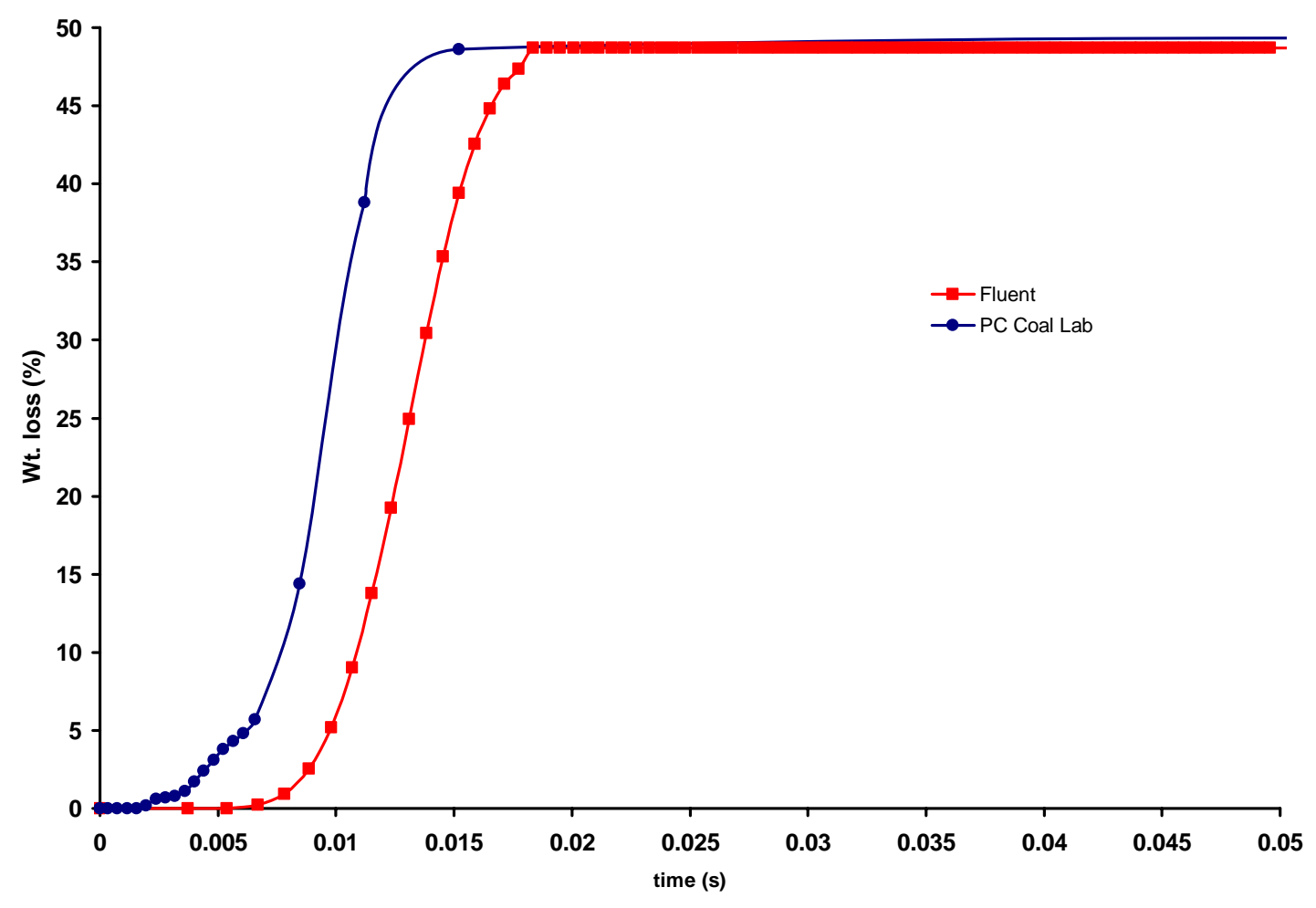

Figure 3.3. Particle mass loss versus time.

In Figure 3.2, it can be seen that particles experience slightly faster heating rates for the Fluent case initially, and then are predicted to be somewhat slower than PC Coal Lab at the end of the heating curve. In Figure 3.3, the predicted particle mass loss versus time is plotted for both PC Coal Lab and Fluent. From Figure 3.3, it is evident that PC Coal Lab predicts quicker mass loss rates than Fluent during the entire heating period. The ultimate yields are in close agreement however. Overall, the two temperature histories are judged to be in good agreement, whereas the mass loss histories are disparate but predict the same ultimate weight loss at the end of the heating period.

The volatile release for the PC Coal Lab model was treated as a gas phase specie that would decompose according to Eq. 3.3. The molecular weight of the composite volatile gas and the stoichiometric coefficients in Eq. 3.3 were computed from the 
predicted dry ash free weight percentages of each product specie from the abovementioned PC Coal Lab drop tube simulation. The soot was treated as gaseous carbon as is discussed in further detail in Section 3.3.

$v o l \rightarrow a S o o t+b \mathrm{CH}_{4}+c \mathrm{C}_{2} \mathrm{H}_{2}+d \mathrm{H}_{2}+e \mathrm{CO}+\mathrm{fCO}_{2}+g \mathrm{H}_{2} \mathrm{O}+h \mathrm{HCN}+i \mathrm{H}_{2} \mathrm{~S} \quad$ Eq. 3.3

Table 3.8 Devolatilization rate parameters.

$\begin{array}{lcccc}\text { Model } & \mathrm{A}_{1} & \mathrm{E}_{1} & \mathrm{~A}_{2} & \mathrm{E}_{2} \\ & 1 / \mathrm{s} & \mathrm{J} / \mathrm{kgmol} & 1 / \mathrm{s} & \mathrm{J} / \mathrm{kgmol} \\ & & & & \\ \text { Kobayashi [22] } & 2 \times 10^{5} & 1.046 \times 10^{8} & 1.3 \times 10^{7} & 1.674 \times 10^{8} \\ \text { PC Coal Lab (SFOR) [2] } & 2.3 \times 10^{5} & 7.84 \times 10^{7} & & \end{array}$

Particles were allowed to swell during devolatilization for both models according to Eq. 3.4 [15]. As mentioned previously, the swelling coefficients were determined by NEA and are summarized in Table 3.9 for each size/density fraction.

$$
\frac{d_{p}}{d_{p_{0}}}=1+\left(C_{s w}-1\right) \frac{\left(1-f_{w_{0}}\right) m_{p_{0}}-m_{p}}{f_{v_{0}}\left(1-f_{w_{0}}\right) m_{p_{0}}}
$$

In the above equation, $d_{p 0}$ is the initial particle diameter, $d_{p}$ is the current particle diameter, and $\mathrm{C}_{\mathrm{sw}}$ is the swelling coefficient. 
Table 3.9. Particle swelling coefficients.

$\begin{array}{lccc}\text { Fraction } & \begin{array}{c}\mathrm{d}_{\text {initial }} \\ (\mu \mathrm{m})\end{array} & \begin{array}{c}\mathrm{d}_{\text {swollen }} \\ (\mu \mathrm{m})\end{array} & \mathrm{C}_{\mathrm{sw}} \\ & & & \\ \text { sg1ps1 } & 750 & 885 & 1.180 \\ \text { sg1ps2 } & 515 & 608 & 1.181 \\ \text { sg1ps3 } & 320 & 378 & 1.181 \\ \text { sg1ps4 } & 180 & 212 & 1.181 \\ \text { sg1ps5 } & 130 & 153 & 1.177 \\ \text { sg1ps6 } & 90 & 106 & 1.178 \\ \text { sg1ps7 } & 40 & 47 & 1.175 \\ \text { sg2ps1 } & 750 & 885 & 1.180 \\ \text { sg2ps2 } & 515 & 608 & 1.181 \\ \text { sg2ps3 } & 320 & 378 & 1.181 \\ \text { sg2ps4 } & 180 & 212 & 1.178 \\ \text { sg2ps5 } & 130 & 153 & 1.177 \\ \text { sg2ps6 } & 90 & 106 & 1.178 \\ \text { sg2ps7 } & 40 & 47 & 1.175 \\ \text { sg3ps1 } & 750 & 885 & 1.180 \\ \text { sg3ps2 } & 515 & 608 & 1.181 \\ \text { sg3ps3 } & 320 & 378 & 1.181 \\ \text { sg3ps4 } & 180 & 212 & 1.178 \\ \text { sg3ps5 } & 130 & 153 & 1.177 \\ \text { sg3ps6 } & 90 & 106 & 1.178 \\ \text { sg3ps7 } & 40 & 47 & 1.175 \\ \text { sg4ps1 } & 750 & 750 & 1.000 \\ \text { sg4ps2 } & 515 & 515 & 1.000 \\ \text { sg4ps3 } & 320 & 320 & 1.000 \\ \text { sg4ps4 } & 180 & 180 & 1.000 \\ \text { sg4ps5 } & 130 & 130 & 1.000 \\ \text { sg4ps6 } & 90 & 90 & 1.000 \\ \text { sg4ps7 } & 40 & 40 & 1.000\end{array}$

\subsection{Combustion and Gasification Chemistry}

Four heterogeneous surface reactions are governed by Eqs. 3.5-8, and seven gas phase reactions are governed by Eqs. 3.9-15 to model gasification and combustion of the fixed carbon in the particle as well as the combustion of volatile gases produced during pyrolysis for the first model $[3,22]$. Additional gas phase reactions had to be defined for the cases that used secondary pyrolysis distributions predicted from PC Coal Lab [2] and 
are given by Eqs. 3.16-18. The reaction rates for the heterogeneous surface reactions were governed by Wen and Chuang's Shrinking Core model [17] defined by Eqs. 2.34-37 and Eq. 2.41 [17]. The pre-exponential factor and activation energy for the Arrhenius reaction rates $\left(\mathrm{k}_{1}\right.$ through $\left.\mathrm{k}_{13}\right)$ defined by Eq. 3.2 for the heterogeneous and homogeneous gas phase reactions are listed in Table 3.10.

$$
\begin{aligned}
& \mathrm{C}+\frac{1}{\phi} \mathrm{O}_{2} \stackrel{k_{1}}{\longrightarrow} 2\left(1-\frac{1}{\phi}\right) \mathrm{CO}+\left(\frac{2}{\phi}-1\right) \mathrm{CO}_{2} \\
& \mathrm{C}+\mathrm{H}_{2} \mathrm{O} \stackrel{k_{2}}{\longrightarrow} \mathrm{CO}+\mathrm{H}_{2} \\
& \mathrm{C}+\mathrm{CO}_{2} \stackrel{k_{3}}{\longrightarrow} \mathrm{CO} \\
& \mathrm{C}+2 \mathrm{H}_{2} \stackrel{k_{4}}{\longrightarrow} \mathrm{CH}_{4} \\
& \mathrm{CH}_{4}+2 \mathrm{O}_{2} \stackrel{k_{5}}{\longrightarrow} \mathrm{CO}_{2}+2 \mathrm{H}_{2} \mathrm{O} \\
& \mathrm{CO}+0.5 \mathrm{O}_{2} \stackrel{k_{6}}{\longrightarrow} \mathrm{CO}_{2} \\
& \mathrm{CO}+\mathrm{H}_{2} \mathrm{O} \stackrel{k_{7}}{\longrightarrow} \mathrm{CO}_{2}+\mathrm{H}_{2} \\
& \mathrm{CO}+\mathrm{H}_{2} \stackrel{k_{8}}{\longrightarrow} \mathrm{CO}_{2} \mathrm{H}_{2} \mathrm{O} \\
& \mathrm{H}_{2}+0.5 \mathrm{O}_{2} \stackrel{k_{9}}{\longrightarrow} \mathrm{H}_{2} \mathrm{O} \\
& \mathrm{CH}_{4}+\mathrm{H}_{2} \mathrm{O} \stackrel{k_{10}}{\longrightarrow} \mathrm{CO}_{+}+3 \mathrm{H}_{2} \\
& \mathrm{CO}+3 \mathrm{H}_{2} \stackrel{k_{11}}{\longrightarrow} \mathrm{CH}_{4}+\mathrm{H}_{2} \mathrm{O} \\
& \mathrm{C}_{2} \mathrm{H}_{2}+2.5 \mathrm{O}_{2} \stackrel{k_{12}}{\longrightarrow} \mathrm{H}_{2} \mathrm{O}+2 \mathrm{CO}_{2} \\
& \mathrm{SoOt}+\mathrm{H}_{2} \mathrm{O} \stackrel{k_{13}}{\longrightarrow} \mathrm{CO}_{+} \mathrm{H}_{2} \\
& \mathrm{SoOt}+\mathrm{O}_{2} \stackrel{k_{\text {soot }}}{\longrightarrow} \mathrm{CO}_{2}
\end{aligned}
$$

Eq. 3.18 
Table 3.10. Kinetic parameters.

\begin{tabular}{ccc} 
Reaction & $\mathrm{A}(1 / \mathrm{s})$ & $\mathrm{E}(\mathrm{J} / \mathrm{kgmol})$ \\
\hline $\mathrm{k}_{1}$ & 8710 & 17967 \\
$\mathrm{k}_{2}$ & 247 & 21060 \\
$\mathrm{k}_{3}$ & 247 & 21060 \\
$\mathrm{k}_{4}$ & 0.12 & 17921 \\
$\mathrm{k}_{5}$ & $2.1 \times 10^{11}$ & $2.0 \times 10^{8}$ \\
$\mathrm{k}_{6}$ & $2.2 \times 10^{12}$ & $1.7 \times 10^{8}$ \\
$\mathrm{k}_{7}$ & $2.75 \times 10^{10}$ & $4.8 \times 10^{8}$ \\
$\mathrm{k}_{8}$ & 0.0265 & 3960 \\
$\mathrm{k}_{9}$ & $6.8 \times 10^{15}$ & $1.68 \times 10^{8}$ \\
$\mathrm{k}_{10}$ & $4.4 \times 10^{11}$ & $4.0 \times 10^{8}$ \\
$\mathrm{k}_{11}$ & $2.1 \times 10^{11}$ & $2.0 \times 10^{8}$ \\
$\mathrm{k}_{12}$ & $1.0 \times 10^{15}$ & $1.0 \times 10^{8}$ \\
$\mathrm{k}_{13}$ & $2.1 \times 10^{11}$ & $2.0 \times 10^{8}$
\end{tabular}

As mentioned previously, the soot that is given off during the initial heating of the coal particle was treated as carbon graphite as a pseudo-gas specie. The soot will proceed to combust and gasify according to Eq. 3.17 and 3.18. The soot oxidation rate was modeled after Park et al., [23] and is defined by Eq. 3.19 for a solid particle.

$$
\begin{gathered}
k_{\text {soot }}=\frac{240 e^{-15100 / T} p_{O_{2}}}{1+21.3 e^{2060 / T}} \chi+5.35 \times 10^{-2} e^{-7640 / T} p_{O_{2}}(1-\chi) \\
\chi=\left(1+\frac{1.51 \times 10^{5} e^{-48800 / T}}{4.46 \times 10^{-3} e^{-7640 / T} p_{O_{2}}}\right)^{-1}
\end{gathered}
$$

In the above equations, $\mathrm{T}$ is the gas temperature (in degrees Kelvin) surrounding the particle and $\mathrm{P}_{\mathrm{O} 2}$ is the partial pressure of oxygen at the particle surface in atmospheres. As mentioned above, Eq. 3.19 is a surface rate equation which has units of $\mathrm{g} / \mathrm{cm}^{2}$-s. In order to treat soot as a pseudo-gas phase specie it was necessary to convert the units for a surface reaction to those for a volumetric reaction. The surface reaction units of $\mathrm{g} / \mathrm{cm}^{2}$-s were converted to the desired units of $\mathrm{kgmol} / \mathrm{m}^{3}$-s using Eq. 3.21. 


$$
\frac{\mathrm{g}}{\mathrm{cm}^{2} \mathrm{~s}} \times \frac{100^{2} \mathrm{~cm}^{2}}{\mathrm{~m}^{2}} \times \frac{6}{d_{p}} \times \frac{1 \mathrm{~kg}}{1000 \mathrm{~g}} \times \frac{1 \mathrm{kgmol}}{12 \mathrm{~kg}_{\text {Carbon }}} \times \varepsilon
$$

In the above, $6 / d_{p}$ is the ratio of surface area to volume of a sphere where $d_{p}$ has units of meters. The last multiplier in Eq. 3.21 represents the void fraction of soot in the computational cell which is defined as the ratio of the volume of soot particles to the volume of the computational cell. In using Eq. 3.21, it was assumed that the soot "particles" would have a constant diameter of 0.8 microns and a density of $2000 \mathrm{~kg} / \mathrm{m}^{3}$ (Niksa, 2006; reference [24]).

\subsection{User Defined Functions}

This section addresses the application of custom subroutines that were used in this study. Fluent allows the user to specify user-defined functions to customize several of the properties and laws that are associated with the Discrete Phase Model. Figure 3.4 illustrates how the UDF that governs combustion and gasification of the coal particles used in this study operates. This UDF was developed by Shi et al. [3,16]. The UDF consists of several different macros that each perform a job in controlling the mass and energy exchange between the discrete and continuous phase along each particle's trajectory. At the start of the DPM update, the solver calls the DEFINE_DPM_INJECTION_INIT macro for all of the defined injections. Here, the user-defined memory variable are initialized, the ultimate and proximate analysis and chemical rate constants are read in from the custom scheme panel, and the volatile specie mass fractions are computed. DEFINE_DPM_SCALAR_UPDATE is called at the beginning of each particles time step. This macro is used to initialize variables that are used in the particle laws that are described in detail in Chapter 2. 


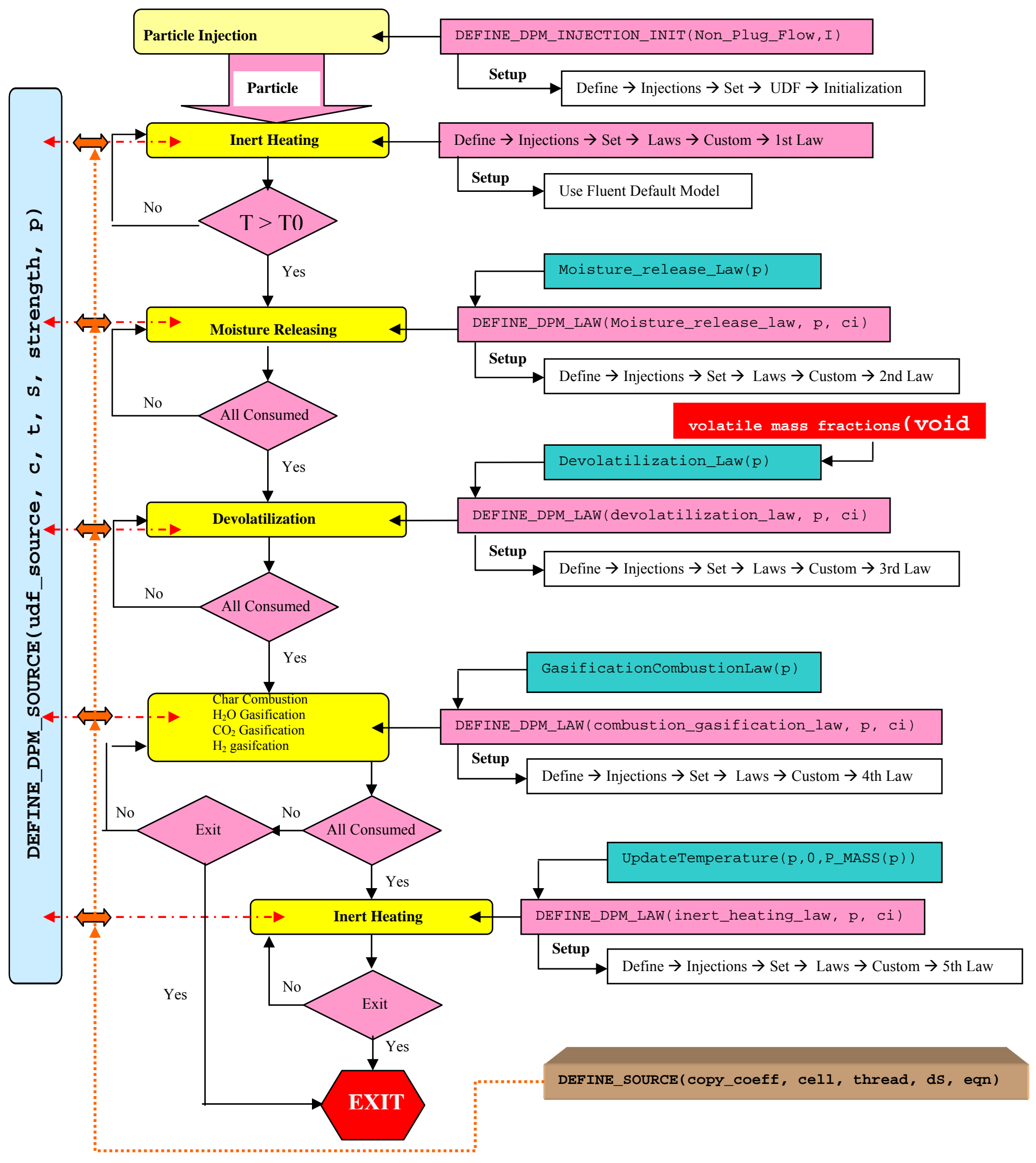

Figure 3.4. Gasification UDF flowchart [16]. 
The first law the particle will experience is the inert heating law governed by Eq. 2.21. The particles will undergo inert heating until the particle temperature reaches the vaporization temperature (T0 in Figure 3.3). Once the particles reach the vaporization temperature, the solver will call the next law which is the moisture release law governed by Eq. 2.25 and Eq. 2.26. The particles will undergo moisture release until all of their moisture content has been evaporated. Once this condition has been satisfied, the solver will next call the devolatilization law governed by Eqs. 2.27-29. The solver will continue to call this law during each particles time step until all of the volatile mass has been released. When this condition is satisfied, the solver will next call the combined combustion and gasification laws that are governed by Eqs. 2.31-41. Once all of the fixed carbon has been converted, the solver will again execute the inert heating law until the particle consisting entirely of ash exits the domain. Whenever a particle exits a computational cell, or when the particle law is incremented, the solver will call the DEFINE_DPM_SOURCE macro. Here, the source terms for the mass and energy exchange between the discrete and continuous phase are specified. If the current law corresponds to moisture release, then the energy sink is defined as the product of the mass loss (difference between the particle mass entering and leaving the control volume) with the heat of vaporization. This is then multiplied by the strength (defined as the number of particles per second) of the stream represented by that particle. The mass source to the continuous phase if the particle is undergoing moisture release is defined as the mass loss multiplied by the DPM under-relaxation factor multiplied by the strength of the particle stream. This is added to the cell storage as an $\mathrm{H}_{2} \mathrm{O}$ source. If the current law corresponds to devolatilization, then the energy sink is defined as the product of the mass 
loss with the heat of pyrolysis. Similarly, this is then multiplied by the strength of the particle stream. The mass fractions computed in the DEFINE_DPM_INJECTION_INIT macro are used here to compute the mass source of each devolatilizing specie to the continuous phase. During combustion and gasification, the energy and mass source terms are computed in a similar manner to the above for each surface reaction.

The UDF developed by Shi et al. $[3,16]$ was modified in two ways for the present study. The first allowed the user to specify multiple different coal injections. This involved rearranging the source code considerably so that when each macro is called by the solver, the correct values where used in the variables corresponding to the current law depending on which injector the particle being tracked originated from. This involved converting most variables to arrays and adding switch and "if" statements to check which injection the particles belong to. The second modification was an additional macro written to record data relating to the state of the particle when it impacts a boundary wall. DEFINE_DPM_BC is a macro which allows the user to hook a subroutine to the Fluent solver which will execute whenever a particle touches a boundary. The DEFINE_DPM_BC macro was most frequently hooked to the second stage gasifier wall in this study. The portion of the UDF which is called at the boundary is listed in Appendix B and is described below. A pre-made subroutine to determine normal impact velocity and particle restitution coefficients is provided in the Fluent User-Defined Function user manual and was adapted for this study. The macro listed in Appendix B was used to record the normal impact velocity, impact angle, particle diameter, particle density, particle temperature, and the fixed carbon remaining in the particle at impact. The impact angle, defined in Figure 3.5, was computed using Eq. 3.22. In Eq. 3.22, $\mathbf{n}$ is 
the wall face normal vector and $\mathbf{V}$ is the particle impact velocity vector. The normal velocity is computed from Eq. 3.23 and is written to a file along with the other variables mentioned above each time a particle touches a wall boundary of interest.

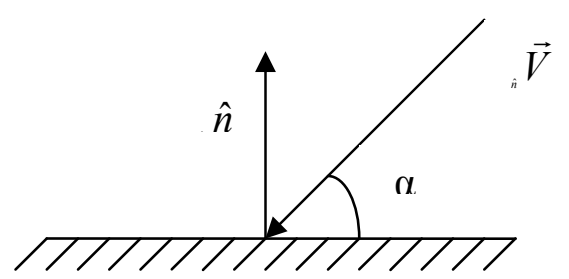

Figure 3.5. Impact angle definition.

$$
\begin{gathered}
\alpha=\frac{\pi}{2}-\cos ^{-1}\left(\frac{\hat{n} \cdot \vec{V}}{|\vec{V}|}\right) \\
V_{n}=\vec{V} \cdot \hat{n}
\end{gathered}
$$




\section{Chapter 4. Results}

\subsection{Introduction}

This chapter presents results obtained for the two different devolatilization models described in Chapter 3. Section 4.2 discusses simulations that used the phenomenological model and two-competing rates Kobayashi volatile release rate equation that were employed by Dr. Shaoping Shi [16], as discussed in Section 3.6. Section 4.3 presents some preliminary results that where obtained using volatile specie distributions obtained from a PC Coal Lab drop tube simulation and described in detail in Section 3.6. Both setups used the same combustion and gasification chemistry described in Section 3.7.

\subsection{Comparison Between Single and Multiple Surface Injections}

Data for four separate simulations that employed devolatilization kinetics developed by Shi et al., $[3,16]$ and described in Section 3.6 are presented in this section. In all figures, labels a, b, c, and d correspond to these different cases. For case 1, variable gas specific heats were used with constant gas thermal conductivity and viscosity for each specie. Case 2 used constant specific heats with the kinetic theory model available in Fluent for thermal conductivity and viscosity. Case 3 used variable specific heats with constant gas viscosity and user-defined power law for thermal conductivity. Case 4 used the same gas property definitions as case 3 but used 28 surface injections on each inlet corresponding to each size/density fraction of the Bailey coal sample. The diameter distribution for cases 1,2, and 3 was set to a constant value over each surface injection. In these cases, the Sauter-mean diameter of $108.4 \mu \mathrm{m}$ was used from the analysis of the Bailey coal sample [19]. The above setup conditions are summarized briefly in Table 4.1. 
Table 4.1. Definitions for particle diameter, $C_{p}, k$, and $\mu$ for cases $1-4$.

\begin{tabular}{|c|c|c|c|c|}
\hline Case \# & $\mathrm{C}_{\mathrm{p}}$ & $\mathrm{k}$ & $\mu$ & $d_{p}$ \\
\hline 1 & polynomial & constant & constant & Sauter-mean \\
\hline 2 & constant & kinetic theory & kinetic theory & Sauter-mean \\
\hline 3 & polynomial & power law & constant & Sauter-mean \\
\hline 4 & polynomial & power law & constant & partitioned \\
\hline
\end{tabular}

Particle laws were governed in each case based on the gasification User Defined Function (UDF) that was developed by Shi et al., 2006 [3]. The UDF governed volatile specie distributions, devolatilization rates, gasification, and combustion rates as well as the conservation of mass and energy with regard to the interaction between the discrete and continuous phase, as has been summarized in Chapter 3. In order to account for multiple simultaneous surface injections, the UDF had to be modified during the course of this study.

Figure 4.1 illustrates the variation in the computed gas phase temperature distribution for the up-flow CFD model versus different relationships used for the dependence of specific heats, viscosity, and thermal conductivity on temperature as well as the influence of injecting multiple different sizes and densities during each discrete phase update in the solution process. Figure 4.1.a, 4.1.c, and 4.1.d show maximum temperatures in stage 2 of around $1500{ }^{\circ} \mathrm{C}$. In Figure 4.1.b, the maximum temperature in the second stage reaches $2700{ }^{\circ} \mathrm{C}$; this predicted temperature is judged to be unrealistic. Variable specific heats refers to a polynomial variation with gas temperature. The kinetic theory model available in Fluent v6.3.31 was enabled for the second case. It should be noted that though the gas phase specific heats in this case were set to constant values, the maximum temperature was seen to be around $2500{ }^{\circ} \mathrm{C}$ for unreported cases that used the 
same polynomial function for the heat capacities with the kinetic theory model enabled. The cases with this $\mathrm{C}_{\mathrm{p}}$ polynomial variation, but using constant gas phase viscosities with a power law function of temperature for thermal conductivity showed the most realistic maximum second stage gas temperatures. In Figure 4.1.d, the temperature in the first stage is asymmetric due to the tendency of the heavier particles to circulate in this region.

Figure 4.2 illustrates the gas phase velocity predicted by the four steady state simulations. The mixture was modeled using an ideal gas law to relate density, pressure, and temperature. The velocity field was initialized to zero and the temperature field was initialized to $1800 \mathrm{~K}$ and $273 \mathrm{~K}$ in the first and second stages, respectively, to begin each of the four solutions. The results here have been produced from simulations that ran 10,000 iterations.

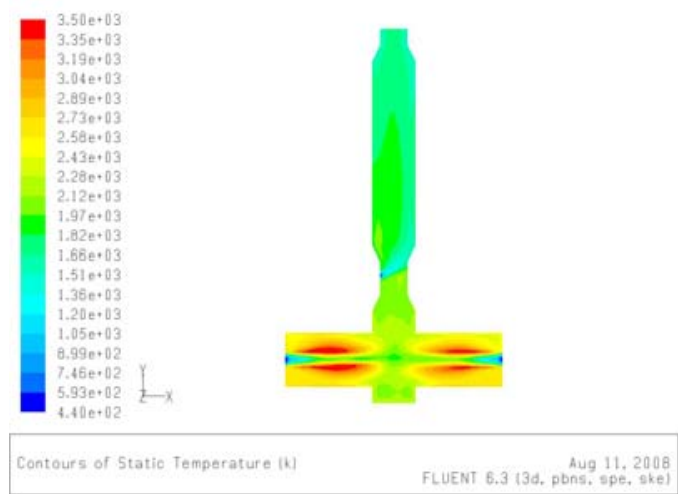

a) Case 1

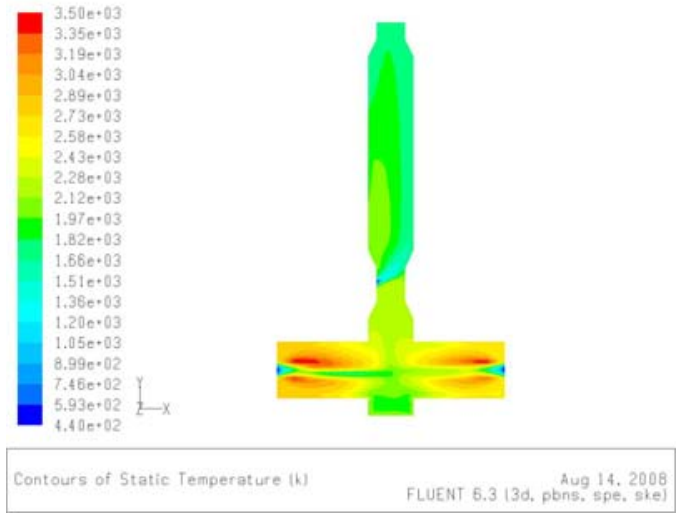

c) Case 3

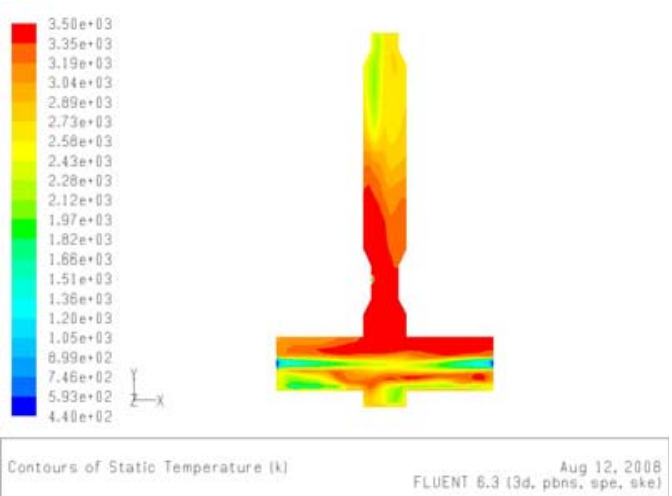

b) Case 2

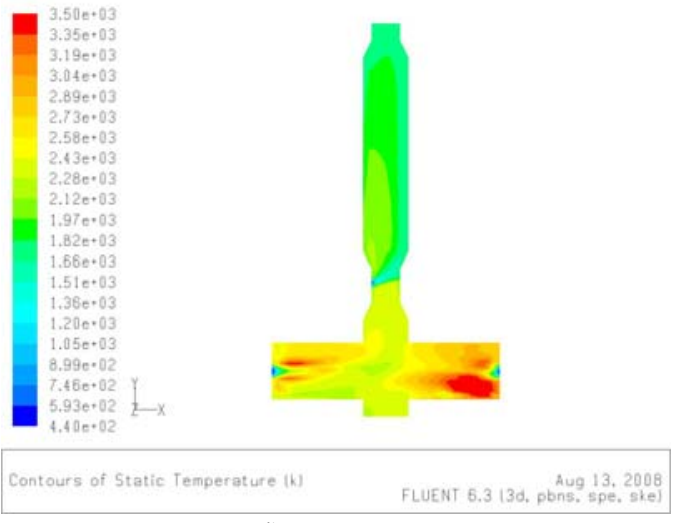

d) Case 4

Figure 4.1. Center-plane temperature contours. 


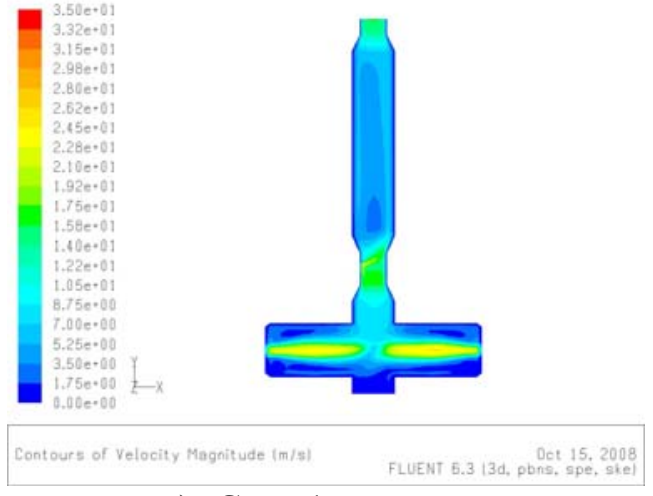

a) Case 1, contours

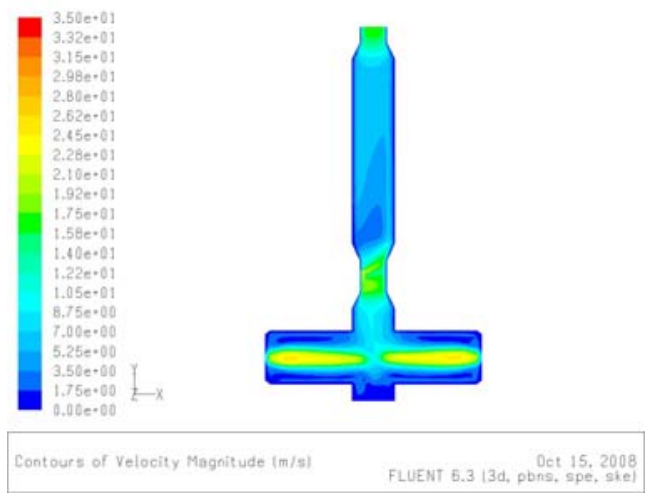

c) Case 3, contours

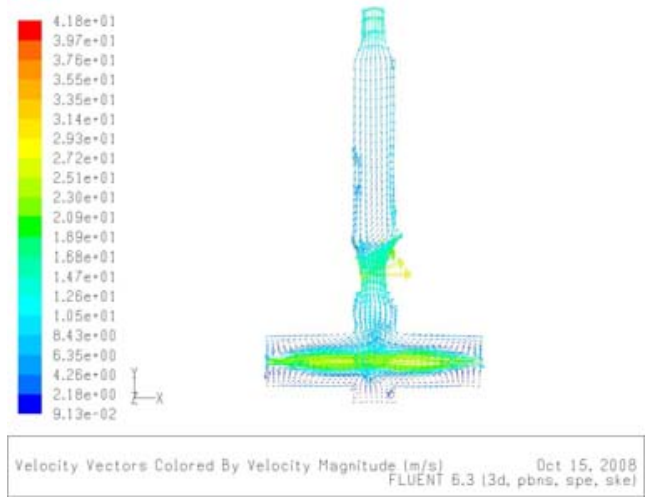

e) Case 1, vectors

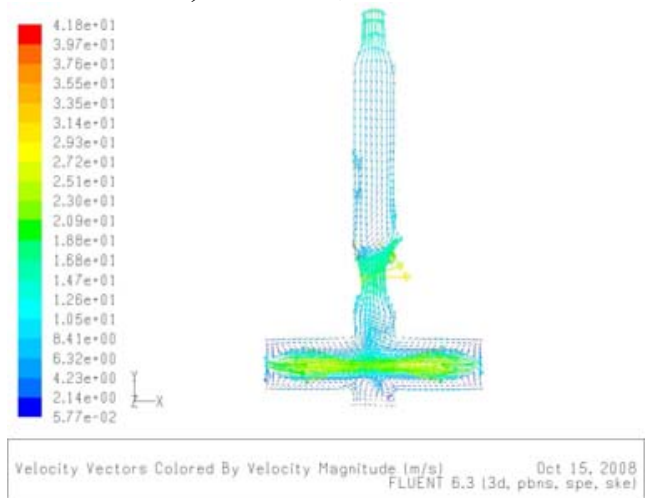

g) Case 3, vectors

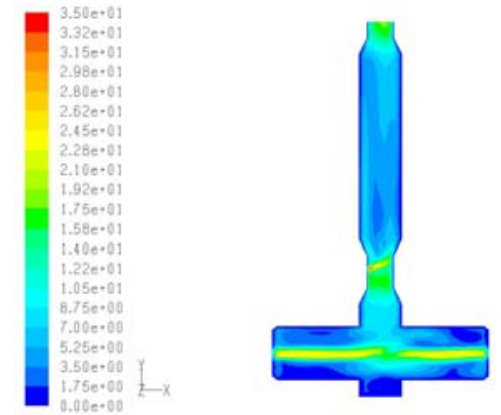

Contours of Velocity Magnitude $(m / s)$ FLUENT 6.3 l3d, pbns, spe, stel

b) Case 2, contours

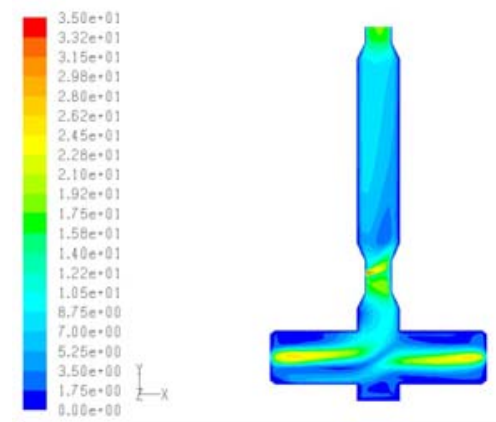

Contours of Velocity Magnitude (m/s) FLUENT 5.3 $13 \mathrm{~d}$, pons, spe, stel

d) Case 4, contours
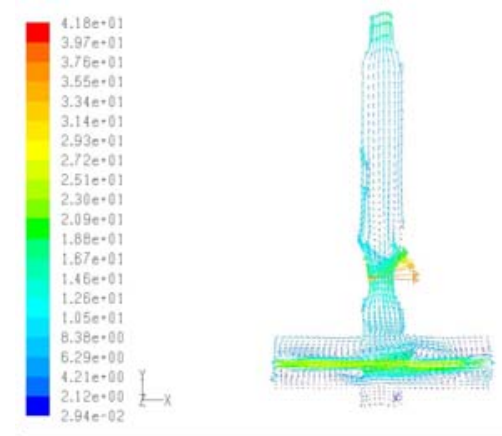

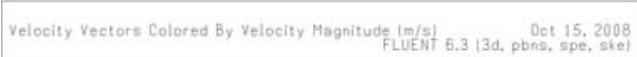

f) Case 2, vectors
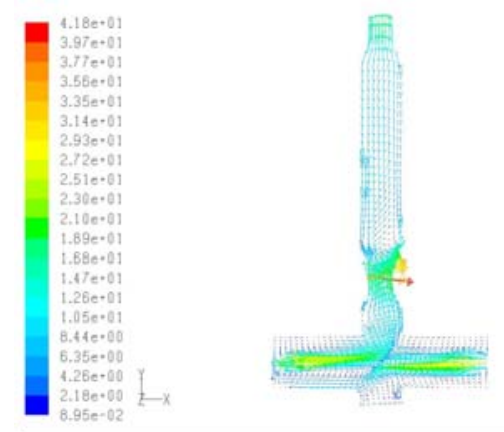

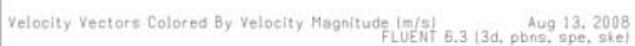

h) Case 4, vectors

Figure 4.2. Center-plane gas velocity. 
The gas velocity in the region near the center of the bottom of the second stage was influenced by the solids flow rate from the second stage inlet. Cases 3 and 4 are of special interest because they highlight the difference between using single and multiple injections to represent a sample of coal for identical case setups. Gas and wall temperatures calculated in stages 1 and 2 for the four cases discussed in this section are summarized in Table 4.2.

Table 4.2. Average temperatures and fixed carbon conversion for cases 1-4.

\begin{tabular}{|c|c|c|c|c|c|}
\hline Case \# & $\begin{array}{l}\mathrm{T}_{\text {gas }} \text {-stg. } 1 \\
(\mathrm{~K})\end{array}$ & $\begin{array}{l}\mathrm{T}_{\mathrm{gas}}-\mathrm{stg} .2 \\
(\mathrm{~K})\end{array}$ & $\begin{array}{l}\mathrm{T}_{\text {wall-stg.1 }} \\
(\mathrm{K})\end{array}$ & $\begin{array}{c}\mathrm{T}_{\text {wall-stg. } 2} \\
(\mathrm{~K})\end{array}$ & $\begin{array}{c}\text { FC conversion (total) } \\
(\%)\end{array}$ \\
\hline 1 & 2590 & 1760 & 2606 & 1734 & 85.6 \\
\hline 2 & 3056 & 2972 & 3014 & 3009 & 20.4 \\
\hline 3 & 2522 & 1818 & 2560 & 1796 & 85.5 \\
\hline 4 & 2574 & 1805 & 2568 & 1750 & 89.8 \\
\hline
\end{tabular}

Carbon monoxide contours on the center-plane are illustrated in Figure 4.3 a)-d). $\mathrm{CO}$ is introduced in the volatile stream but is primarily produced from char-steam and char- $\mathrm{CO}_{2}$ gasification, char oxidation, and the gas phase reaction of $\mathrm{CH}_{4}$ with $\mathrm{O}_{2}$. Figure 4.3 e)-h) illustrates center-plane $\mathrm{CO}_{2}$ contours produced from reactions of methane and carbon monoxide with oxygen and the water-gas shift reaction. In Figure 4.3 i)-1), it can be seen where devolatilization takes place in the shape of the center-plane contour of $\mathrm{CH}_{4}$ volume fraction. In stage 1, the coal particles are injected with a high relative velocity and the volatile release of methane is spread out in a nearly straight line. The reaction of methane and oxygen immediately takes place, and the product species consisting of carbon dioxide and water vapor are formed. Figure $4.3 \mathrm{~m}$ )-p) illustrates center-plane hydrogen contours for cases 1, 2,3, and 4. Hydrogen is a combustible fuel and is one of the motivators for continued research in coal gasification. 


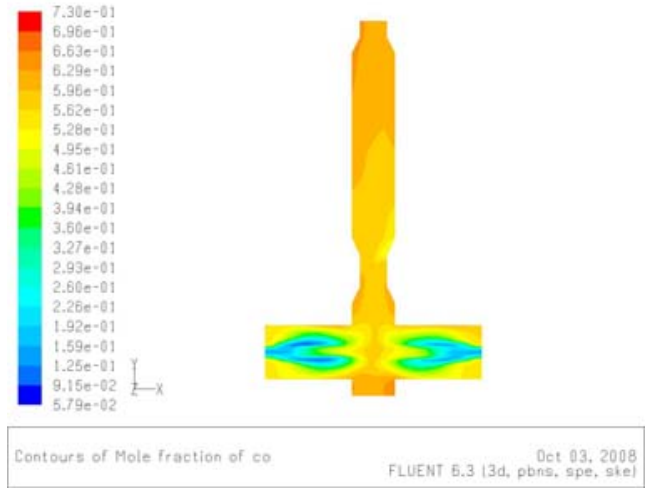

a) Case 1, CO

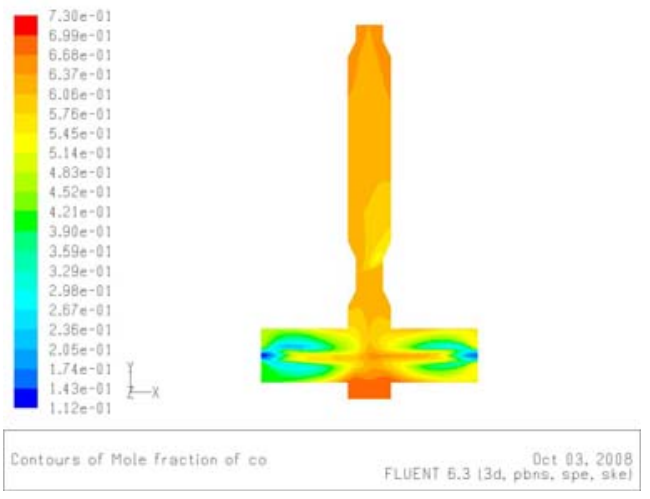

c) Case 3, $\mathrm{CO}$

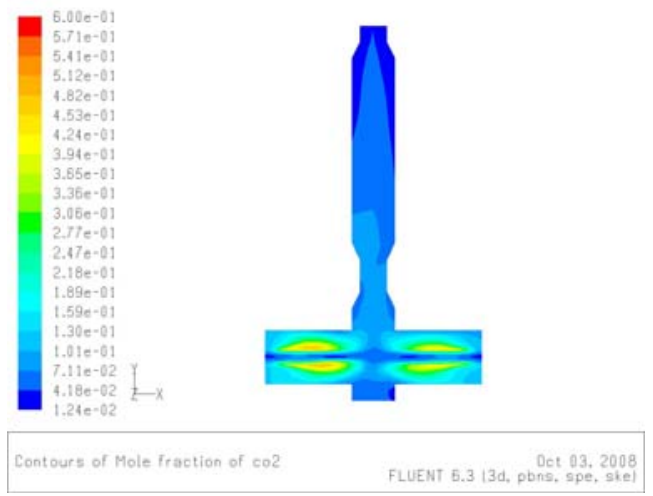

e) Case $1, \mathrm{CO}_{2}$

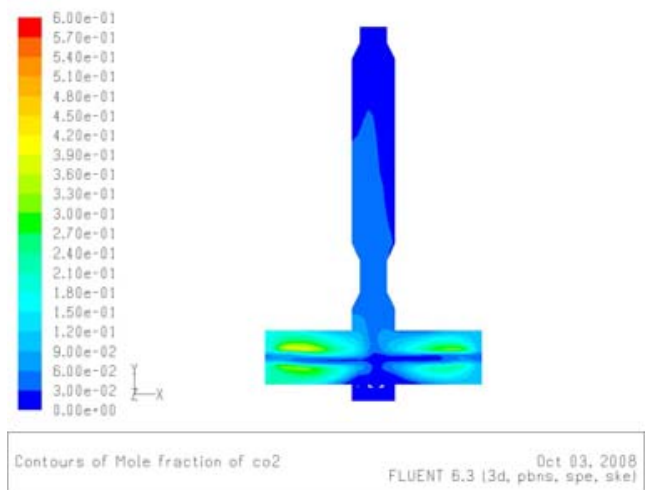

g) Case $3, \mathrm{CO}_{2}$

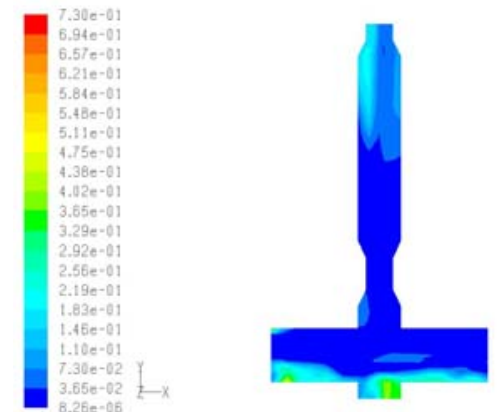

b) Case 2, $\mathrm{CO}$

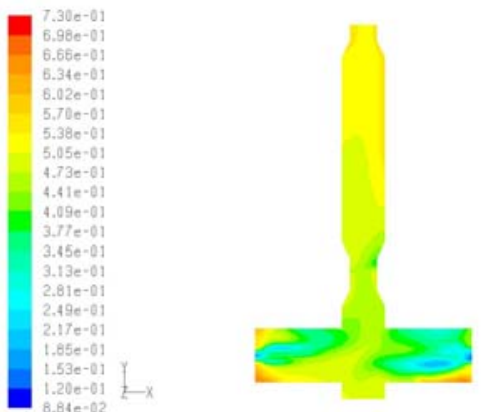

Contours of Mole fraction of co FLUENT 5.3 13d, pbns, 9pe, stel

d) Case 4, CO
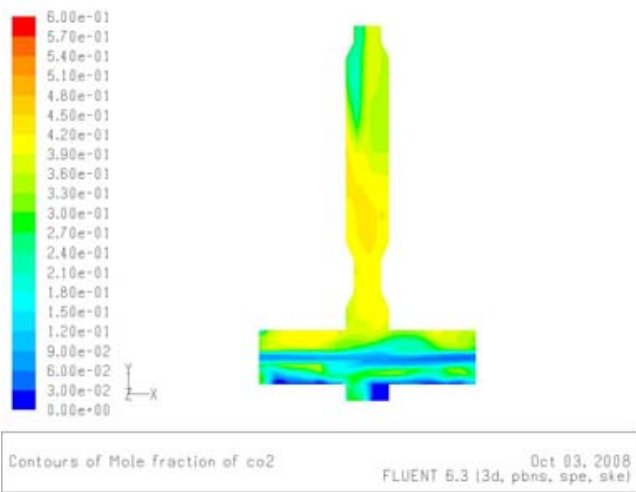

f) Case 2, $\mathrm{CO}_{2}$

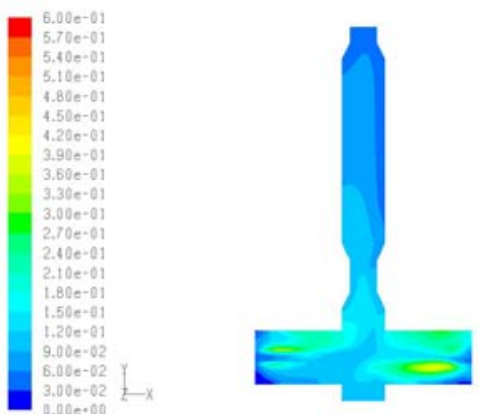

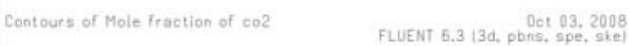

h) Case 4, $\mathrm{CO}_{2}$

Figure 4.3. Center-plane gas contours. 

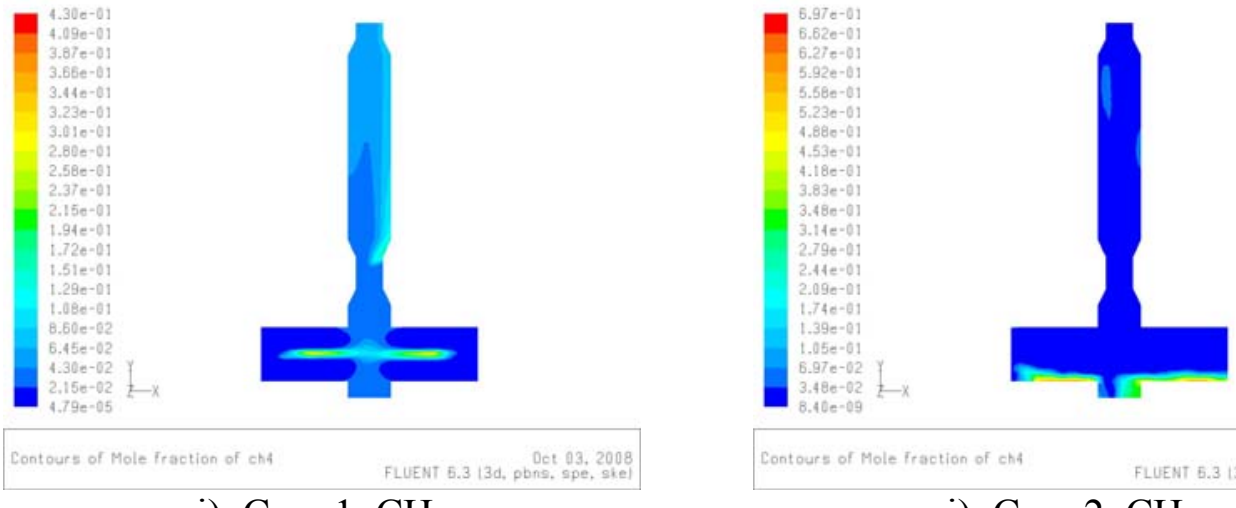

i) Case $1, \mathrm{CH}_{4}$
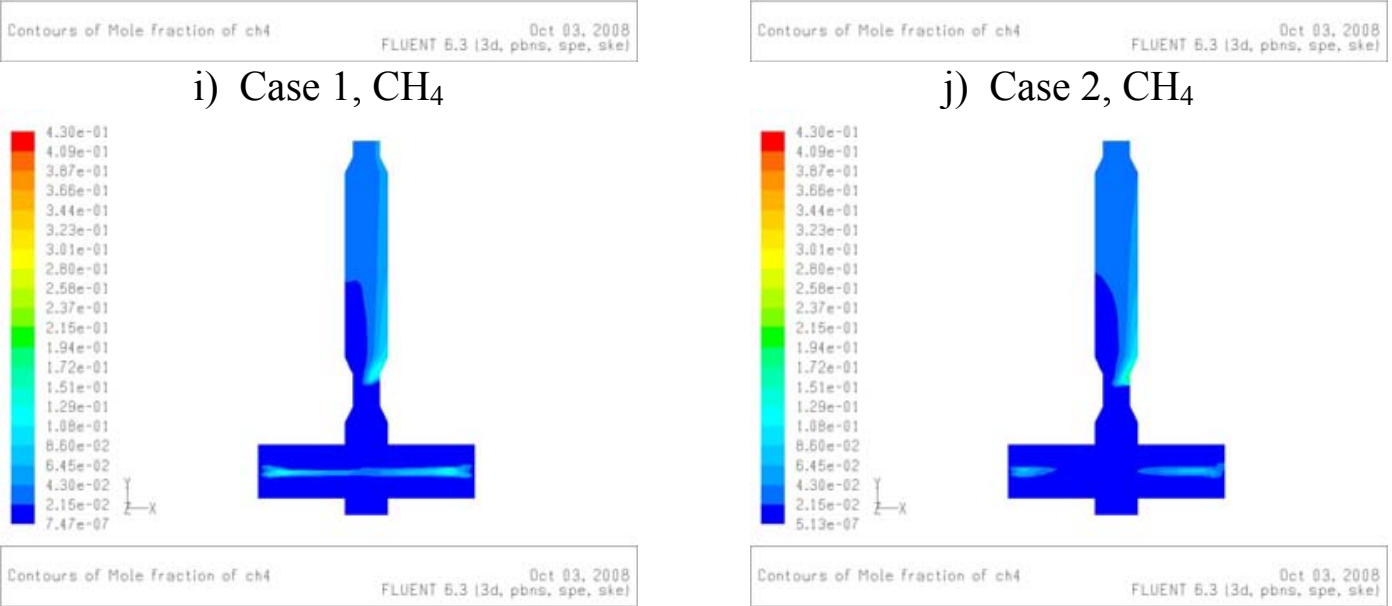

k) Case $3, \mathrm{CH}_{4}$
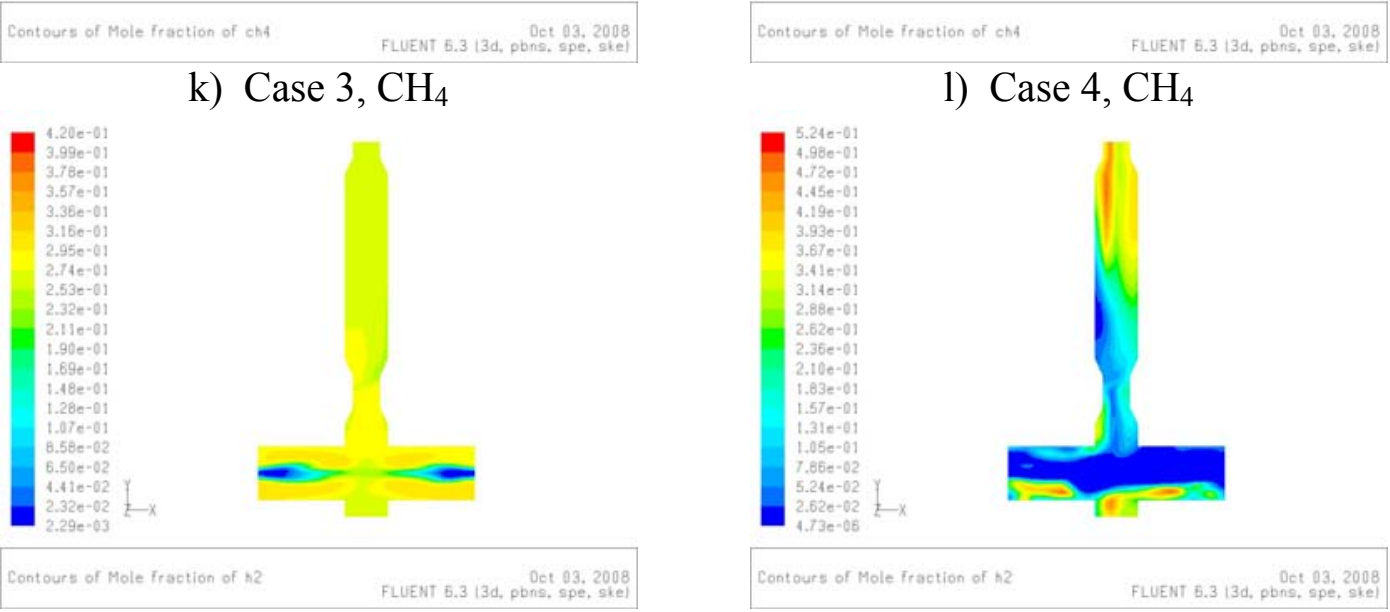

m) Case $1, \mathrm{H}_{2}$

1) Case $4, \mathrm{CH}_{4}$
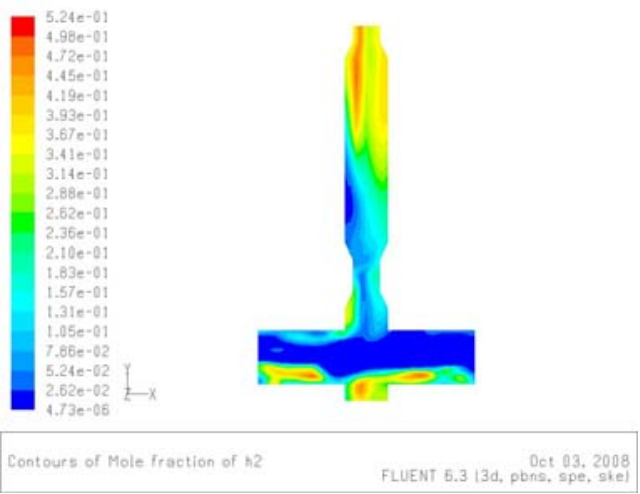

n) Case $2, \mathrm{H}_{2}$

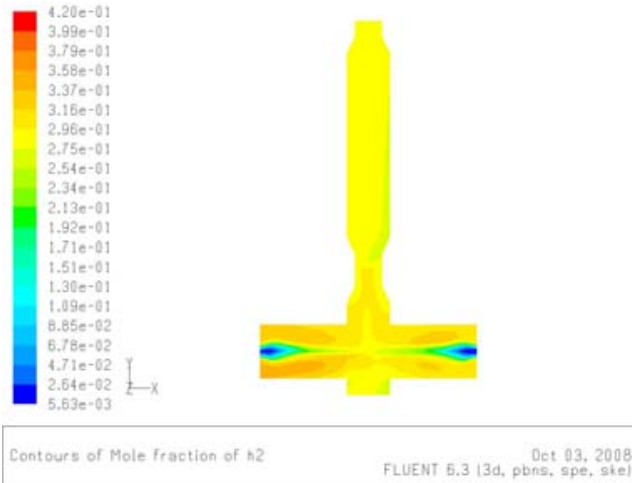

o) Case $3, \mathrm{H}_{2}$

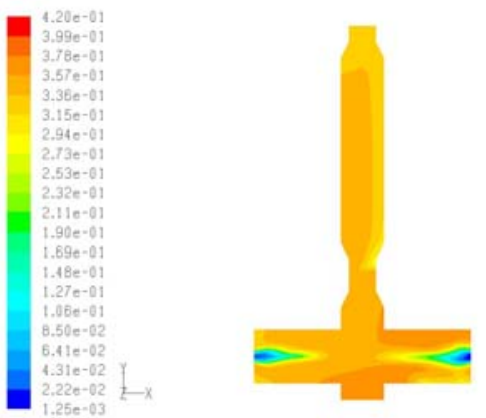

Contours of Mole fraction of h2 FLuENT 5.3 13d, pbns, spe, stel

p) Case $4, \mathrm{H}_{2}$

Figure 4.3. Center-plane gas contours. 


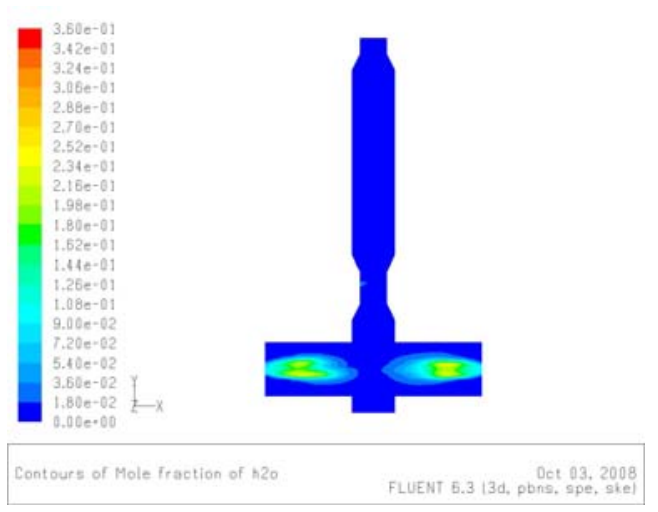

q) Case $1, \mathrm{H}_{2} \mathrm{O}$

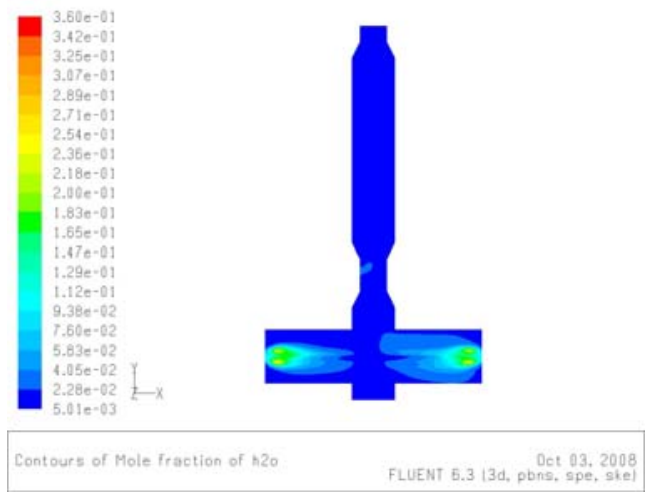

s) Case $3, \mathrm{H}_{2} \mathrm{O}$

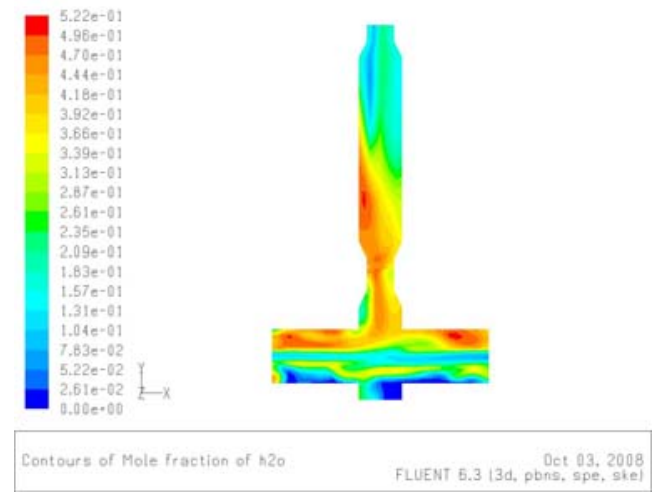

r) Case $2, \mathrm{H}_{2} \mathrm{O}$

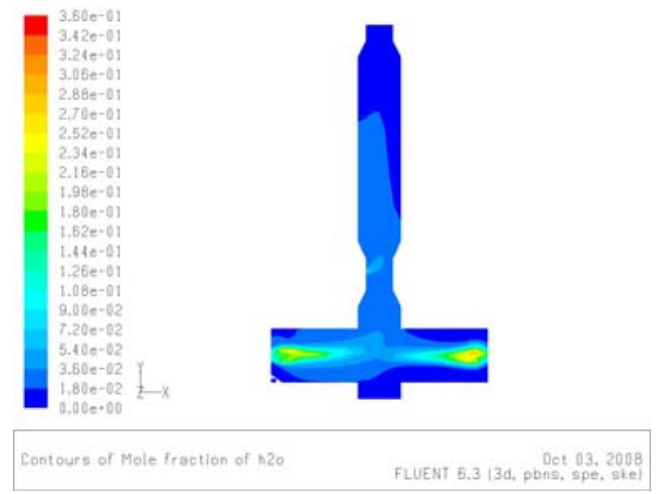

t) Case $4, \mathrm{H}_{2} \mathrm{O}$

Figure 4.3. Center-plane gas contours (concluded).

In this study, hydrogen was produced from gasification of fixed carbon with steam as well as reactions of methane with steam and the water-gas shift reaction. Center-plane contours of $\mathrm{H}_{2} \mathrm{O}$ are presented in Figure 4.3 q)-t). It is apparent that the water droplets injected with the solid fuel evaporate rapidly in both stages to produce steam which proceeds to gasify with the fixed carbon. $\mathrm{H}_{2} \mathrm{O}$ is also converted into carbon dioxide and hydrogen via the water-gas shift reaction.

Computed exit gas volume fractions (area-weighted averages) are presented for each of the four cases in Table 4.3, and exit gas mass fractions are given in Table 4.4 for comparison. The case with kinetic theory thermodynamics (labeled case 2 in the above figures) produced inaccurate results for the gaseous species due to an unrealistically high and uneven temperature distribution. 
Table 4.3. Exit gas volume fractions.

$\begin{array}{ccccccccc}\text { Case \# } & \mathrm{CO} & \mathrm{CO}_{2} & \mathrm{CH}_{4} & \mathrm{H}_{2} & \mathrm{H}_{2} \mathrm{O} & \mathrm{H}_{2} \mathrm{~S} & \mathrm{~N}_{2} & \mathrm{Ar} \\ 1 & 0.625 & 0.03 & 0.06 & 0.258 & 0.002 & 0.007 & 0.008 & 0.011 \\ 2 & 0.089 & 0.275 & 0.121 & 0.156 & 0.273 & 0.011 & 0.015 & 0.016 \\ 3 & 0.649 & 0.004 & 0.041 & 0.276 & 0.009 & 0.006 & 0.003 & 0.011 \\ 4 & 0.549 & 0.042 & 0.045 & 0.329 & 0.011 & 0.007 & 0.008 & 0.010\end{array}$

Table 4.4. Exit gas mass fractions.

\begin{tabular}{|c|c|c|c|c|c|c|c|c|}
\hline Case \# & $\mathrm{CO}$ & $\mathrm{CO}_{2}$ & $\mathrm{CH}_{4}$ & $\mathrm{H}_{2}$ & $\mathrm{H}_{2} \mathrm{O}$ & $\mathrm{H}_{2} \mathrm{~S}$ & $\mathrm{~N}_{2}$ & $\mathrm{Ar}$ \\
\hline 1 & 0.823 & 0.062 & 0.045 & 0.025 & 0.001 & 0.011 & 0.012 & 0.021 \\
\hline 2 & 0.094 & 0.660 & 0.004 & 0.029 & 0.152 & 0.013 & 0.020 & 0.027 \\
\hline 3 & 0.887 & 0.008 & 0.034 & 0.026 & 0.008 & 0.011 & 0.006 & 0.021 \\
\hline 4 & 0.775 & 0.093 & 0.037 & 0.033 & 0.010 & 0.012 & 0.018 & 0.021 \\
\hline
\end{tabular}

From Table 4.3 it can be seen that the computed exit volume fractions did not vary much between cases 1,3 , and 4 . The relatively large amount of carbon dioxide and water present at the exit for case 2 indicates that gasification was hindered during this inaccurate simulation.

Figures 4.4-9 were generated for cases 3 and 4 to compare the results for the setup using a single average diameter distribution to one that used a partitioned distribution to represent the Bailey coal sample. Figures 4.4 and 4.5 were generated by recording the local mass fractions of $\mathrm{CO}_{2}, \mathrm{CO}, \mathrm{H}_{2}$, and $\mathrm{H}_{2} \mathrm{O}$ in the gas phase along each particles trajectory through the second stage region in the up-flow gasifier. The recorded data was then sorted and averaged in bins of the axial y-coordinate of particle position in stage 2, and plotted on a single graph for both case 3 and case 4 . Particles were injected with a uniform Sauter-mean diameter from the first and second stages which correspond to vertical distances of 0 and $3.1 \mathrm{~m}$, respectively. The exit of the gasifier corresponds to a vertical distance of $12.2 \mathrm{~m}$. Figure 4.5 was generated from injections corresponding to 
the 28 different size/density classes of the Bailey coal sample. The origin was located at the centroid of the horizontal first stage. It is noticeable that the curves in Figures 4.4 and 4.5 are similar in shape for both case 3 and case 4 . Mass fractions of carbon monoxide gradually increase throughout the second stage region as the second stage slurry combusts and gasifies with the available carbon dioxide and steam. As a result, carbon dioxide levels gradually decrease throughout stage 2. Steam levels are relatively low in the second stage for both cases. The evolution of carbon monoxide and hydrogen throughout the second stage is of primary concern along with the amount of fixed carbon converted during gasification and combustion. The conversion of solid fuels such as coal to synthetic gases such as carbon monoxide and hydrogen is the primary focus of the research on gasification and its implementation to combined cycle power plants.

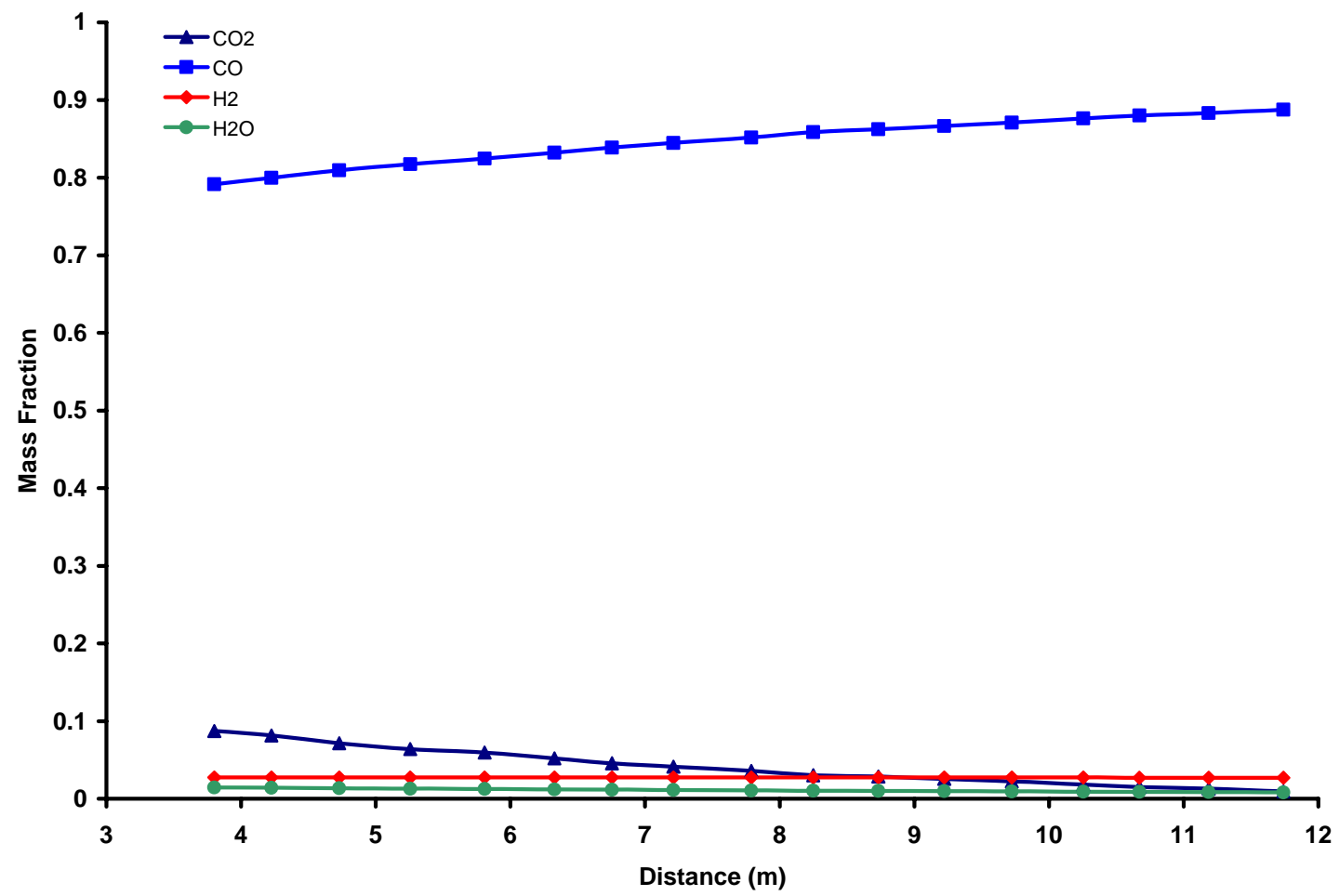

Figure 4.4. Average gas mass fractions versus distance in stage 2 for Case 3. 


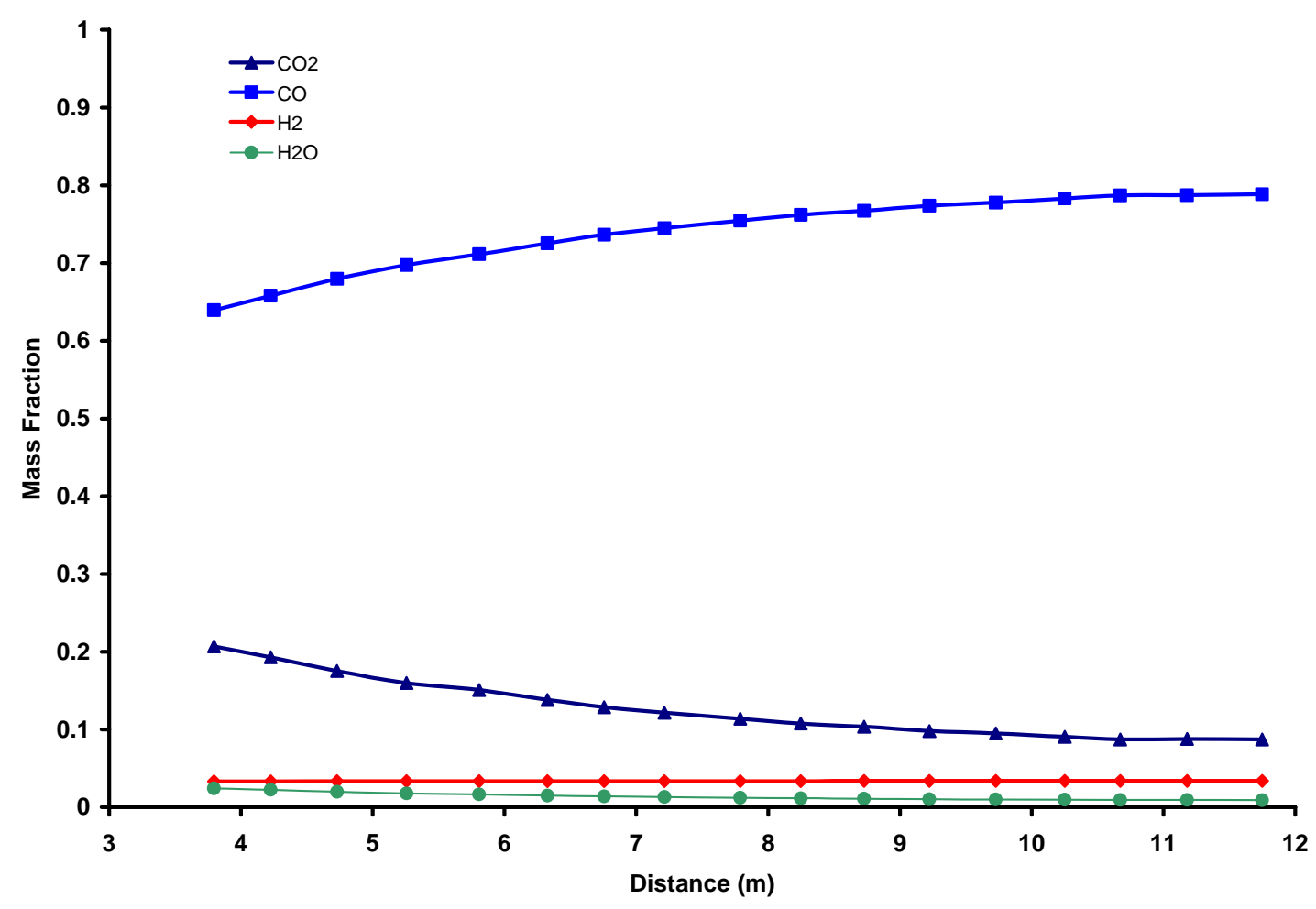

Figure 4.5. Average gas mass fractions versus distance in stage 2 for Case 4.

Figures 4.6-9 were generated in a similar manner to the above and illustrate average particle mass loss and temperature along their trajectories throughout stage 2. Mass loss shown in Figures 4.6-9 is reported as the ratio of the current to initial particle mass at each point along the particle's trajectory in the second stage region. The particle mass decreases gradually as expected due to moisture release, devolatilization, combustion, and gasification as it proceeds through the second stage of the gasifier. Particles were injected from both stage 1 and stage 2 in Figures 4.6 and 4.8 explaining why the current particle mass is not closer to the initial mass as would be expected if all the data was reported for stage 2 injections only. Similarly, average particle temperatures are given in Figures 4.8 and 4.9 and follow similar patterns for both case 3 and case 4. Particles enter the second stage region of the gasifier model at temperatures around $1900 \mathrm{~K}$ and gradually cool off as they pass thru the relatively colder flow field that is the result of the 


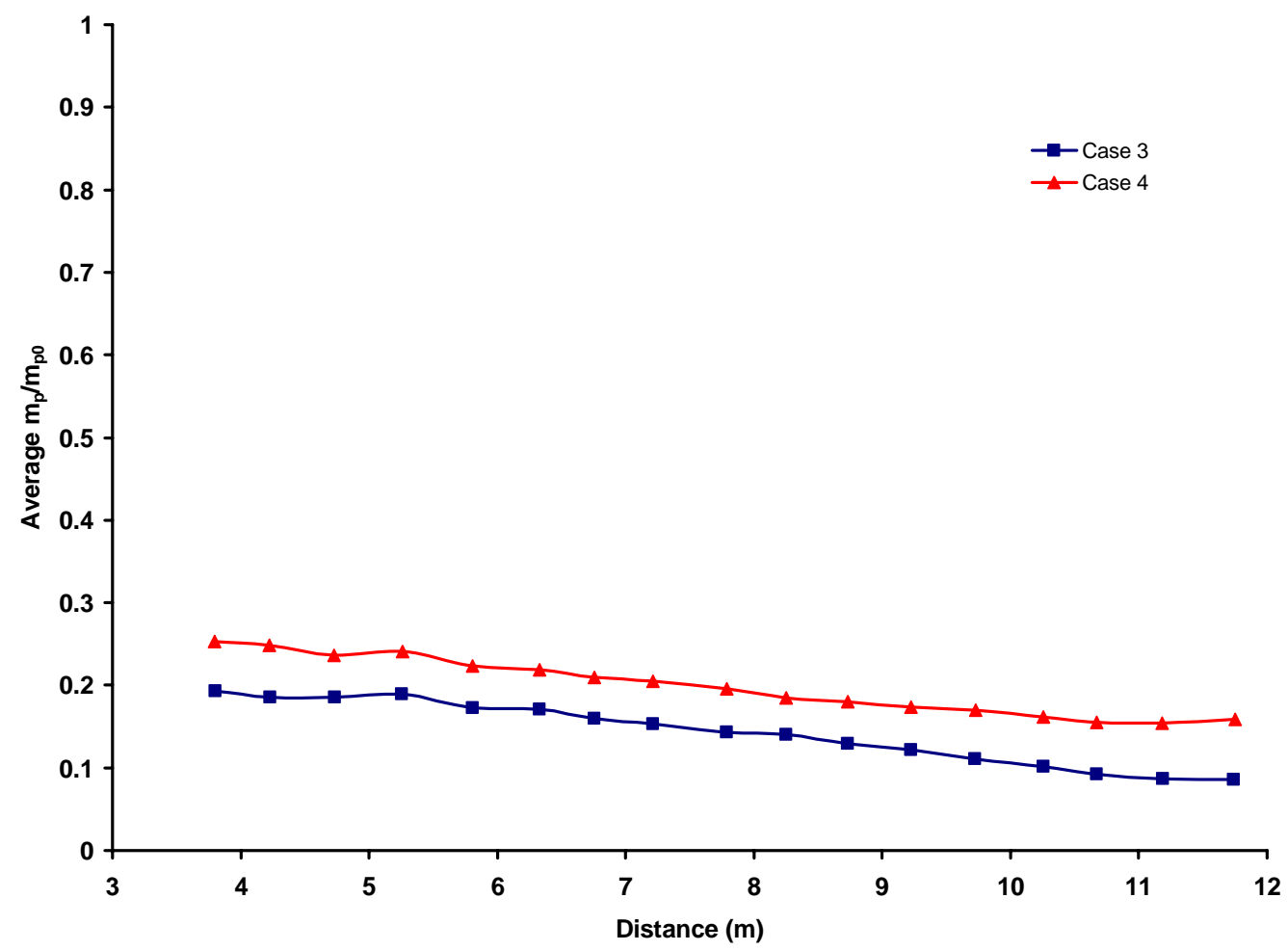

Figure 4.6. Average particle mass loss versus distance in stage 2 (all injected).

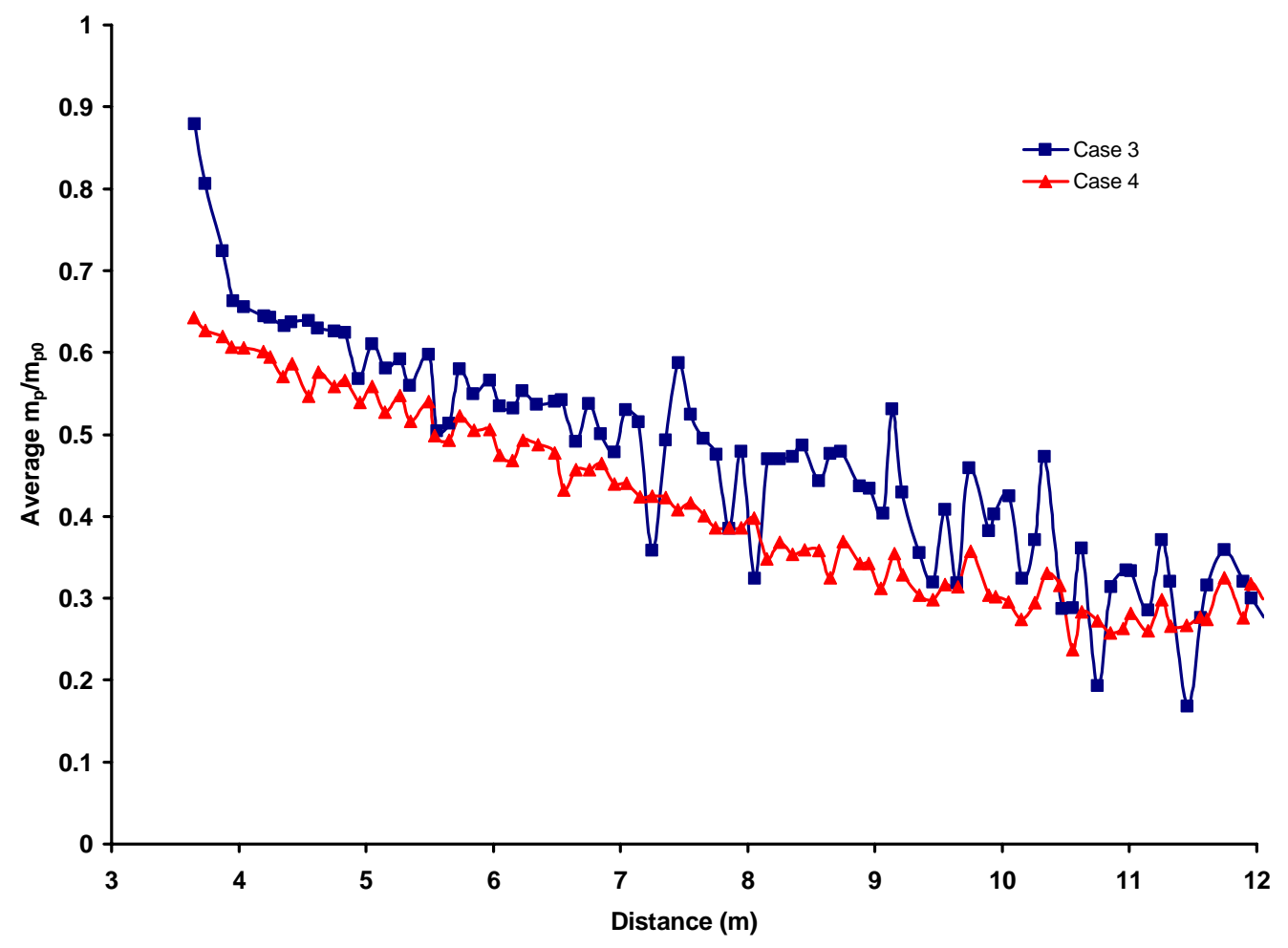

Figure 4.7. Average particle mass loss versus distance in stage 2 (stage 2 injection). 


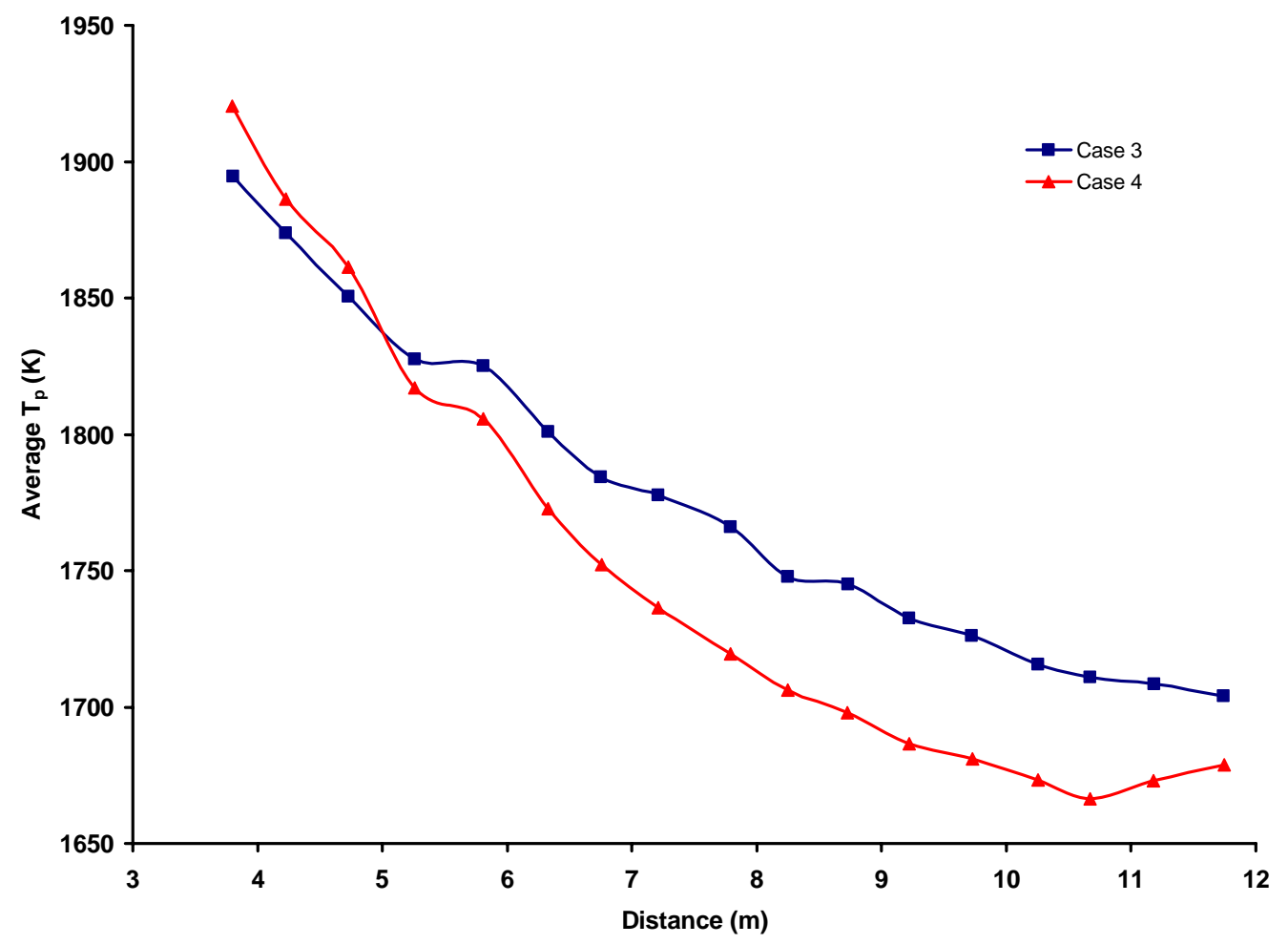

Figure 4.8. Average particle temperature versus distance in stage 2 (all injected).

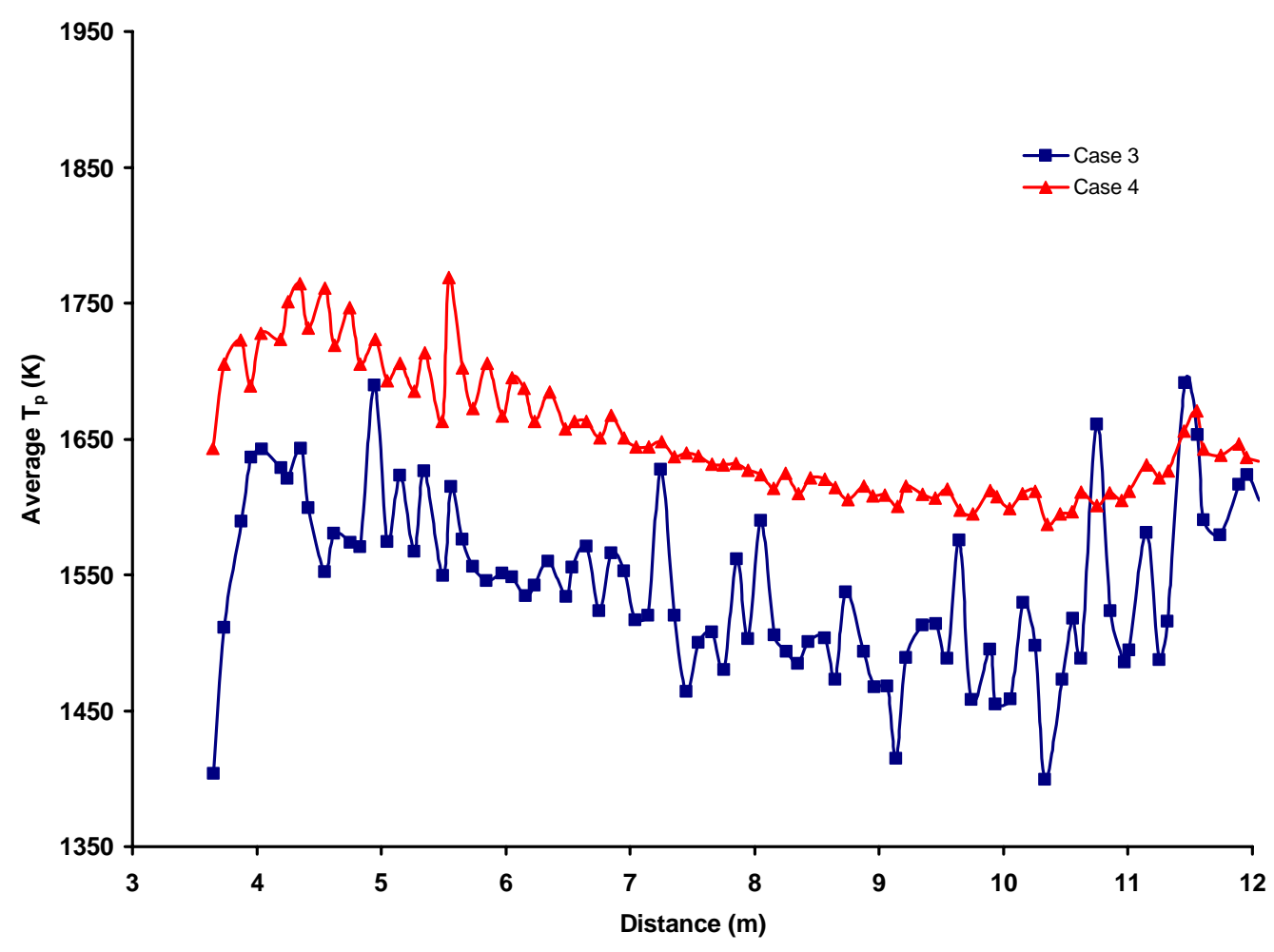

Figure 4.9. Average particle temperature versus distance in stage 2 (stage 2 injection). 
endothermic gasification reactions that are taking place there. It should be noted that though again the curves are similar in shape in the above figures, they differ in magnitude because the data recorded for case 4 are composite averages in the sense that 28 separate injections were tracked and the mass and temperature of each particle were averaged together in the same bin to form the displayed averages.

Computed fixed carbon conversion for specific gravity cuts, SG1, SG2, and SG3 are compared for case 3 and case 4 in Figures 4.10-11. Specific gravity cut SG4 has been omitted because this fraction was set to inert in the numerical model. Particles belonging to this fraction consist mostly of mineral matter and therefore would not convert any appreciable amount of fixed carbon. For both case 3 and case 4, fixed carbon conversion averaged over all injections (Figure 4.10) increases from around 40\% for size class PS1 as the particle initial diameter decreases to $100 \%$ conversion for size class PS7. Conversion levels for the larger size classes are much lower when only the second stage

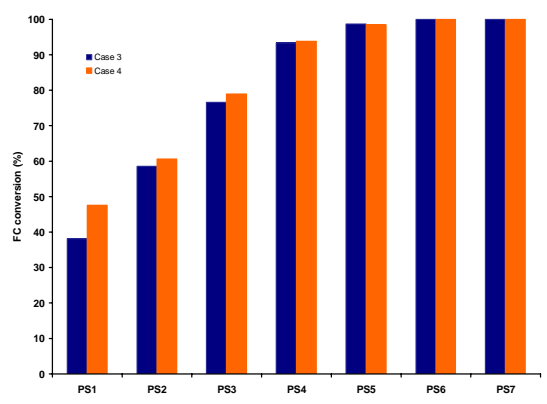

a) SG1

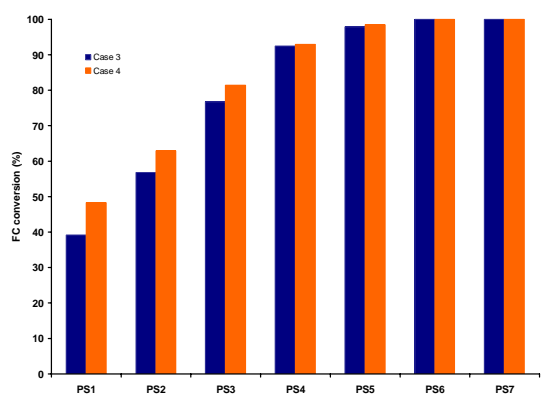

b) SG2

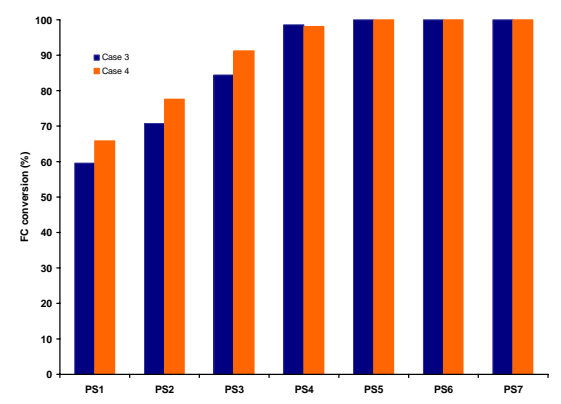

c) SG3

Figure 4.10. Fixed carbon conversion (all injections). 


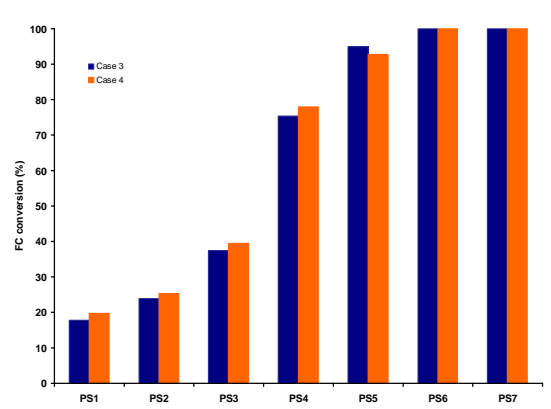

a) SG1

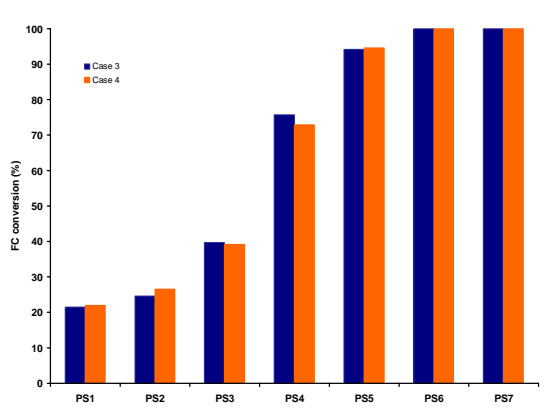

b) SG2

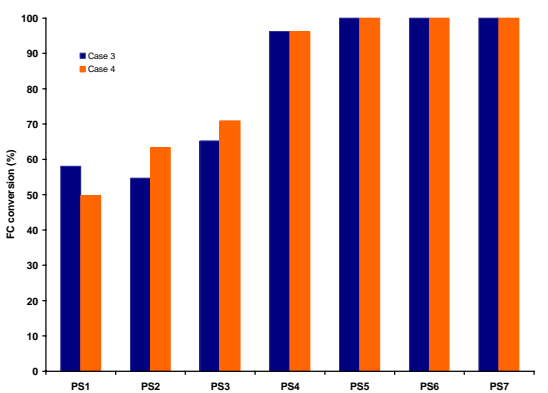

c) SG3

Figure 4.11. Fixed carbon conversion (stage 2 injection).

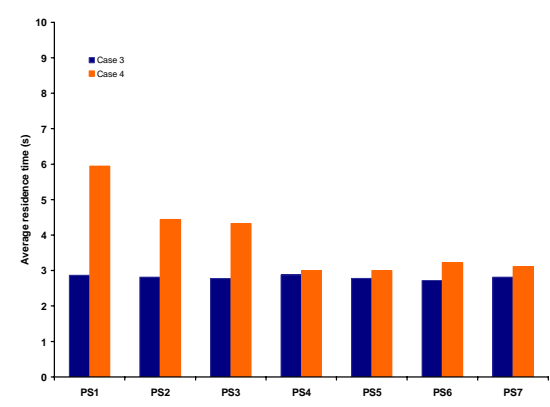

a) SG1

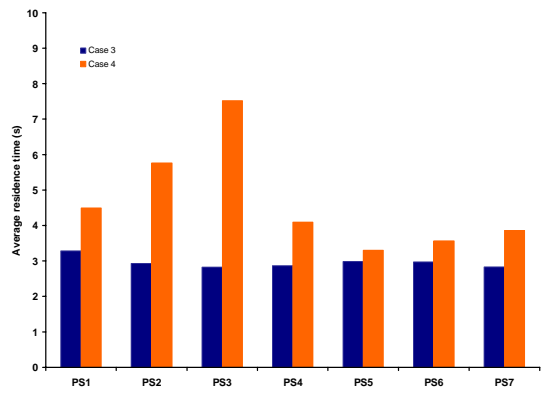

c) SG3

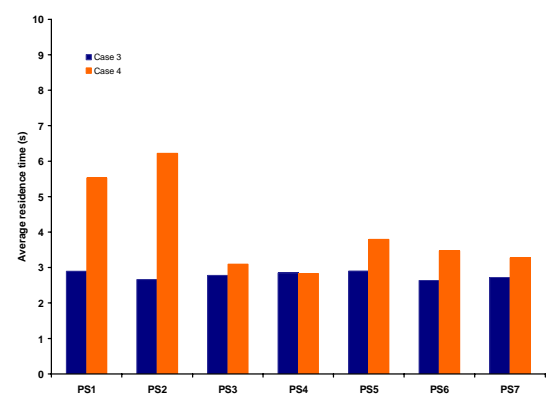

b) $\mathrm{SG} 2$

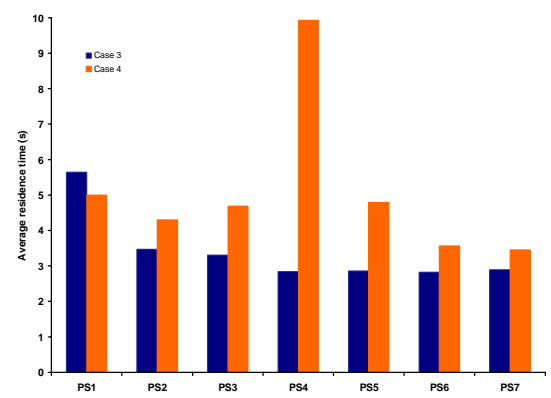

d) SG4

Figure 4.12. Average particle residence time (all injections). 


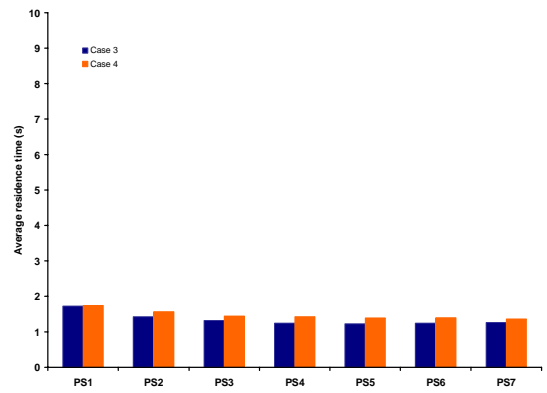

a) SG1

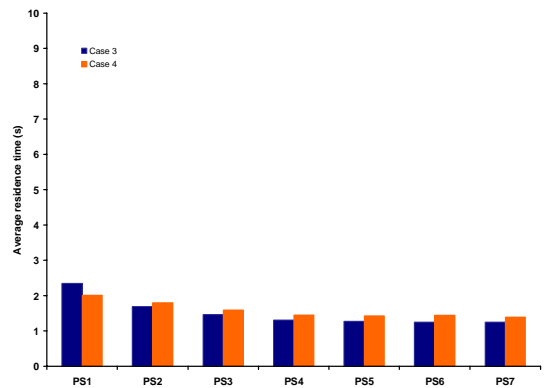

c) SG3

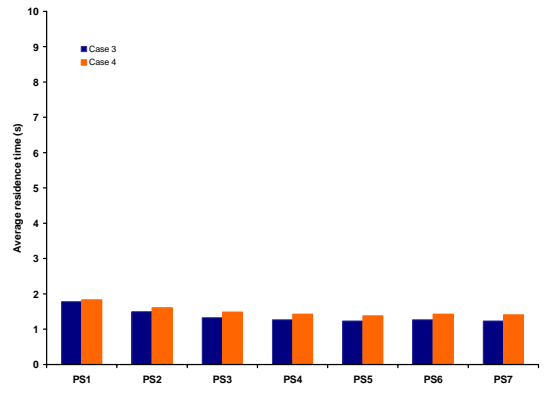

b) $\mathrm{SG} 2$

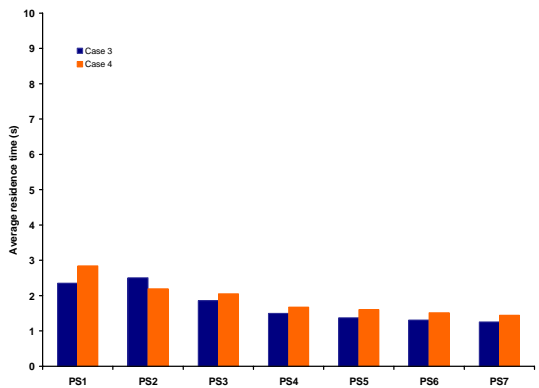

d) $\mathrm{SG} 4$

Figure 4.13. Average particle residence time (stage 2 injection).

injections are averaged (Figure 4.11). Similar conversion histories are evident for both case 3 and case 4. Figures 4.12-13 summarize predicted particle residence times for each size and density class injected into flow fields obtained for case 3 and case 4 . Particles spend around three seconds in the entire reactor on average for case 3 computed based on all particles injected. Case 4 generated more variation in residence time with a maximum predicted residence time of ten seconds for SG4PS4 when all particles are injected. Average particle residence times for stage 2 injections only are shorter (1.5-2.5 s) and show less variability (Figure 4.13).

Figures 4.14-21 compare the component of particle impact velocity normal to the wall versus distance along the second stage wall for cases 3 and 4 . Impact velocity is highest for both cases in the regions near the entrance and exit of the second stage. Particles have mostly become entrained with the flow field throughout most of the second stage resulting in impact velocities around $10 \%$ of the velocity magnitude. 


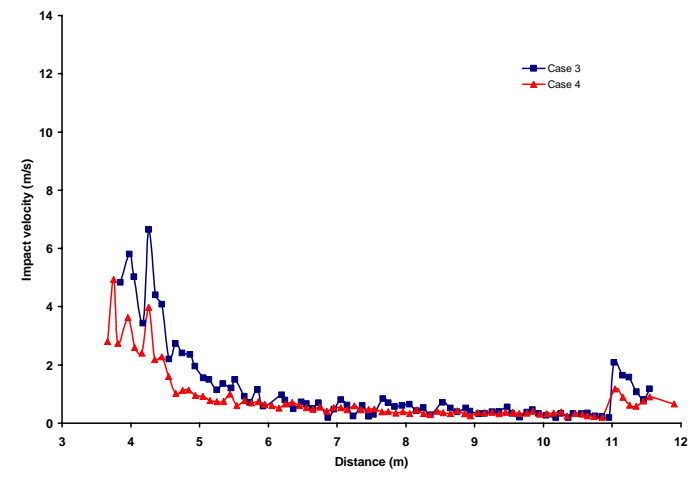

a) PS1

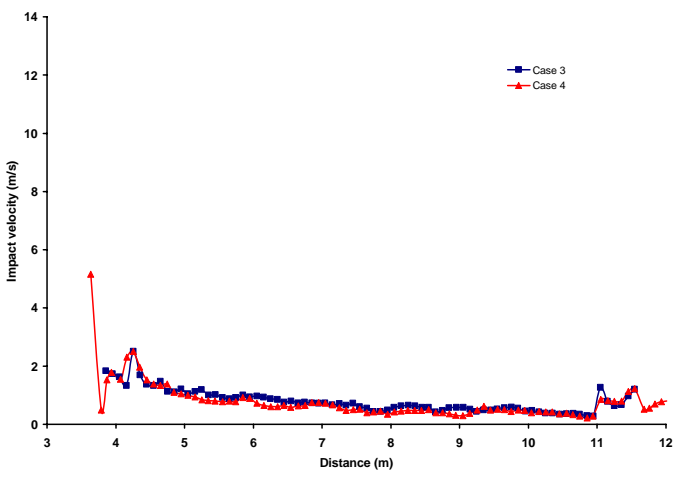

c) PS3

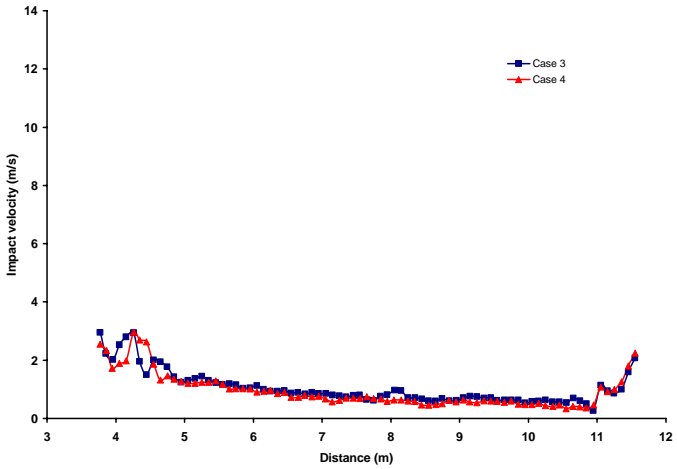

e) PS5

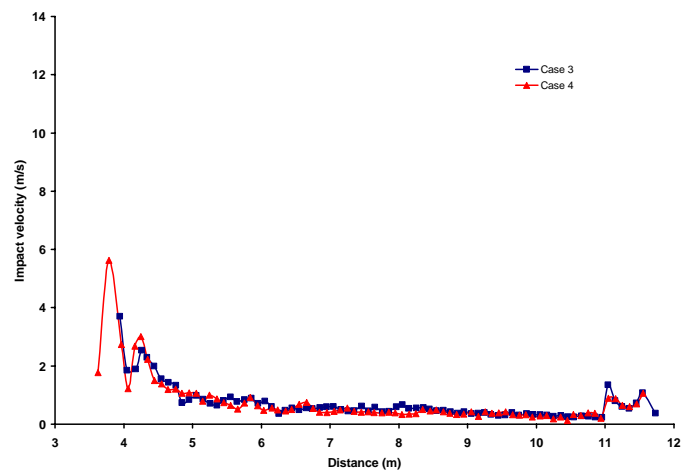

b) PS2

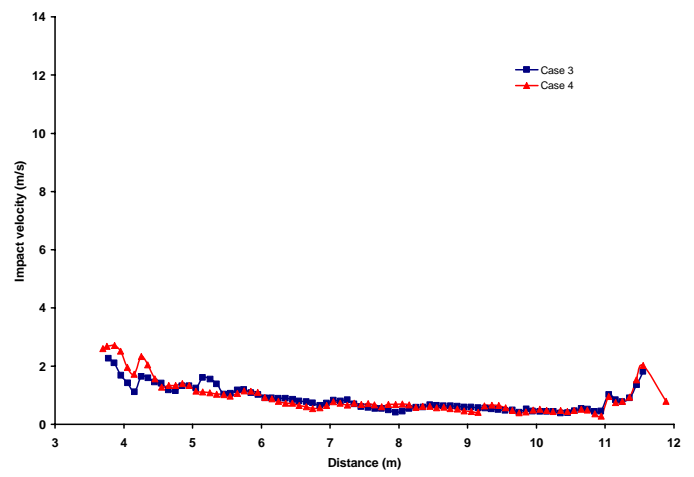

d) PS4

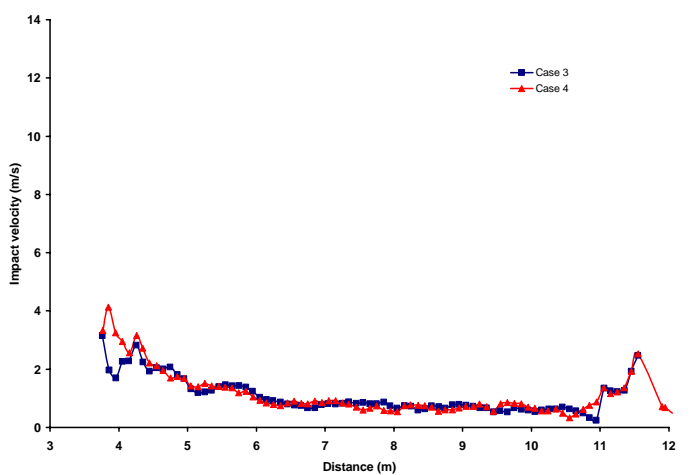

f) PS6

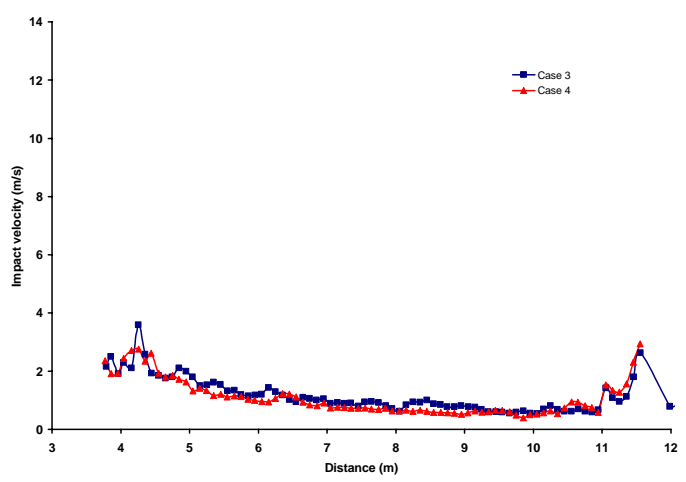

g) PS7

Figure 4.14. Impact velocity normal to the wall versus axial location in second stage for density class SG1. Particles injected from both left and right stage 1 inlets. 


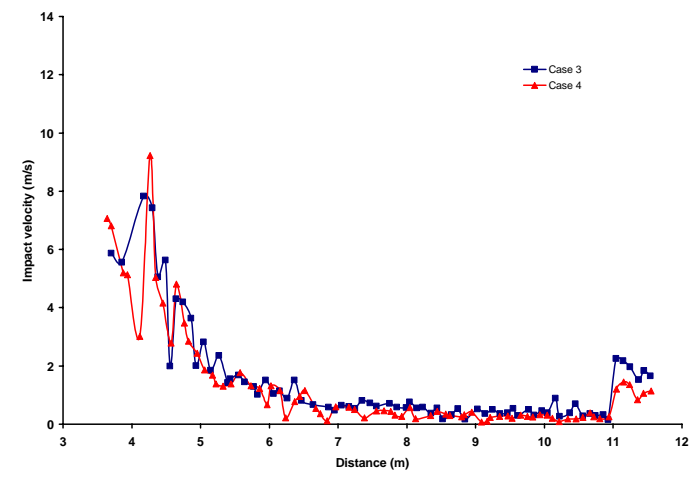

a) PS1

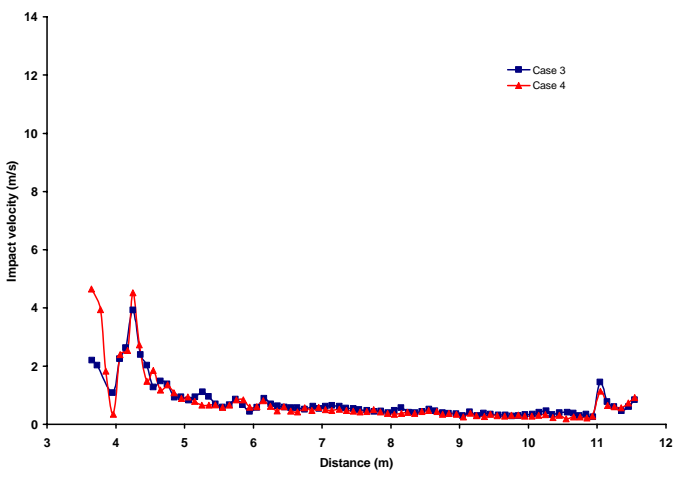

c) PS3

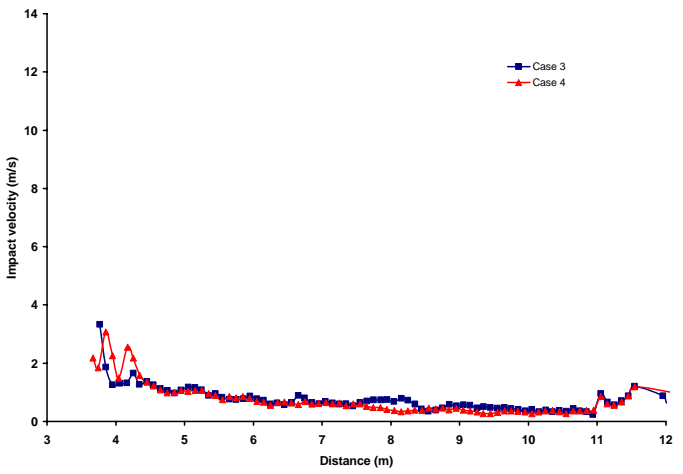

e) PS5

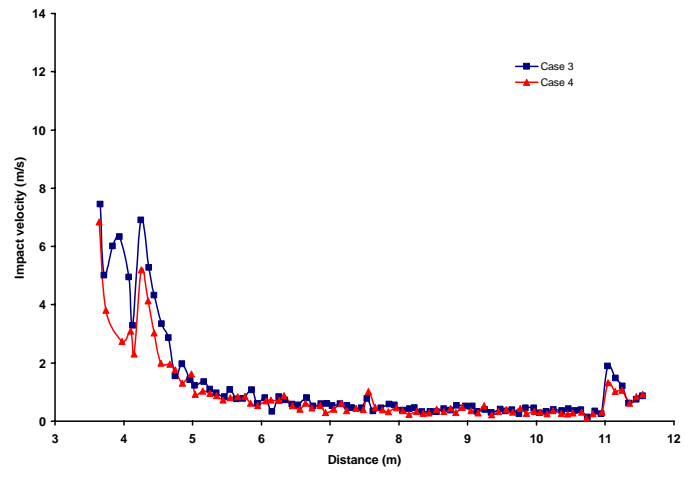

b) PS2

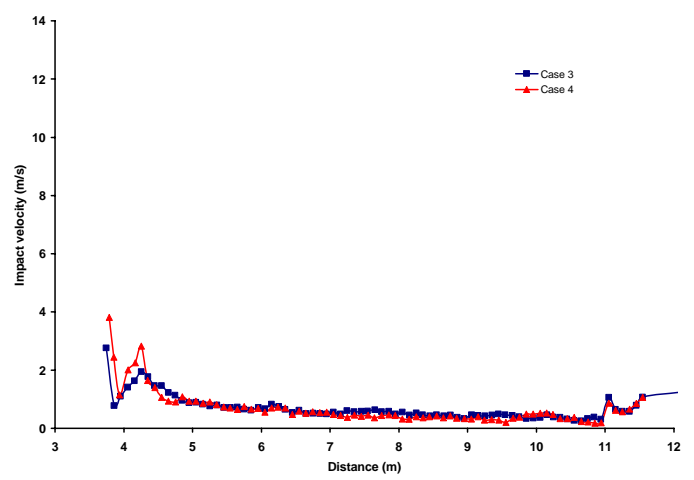

d) PS4

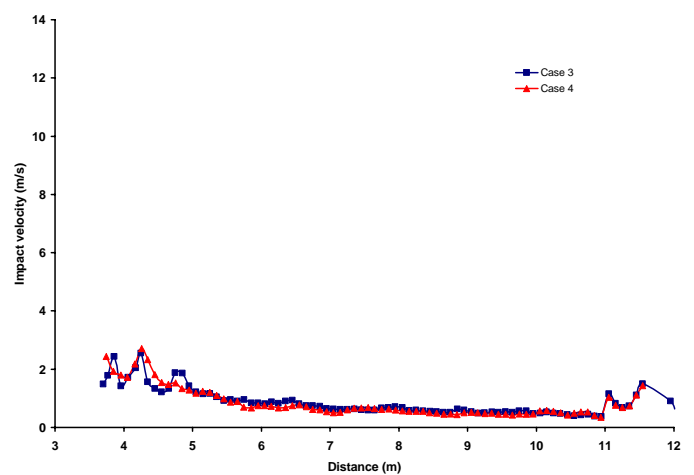

f) PS6

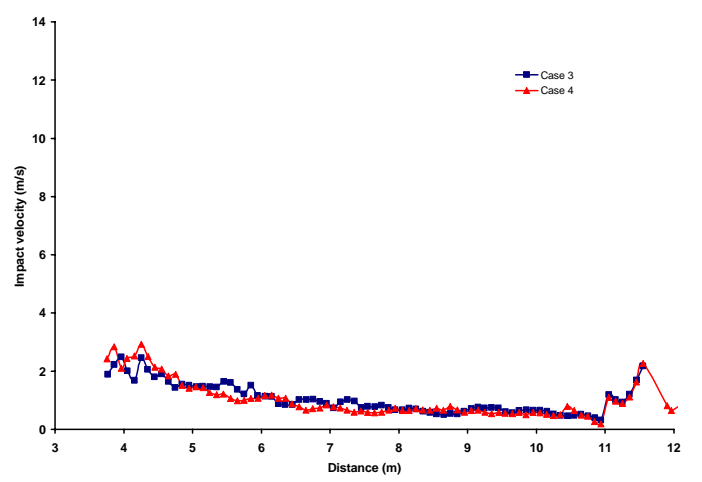

g) PS7

Figure 4.15. Impact velocity normal to the wall versus axial location in second stage for density class SG2. Particles injected from both left and right stage 1 inlets. 


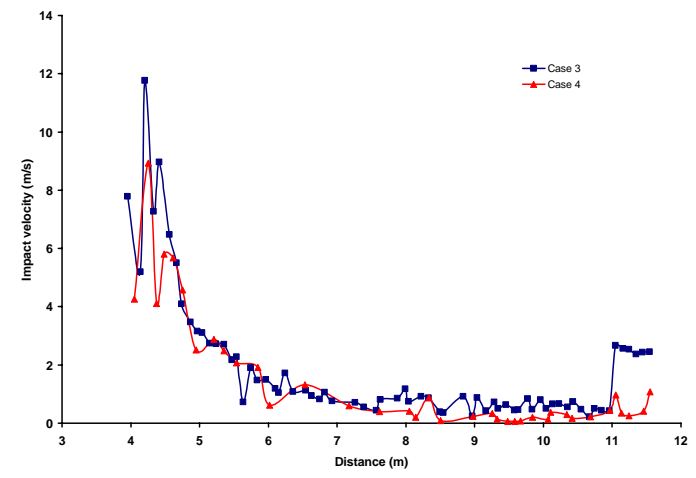

a) PS1

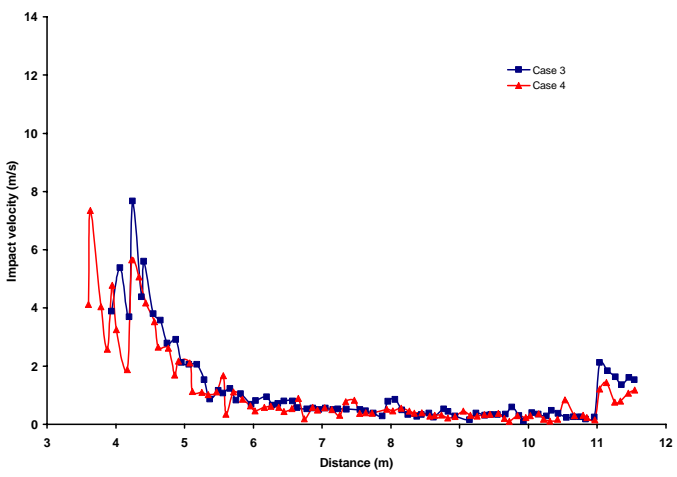

c) PS3

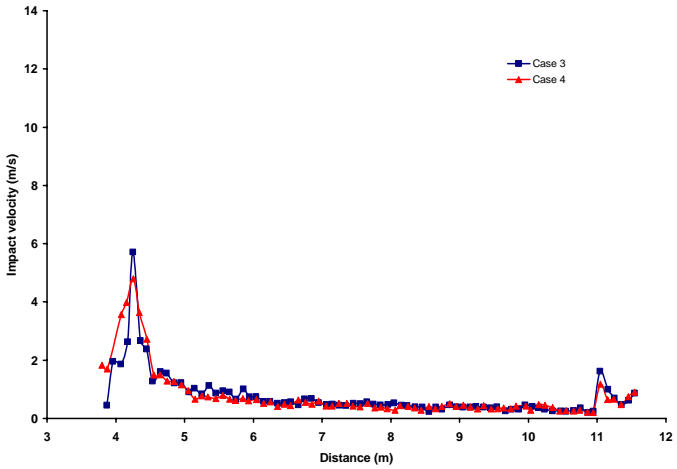

e) PS5

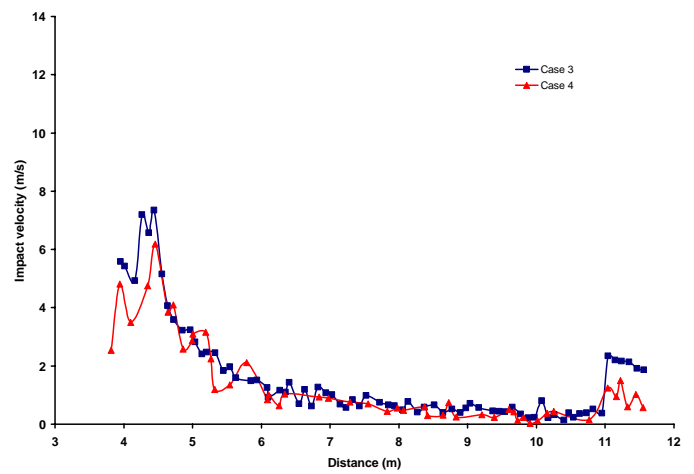

b) PS2

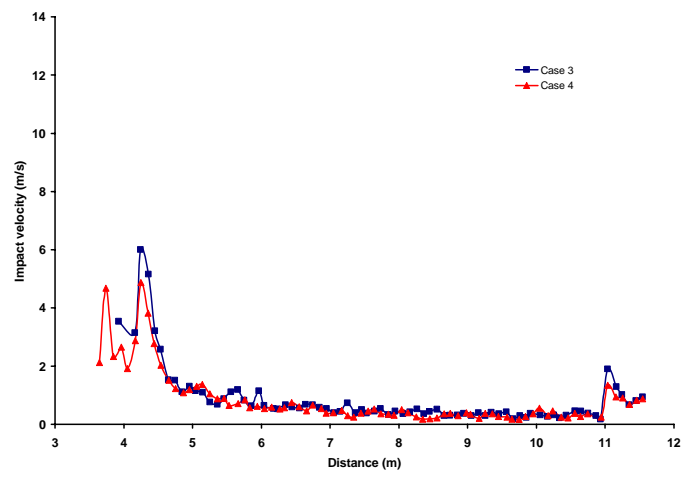

d) PS4

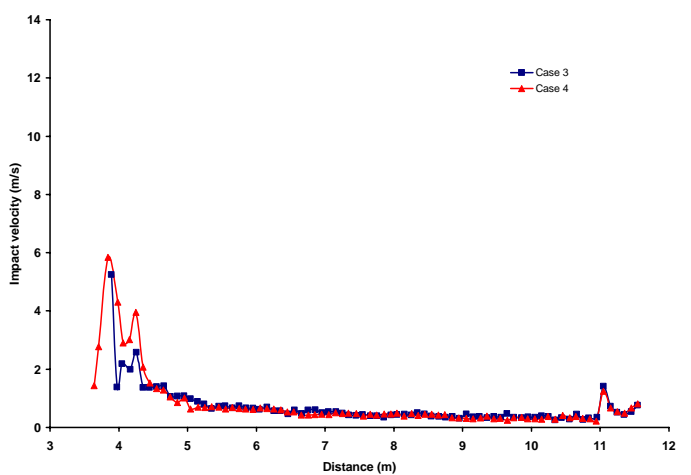

f) PS6

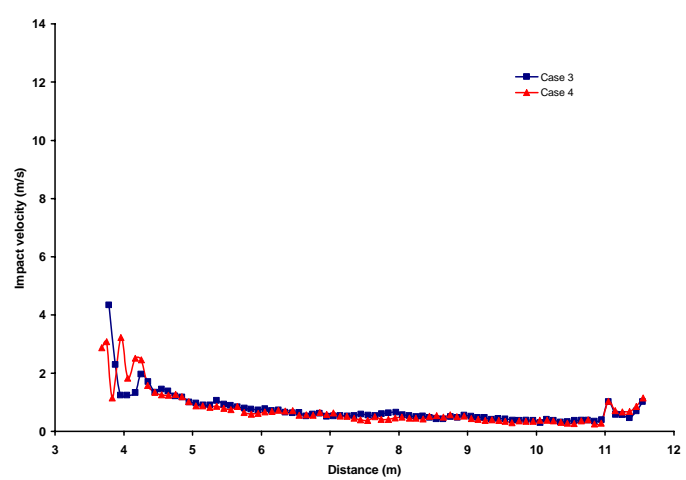

g) PS7

Figure 4.16. Impact velocity normal to the wall versus axial location in second stage for density class SG3. Particles injected from both left and right stage 1 inlets. 


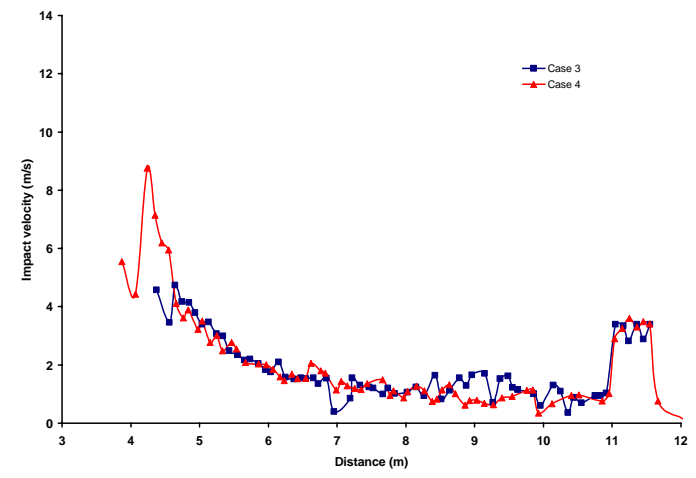

a) PS1

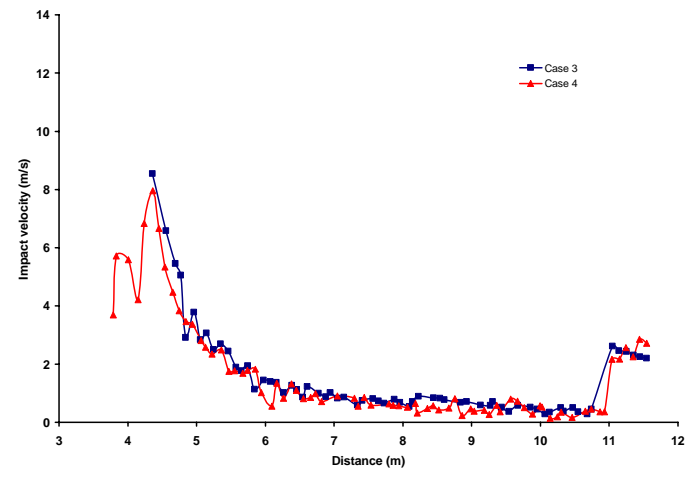

c) PS3

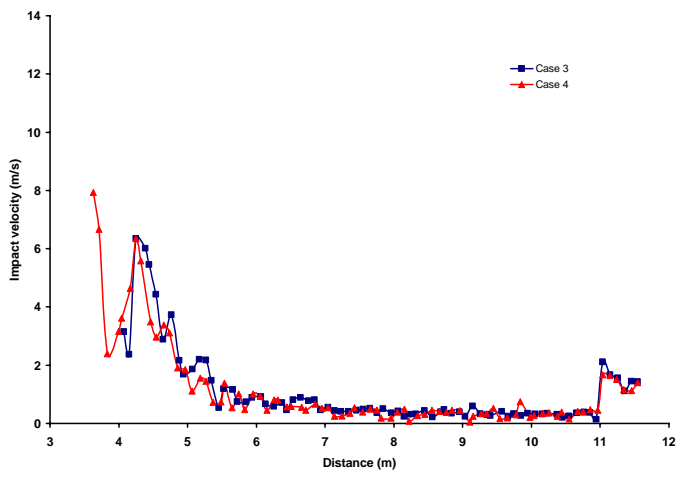

e) PS5

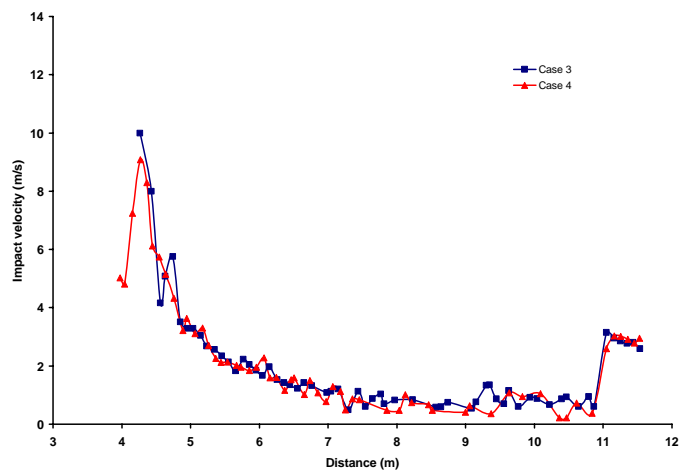

b) PS2

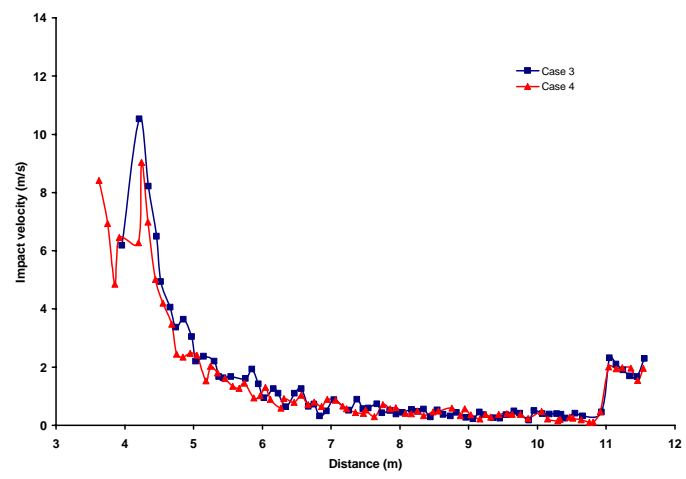

d) PS4

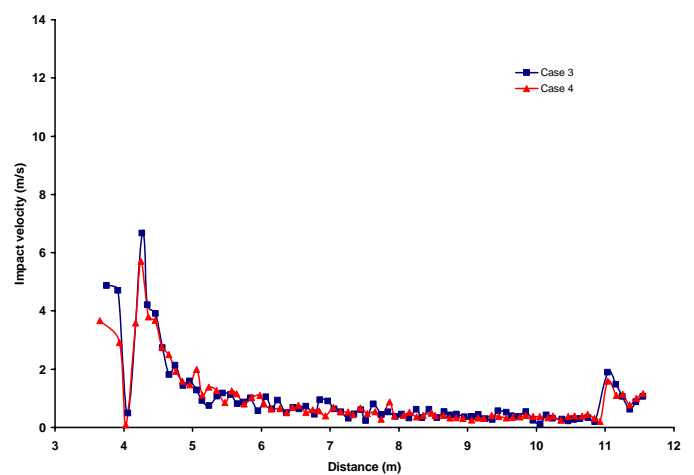

f) PS6

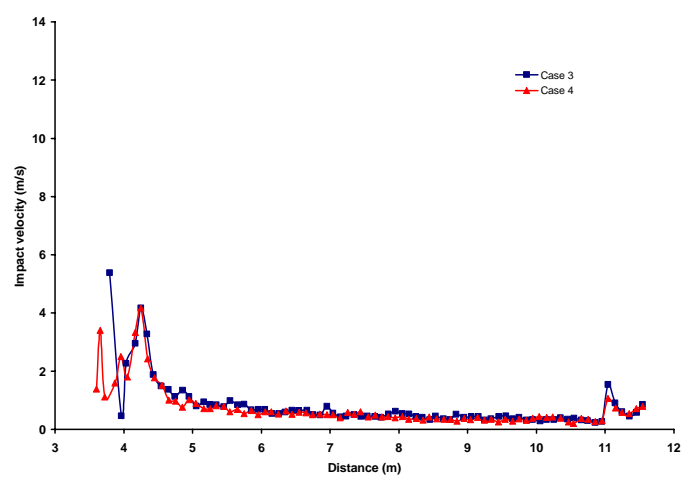

g) PS7

Figure 4.17. Impact velocity normal to the wall versus axial location in second stage for density class SG4. Particles injected from both left and right stage 1 inlets. 


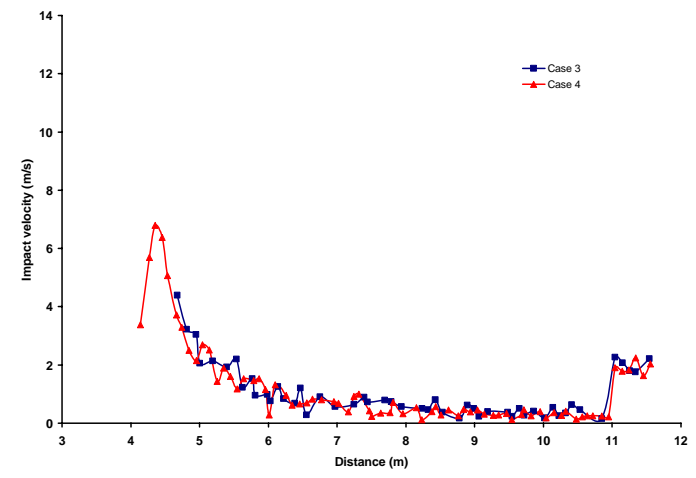

a) PS1

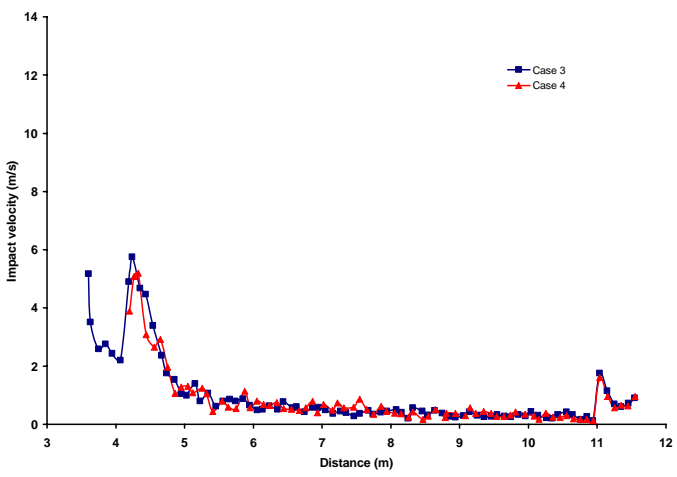

c) PS3

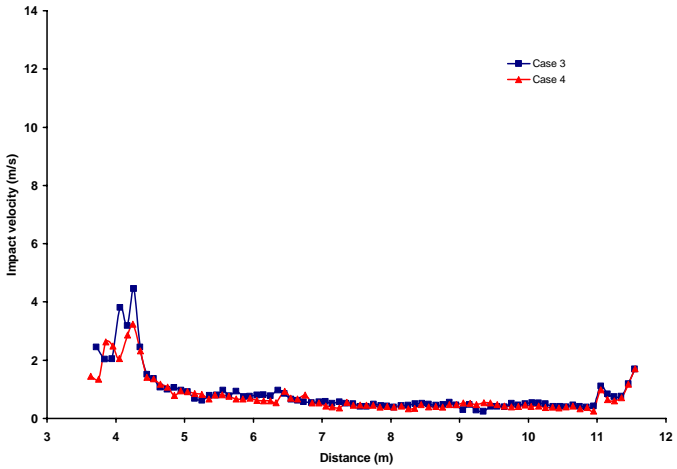

e) PS5

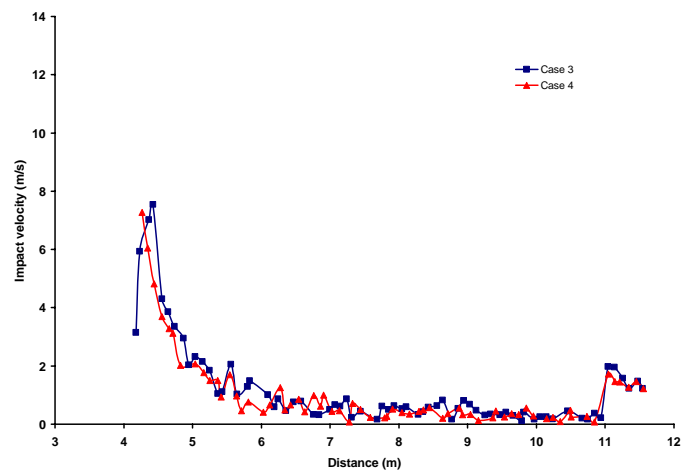

b) PS2

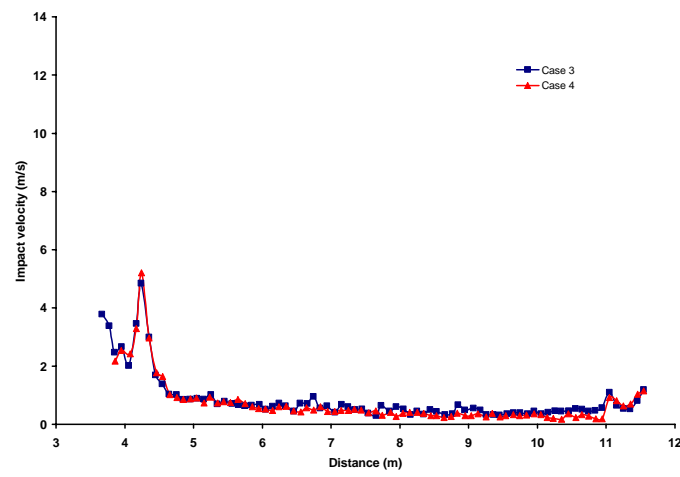

d) PS4

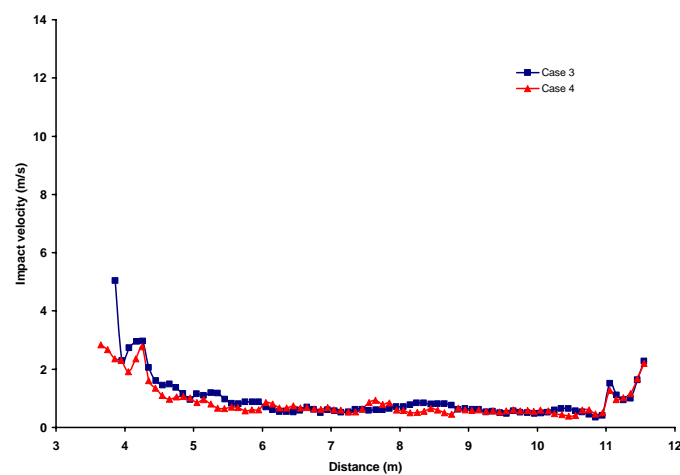

f) PS6

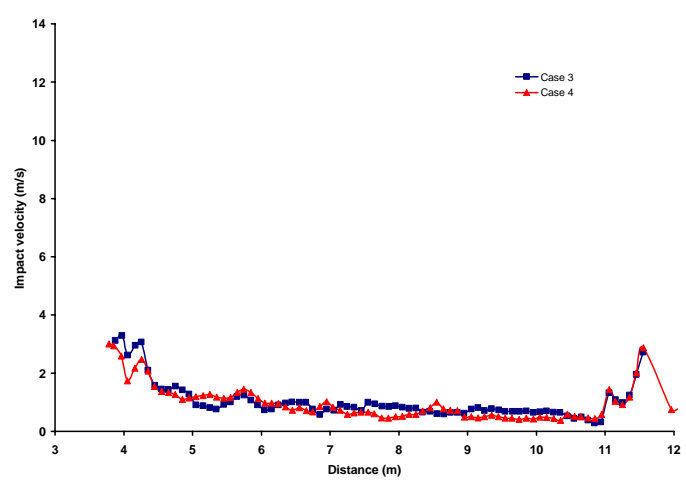

g) PS7

Figure 4.18. Impact velocity normal to the wall versus axial location in second stage for density class SG1. Particles injected from stage 2 inlet. 


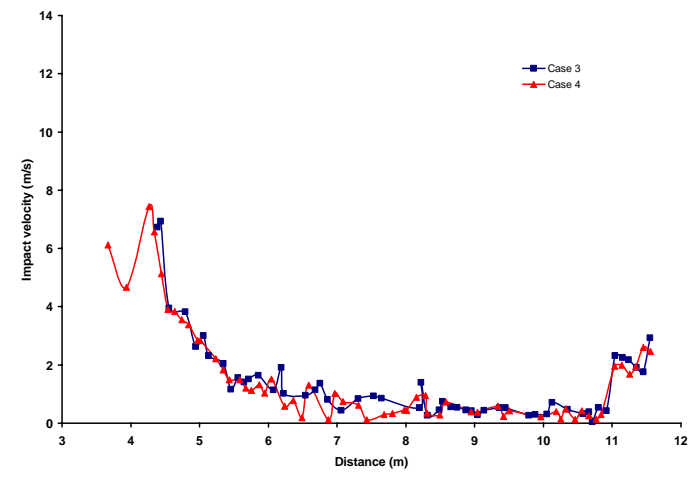

a) PS1

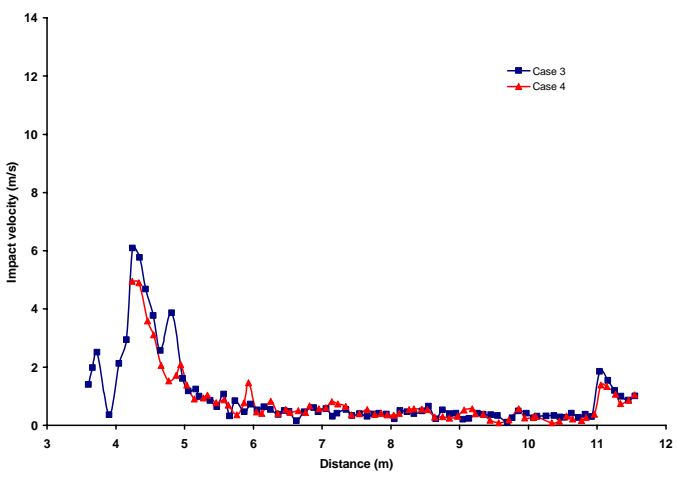

c) PS3

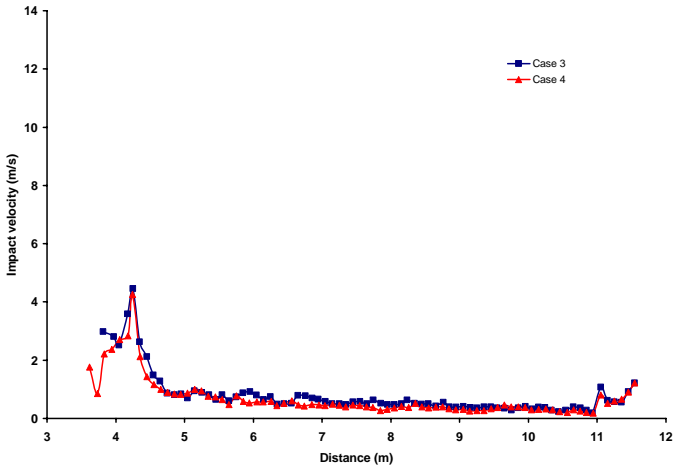

e) PS5

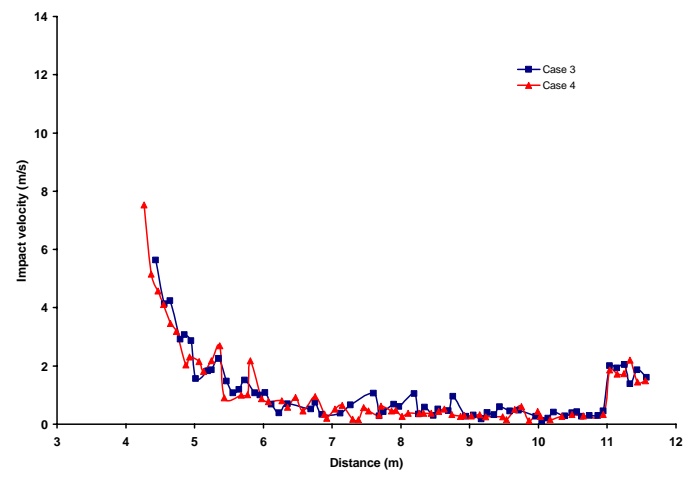

b) PS2

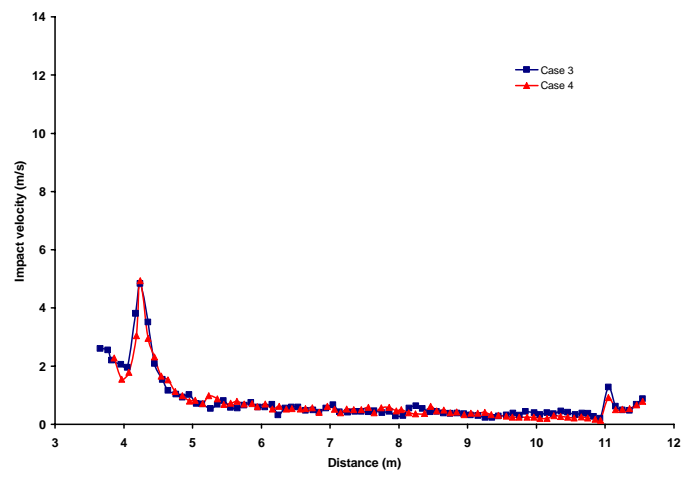

d) PS4

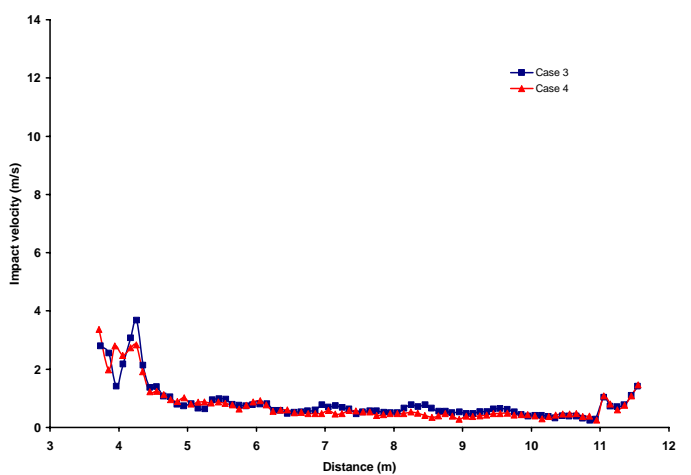

f) PS6

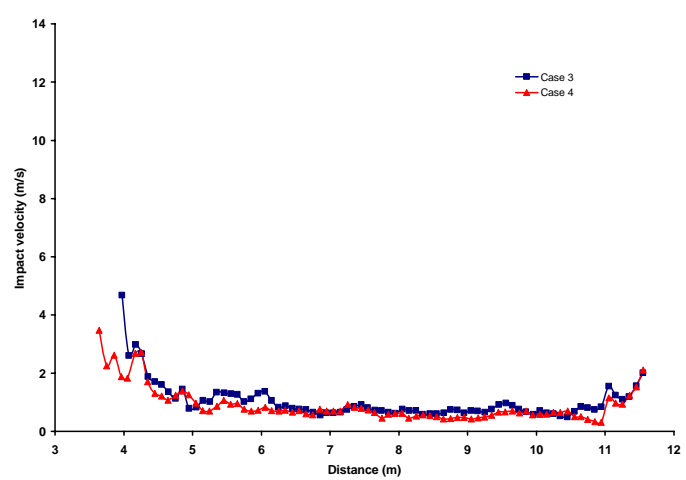

g) PS7

Figure 4.19. Impact velocity normal to the wall versus axial location in second stage for density class SG2. Particles injected from stage 2 inlet. 


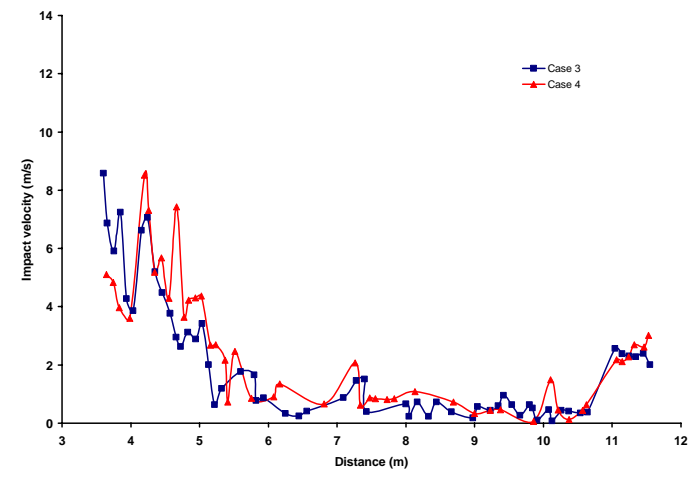

a) PS1

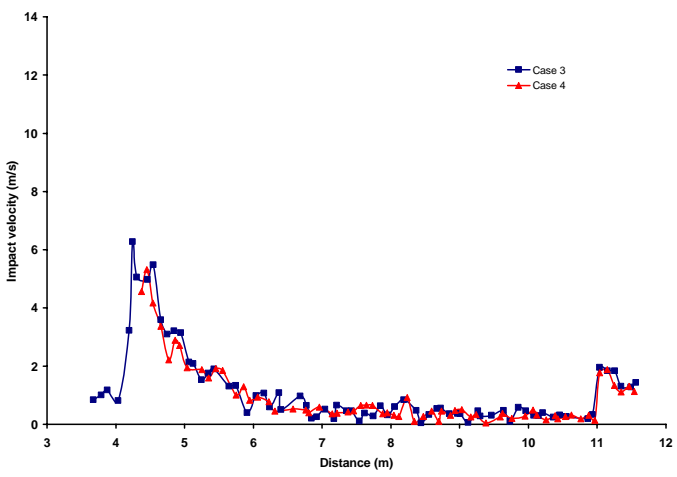

c) PS3

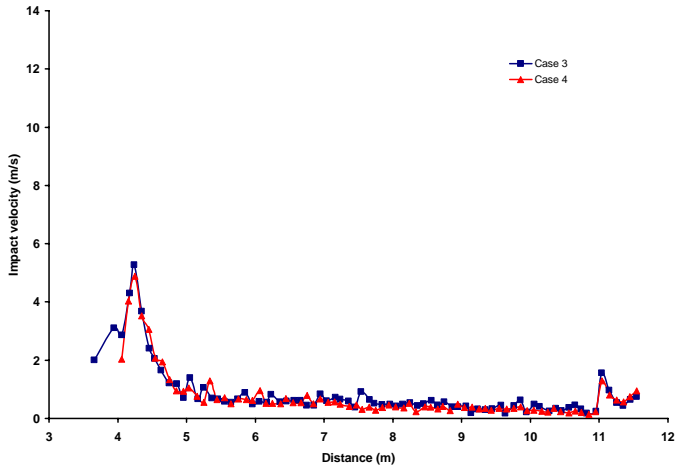

e) PS5

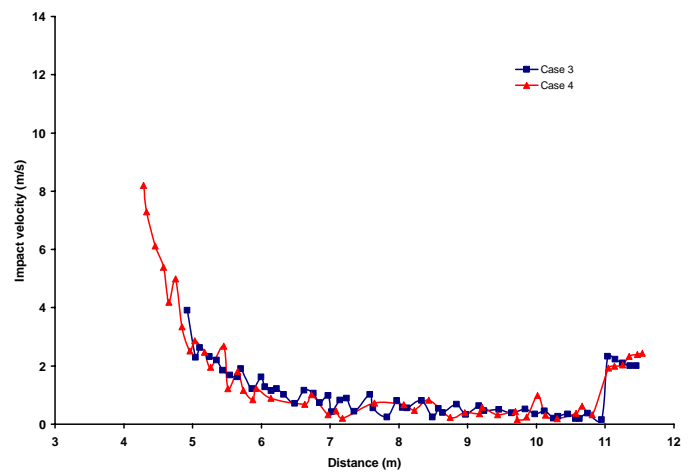

b) PS2

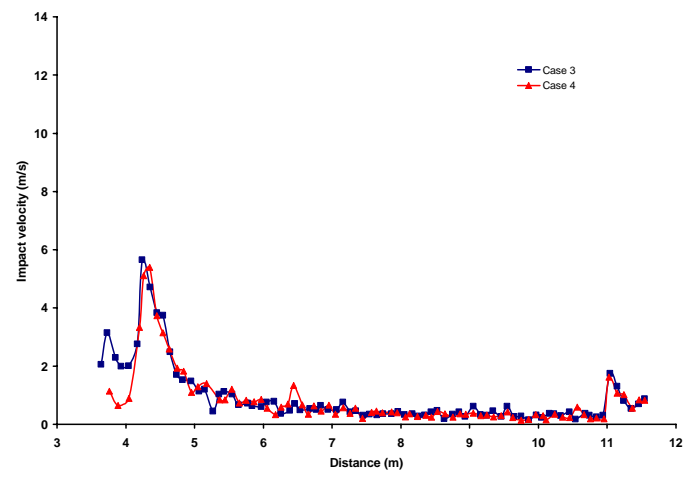

d) PS4

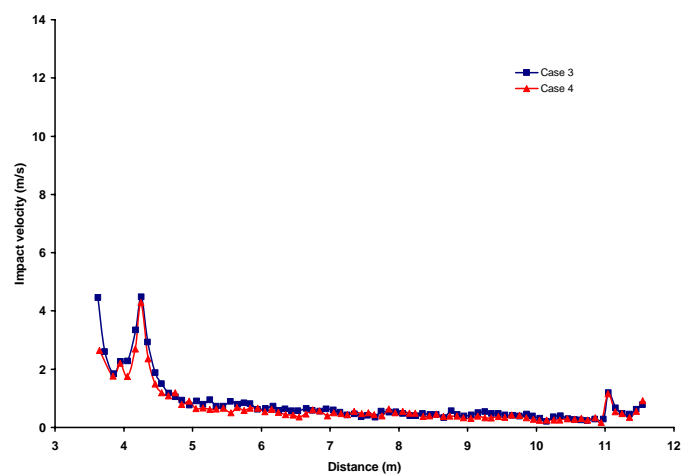

f) PS6

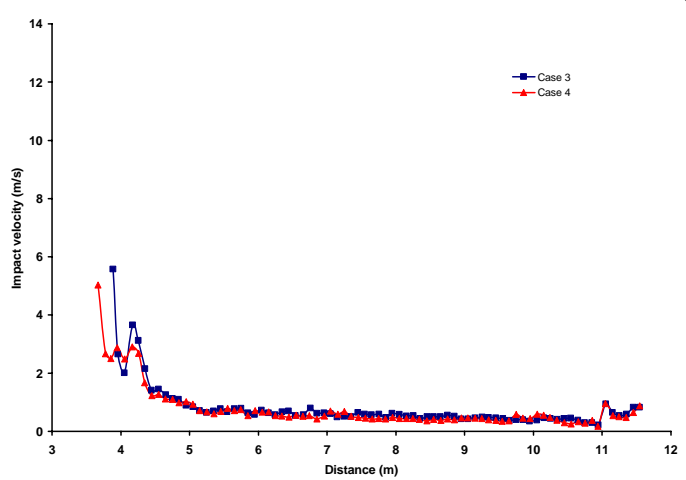

g) PS7

Figure 4.20. Impact velocity normal to the wall versus axial location in second stage for density class SG3. Particles injected from stage 2 inlet. 


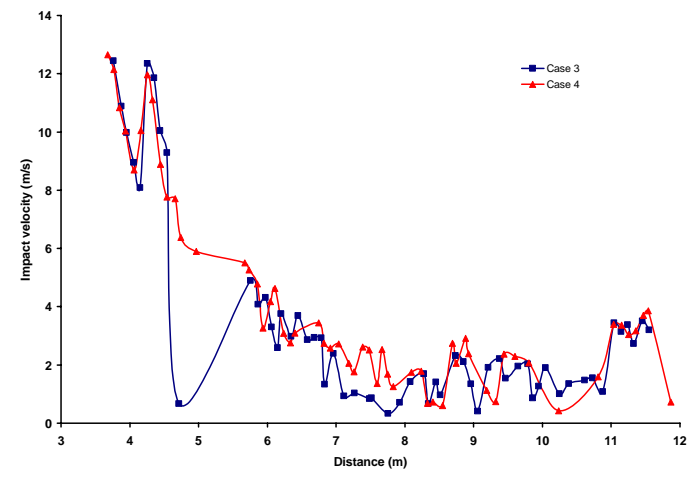

a) PS1

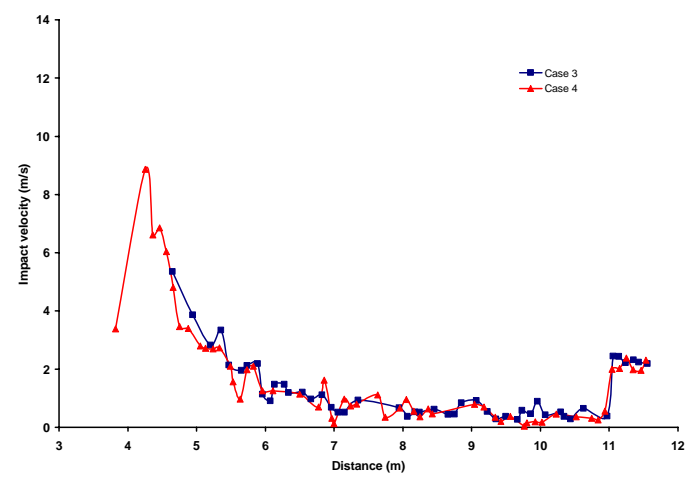

c) PS3

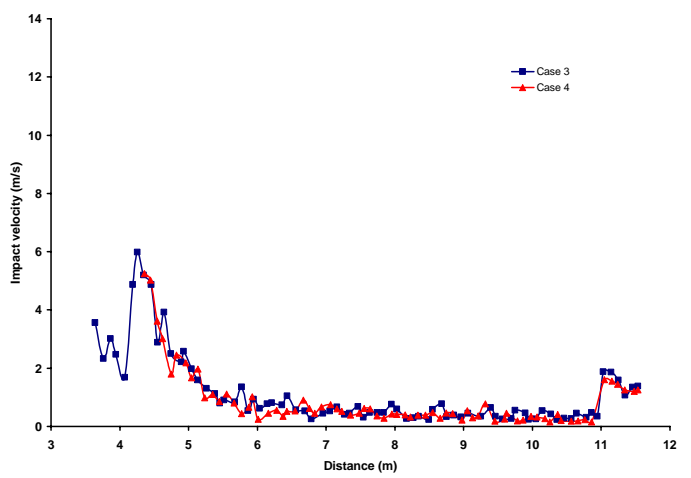

e) PS5

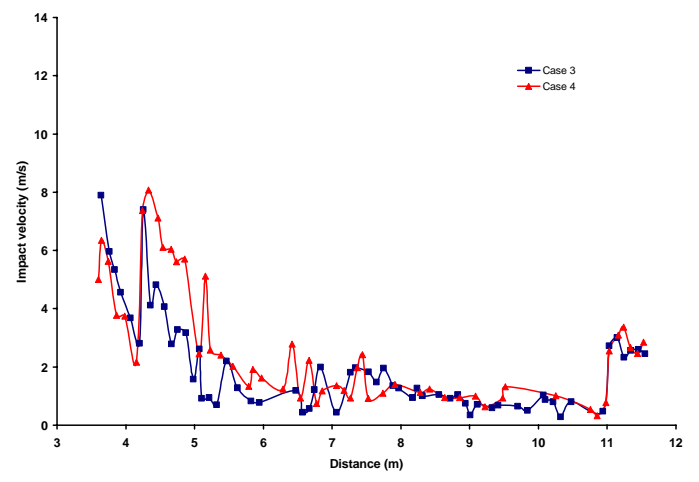

b) PS2

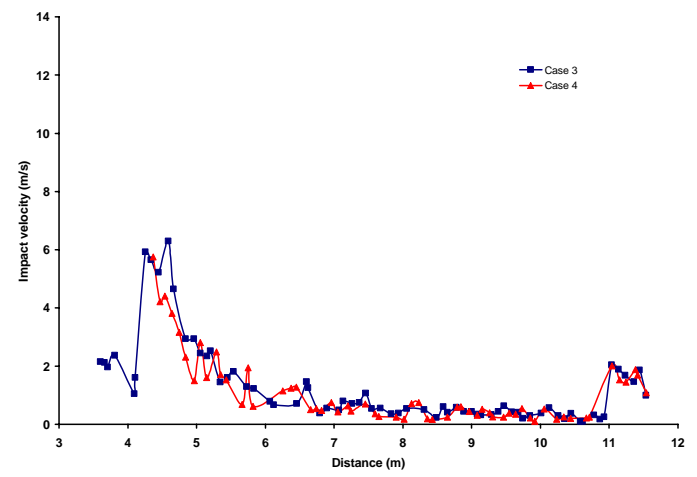

d) PS4

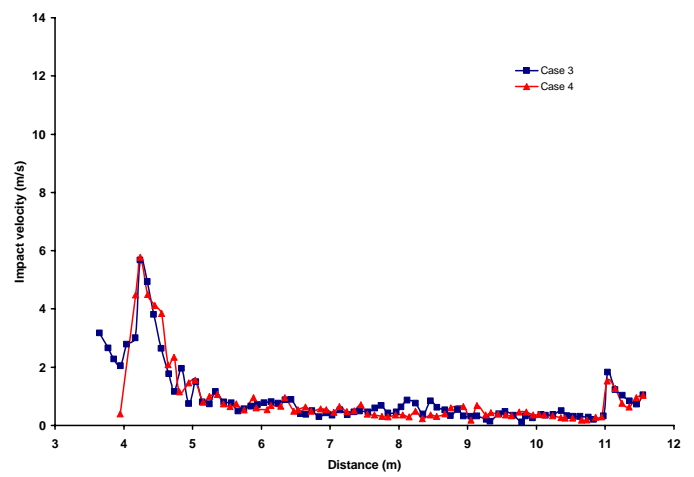

f) PS6

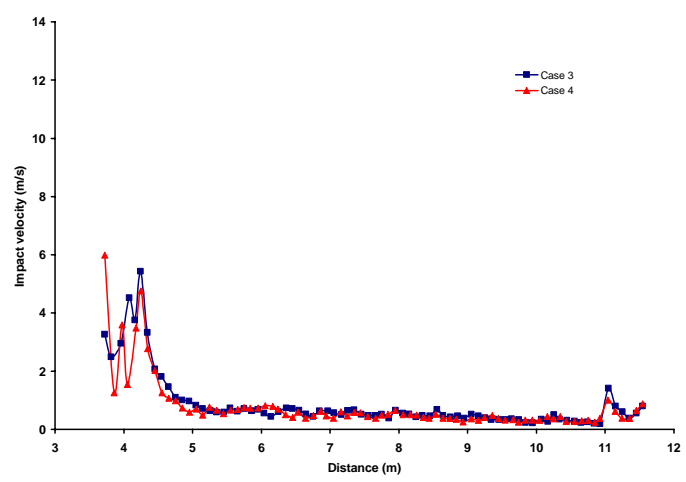

g) PS7

Figure 4.21. Impact velocity normal to the wall versus axial location in second stage for density class SG4. Particles injected from stage 2 inlet. 
Figure 4.22 and Figure 4.23 display average particle impact angle (in radians) versus axial distance along stage 2. Particle impact angle was recorded as the angle between the particle's velocity vector and the wall. Due to the particles being mostly entrained with the gas, impact angles are shallow and are around 20 degrees on average (70 degrees from face normal vector). Impact angles are largest near the entrance and exits of the gasifier region of the two-stage up-flow geometry. Figure 4.23 displays impact angle versus axial distance in stage 2 for particles injected from the stage 2 inlet only. Three different particle sizes and densities are compared for each case. Impact angles are generally closer to the face normal for the SG4 cuts. The bigger and heavier particles are not so easily entrained with the mean gas flow field.

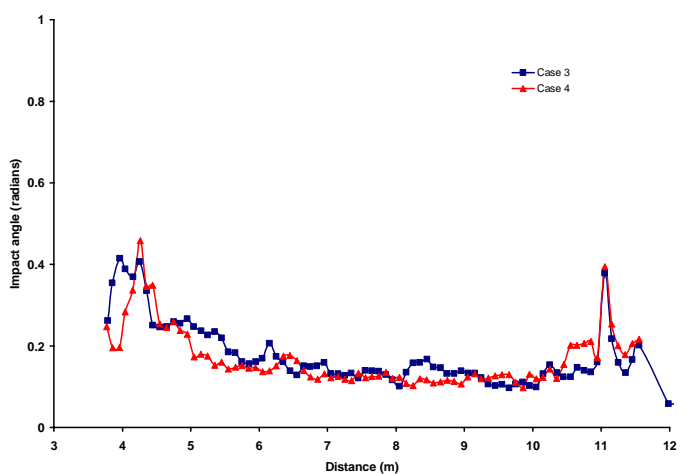

a) SG1PS7

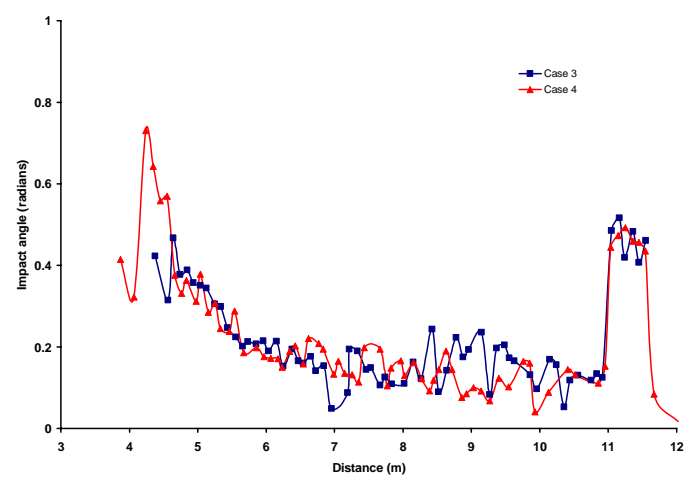

b) SG4PS 1

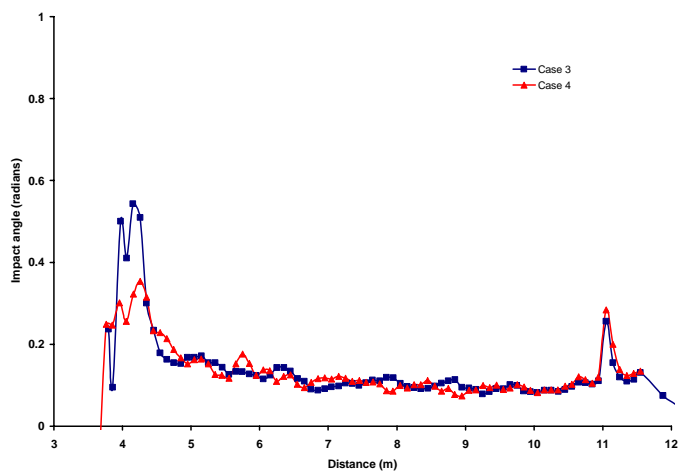

c) Sauter-mean $(108 \mu \mathrm{m})$, composite-average density $\left(1373 \mathrm{~kg} / \mathrm{m}^{3}\right)$

Figure 4.22. Impact angle versus axial location in second stage for particles injected from stage 1 right and left inlets. 


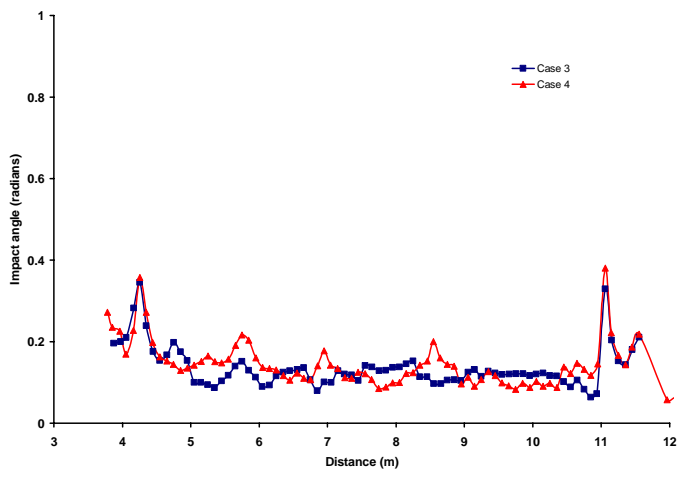

a) SG1PS7

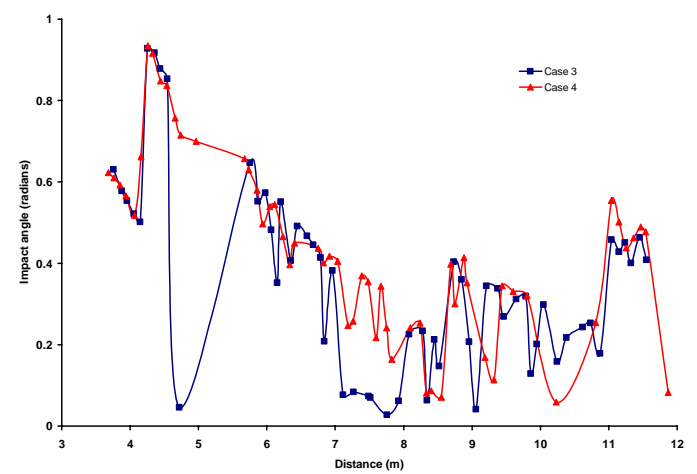

b) SG4PS 1

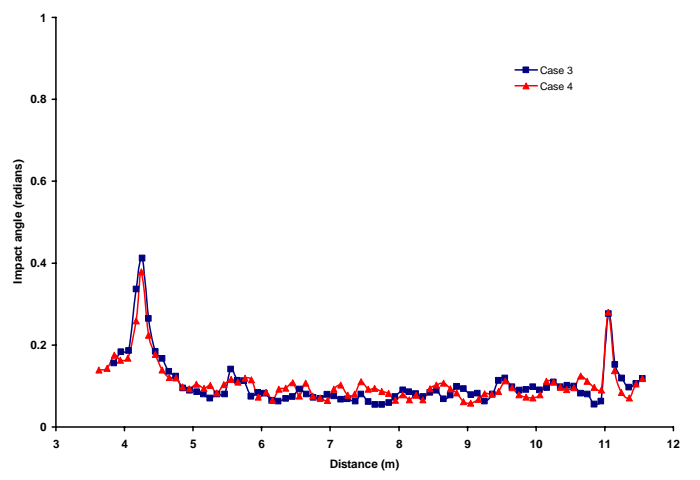

c) Sauter-mean $(108 \mu \mathrm{m})$, composite-average density $\left(1373 \mathrm{~kg} / \mathrm{m}^{3}\right)$

Figure 4.23. Impact angle versus axial location in second stage for particles injected from stage 2 .

Figure 4.24 displays particle impact temperatures in degrees Kelvin for particles injected from the left and right inlets of the first stage. Particle temperature at impact is important to determine whether or not the particles will be incorporated into a separate slag phase that would be attached to the wall of the gasifier. Like the above, particle impact temperatures were recorded for three separate size and densities. SG1PS7 corresponds to a particle diameter equal to $50 \mu \mathrm{m}$ and a density of $1200 \mathrm{~kg} / \mathrm{m}^{3}$ (the smallest, lightest cut). SG4PS1 corresponds to the largest and heaviest particles of $800 \mu \mathrm{m}$ diameter and 3300 $\mathrm{kg} / \mathrm{m}^{3}$ density. The third sample corresponds to an average diameter and density to get mean values for impact angle and temperature in between the smallest and largest 
particles. In all figures, impact properties are plotted for both case 3 and case 4 flow fields for comparison.

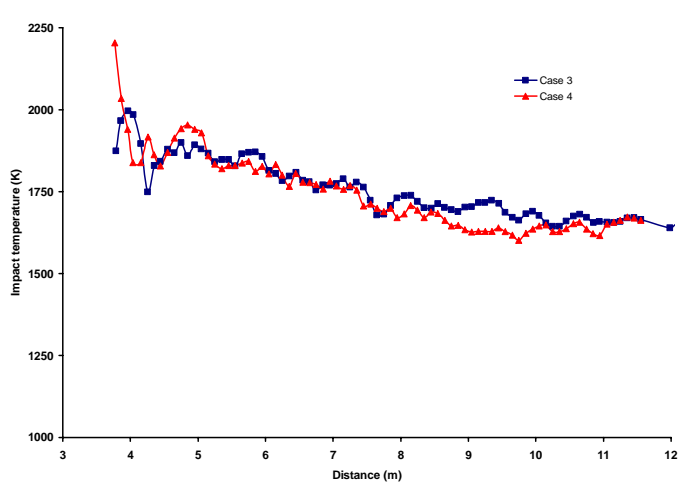

a) SG1PS7

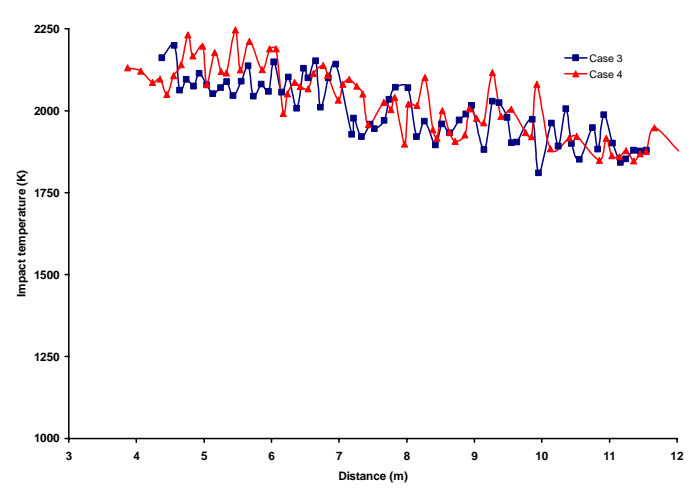

b) SG4PS1

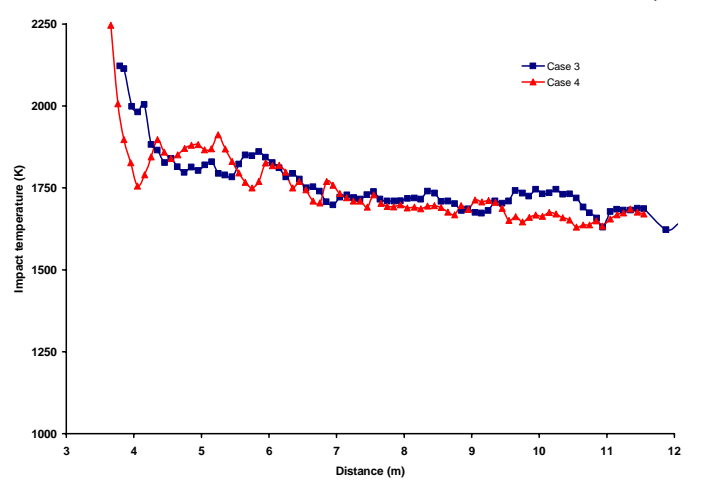

c) Sauter-mean $(108 \mu \mathrm{m})$, composite-average density $\left(1373 \mathrm{~kg} / \mathrm{m}^{3}\right)$

Figure 4.24. Impact temperature versus axial location in second stage for particles injected from stage 1 right and left inlets.

Figure 4.25 displays particle impact temperature for particles injected from the stage 2 inlet only. Particles enter the second stage at much higher temperatures (over $2000 \mathrm{~K}$ ) when tracked from the first stage inlets. Particles are injected through the second stage inlet at 440 degrees Kelvin, but heat up rapidly to temperatures of around 1700 Kelvin within a fraction of a second. Due to the lower temperatures experienced in the second stage, particles will only reach the maximum gas temperature in this region when injected from the second inlet only. In Figure 4.24, particles enter the second stage after experiencing the combusting atmosphere of stage 1 and consist mainly of ash. The 
curves in Figure 4.24 then gradually decrease to temperatures around $1700 \mathrm{~K}$. The larger and heavier particles experience lower temperature changes with respect to time for both cases.

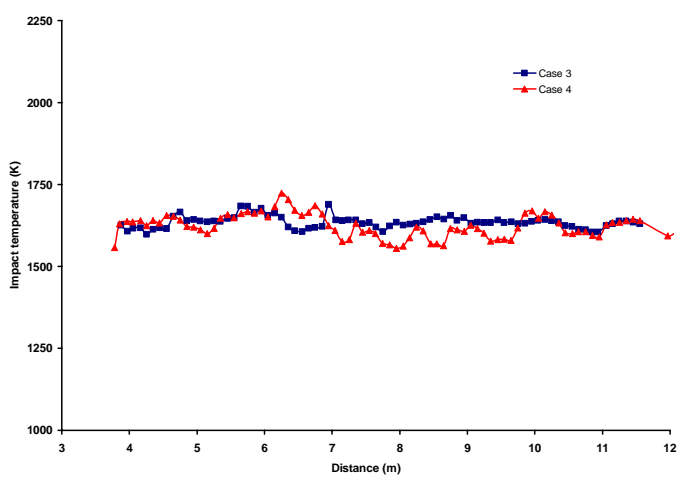

a) SG1PS7

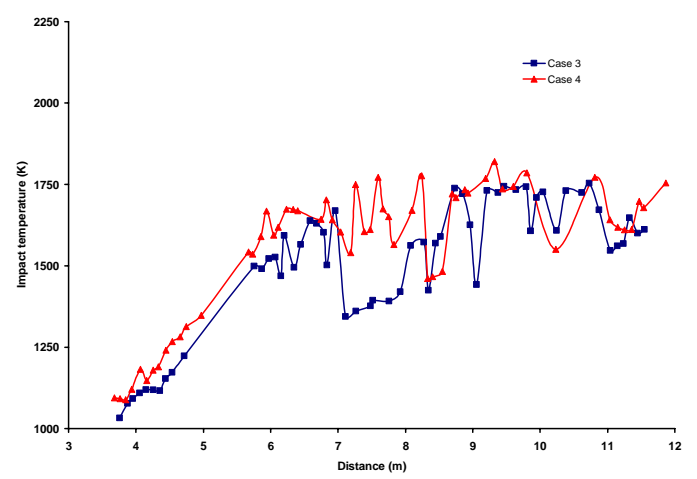

b) SG4PS1

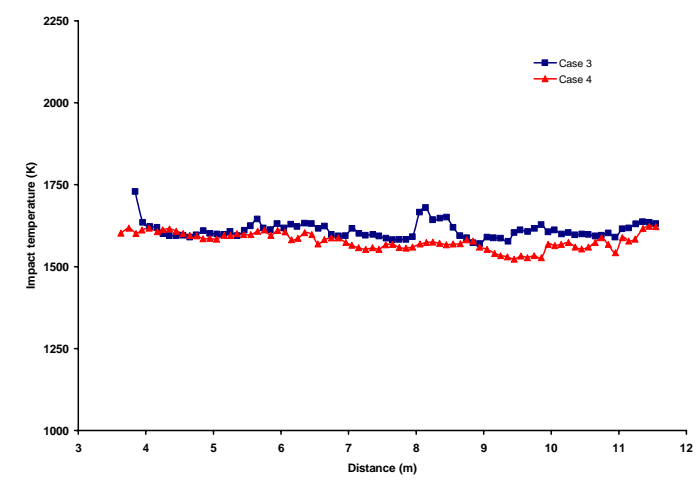

c) Sauter-mean $(108 \mu \mathrm{m})$, composite-average density $\left(1373 \mathrm{~kg} / \mathrm{m}^{3}\right)$

Figure 4.25. Impact temperature versus axial location in second stage for particles injected from stage 2 .

Figures 4.26 and 4.27 display average particle char content at impact versus axial distance along stage 2 for particles injected from stage 1 and stage 2, respectively. Particles exiting stage 1 consist mostly of ash as mentioned above. Figure 4.26 confirms this. Figure $4.26 \mathrm{~b}$ ) displays particle char content for the SG3PS1 size/density class because SG4 particles have very little fixed carbon to begin with and were set to inert in this study. For both case 3 and case 4, particles of the SG3PS1 cut enter stage 2 with maximum char contents of only around $20 \%$ of the current particle mass. The remaining 
fixed carbon is then gradually converted as it reacts with the available gasifying agents. Figure 4.26 a) displays impact char content for particles injected with diameters of 50 microns and densities of $1200 \mathrm{~kg} / \mathrm{m}^{3}$. This corresponds to the lightest and smallest size class. Figure $4.26 \mathrm{c}$ ) displays impact char content for the average diameter and density injection and follows similar patterns. Figures $4.26 \mathrm{~b}$ ) and $4.27 \mathrm{~b}$ ) display impact char content for the largest and heaviest particles. These particles enter the second stage region with most of their fixed carbon remaining. The fixed carbon is then gradually converted as the particles proceed toward the exit. These curves are coincidentally similar due to the fact that the SG3 density class did not contain much fixed carbon at injection.

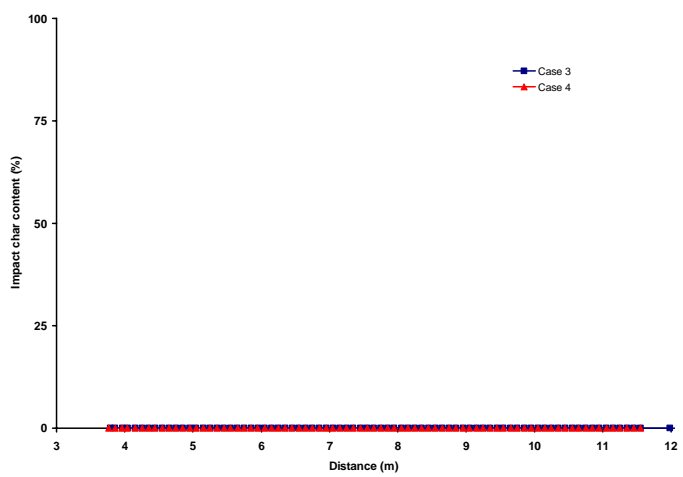

a) SG1PS7

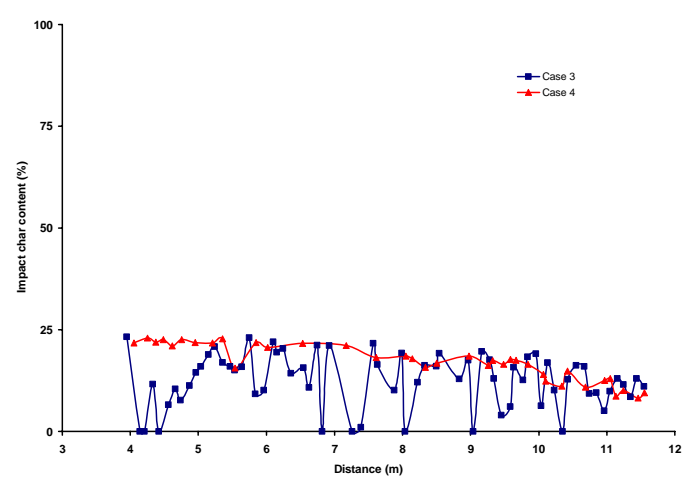

b) SG3PS1

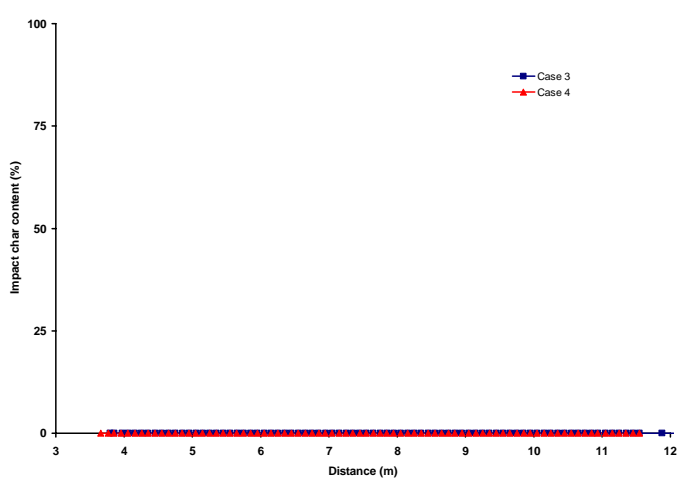

c) Sauter-mean $(108 \mu \mathrm{m})$, composite-average density $\left(1373 \mathrm{~kg} / \mathrm{m}^{3}\right)$

Figure 4.26. Impact char content versus axial location in second stage for particles injected from stage 1 . 


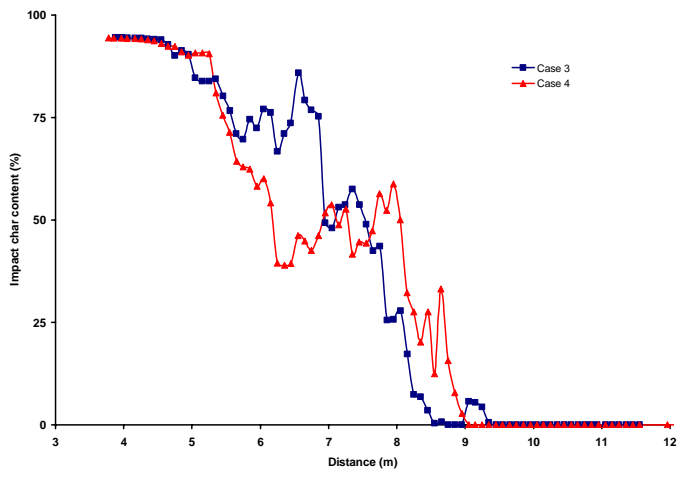

a) SG1PS7

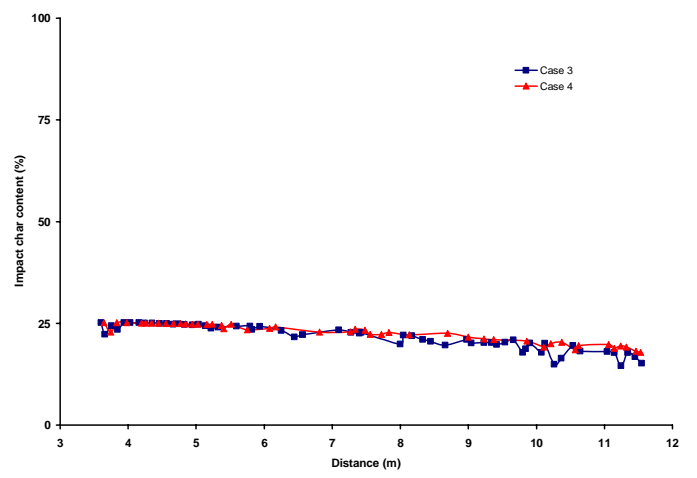

b) SG3PS1

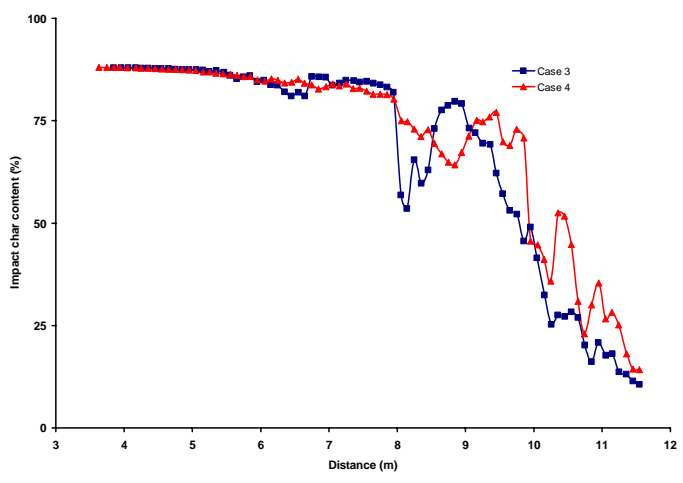

c) Sauter-mean $(108 \mu \mathrm{m})$, composite-average density $\left(1373 \mathrm{~kg} / \mathrm{m}^{3}\right)$

Figure 4.27. Impact char content versus axial location in second stage for particles injected from stage 2 .

The particles injected directly into stage 2 (Figure 4.27) display widely different char content at impact behavior as the particle size and density are varied. Char content for the smallest, lightest particles (SG1PS7) decompose the fastest, while for the intermediate case (Sauter-mean diameter) essentially all of the char is gasified or combusted by the time particles impact the wall near the exit. The large, heavy SG3PS1 particles show only a very small reduction in char content at impact along the gasifier. Particles injected from stage 2 experience residence times less than two seconds on average.

Figures 4.28-31 illustrate particle impact probability versus second stage distance for particles injected into flow fields obtained from case 3 and case 4. Figure 4.28 
displays probability of impact when all 28 size/density fractions are injected simultaneously into the gasifier from both stage 1 and stage 2, while Figure 4.29 for particles injected from stage 2 only. These figures show that impact probability is roughly constant and relatively low beyond the entrance region of the second stage. Figures 4.30-31 display impact probabilities for particles injected with a uniform diameter equal to the Sauter-mean value of the Bailey coal sample and at the composite average density. In all figures, the probability of impact does not seem to change much whether the particles are injected into flow fields obtained using case 3 setup or case 4 . The impact probabilities displayed in Figures 4.28-31 all add up to one. The probabilities were computed based on the assumption that particles would only experience one impact before sticking to the wall.

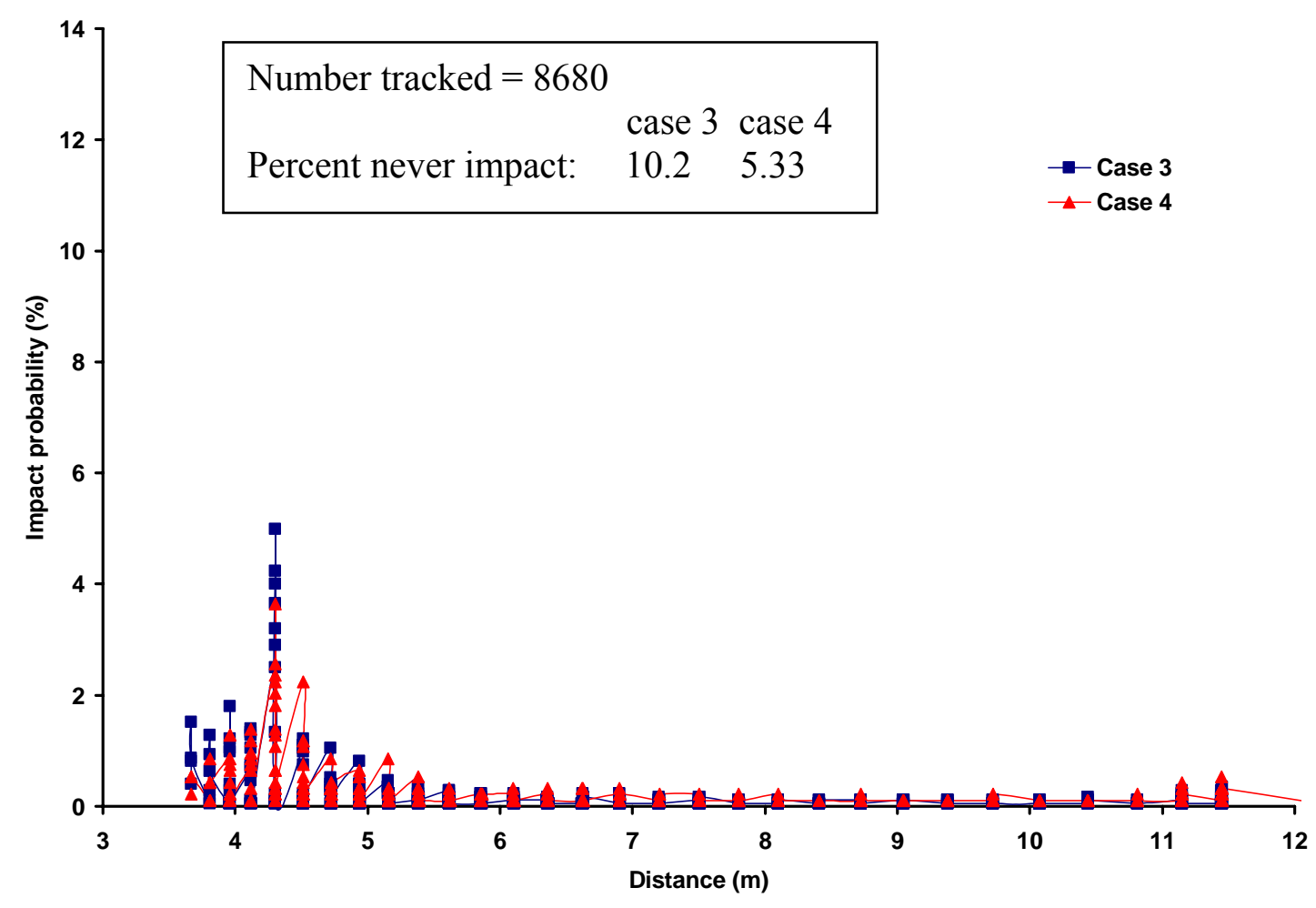

Figure 4.28. Impact probability versus second stage distance for 28 size/density fractions. Particles injected from stage 1 and stage 2. 


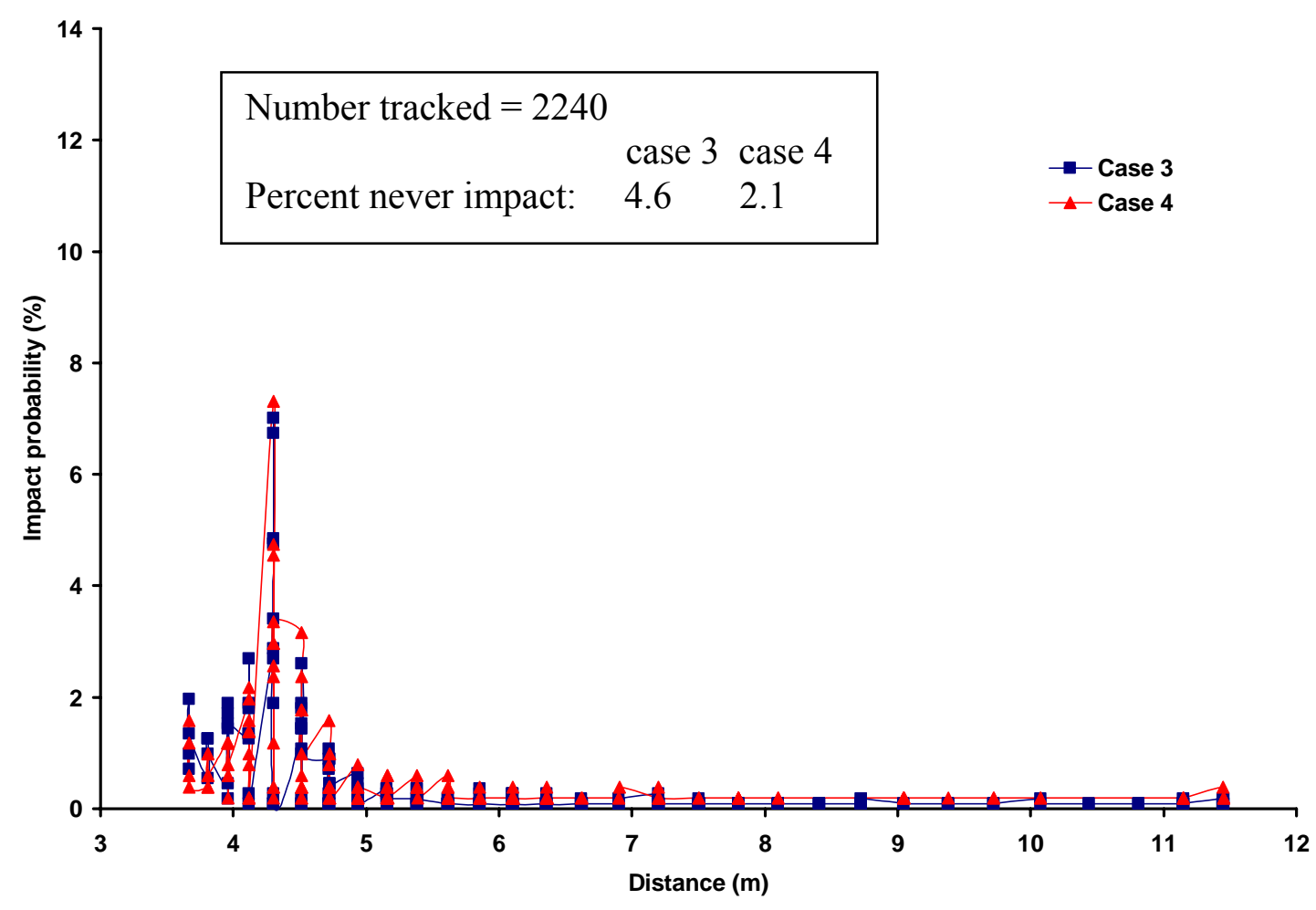

Figure 4.29. Impact probability versus second stage distance for 28 size/density fractions. Particles injected from stage 2 only.

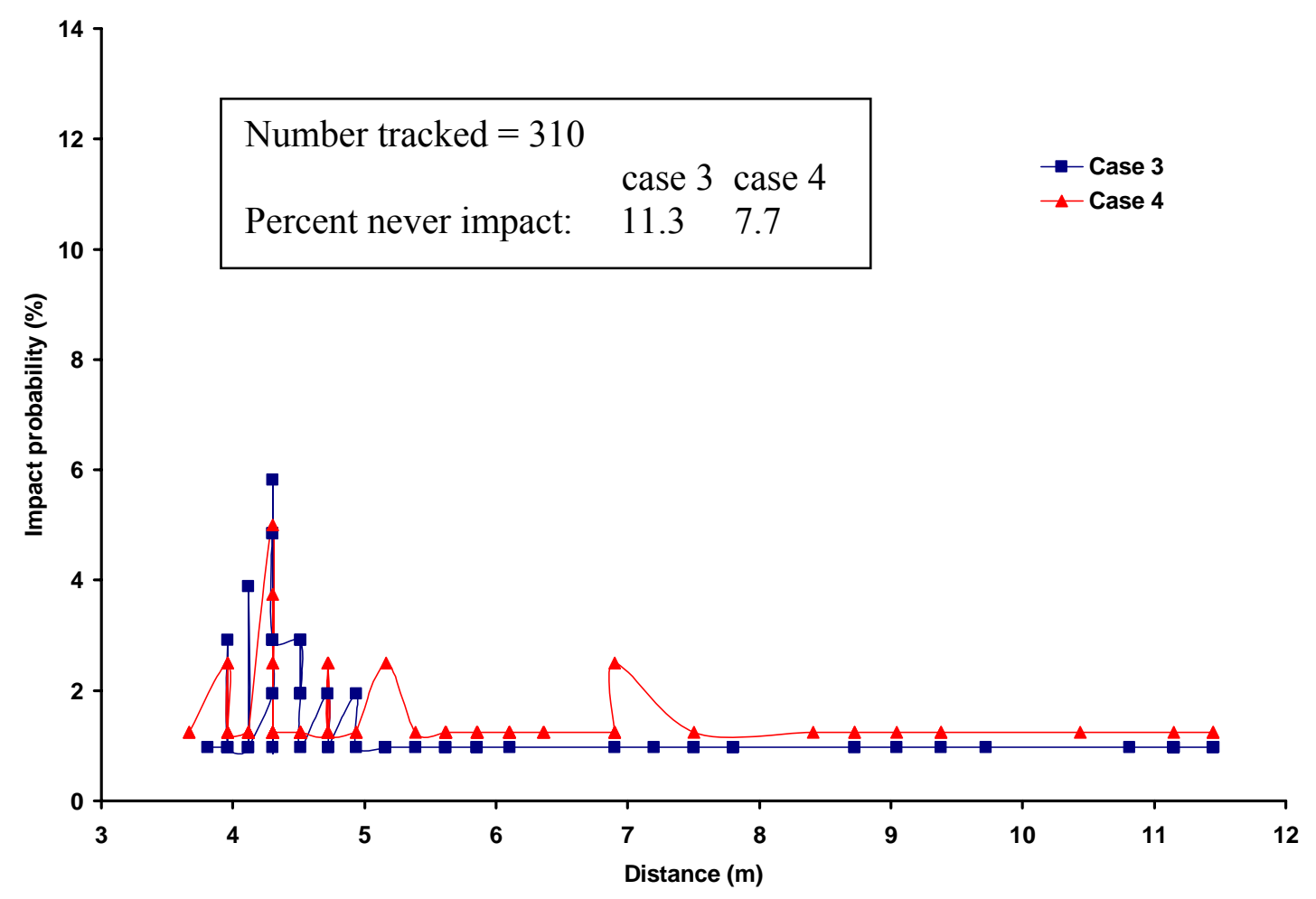

Figure 4.30. Impact probability versus second stage distance for Sauter-mean diameter and composite average density. Particles injected from stage 1 and stage 2. 


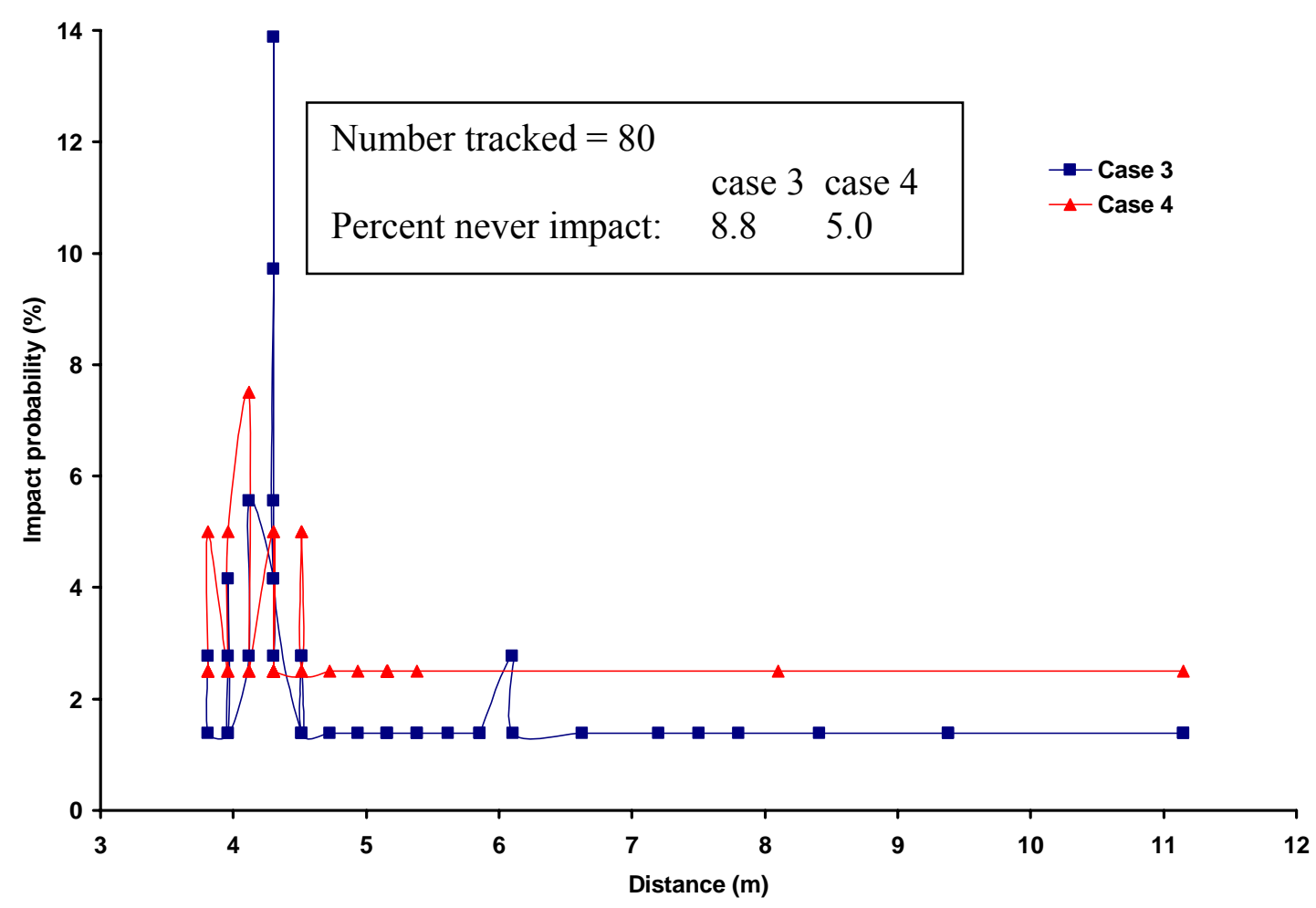

Figure 4.31. Impact probability versus second stage distance for Sauter-mean diameter and composite average density. Particles injected from stage 2 only.

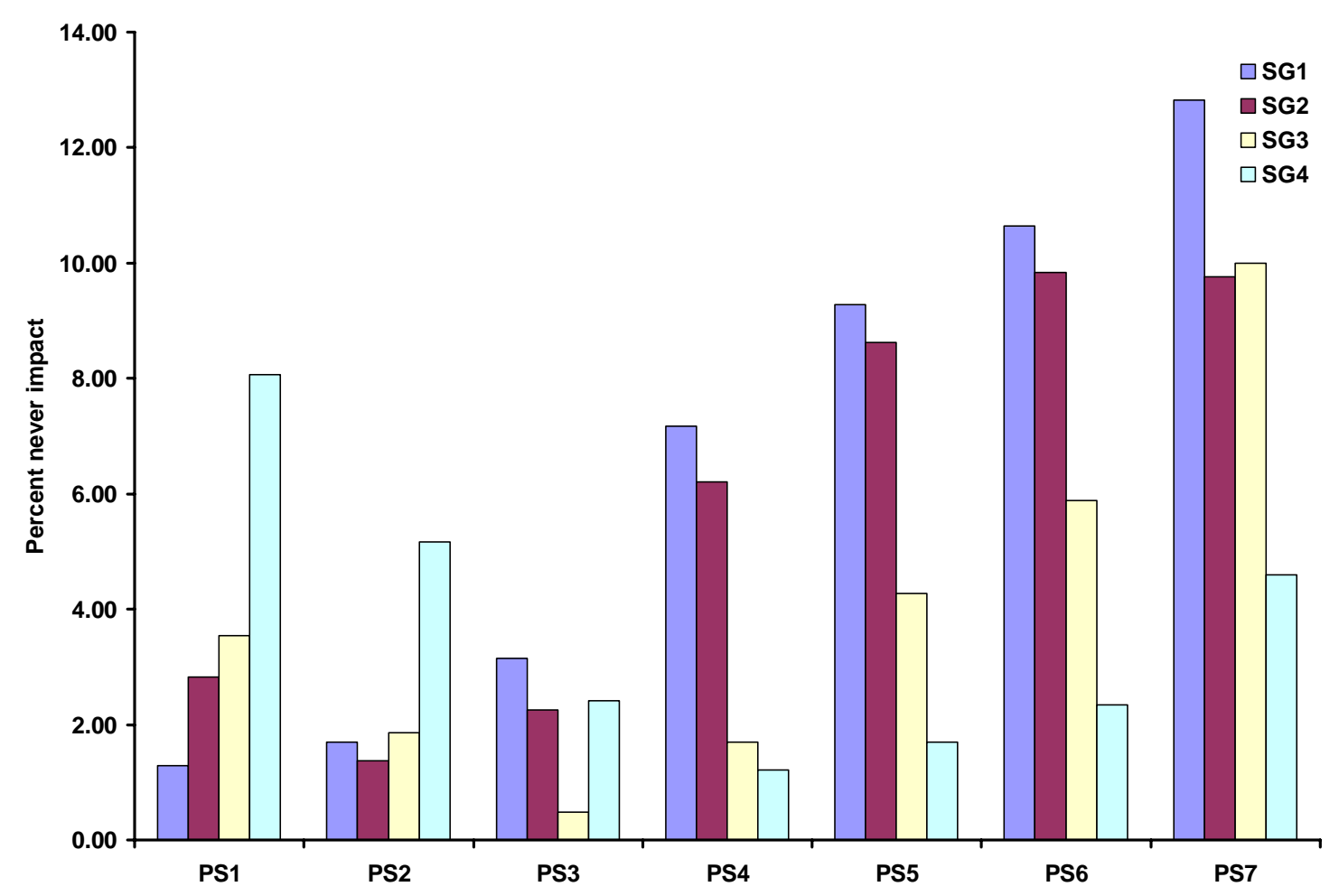

Figure 4.32. Percent of particles that escape allowing 1 impact. 
Figure 4.32 displays the likelihood that particles will escape the reactor without impacting any wall when injected into a flow field obtained from case 4 . Particles were allowed to impact once and then they would stick to the wall. The likelihood that particles would escape generally increases as the particle diameter decreases for the density classes SG1 and SG2. SG3 and SG4 show a different pattern because the bigger particles injected from stage 1 would tend to fall out of the reactor through the slag exit.

Figures 4.33-41 illustrate contours of impact frequency along the surface of the reactor, for three different particle-wall collision assumptions. In Figures 4.33-37, particles were injected at the Sauter-mean diameter and composite average density of the Bailey coal from both the stage 1 and stage 2 inlets. Collisions occur mostly right after the second stage injection in the gasifier region of the model, on the opposite wall to the injection port. Figure 4.33 displays contours of collision frequency for particles that were allowed to impact only once and then were assumed to stick to the wall. Figures 4.34 and 4.35 display collision frequency for 10 and unlimited impacts, respectively. The unlimited impacts case shows what are believed to be unrealistic impact peaks near the gasifier exit (Figure 4.35). Figures 4.36-37 display contours of impact mass flux for particles injected from both stage 1 and stage 2 at the Sauter-mean diameter and composite average density of the Bailey coal. Assuming that $100 \%$ of the particles impact the wall and $80 \%$ of the carbon has been converted prior to impact, then, given the initial conditions listed in Table 3.5, the average mass flux impacting the second stage wall would then be approximately equal to the area-averaged value obtained from the data shown in Figure 4.36. Figures 4.38 and 4.39 display impact mass flux generated for the SG1PS7 (lightest and smallest) injection for 1 and 10 impacts, respectively. 

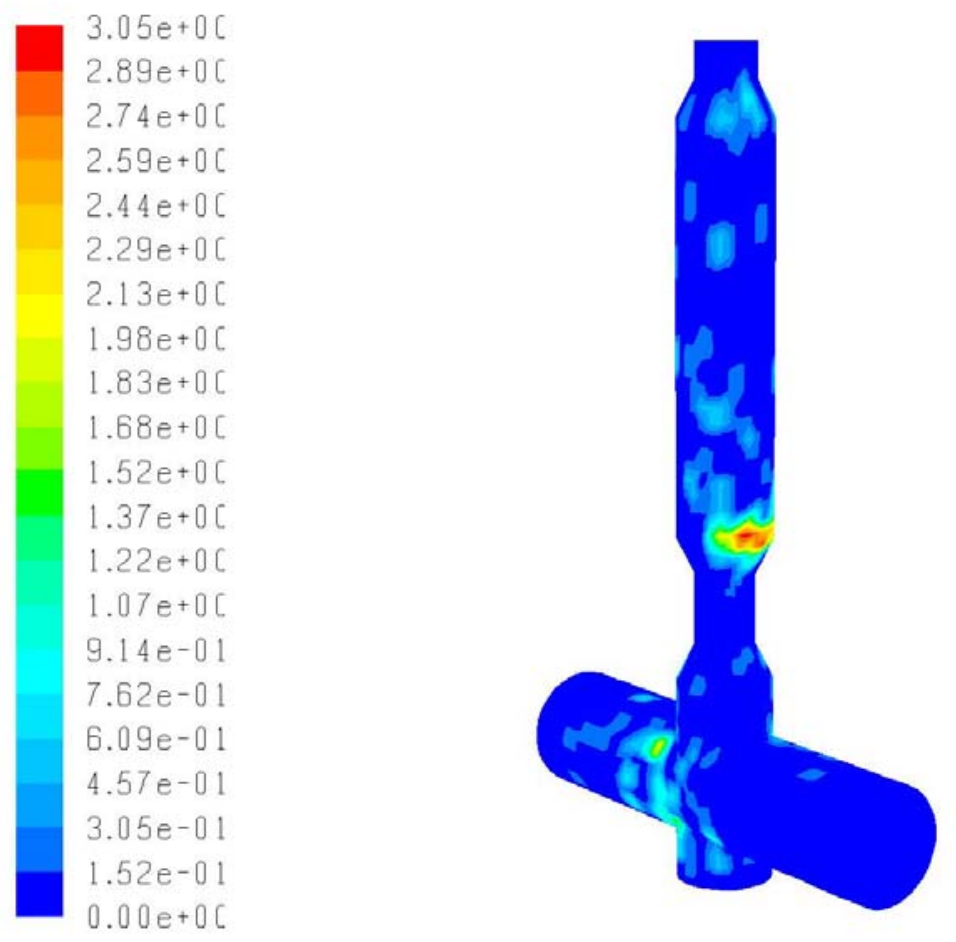

Figure 4.33. Contours of collision frequency for Sauter-mean diameter and composite average density. Particles impact once and then stick.
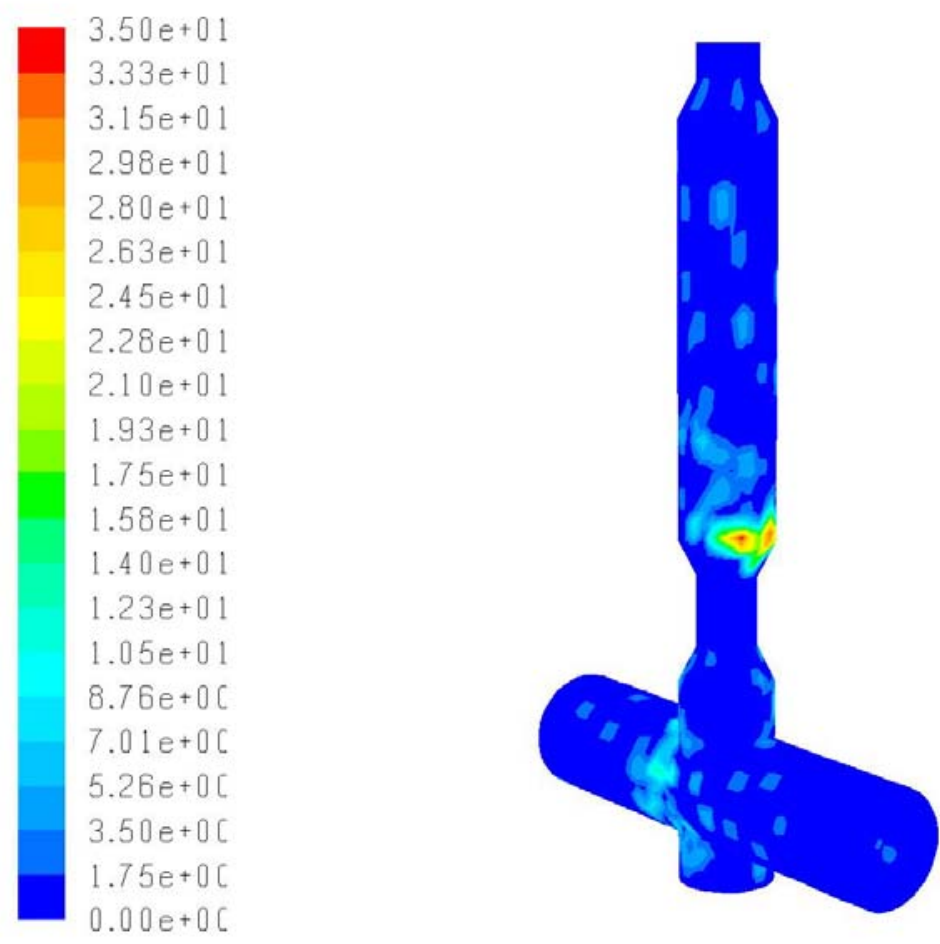

Figure 4.34. Contours of collision frequency for Sauter-mean diameter and composite average density. Particles impact 10 times and then stick. 

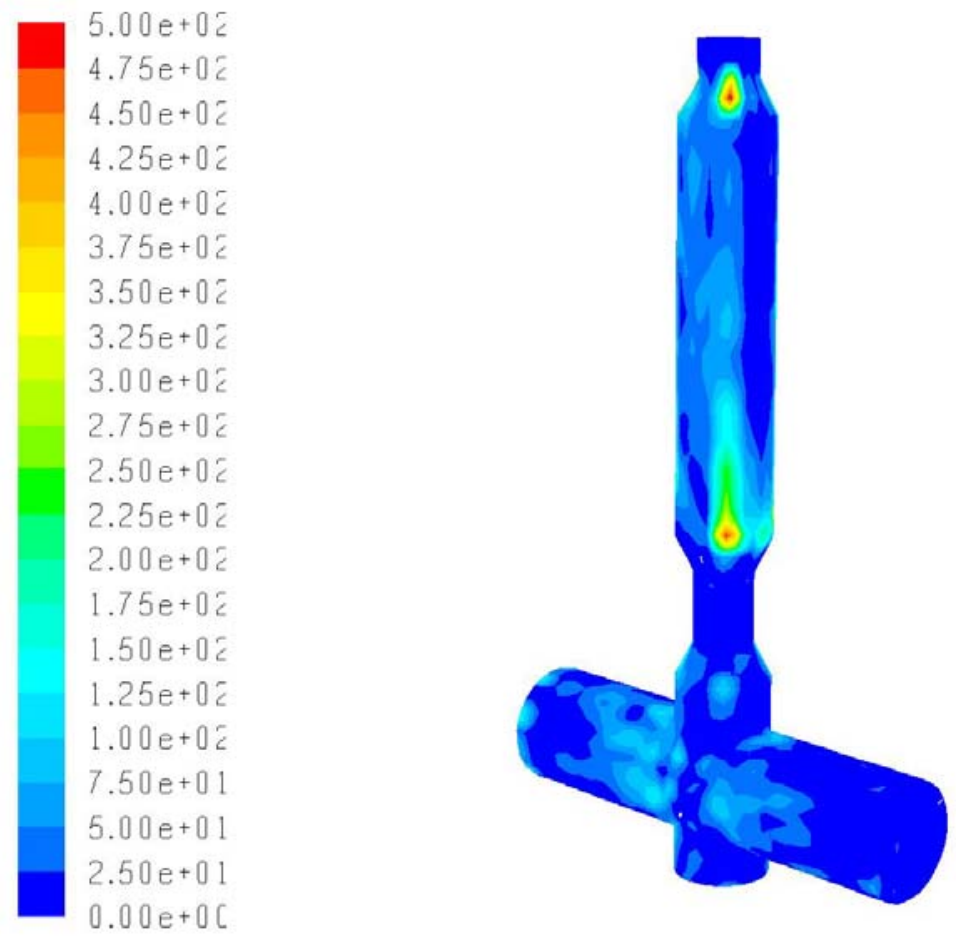

Figure 4.35. Contours of collision frequency for Sauter-mean diameter and composite average density. Unlimited impacts.
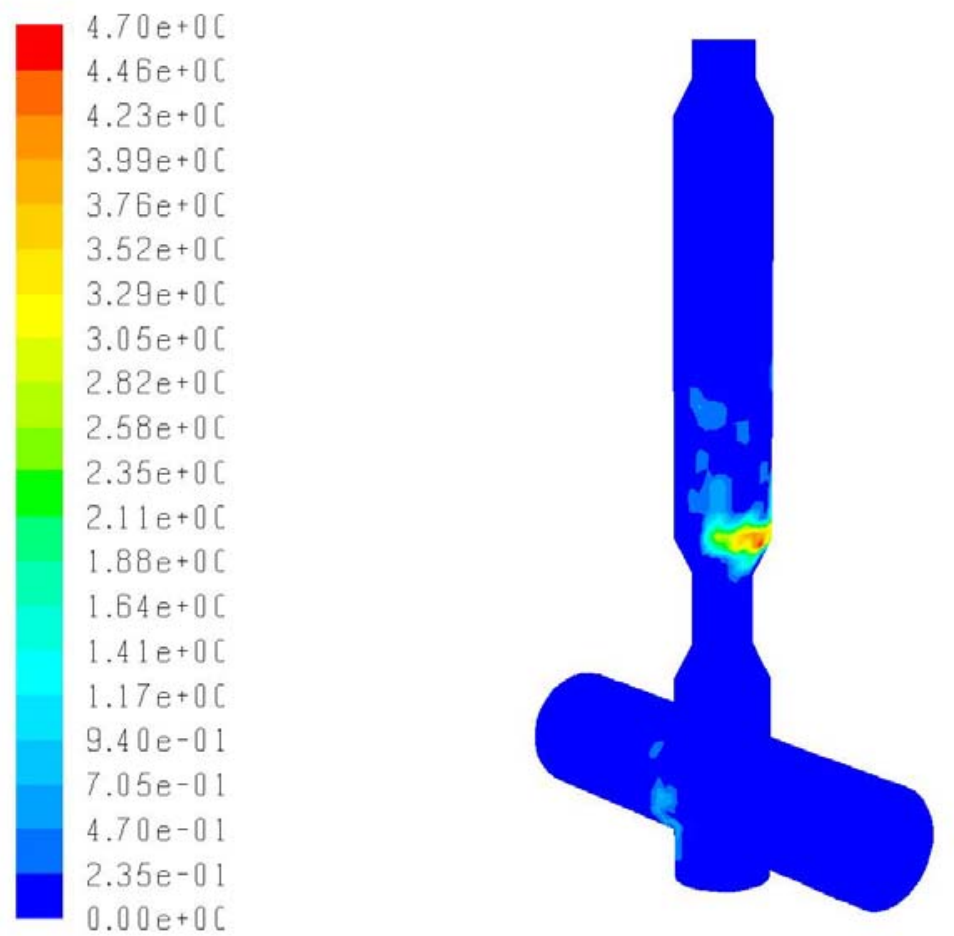

Figure 4.36. Contours of mass flux $\left(\mathrm{kg} / \mathrm{m}^{2}-\mathrm{s}\right)$ for Sauter-mean diameter and composite average density. Particles impact once and then stick. 

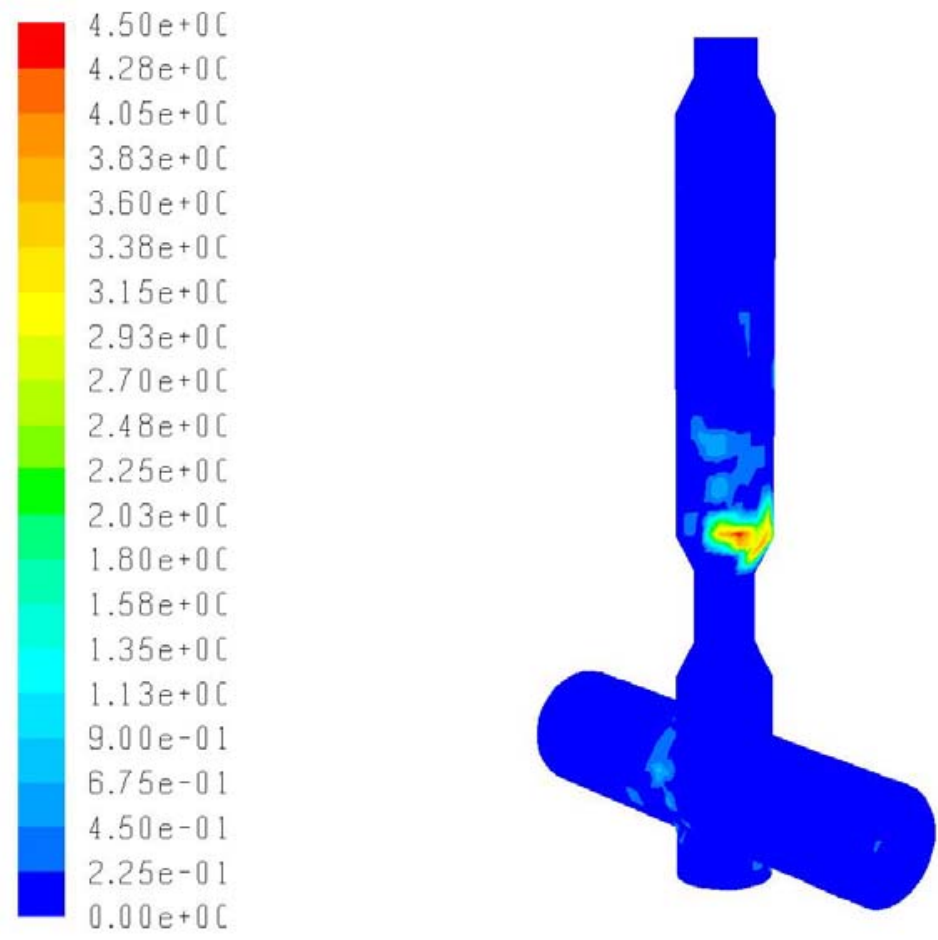

Figure 4.37. Contours of mass flux $\left(\mathrm{kg} / \mathrm{m}^{2}-\mathrm{s}\right)$ for Sauter-mean diameter and composite average density. Particles impact ten times and then stick.
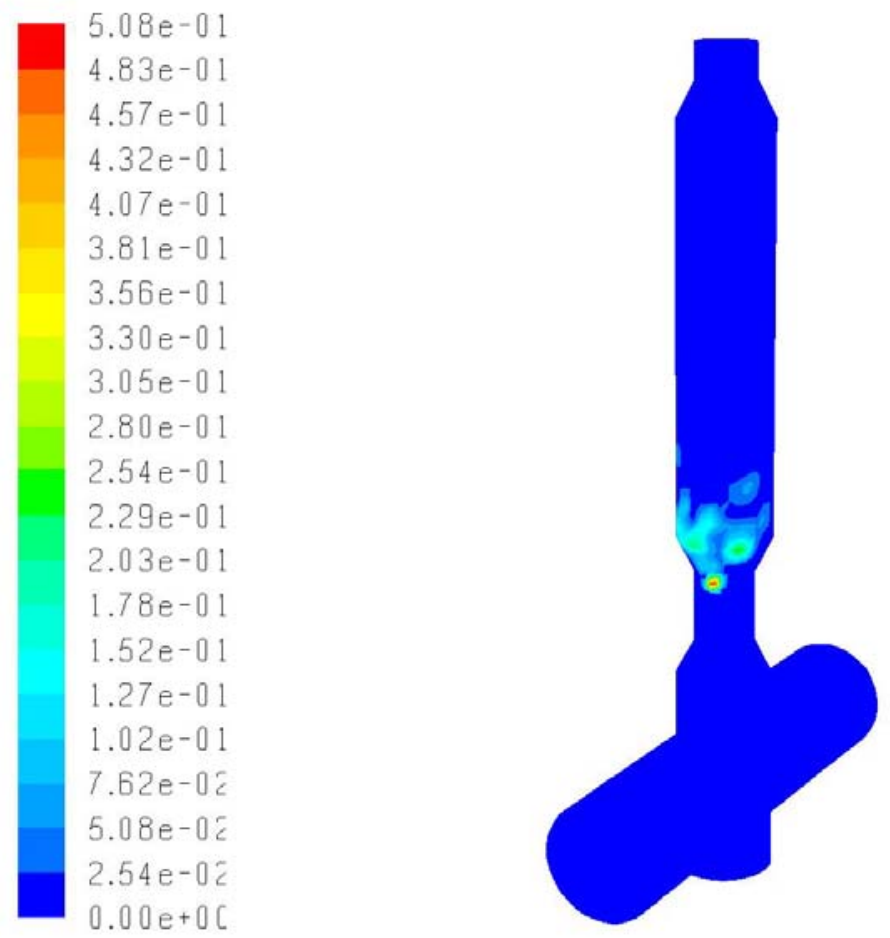

Figure 4.38. Contours of mass flux $\left(\mathrm{kg} / \mathrm{m}^{2}-\mathrm{s}\right)$ for density/size class SG1PS7. Particles impact once and then stick. 

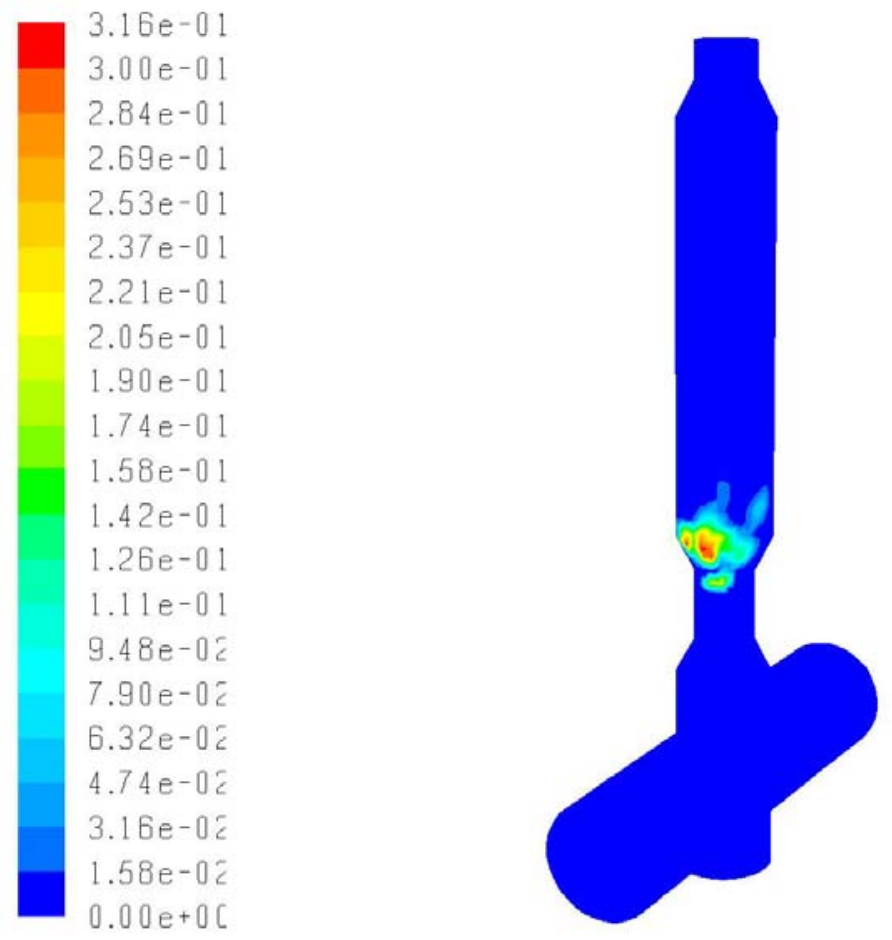

Figure 4.39. Contours of mass flux $\left(\mathrm{kg} / \mathrm{m}^{2}-\mathrm{s}\right)$ for density/size class SG1PS7. Particles impact ten times and then stick.
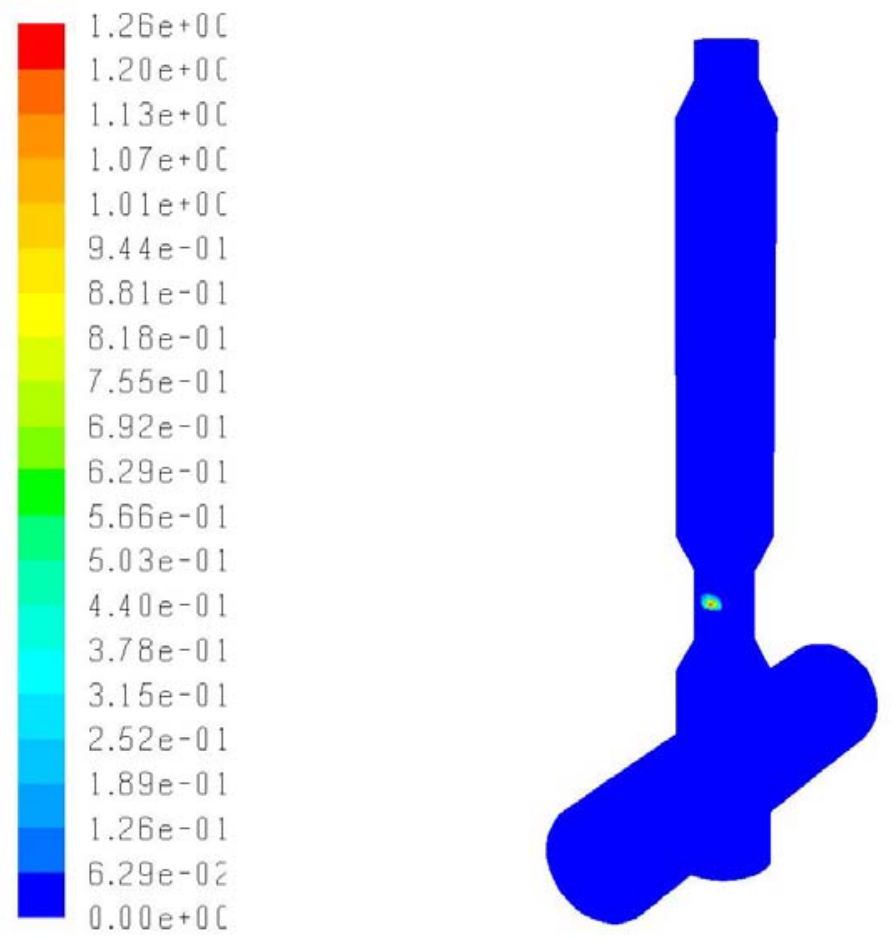

Figure 4.40. Contours of mass flux $\left(\mathrm{kg} / \mathrm{m}^{2}-\mathrm{s}\right)$ for density/size class SG3PS1. Particles impact once and then stick. 

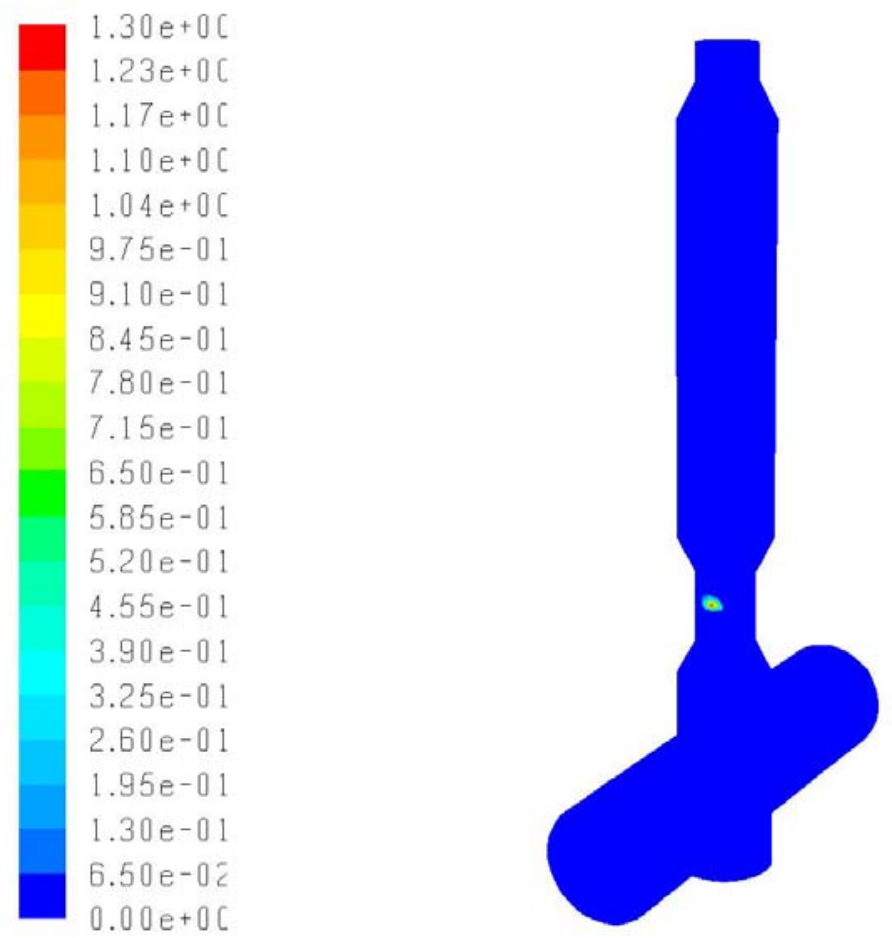

Figure 4.41. Contours of mass flux $\left(\mathrm{kg} / \mathrm{m}^{2}-\mathrm{s}\right)$ for density/size class SG3PS1. Particles impact ten times and then stick.

Figures 4.40 and 4.41 illustrate impact mass flux for the SG3PS1 injection. Particles originating from the SG3PS1 fraction are heavier and have the largest diameters. The mass flux for this fraction is concentrated opposite the second stage injector due to the high initial velocity.

Figures 4.42 and 4.43 illustrate typical particle trajectories colored by residence time throughout the up-flow gasifier model for particle size/density classes SG1PS7 through SG4PS1 injected into a flow field described by cases 1 and 4 above. Additional trajectory plots are provided in the Appendix C for all 28 size/density class injections in flow fields described by cases 1 through 4 . The time history of the particle locations should influence the chemical composition and temperature within the gasifier, as well as the distribution of slag deposited to the wall. Different sizes and densities were injected 
and compared in order to determine whether or not it could be sufficiently accurate to represent an entire coal sample with an average diameter and density in a CFD code. For nearly all stage 1 injections the velocity field for case 2 was insufficient to carry the particles through the second stage. This could explain some of the excess $\mathrm{CO}_{2}$ and $\mathrm{H}_{2} \mathrm{O}$ present at the exit and hence higher temperatures seen from this unrealistic simulation. A larger total number of trajectories can be noticed in case 4 . This can be explained by the fact that multiple surface injections for all of the 28 different size/density cuts were defined on each inlet boundary. Overall mass flow rates were set equal to the single injection cases, though more trajectories had to be tracked and longer computational times resulted from segregating the size/density fractions. As the particle initial density and diameter increases, an increasing percentage of the injected particles get trapped in the horizontal first stage portion of the gasifier and never make it into the second stage to gasify with the steam supplied from the upper slurry inlet. These patterns are most pronounced for the SG4 cases were the initial density was $3300 \mathrm{~kg} / \mathrm{m}^{3}$ compared to 1200 $\mathrm{kg} / \mathrm{m}^{3}$ for the SG1 fraction. It should be noted that due to anomalies in the coal analysis data, the particle types were set to inert for all of the SG4 injections in case 4; this density fraction contains only about $1 \%$ of the total carbon. 


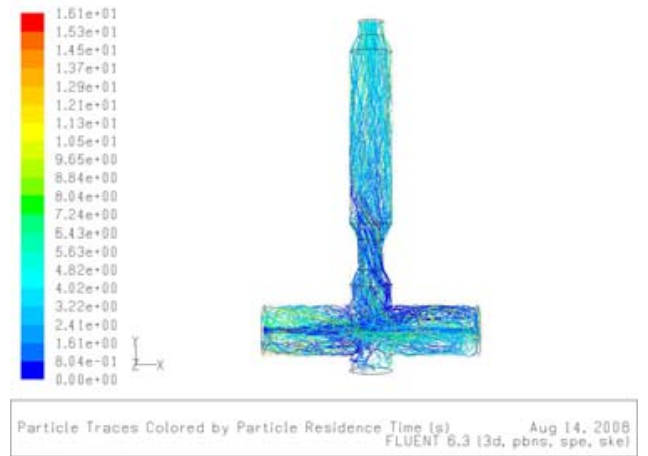

A.) SG1PS7 stage 1
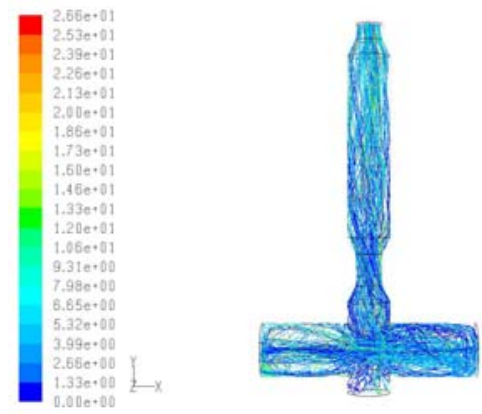

Particle Traces Colored by Particle Residence Time Is)
FLUENT 6.3 (3d, pbos, spe, ske)

C.) SG1PS5 stage 1
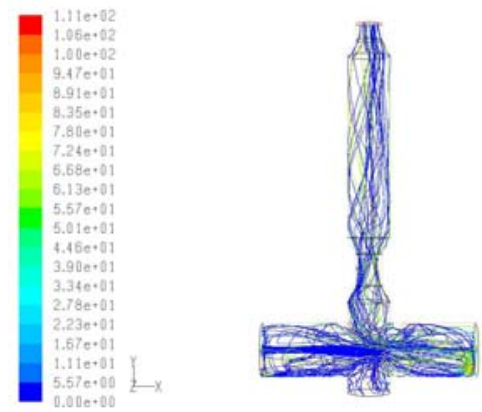

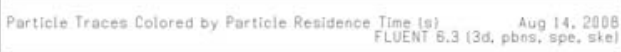

E.) SG1PS3 stage 1
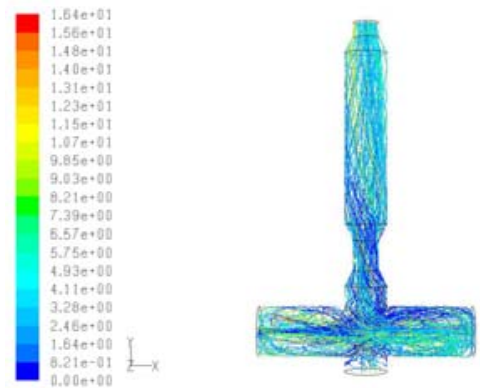

Particle Traces Colored by Particle Residence Fine (f5) 6.3 13d, Dbng, spo, site)

B.) SG1PS6 stage 1
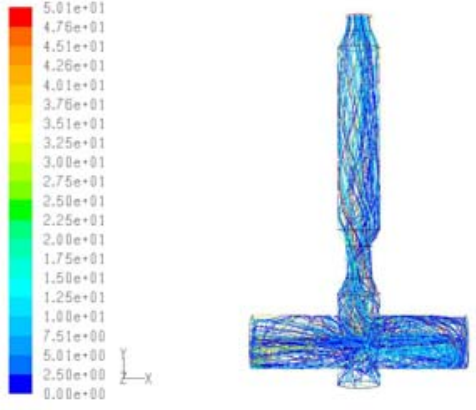

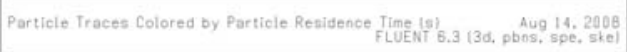

D.) SG1PS4 stage 1
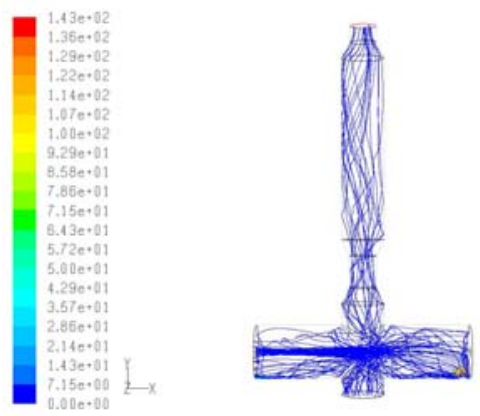

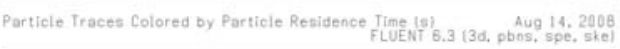

F.) SG1PS2 stage 1
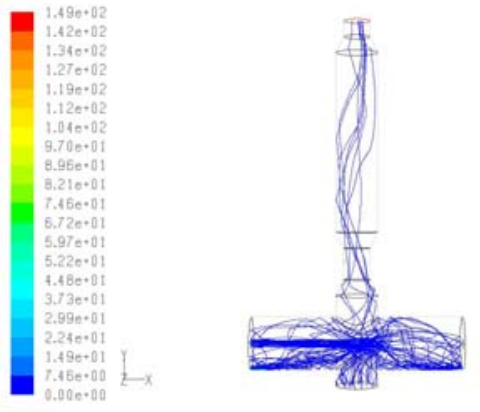

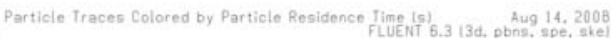

G.) SG1PS1 stage 1

Figure 4.42. Case 1 particle tracks for Bailey coal for first stage injection of specific gravity cut \#1 ( $\mathrm{SG}=1.2)$, for particle size cuts \#7 $(50 \mu \mathrm{m})$ through \#1 $(800 \mu \mathrm{m})$. 


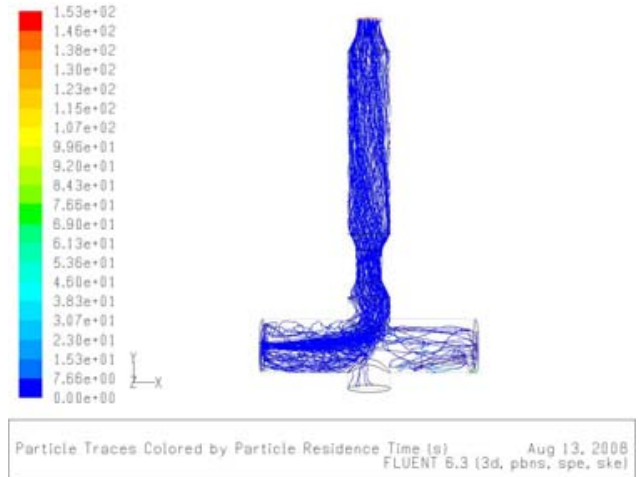

A.) SG4PS7 stage 1
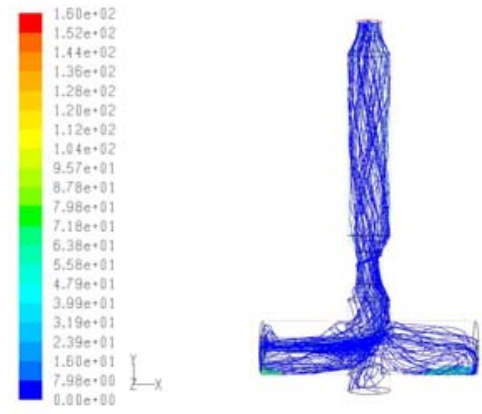

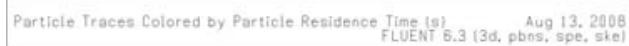

C.) SG4PS5 stage 1
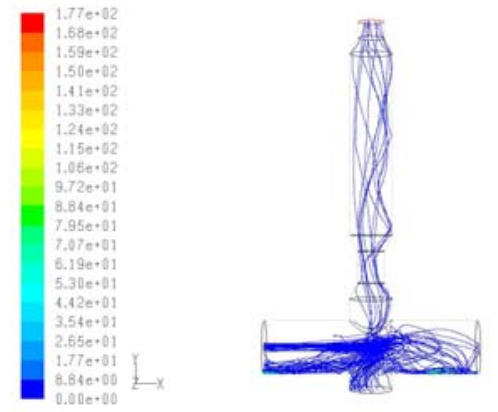

Particle Traces Colored by Particle Renidence Time (s)
FLUENT 6.3 (3d, pbos, spe, ske)

E.) SG4PS3 stage 1

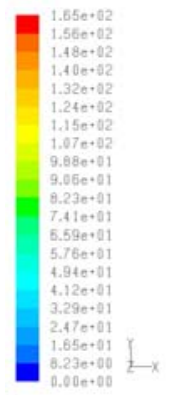

G.) SG4PS1 stage 1

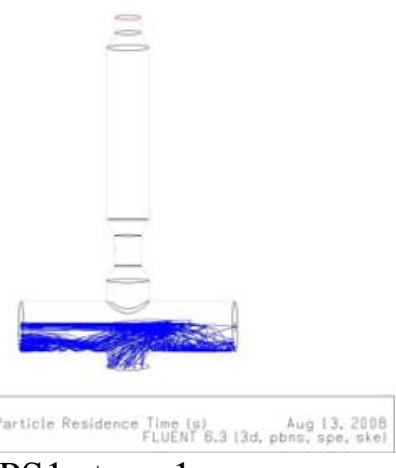

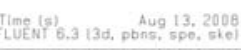

F.) SG4PS2 stage 1

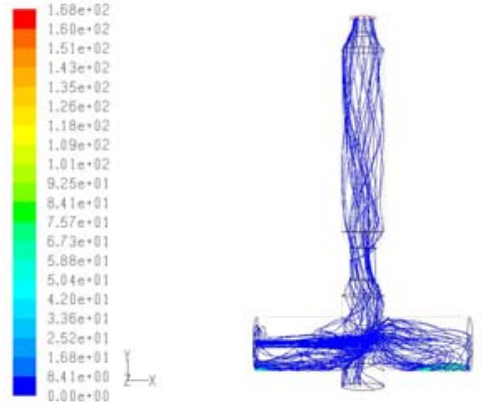

D.) SG4PS4 stage 1
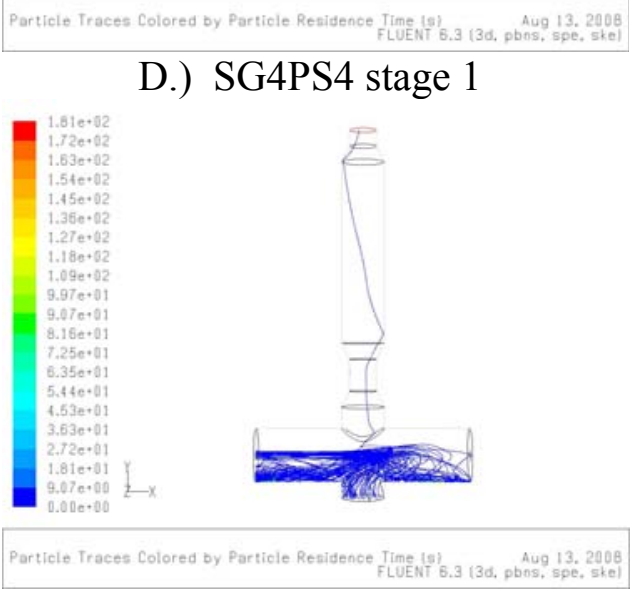

$$
1
$$




\section{$\underline{4.3 \text { Comparison Between Devolatilization Models }}$}

This section presents and discusses the results of a simulation that used devolatilization kinetics and specie distributions discussed in Section 3.6 for the up-flow geometry described in Section 3.3. The application of PC Coal Lab [2] to predict secondary pyrolysis specie distributions in a CFD code is explored here. The case setup, geometry, and boundary conditions are identical to the ones described in Chapter 3. For this simulation, the Sauter-mean diameter of the Bailey coal sample was used on each uniform surface injection. Results from this preliminary simulation using PC Coal Lab secondary pyrolysis results are compared to those corresponding to case 3 in section 4.2.

Computed contours of gas temperature and velocity are compared in Figures 4.44 and 4.45-46. Figure 4.44 compares temperature fields obtained for two different devolatilization specie distributions. Figure 4.44 a) corresponds to PC Coal Lab secondary pyrolysis distributions and Figure 4.44 b) corresponds to the phenomenological devolatilization model employed by Shi et al., [3]. Average gas temperatures reach $2700 \mathrm{~K}$ in stage 1 for the PC Coal Lab kinetics [2] compared to 2500 $\mathrm{K}$ for the phenomenological model [3]. Second stage temperatures are 200 degrees colder for the PC Coal Lab case.

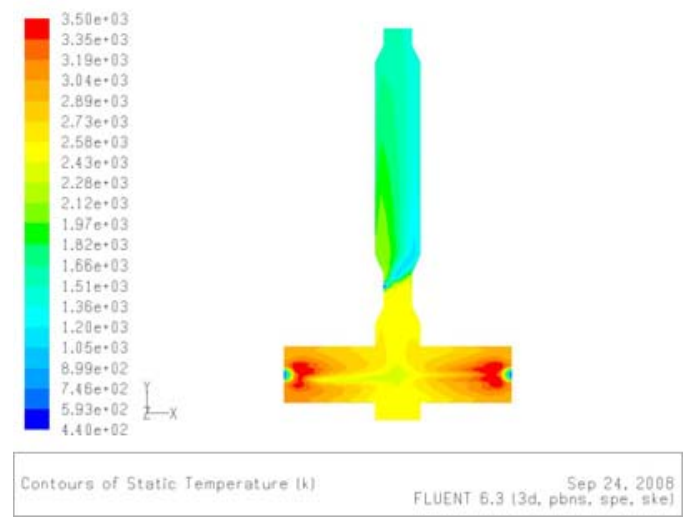

a) PC Coal Lab

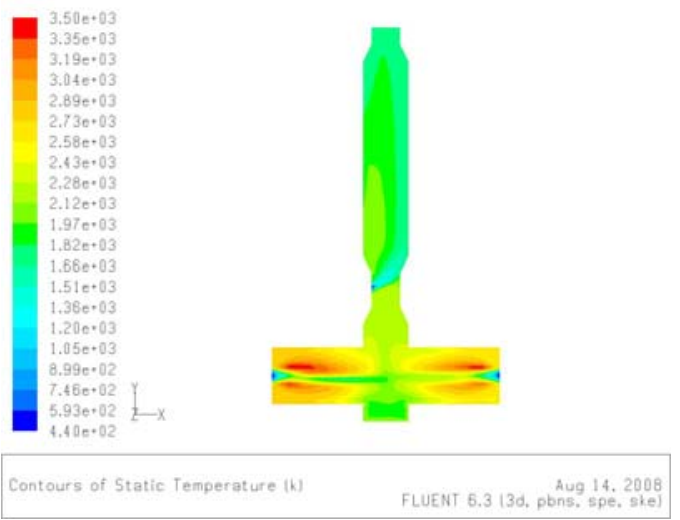

b) Shi et al., 2006

Figure 4.44. Center-plane temperature. 

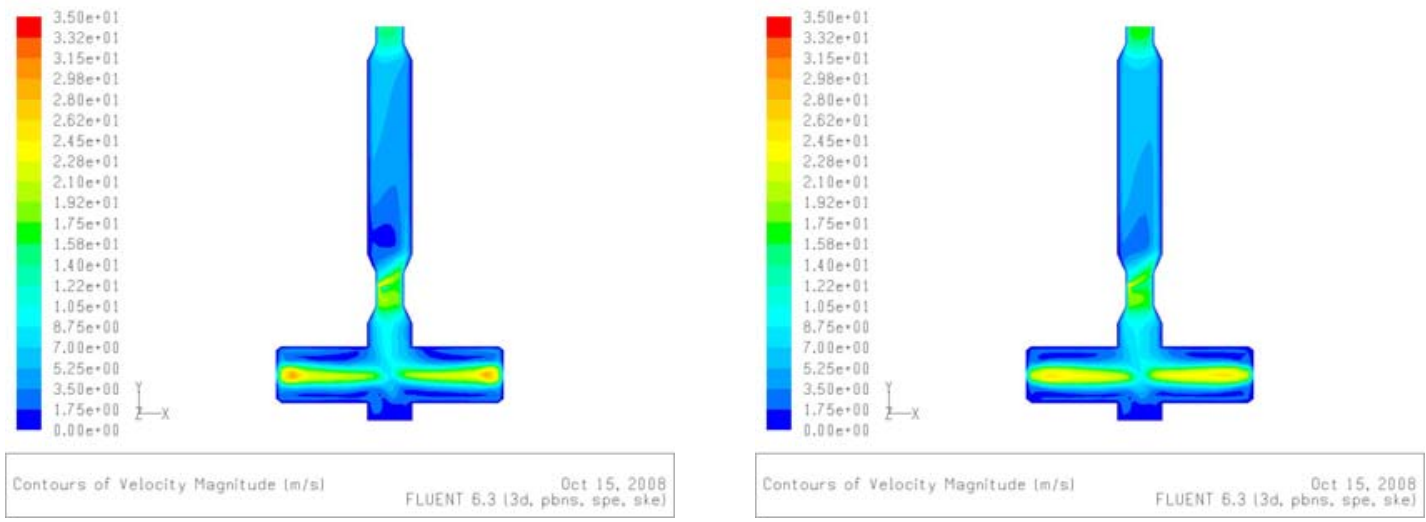

a) PC Coal Lab

b) Shi et al., 2006

Figure 4.45. Center-plane velocity magnitude.
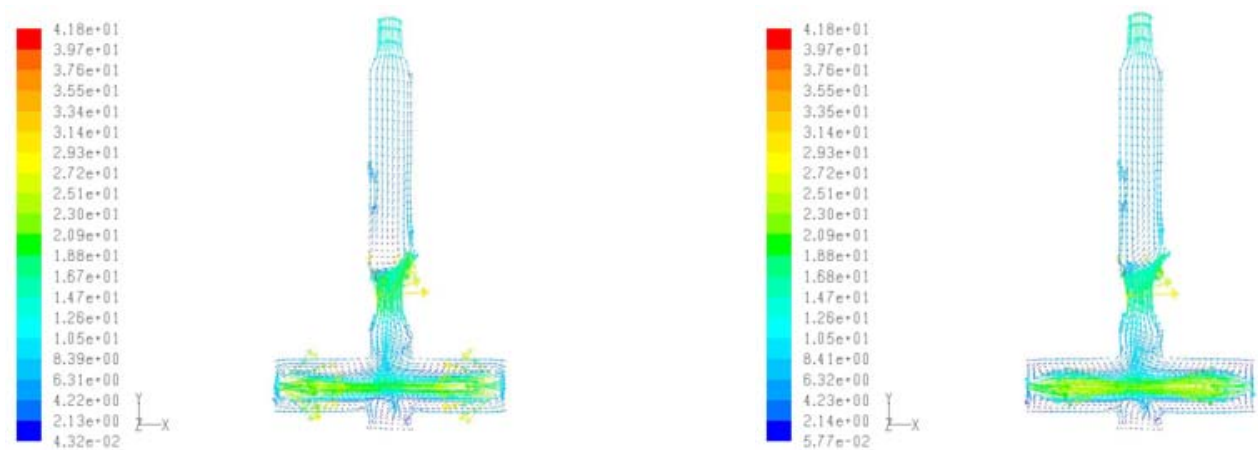

Velocity Veotors Colored 8y Velocity Magnitude In/sist 6.3130 , pot 15, 2006

a) PC Coal Lab

Figure 4.46. Center-plane velocity vectors.

Figure 4.47 compares computed center-plane gas volume fractions for the simulation using PC Coal Lab secondary pyrolysis distributions and for the simulation using the phenomenological model. The distribution of each specie takes similar patterns for both cases. Exit gas volume fractions of $\mathrm{CH}_{4}, \mathrm{CO}_{2}, \mathrm{CO}, \mathrm{H}_{2}$, and $\mathrm{H}_{2} \mathrm{O}$ for both cases are compared in Figure 4.48. It is evident that carbon monoxide dominates the exit gas composition for both of the two models, but the predicted exit $\mathrm{CO}$ and $\mathrm{H}_{2}$ volume fractions are somewhat lower for the PC Coal Lab case. 


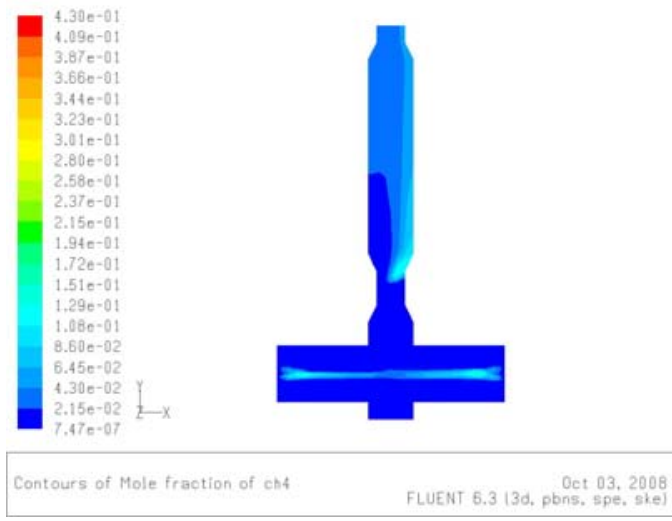

a) Center-plane $\mathrm{CH}_{4}$ mole fraction.

Shi et al., 2006.
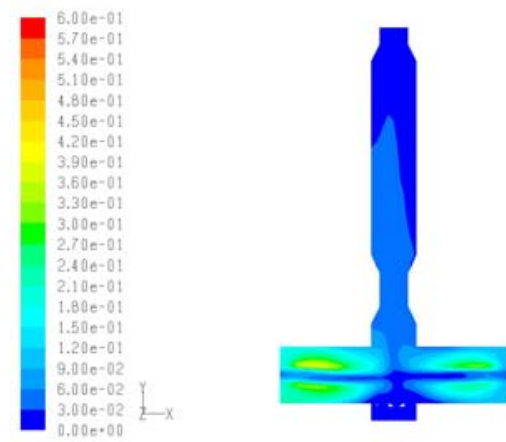

Contours of Mole fraction of $\mathrm{co} 2$

c) Center-plane $\mathrm{CO}_{2}$ mole fraction.

Shi et al., 2006.
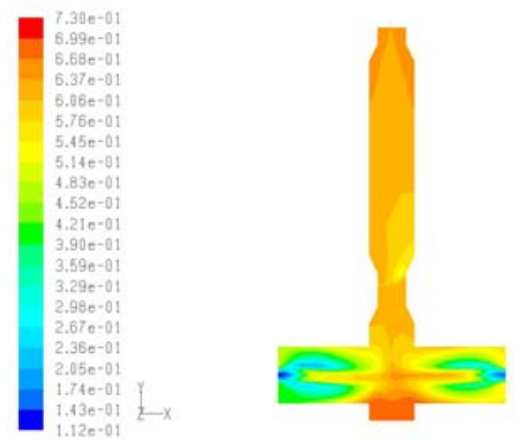

e) Center-plane $\mathrm{CO}$ mole fraction.

Shi et al., 2006.

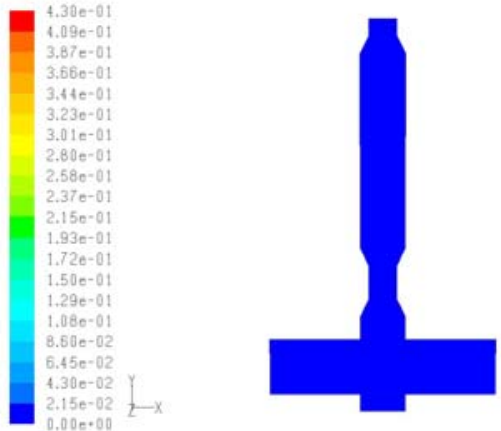

1.0000 .00

b) Center-plane $\mathrm{CH}_{4}$ mole fraction. PC Coal Lab.
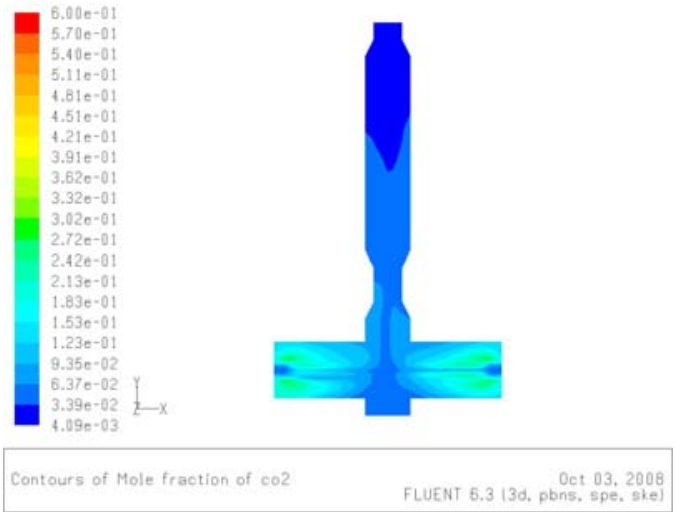

d) Center-plane $\mathrm{CO}_{2}$ mole fraction. PC Coal Lab.
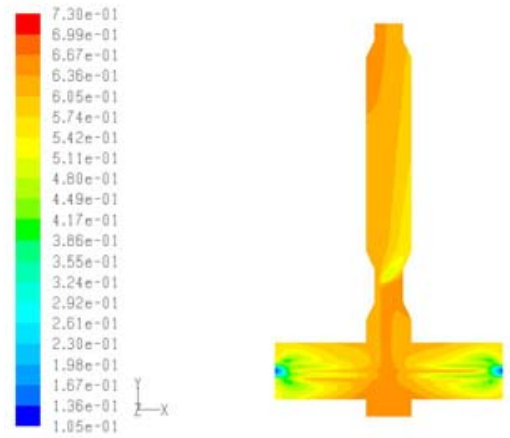

Contours of Mole fraction of co FLUENT 6.3 13d, pbots, 03, 2008

f) Center-plane $\mathrm{CO}$ mole fraction. PC Coal Lab.

Figure 4.47. Center-plane gas mole fractions. 


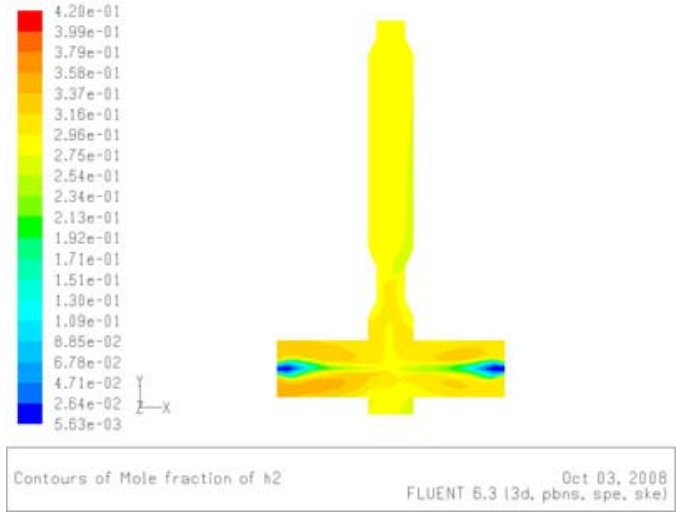

g) Center-plane $\mathrm{H}_{2}$ mole fraction. Shi et al., 2006.
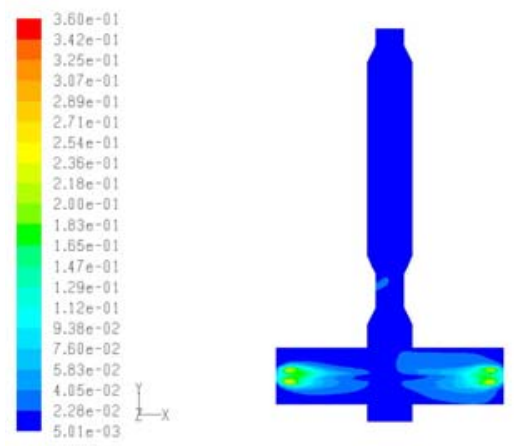

i) Center-plane $\mathrm{H}_{2} \mathrm{O}$ mole fraction. Shi et al., 2006.
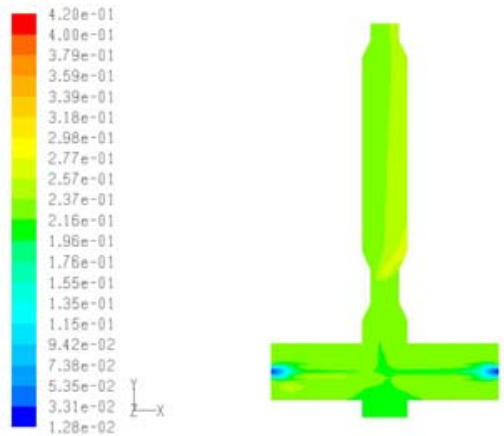

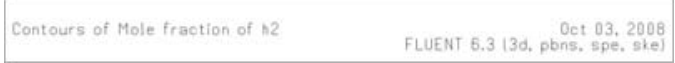

h) Center-plane $\mathrm{H}_{2}$ mole fraction. PC Coal Lab.
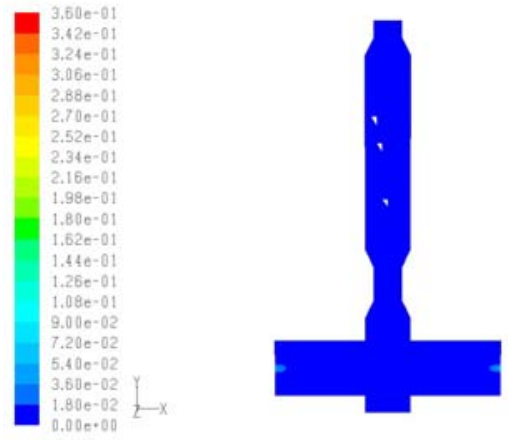

j) Center-plane $\mathrm{H}_{2} \mathrm{O}$ mole fraction. PC Coal Lab.

Figure 4.47. Center-plane gas mole fractions (concluded).

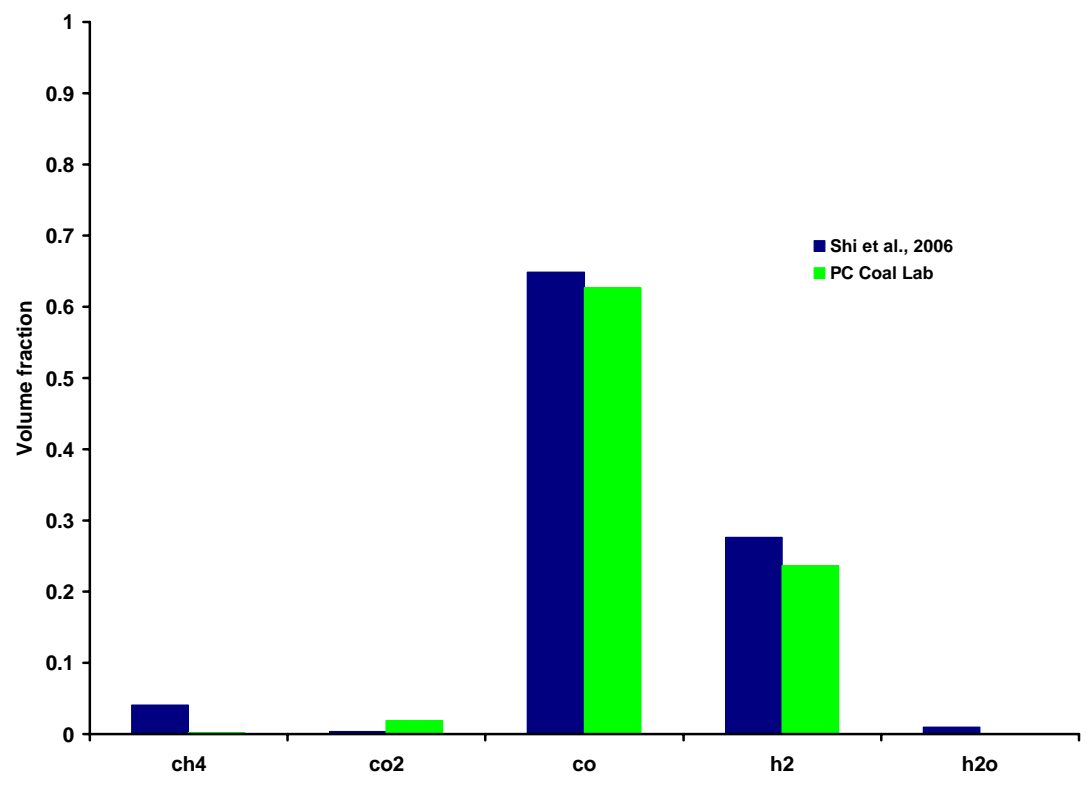

Figure 4.48. Exit gas volume fractions. 
Figure 4.49 illustrates the computed gas mass fractions of $\mathrm{CO}, \mathrm{CO}_{2}, \mathrm{H}_{2}$, and $\mathrm{H}_{2} \mathrm{O}$ throughout the second stage of the up-flow gasifier for the flow field obtained using PC Coal Lab secondary pyrolysis distributions. Carbon monoxide levels gradually increase as the available $\mathrm{CO}_{2}$ and $\mathrm{H}_{2} \mathrm{O}$ gasifies with the fixed carbon in the coal. $\mathrm{H}_{2} \mathrm{O}$ is evaporated and gasified immediately upon injection explaining the very low levels throughout the second stage.

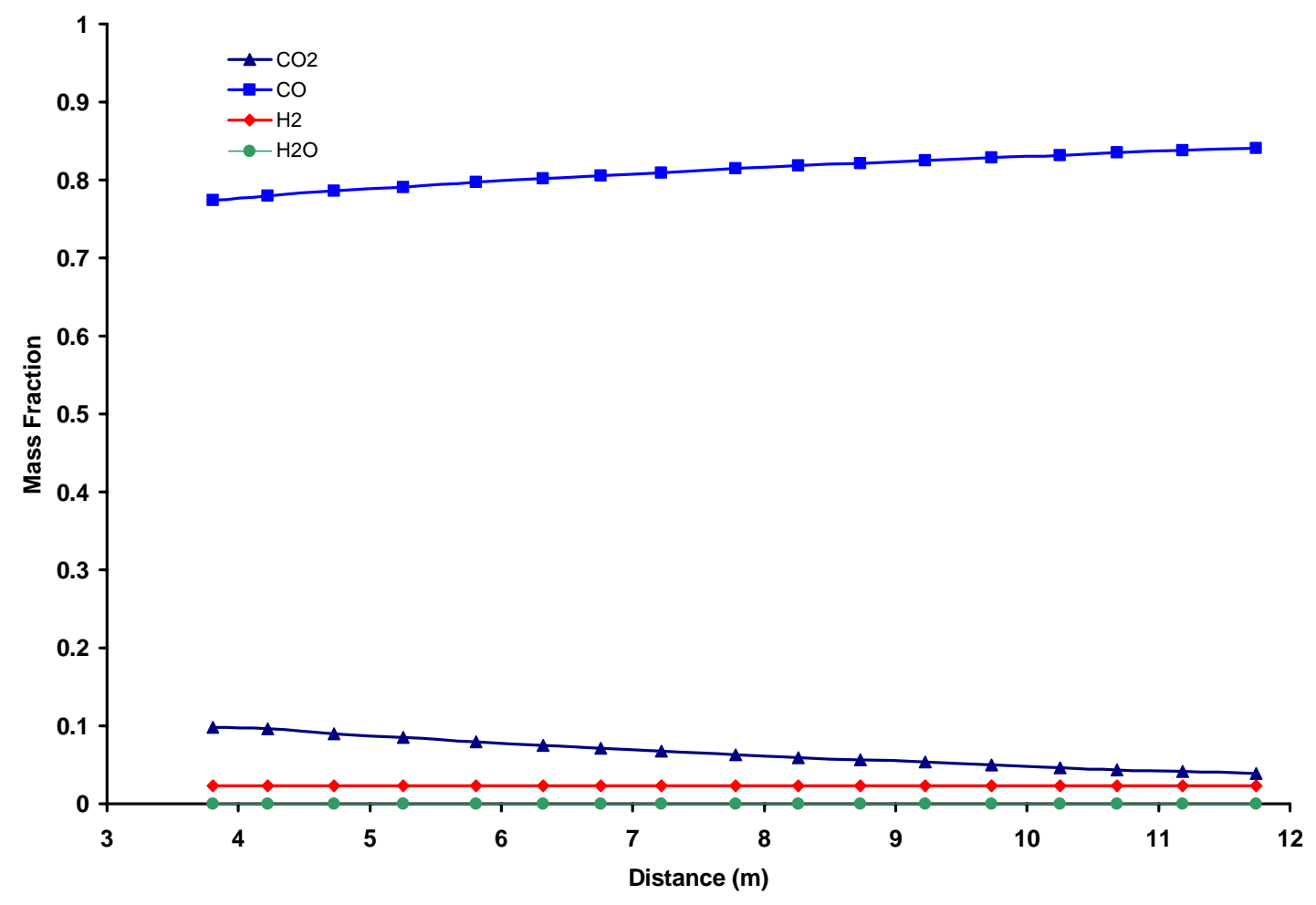

Figure 4.49. Average gas mass fractions versus distance in stage 2.

Figures 4.50-53 present the predicted particle mass loss and temperature for both cases versus vertical distance along the second stage. Figures 4.50 and 4.52 were generated by tracking particles injected from both the first and second stage inlets. Along each particles trajectory throughout stage 2 , the particle mass, temperature, and local gas composition was recorded. This data was then averaged in bins of axial y-coordinate and 


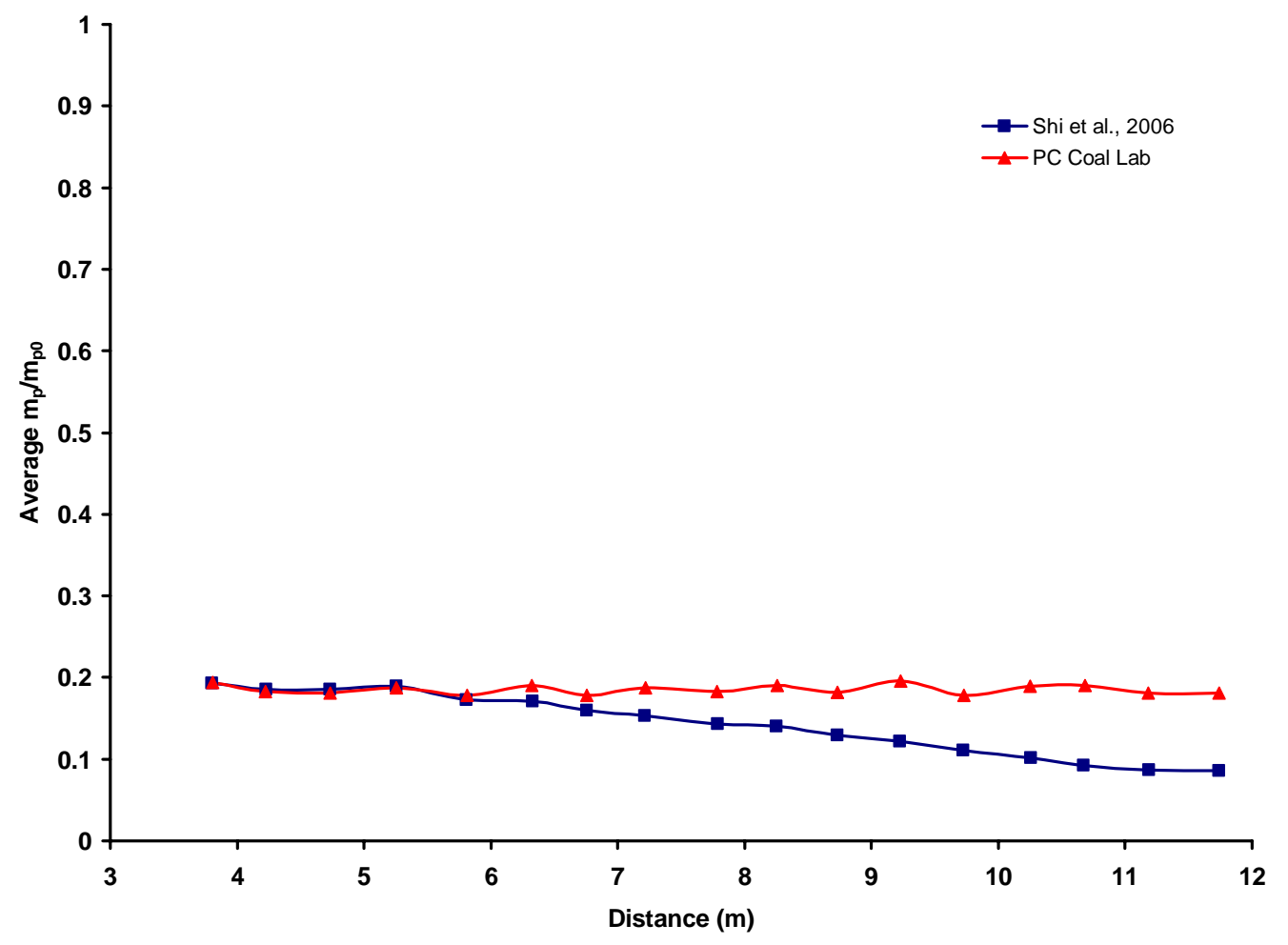

Figure 4.50. Average particle mass loss versus distance in stage 2 (all injected).

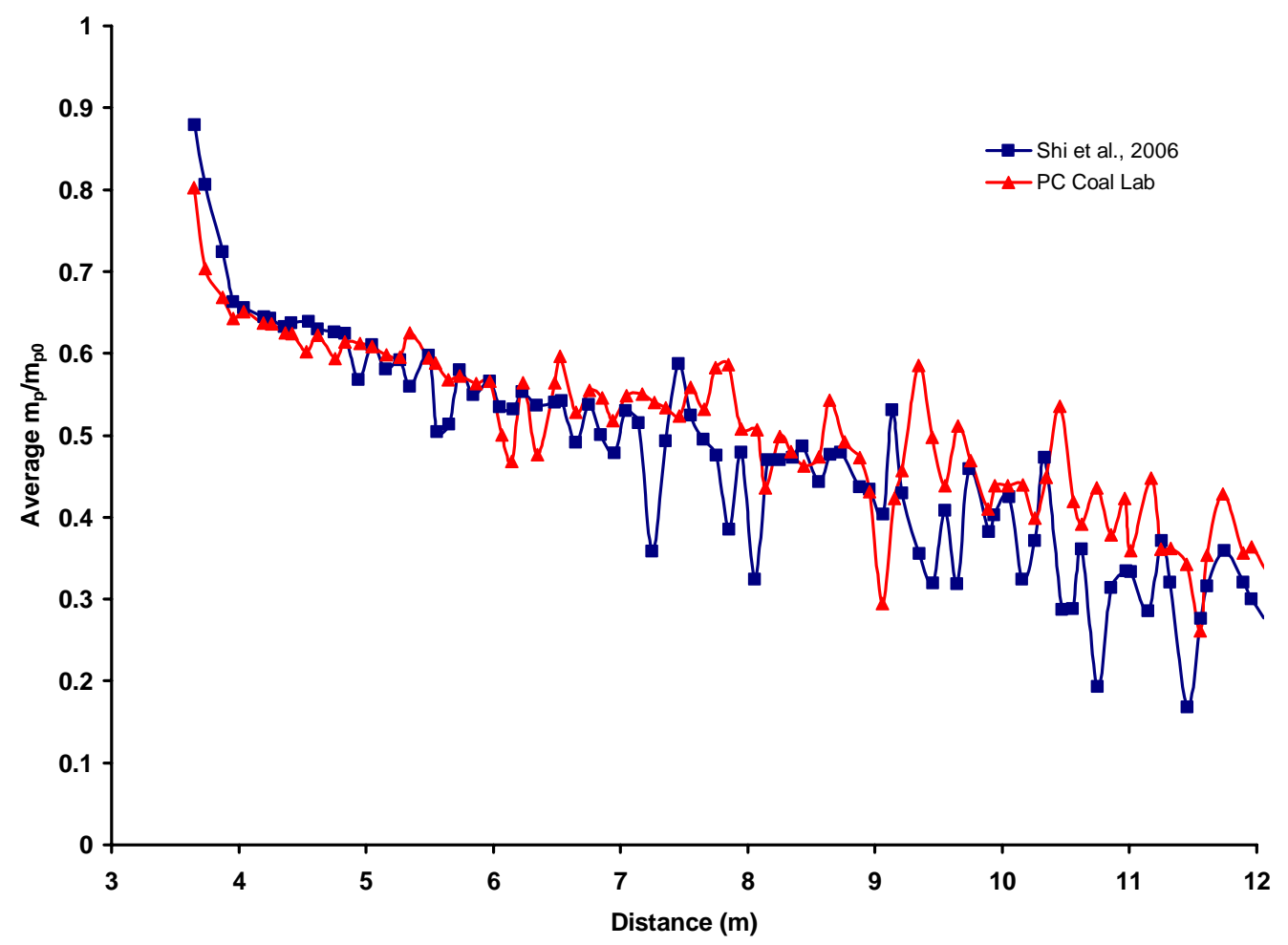

Figure 4.51. Average particle mass loss versus distance in stage 2 (stage 2 injection). 


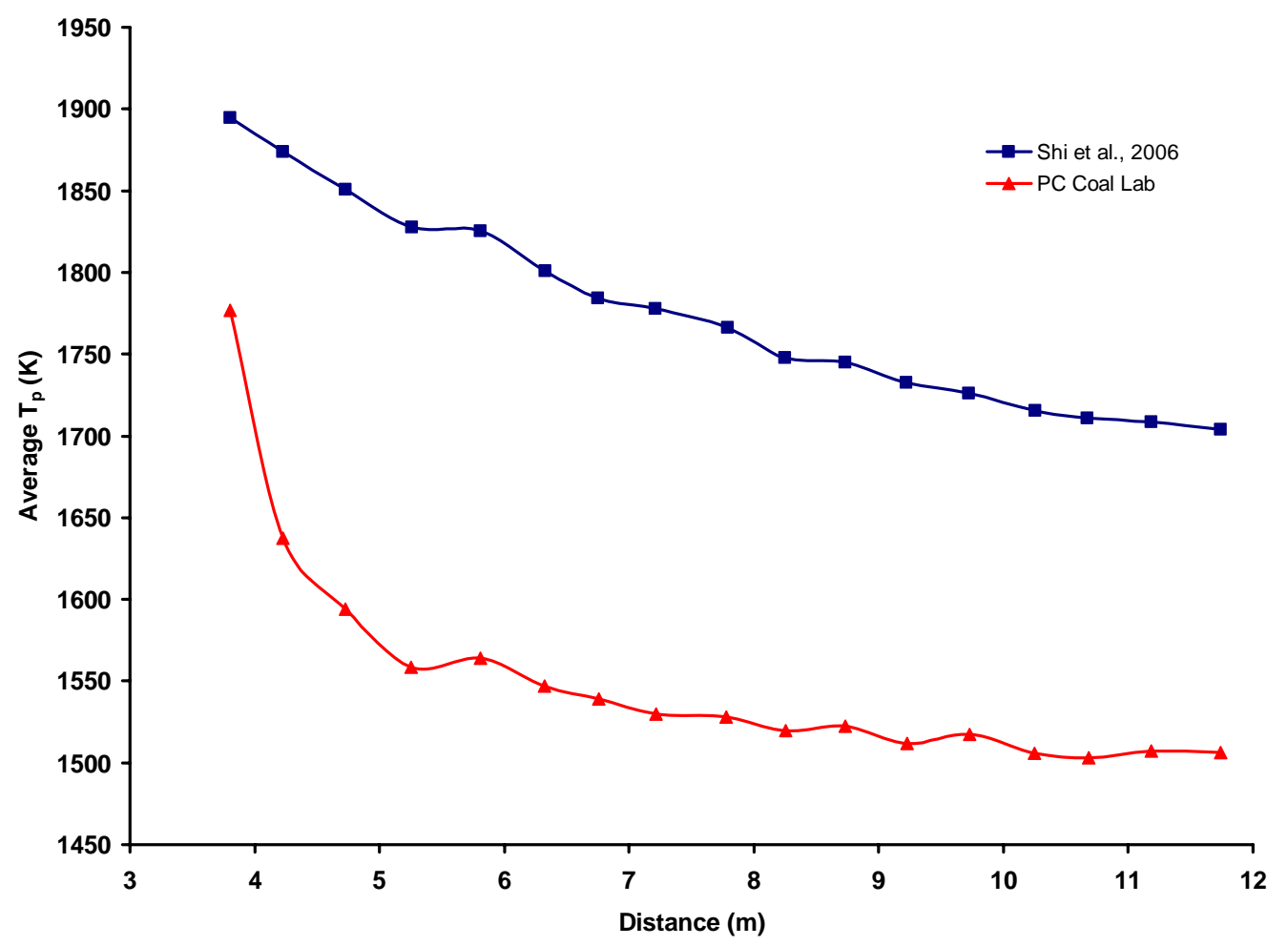

Figure 4.52. Average particle temperature versus distance in stage 2 (all injected).

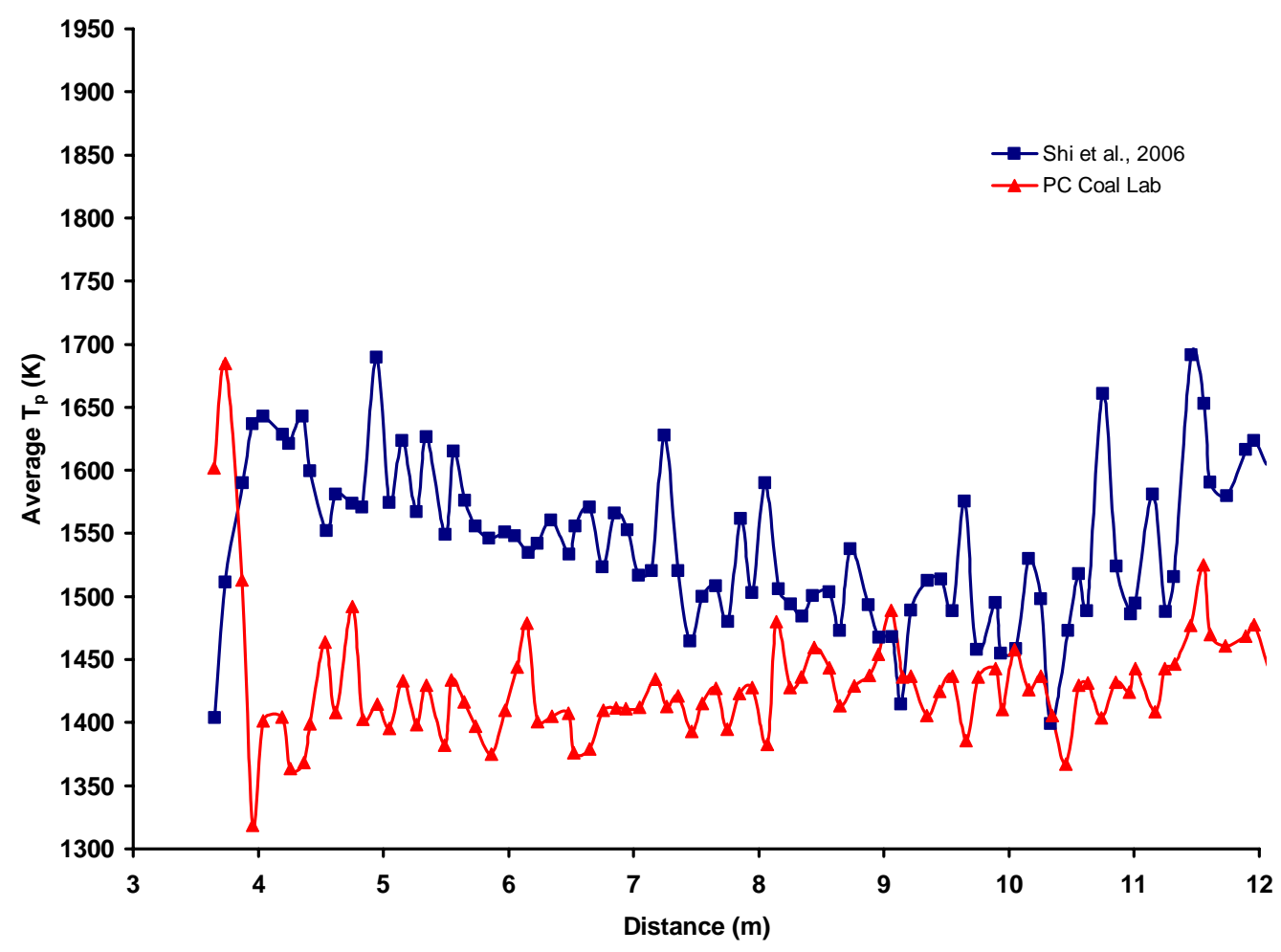

Figure 4.53. Average particle temperature versus distance in stage 2 (stage 2 injection). 
plotted. Particles were injected with a uniform diameter equal to the Sauter-mean diameter of the Bailey coal. Particle mass versus distance for the case using the phenomenological model employed by Shi et al., [3] show a gradual decrease throughout the second stage. Both cases show particles with mass around $20 \%$ of their initial mass upon entry into the second stage. Most of the mass loss occurs in the first stage combustion region where the volatiles are released and the fixed carbon is gasified. The second stage injection serves only to gasify the fixed carbon with steam, hydrogen, and carbon dioxide. Particle temperatures are colder for the PC Coal Lab case due to the presence of a colder gas flow field in that region. Table 4.5 lists a brief quantitative summary of the average temperature and exit gas composition results discussed in this section. In spite of the differences in predicted average temperatures, the predicted major specie volume fractions and fixed carbon conversion are in good agreement.

Table 4.5. Gas and wall temperature, fixed carbon conversion, and exit volume percentages.
Devolatilization model
Shi et al., 2006
PC Coal Lab

$\begin{array}{rcc}\text { FC conversion (\% total) } & 85.5 & 83.1 \\ \text { Gas Temperature (avg., Stage 1) (K) } & 2522 & 2775 \\ \text { Gas Temperature (avg., Stage 2) (K) } & 1818 & 1601 \\ \text { Wall Temperature (avg., Stage 1) (K) } & 2560 & 2808 \\ \text { Wall Temperature (avg., Stage 2) (K) } & 1796 & 1596 \\ \mathrm{CH}_{4} \text { (exit volume \%) } & 4.10 & 0.16 \\ \mathrm{CO}_{2} \text { (exit volume \%) } & 0.34 & 1.89 \\ \mathrm{CO} \text { (exit volume \%) } & 64.90 & 62.66 \\ \mathrm{O}_{2} \text { (exit volume \%) } & 0.0 & 0.0 \\ \mathrm{H}_{2} \text { (exit volume \%) } & 27.64 & 23.60 \\ \mathrm{H}_{2} \mathrm{~S} \text { (exit volume \%) } & 0.63 & 0.45 \\ \mathrm{H}_{2} \mathrm{O} \text { (exit volume \%) } & 0.94 & 0.0 \\ \mathrm{Soot} \text { (exit volume \%) } & \mathrm{N} / \mathrm{A} & 8.60 \\ \mathrm{HCN} \text { (exit volume \%) } & \mathrm{N} / \mathrm{A} & 0.39 \\ \mathrm{C}_{2} \mathrm{H}_{2} \text { (exit volume \%) } & \mathrm{N} / \mathrm{A} & 0.49 \\ \mathrm{~N}_{2} \text { (exit volume \%) } & 0.35 & 2.65 \times 10^{-6} \\ \mathrm{Ar} \text { (exit volume \%) } & 1.1 & 1.1\end{array}$


Sample particle trajectories are shown in Figure 4.54 for the flow field obtained using the volatile distributions predicted from PC Coal Lab. Figure 4.54 a) illustrates trajectories for particles injected from the stage 1 left inlet and Figure $4.54 \mathrm{~b}$ ) show trajectories for particles originating from the stage 1 right inlet. Particles originating from the second stage inlet are shown in Figure $4.54 \mathrm{c}$ ). In all figures it is evident that the particles are entrained with the gas upon entry into the second stage region which will influence the slag layer buildup in that region.

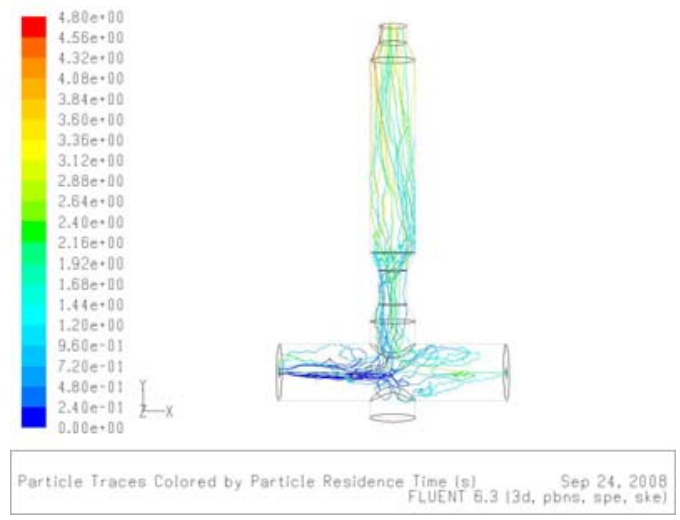

a) Stage 1 left injection.

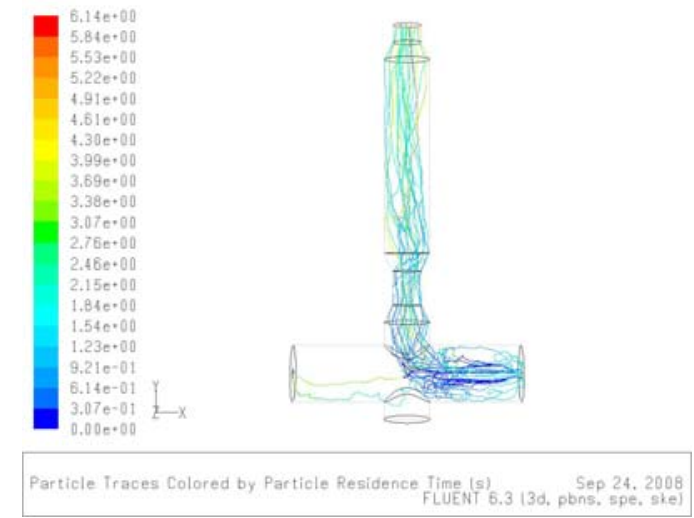

b) Stage 1 right injection.

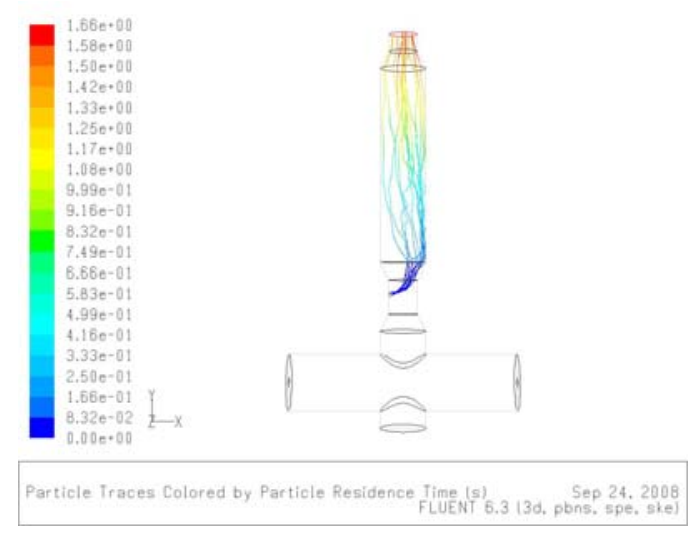

c) Stage 2 injection.

Figure 4.54. Sample particle trajectories. 


\subsection{Grid independence}

The geometry described in Section 3.3 utilized a grid containing 12,256 hexahedral cells (Figure 3.1). This grid is the same as that utilized in the initial study by Shi et al. [3]. In order to determine if this mesh is of appropriate density, three additional simulations have been conducted using identical case file setups corresponding to case 3 and case 4 in Section 4.2. Grids for these setups contained 20,061, 28,264, and 40,112 hexahedral cells and are displayed in Figure 4.55. For all of the grids displayed below, the average equi-angle skew was below 0.3 which is judged to be a quality mesh.

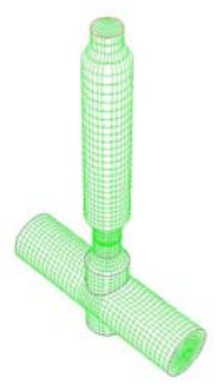

a) 12,256

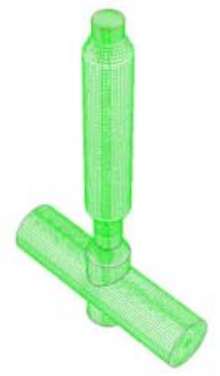

c) 28,264

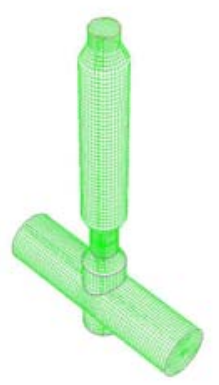

b) 20,061

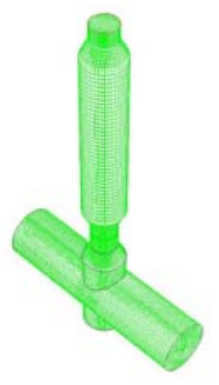

d) 40,112

Figure 4.55. Computational mesh for each grid density.

\subsubsection{Grid independence for case 3}

Contours of center-plane volume fractions are presented in Figure 4.56 for the solutions that were obtained for each grid. Results shown are for simulations that were run to 10,000 iterations. The distribution of $\mathrm{CH}_{4}, \mathrm{CO}_{2}, \mathrm{CO}, \mathrm{H}_{2}, \mathrm{H}_{2} \mathrm{~S}$, and $\mathrm{H}_{2} \mathrm{O}$ have been 


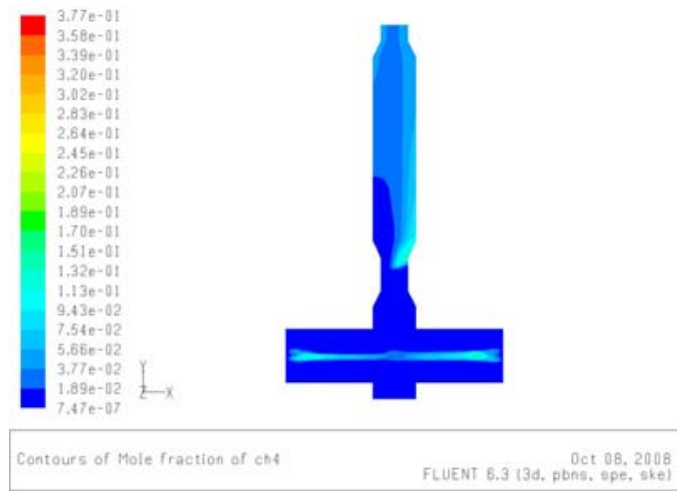

a) $\mathrm{CH}_{4}$ contours, 12,256 cells.
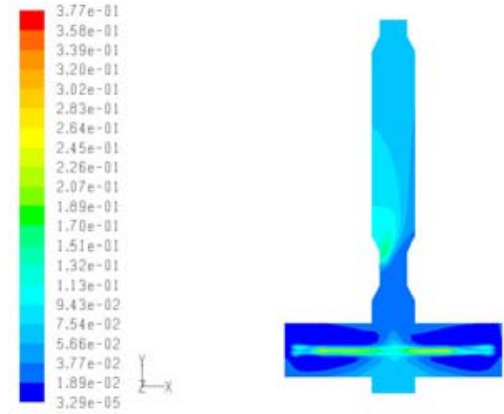

Contours of Mole fraction of chs

c) $\mathrm{CH}_{4}$ contours, 28,264 cells.
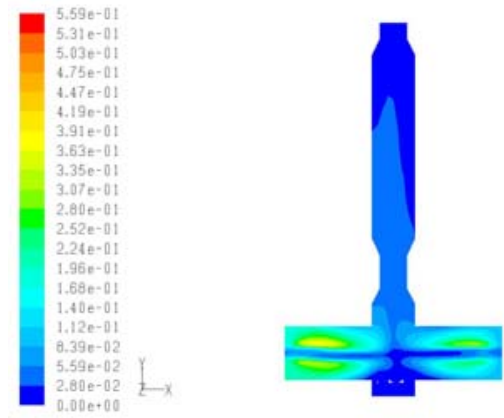

Contours of Mole fraction of co?

e) $\mathrm{CO}_{2}$ contours, 12,256 cells.
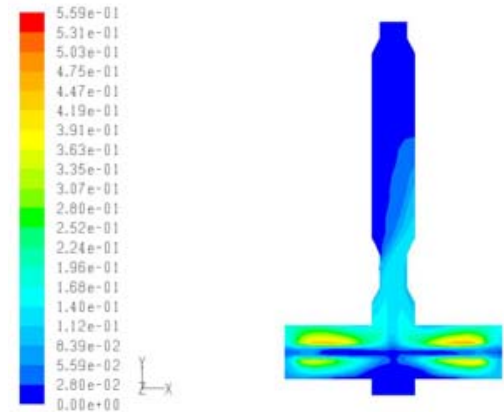

Contours of Mole fraction of $\cos$

g) $\mathrm{CO}_{2}$ contours, 28,264 cells.

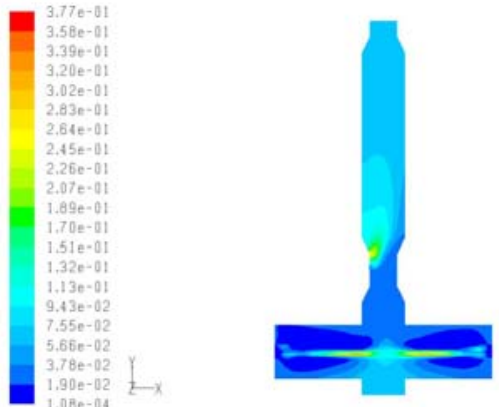

\begin{tabular}{l} 
Contours of Mole fraction of cos \\
FLUENT 6.3 13d, pbots. 08,2008 , oke) \\
\hline
\end{tabular}

b) $\mathrm{CH}_{4}$ contours, 20,061 cells

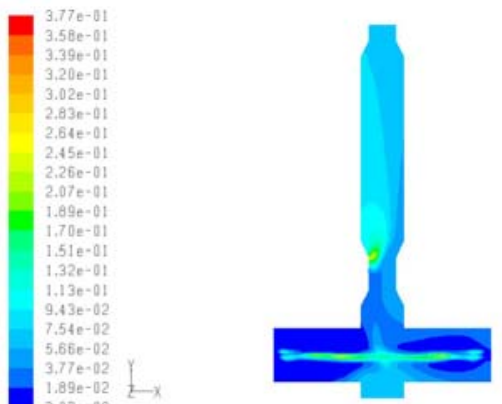

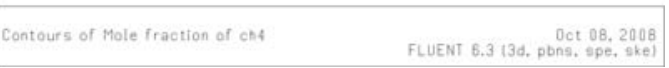

d) $\mathrm{CH}_{4}$ contours, 40,112 cells
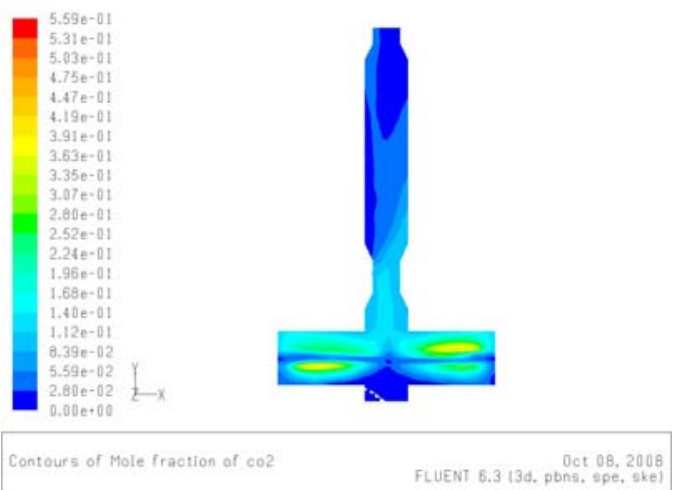

f) $\mathrm{CO}_{2}$ contours, 20,061 cells.
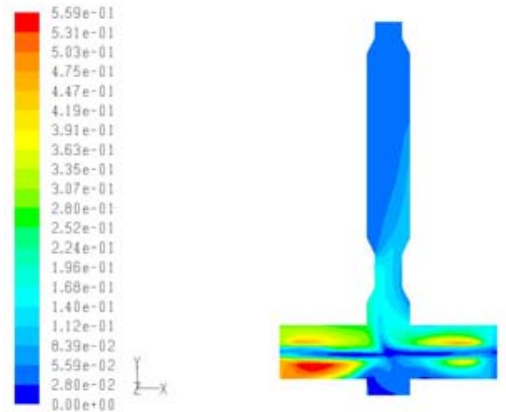

Contours of Mole fraction of co2 FLUENT 6.3 (3d, pbots, 08,2008 , ske)

h) $\mathrm{CO}_{2}$ contours, 40,112 cells

Figure 4.56. Center-plane gas mole fractions. 

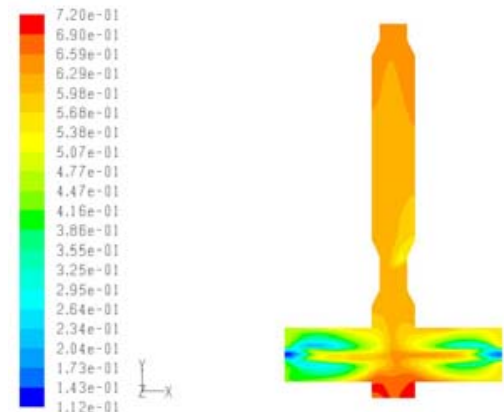

Contours of Mole fraction of co

i) CO contours, 12,256 cells.
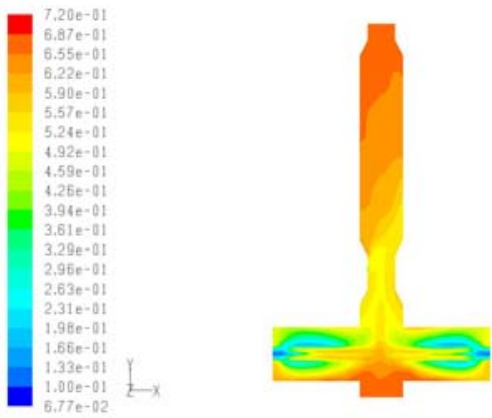

Contours of Mole fraction of co

FLUENT 6.3 (3d, Dong, 08, 2006

k) CO contours, 28,264 cells.
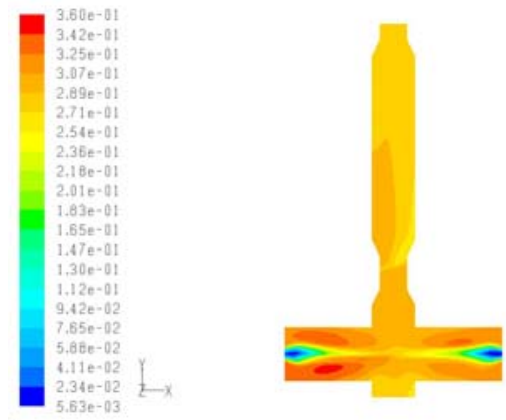

Contours of Mole fraction of 12

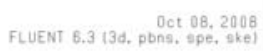

m) $\mathrm{H}_{2}$ contours, 12,256 cells.
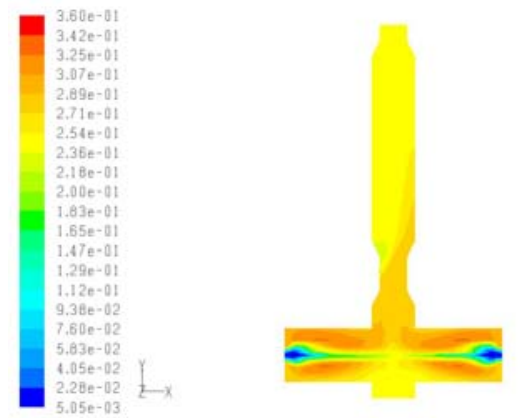

Contours of Mole fraction of th2

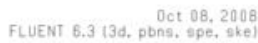

o) $\mathrm{H}_{2}$ contours, 28,264 cells.

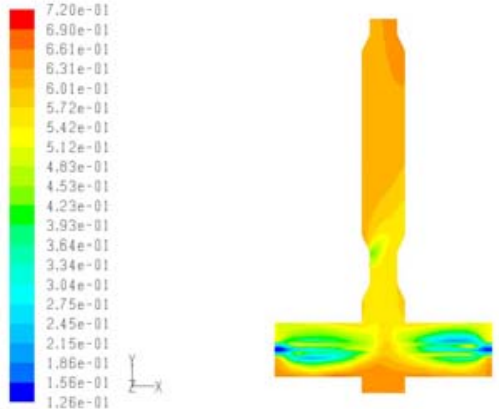

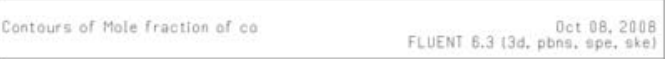

j) CO contours, 20,061 cells.
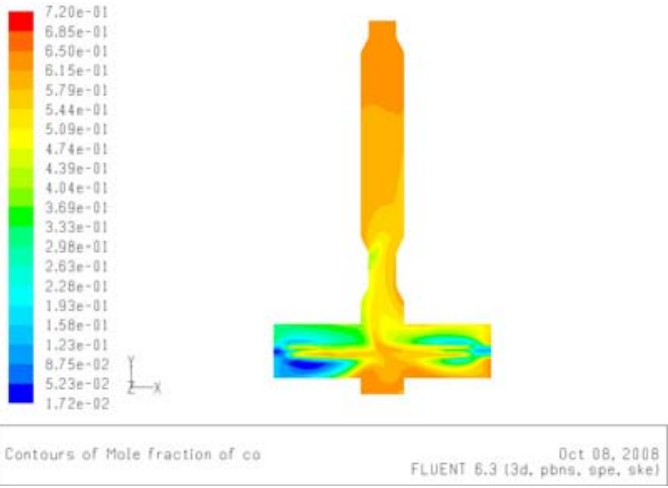

1) CO contours, 40,112 cells.
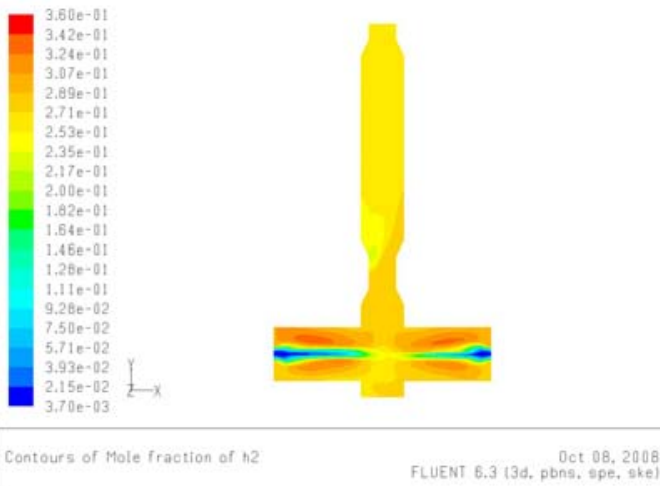

n) $\mathrm{H}_{2}$ contours, 20,061 cells.
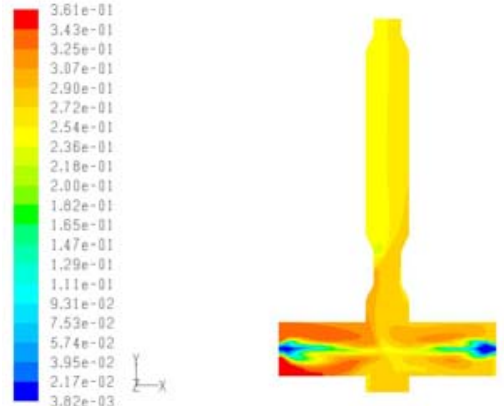

Contours of Mole fraction of th ELUENT 6.3 13d, poot, 08, $2008 \mathrm{~g}, \mathrm{gkg}$

p) $\mathrm{H}_{2}$ contours, 40,112 cells.

Figure 4.56. Center-plane gas mole fractions (continued). 

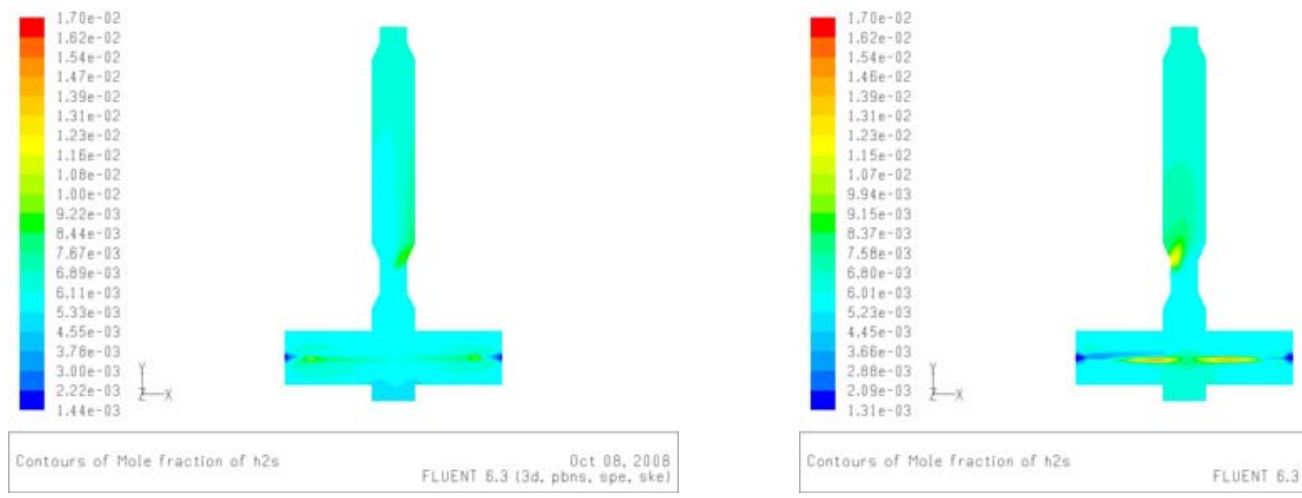

q) $\mathrm{H}_{2} \mathrm{~S}$ contours, 12,256 cells.

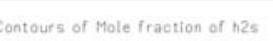

r) $\mathrm{H}_{2} \mathrm{~S}$ contours, 20,061 cells.
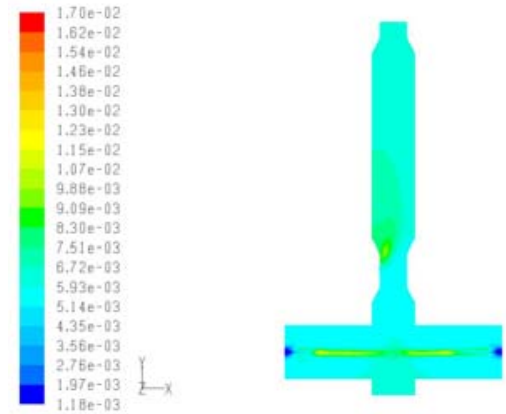

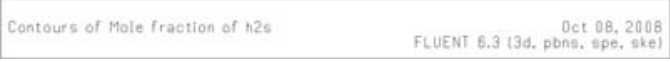

s) $\mathrm{H}_{2} \mathrm{~S}$ contours, 28,264 cells.
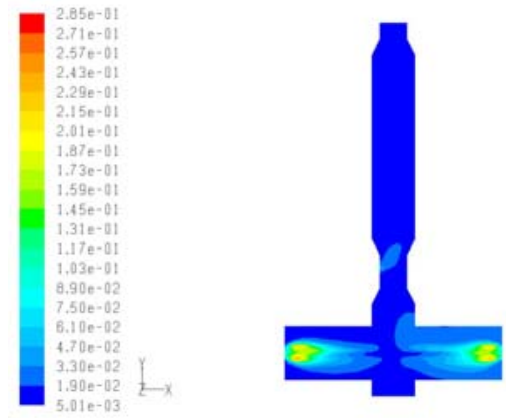

Contours of Mole fraction of 120

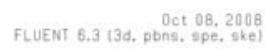

u) $\mathrm{H}_{2} \mathrm{O}$ contours, 12,256 cells.
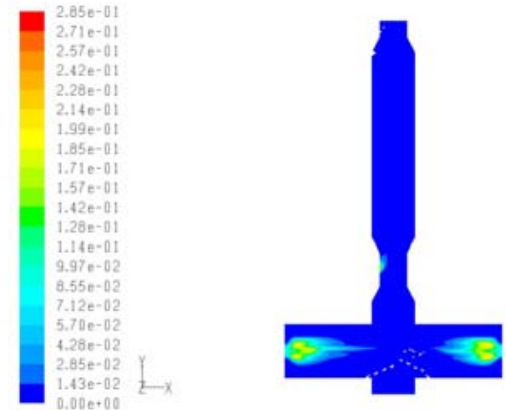

Contours of Mole fraction of the

FLUENT 6.3 (3d, pDos, spe, ske)

w) $\mathrm{H}_{2} \mathrm{O}$ contours, 28,264 cells. Figure 4.56. Center-plane gas mole fractions (concluded). 
plotted side by side for easy comparison between different grid densities. In general, these specie contours are similar for the various meshes. Due to the unstable nature of combusting flow solutions, the spatial distribution of gaseous species in a steady flow field will be to some extent unpredictable. Figure 4.57 shows computed exit gas compositions on a molar basis. Mole fractions for $\mathrm{CH}_{4}, \mathrm{CO}_{2}, \mathrm{CO}, \mathrm{H}_{2}, \mathrm{H}_{2} \mathrm{~S}$, and $\mathrm{H}_{2} \mathrm{O}$ are shown for each grid resolution. It is apparent that the exit gas composition does not change much between the different cases indicating that the grid density used for section 4.2 was sufficient.

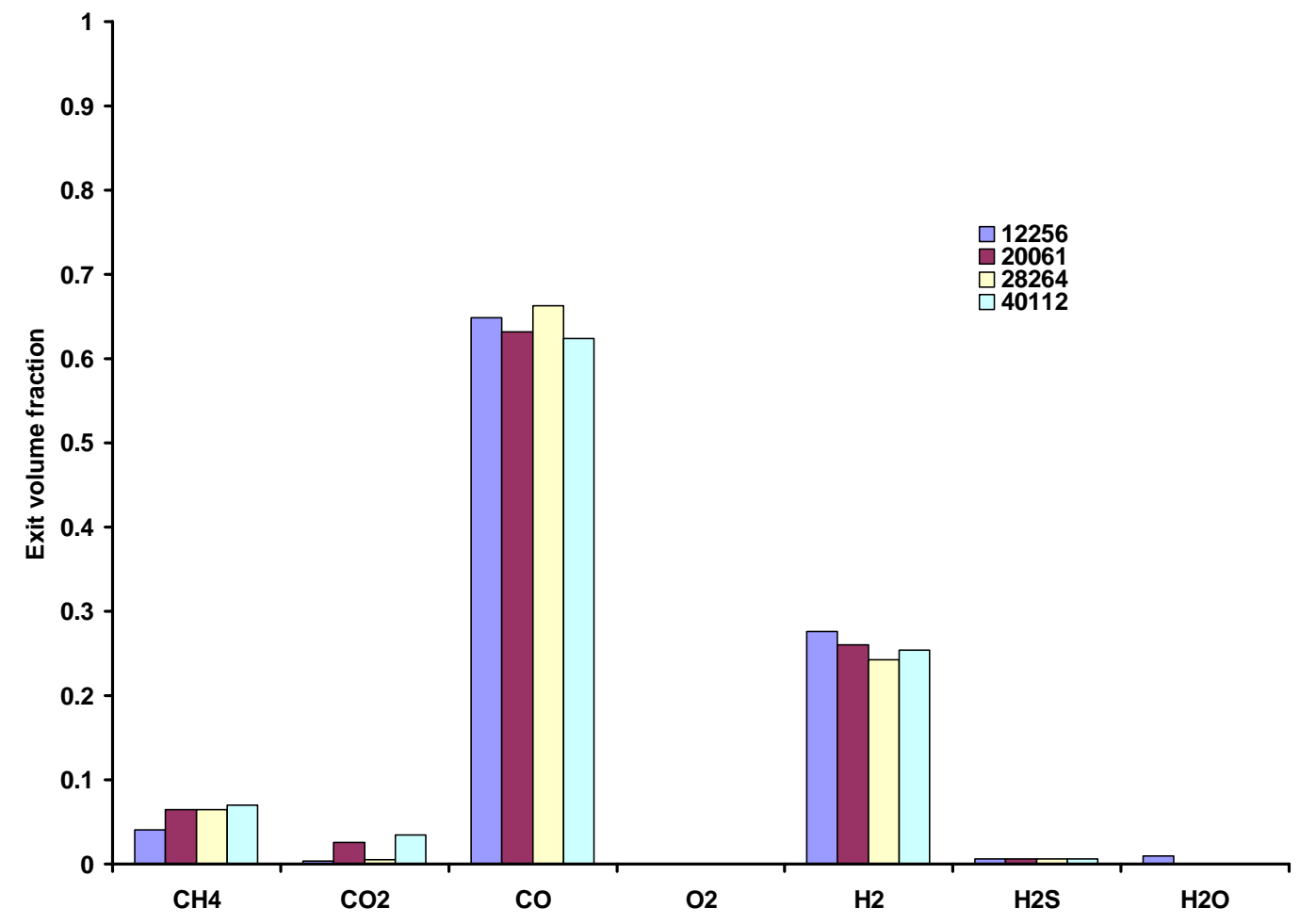

Figure 4.57. Exit gas compositions for 12,256, 20,061, 28,264, and 40,112 elements.

Center-plane gas temperatures throughout the up-flow gasifier are illustrated in Figure 4.58 for each grid density. Figure 4.59 displays the computed area-weighted average gas and wall temperatures. It can be seen that stage 1 average gas temperature 
goes up by $197 \mathrm{~K}$ as the grid/mesh is increased from 12,256 to 40,112 cells. Again, the temperatures do not vary greatly as the grid density is varied.

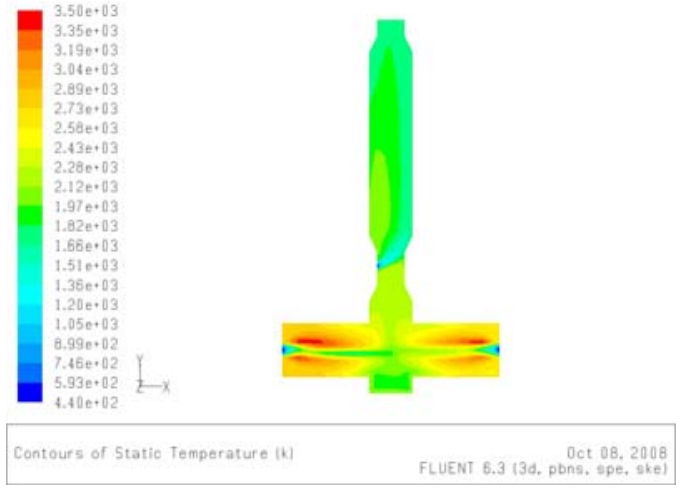

a) 12,256 cells.

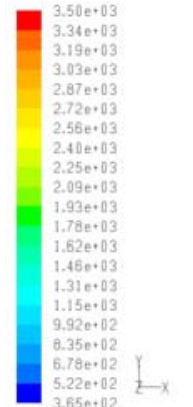

Contours of Statio Temperature [X]

c) 28,264 cells.

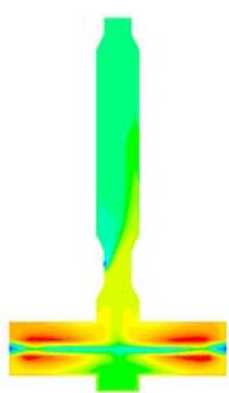

FLUENT 6.3130, Dot 08, 08, 2006
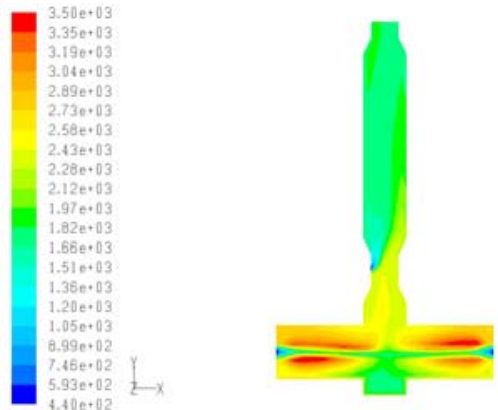

b) 20,061 cells

Figure 4.58. Center-plane gas temperature.

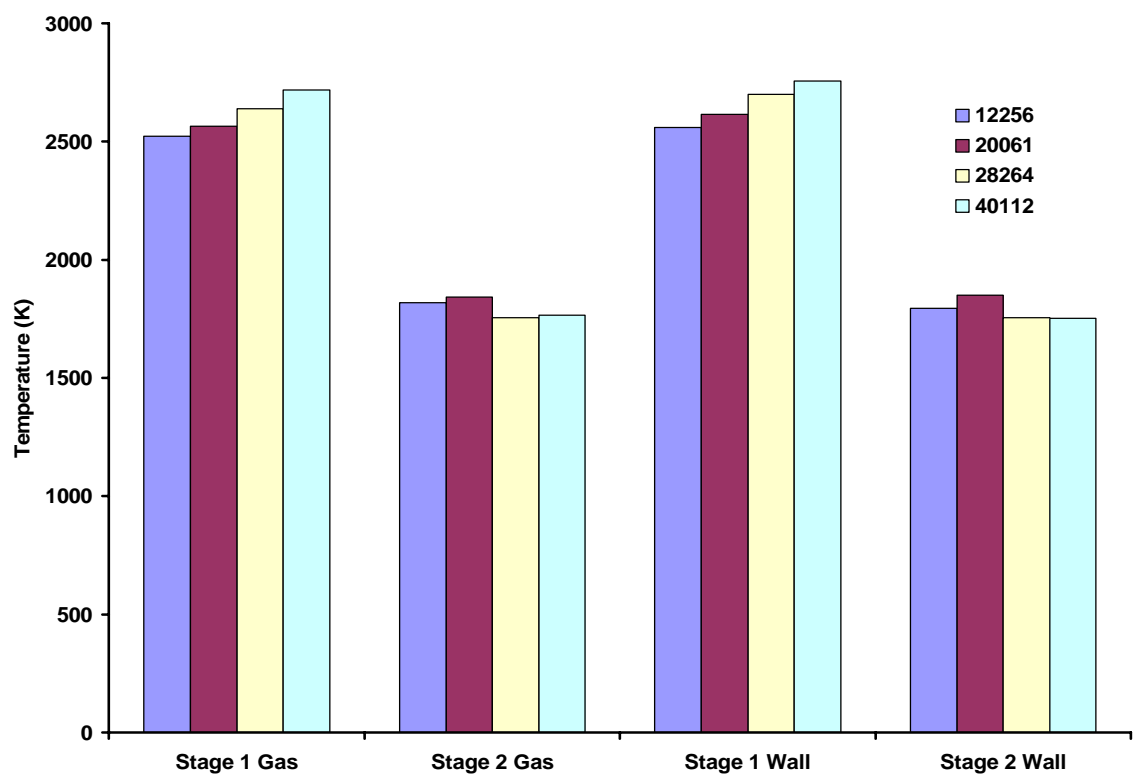

Figure 4.59. Gas and wall temperatures for 12,256, 20,061, 28,264, and 40,112 elements. 
Wall impact normal velocity was recorded for the solution obtained using the finest grid density in this study (40,112 cells) and compared with the curves obtained for the coarser grid used in section 4.2 and 4.3 (12,256 cells) in Figure 4.60. The particle characteristics for the first stage injectors corresponded to the SG2 density fraction for each case.

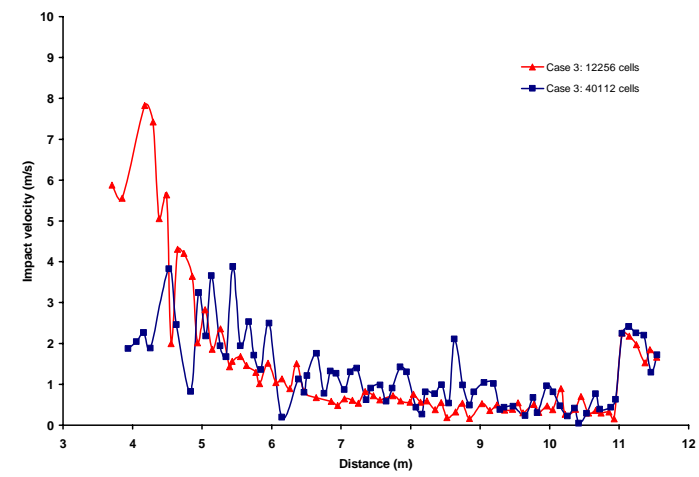

a) PS1

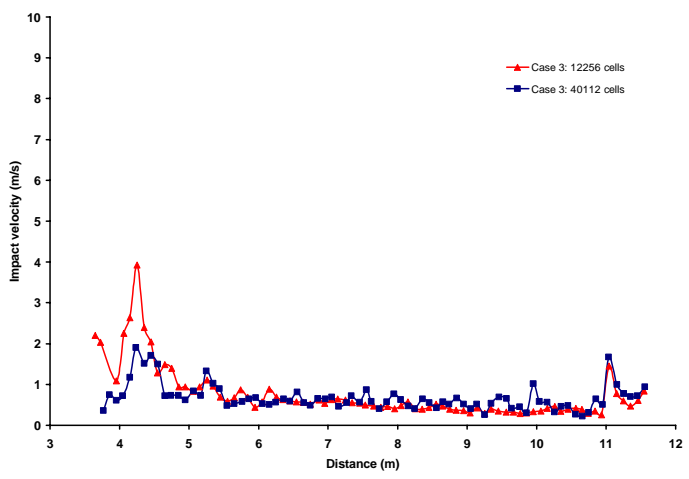

c) PS3

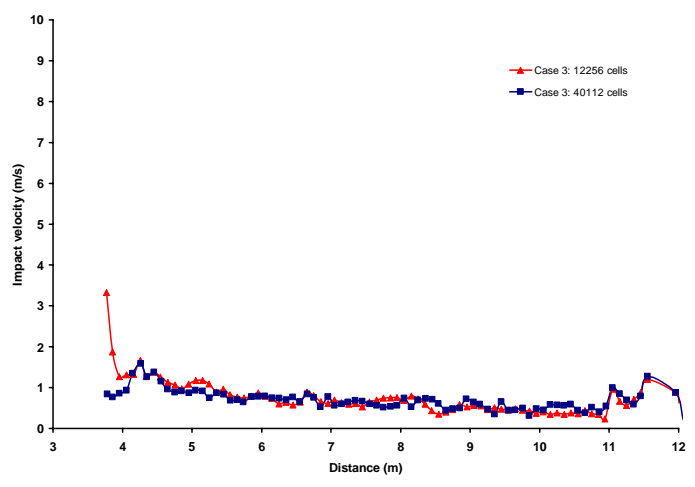

e) PS5

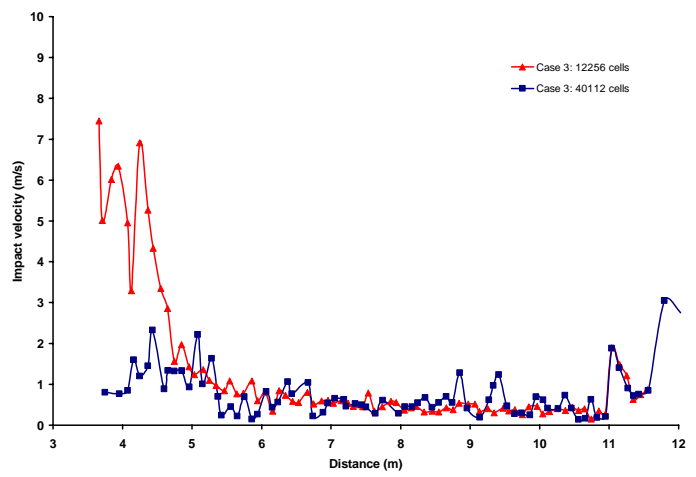

b) PS2

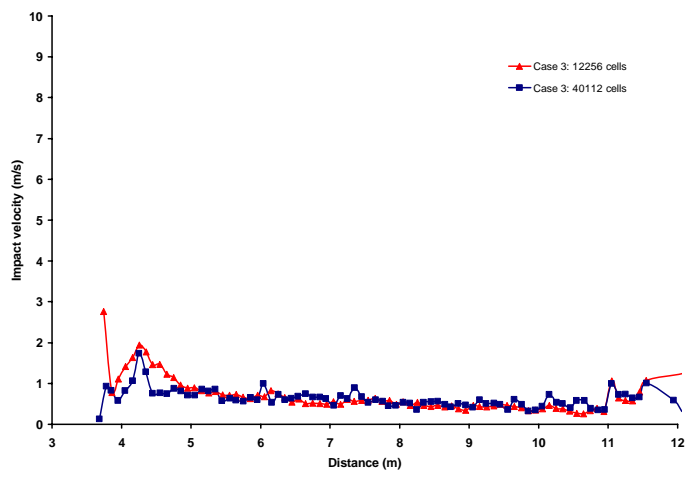

d) PS4

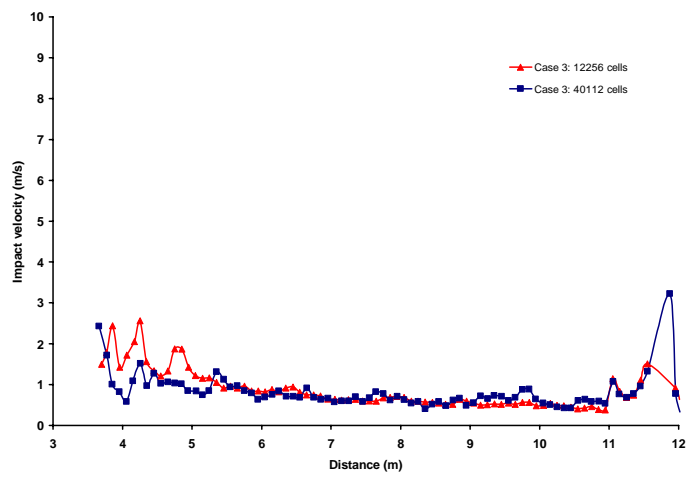

f) PS6

Figure 4.60. Normal impact velocities for 12,256 and 40,112 cells. 


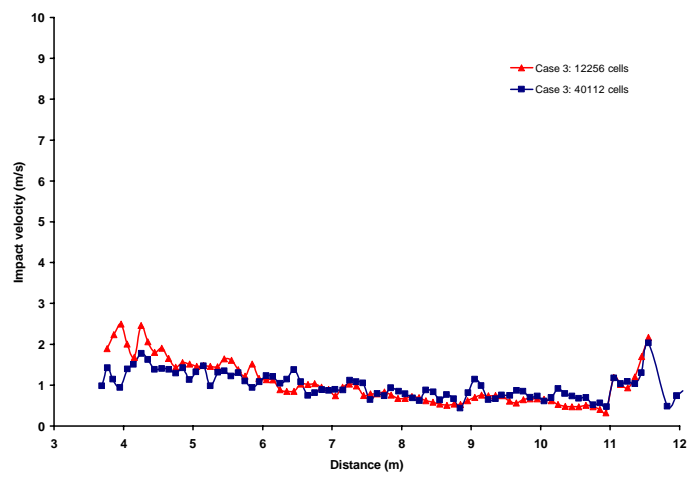

g) PS7

Figure 4.60. Normal impact velocities for 12,256 and 40,112 cells (concluded).

From Figure 4.60, it can be seen that the average impact velocity obtained with the coarsest and finest grids versus second stage distance did not vary greatly beyond the second stage entrance region.

\subsubsection{Grid independence for case 4}

A grid independence study for the case 4 solution described in section 4.2 is presented in this section. Center-plane volume fractions of $\mathrm{CH}_{4}, \mathrm{CO}_{2}, \mathrm{CO}, \mathrm{H}_{2}$, and $\mathrm{H}_{2} \mathrm{O}$ are presented in Figure 4.61 for grids containing 12,256 cells and 40,112 cells, respectively. $\mathrm{CH}_{4}$ is spread out more in the second stage for the finer grid. The other center-plane contours bear similar resemblance for the coarse and fine grids. Exit volume fractions of these species are given in Figure 4.62. The solution obtained with the coarser grid produced somewhat more $\mathrm{CO}_{2}$ at the exit with less $\mathrm{CH}_{4}$ and $\mathrm{CO}$. The finer grid solution showed less $\mathrm{H}_{2}$ and $\mathrm{H}_{2} \mathrm{O} . \mathrm{H}_{2} \mathrm{~S}$ volume fractions at the exit were approximately the same for the two solutions. 


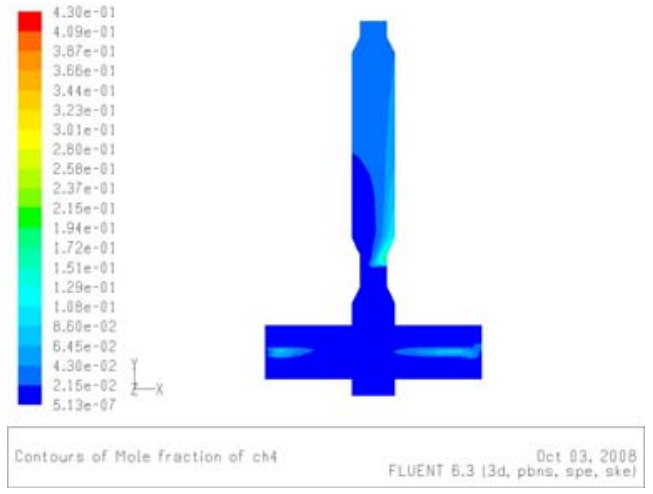

a) $\mathrm{CH}_{4}$ contours, 12,256 cells

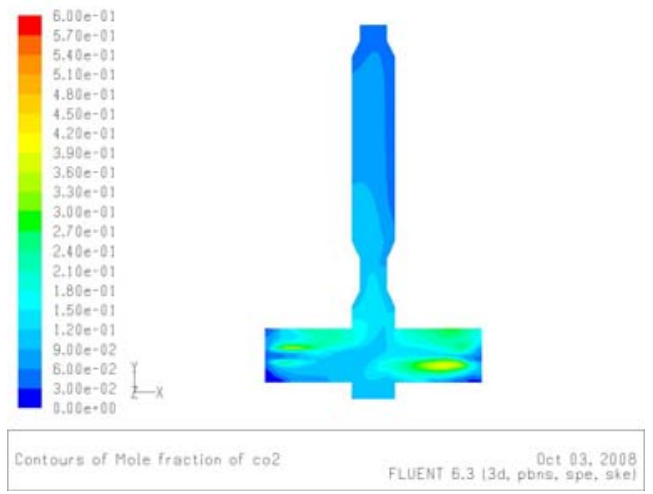

c) $\mathrm{CO}_{2}$ contours, 12,256 cells

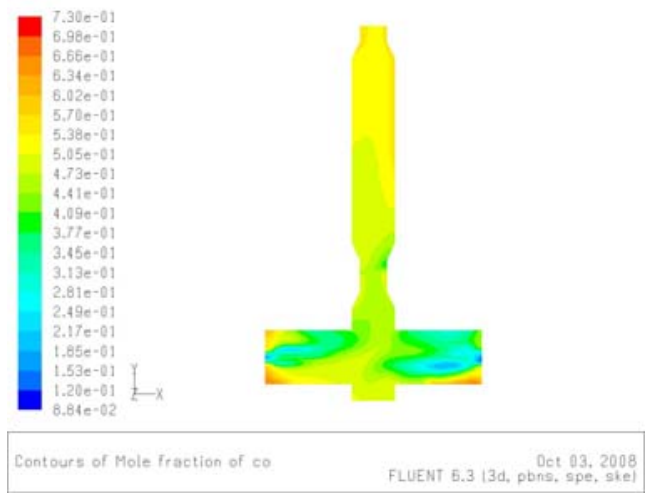

e) CO contours, 12,256 cells

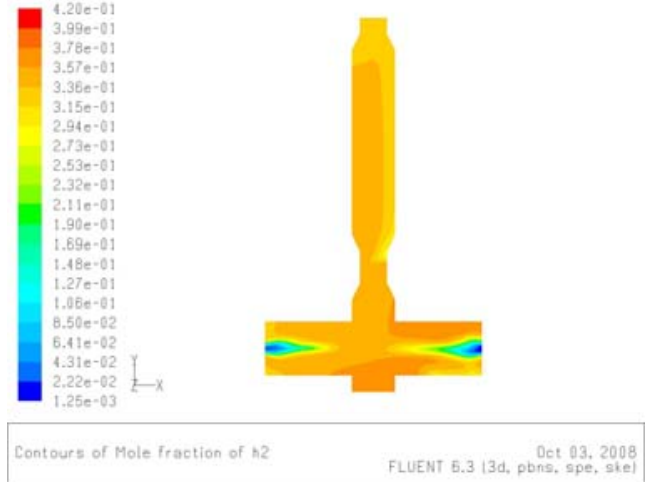

g) $\mathrm{H}_{2}$ contours, 12,256 cells

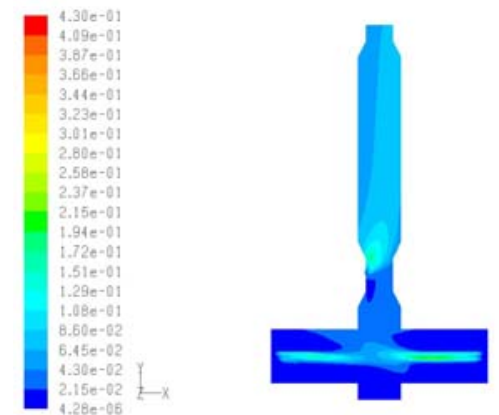

Contours of Mole fraction of ch4 FLUENT 5.3 13d, pbns, 12, 2008

b) $\mathrm{CH}_{4}$ contours, 40,112 cells

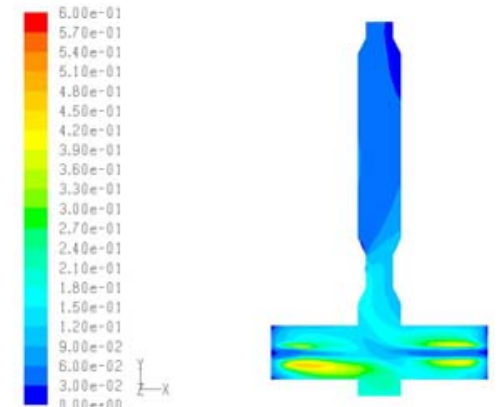

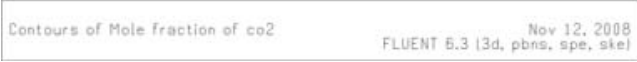

d) $\mathrm{CO}_{2}$ contours, 40,112 cells

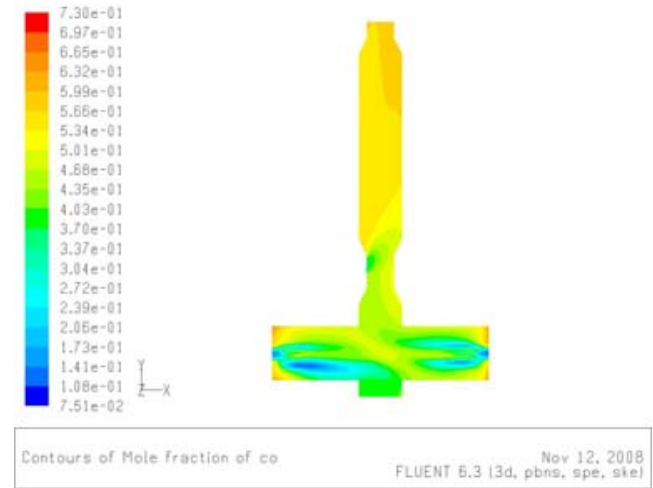

f) $\mathrm{CO}$ contours, 40,112 cells

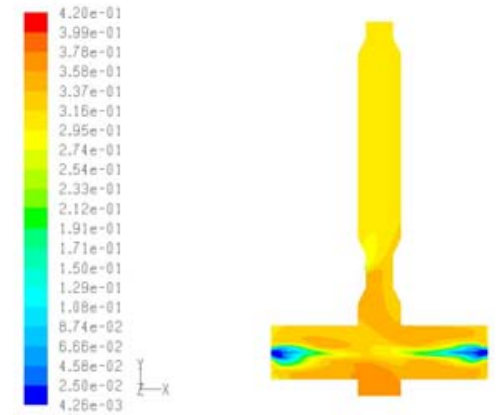

Contours of Mole fraction of $\mathrm{h} 2$ FLUENT 6.3 13d, pbrs, 12,2008

h) $\mathrm{H}_{2}$ contours, 40,112 cells

Figure 4.61. Center-plane gas mole fractions. 


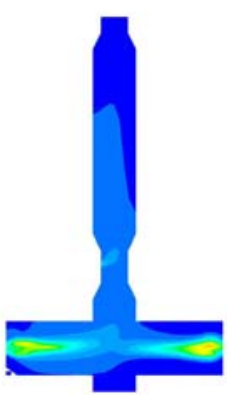

i) $\mathrm{H}_{2} \mathrm{O}$ contours, 12,256 cells

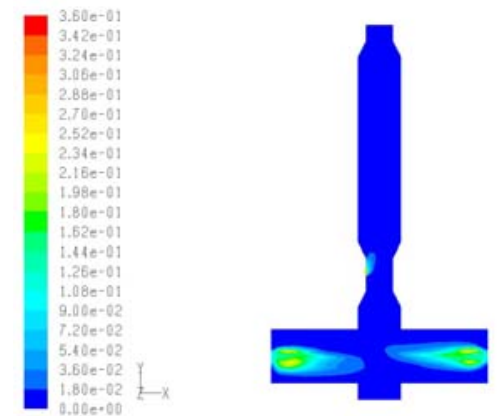

j) $\mathrm{H}_{2} \mathrm{O}$ contours, 40,112 cells

Figure 4.61. Center-plane gas mole fractions (concluded).

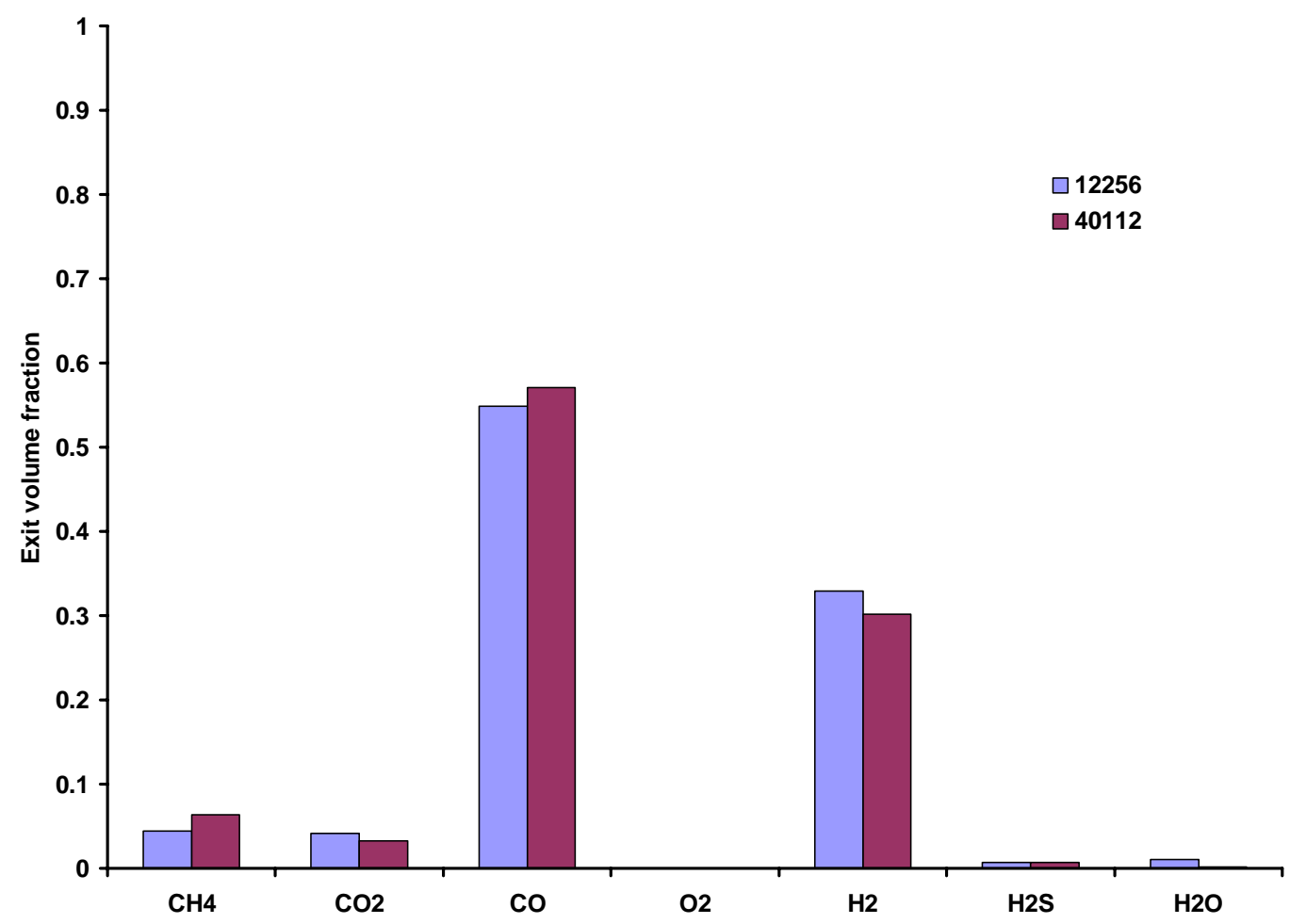

Figure 4.62. Exit gas compositions for 12,256 and 40,112 elements.

Center-plane gas temperature is illustrated in Figure 4.63 for the coarse and fine grid solutions. As can be seen in Figure $4.63 \mathrm{~b}$ ), the finer grid produced a more symmetric stage 1 temperature contour, though average gas and wall temperatures for the two solutions are in good agreement as shown in Figure 4.64. 


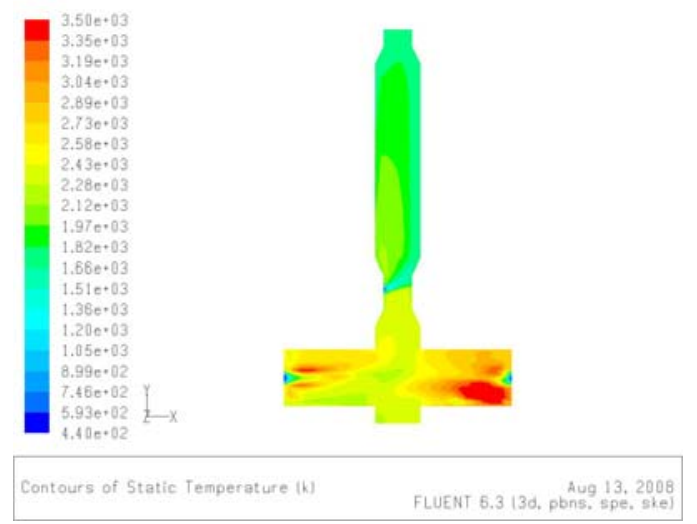

a) 12,256 cells

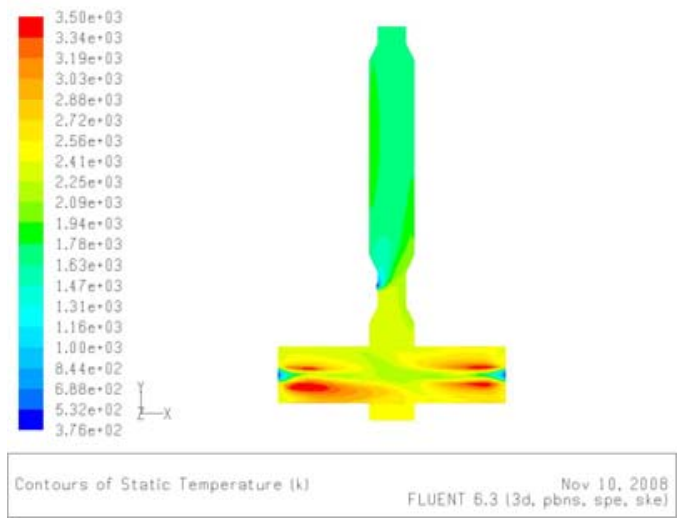

b) 40,112 cells

Figure 4.63. Center-plane gas temperature.

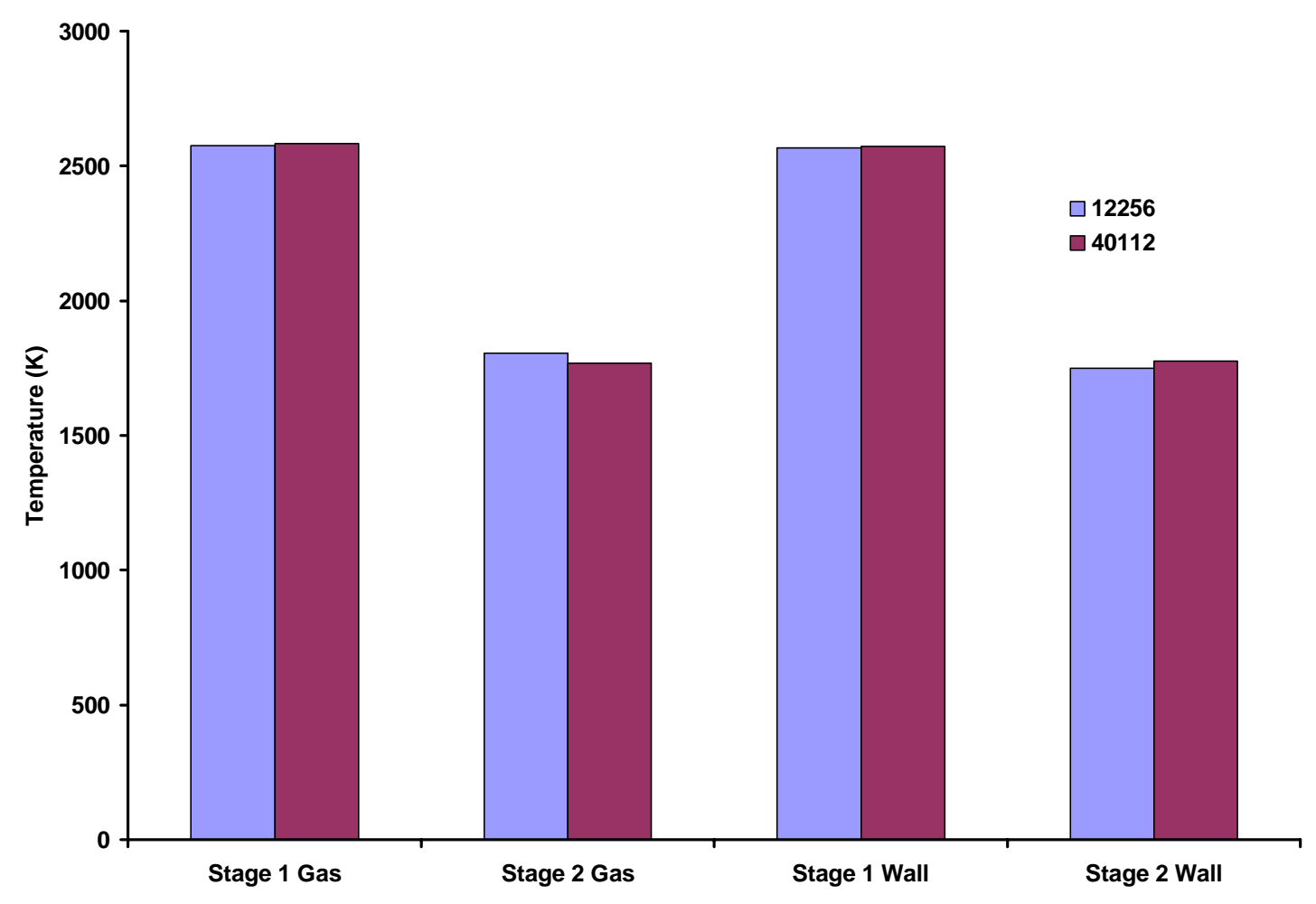

Figure 4.64. Gas and wall temperatures for 12,256 and 40,112 elements.

Similar to section 4.4.1, wall impact normal velocity was recorded for the solution obtained using the finest grid density in this study (40,112 cells) and compared with the curves obtained for the coarser grid used in section 4.2 and 4.3 (12,256 cells) in Figure 4.65. Impact velocity is also in good agreement beyond the second stage entrance region for the case 4 grid independence check. 


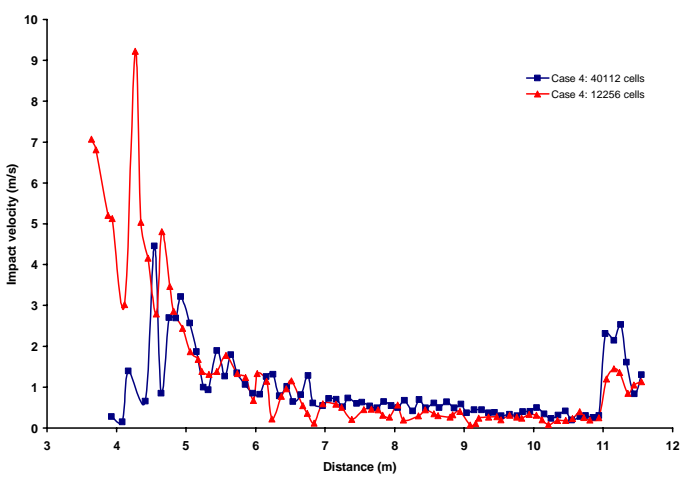

a) PS1

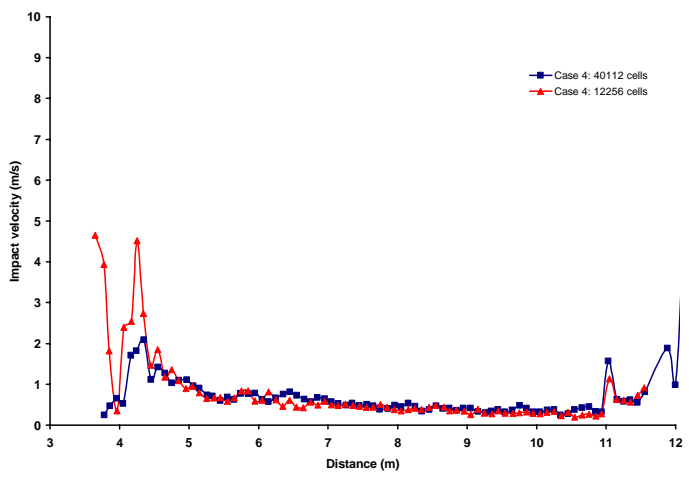

c) PS3

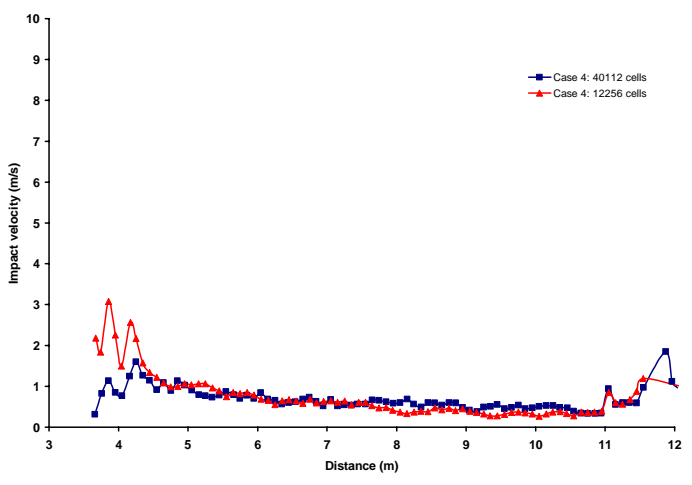

e) PS5

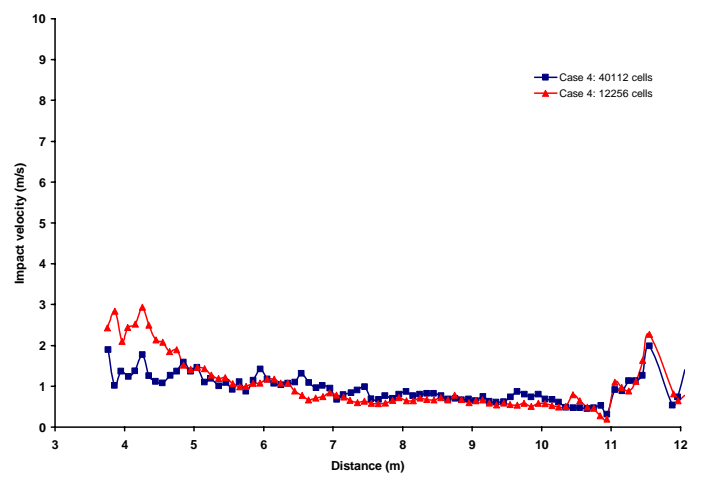

g) PS7

Figure 4.65. Normal impact velocities for 12,256 and 40,112 cells. 


\section{$\underline{4.5 \text { Validation }}$}

The Radiant Coal Flow Reactor at SRI International was modeled in Fluent to compare model predictions using Wen and Chaung's shrinking core model and the devolatilization model developed by Shi et al. [3] to experimental results obtained at SRI for the Bailey coal as a part of the current Coal Partitioning Project [25]. These gasification chemistry models formed the basis for the simulations that were presented in sections 4.2 and 4.3. The geometry of the SRI facility and the computational model are presented in Figures 4.66 and 4.67, respectively. Researchers at SRI performed gasification and pyrolysis experiments on several different size/density fractions of the Bailey coal sample. In the present validation study, the SG2PS5 fraction was chosen as the fuel injection to the computational model displayed in Figure 4.67 to compare with SRI's results for this fraction. This choice was made because this coal fraction was the center point of the SRI test matrix.

The computational grid displayed in Figure 4.67 contains 91,584 hexahedral cells. The coal was injected via the core flow inlet as displayed in Figure 4.67. The carrier gas in the experiments consisted entirely of Ar, and the oxygen was introduced via an outer sheath flow. Steam was injected through the conical inlet as displayed in the above. Wall temperature boundary conditions were chosen to match the experimental setup at SRI as closely as possible. A summary of the operating conditions for the three SRI runs chosen for this validation study is presented in Table 4.6. The inlet velocity of the coal particles was set at $24 \mathrm{~cm} / \mathrm{s}$ and the wall temperature boundary condition is illustrated in Figure 4.68. 


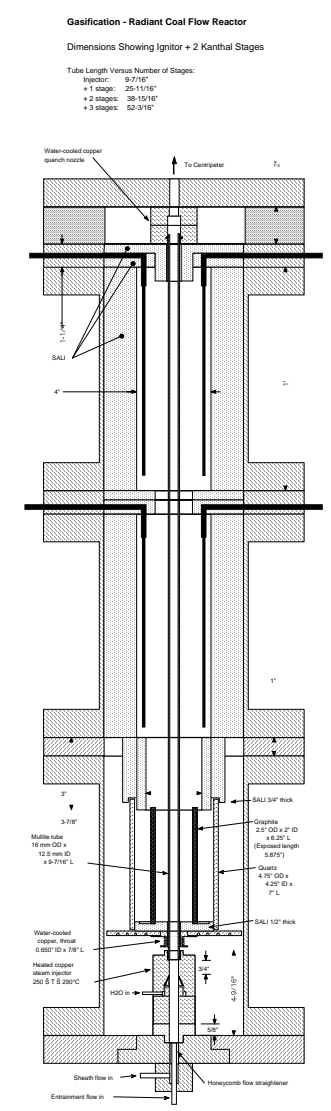

Figure 4.66. Schematic of SRI facility.

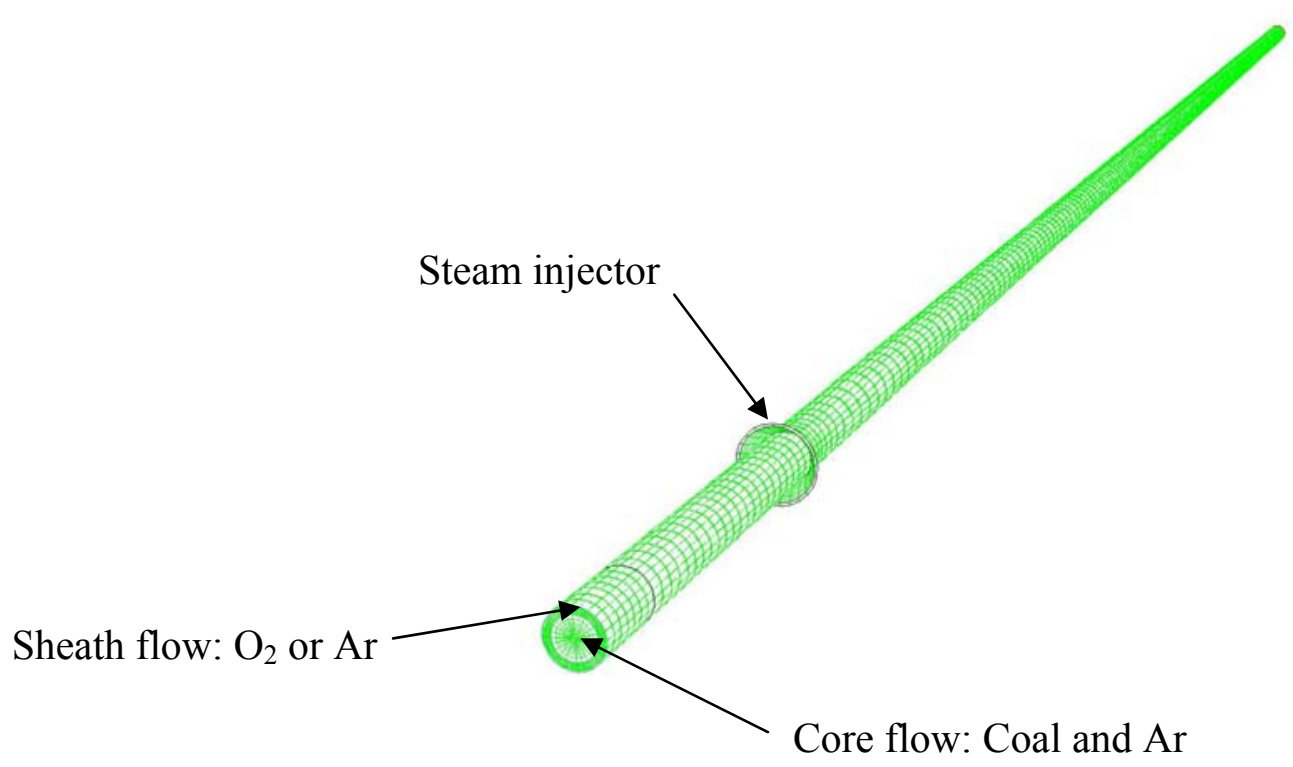

Figure 4.67. Computational model of SRI facility. 
Table 4.6. Operating conditions for SG2PS5 sample runs.

$\begin{array}{cccccc}\text { Run \# } & \begin{array}{c}\text { Oven length } \\ (\mathrm{cm})\end{array} & \begin{array}{c}\text { Coal loading } \\ \text { (Wt. \%) }\end{array} & \begin{array}{c}\text { Oxygen loading } \\ \text { (Wt. \%) }\end{array} & \begin{array}{c}\text { Steam loading } \\ \text { (Wt. \%) }\end{array} & \text { SR } \\ 80 & 120 & 2.10 & 3.22 & & \\ 81 & 120 & 1.88 & 2.88 & 9.0 & 0.68 \\ 49 & 15 & 1.5 & 0.0 & 0.0 & 0.68 \\ & & & & 0.0\end{array}$

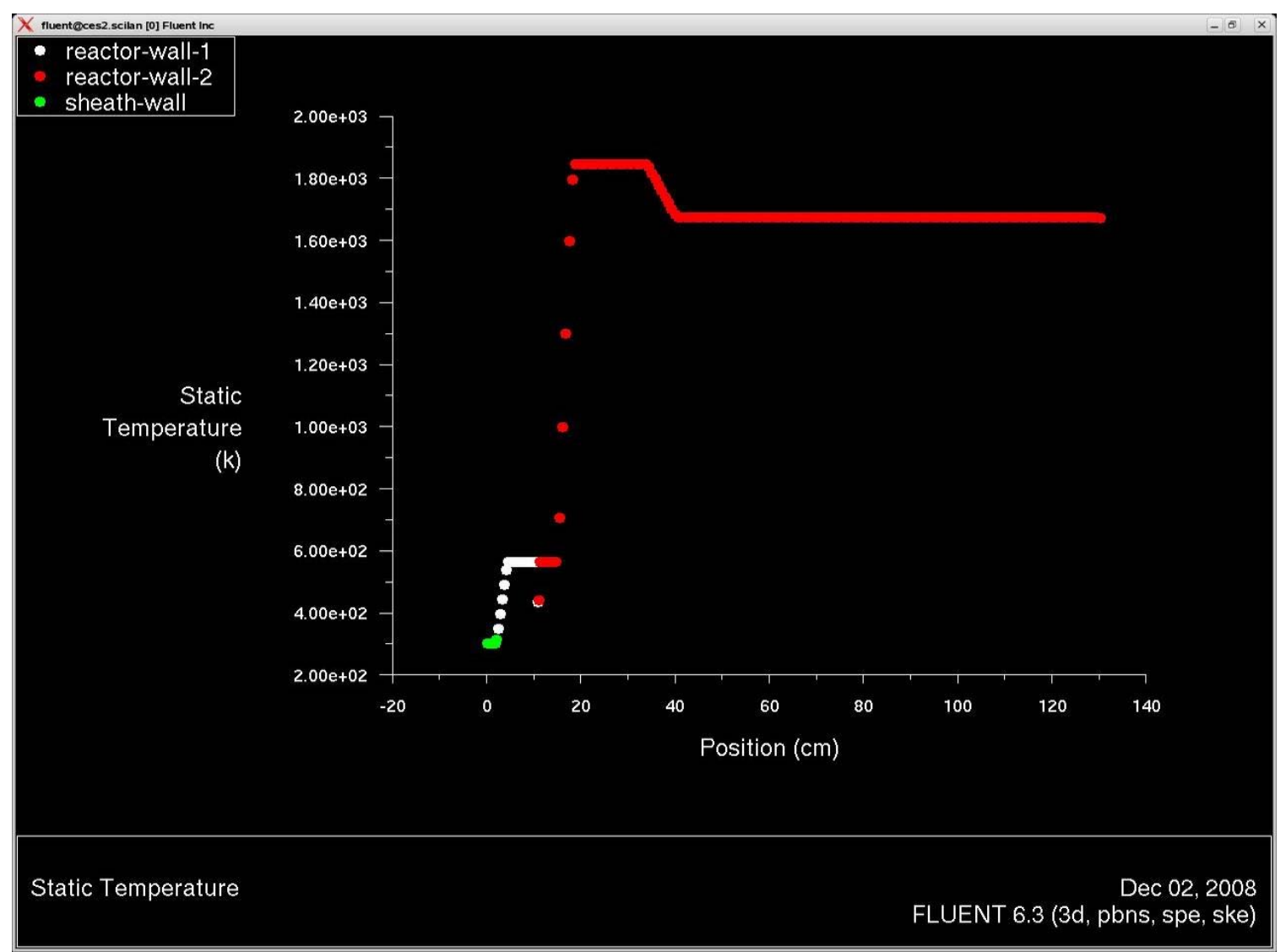

Figure 4.68. Wall temperature profile.

The conditions in Table 4.6 were specified in the boundary conditions for each run in Fluent. Center-line gas temperature for runs 49, 80, and 81 is displayed in Figure 4.69. Gas temperature does not vary much between runs 80 and 81 . Run 49 corresponds to the shorter reactor and therefore is not readily compared to the other simulations. Results for the $\mathrm{CO}_{2}, \mathrm{H}_{2}$, and $\mathrm{CO}$ yields obtained from the CFD simulation are now compared to the experimental measurements for run 80 in Figure 4.70. 


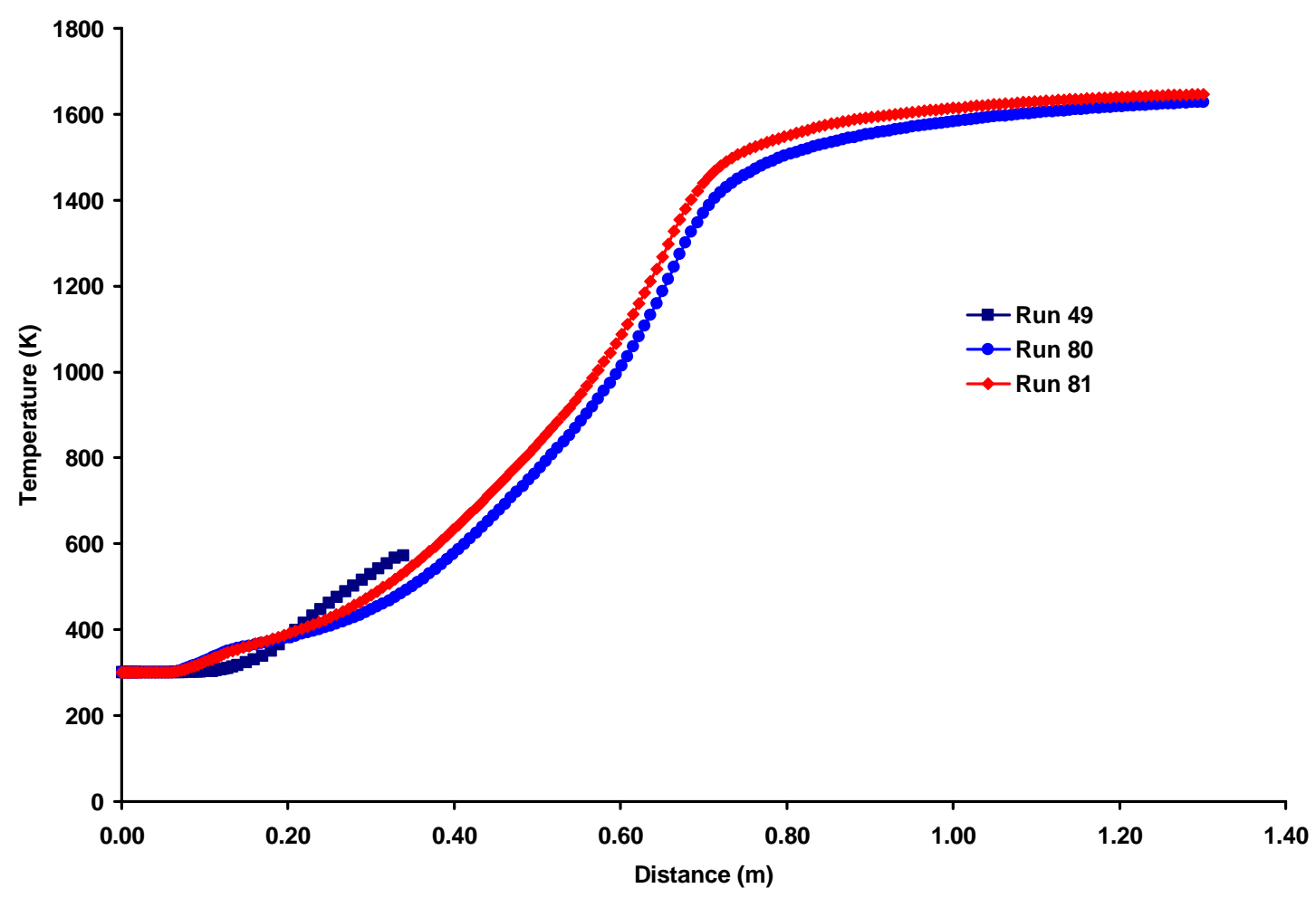

Figure 4.69. Computed center-line gas temperature.

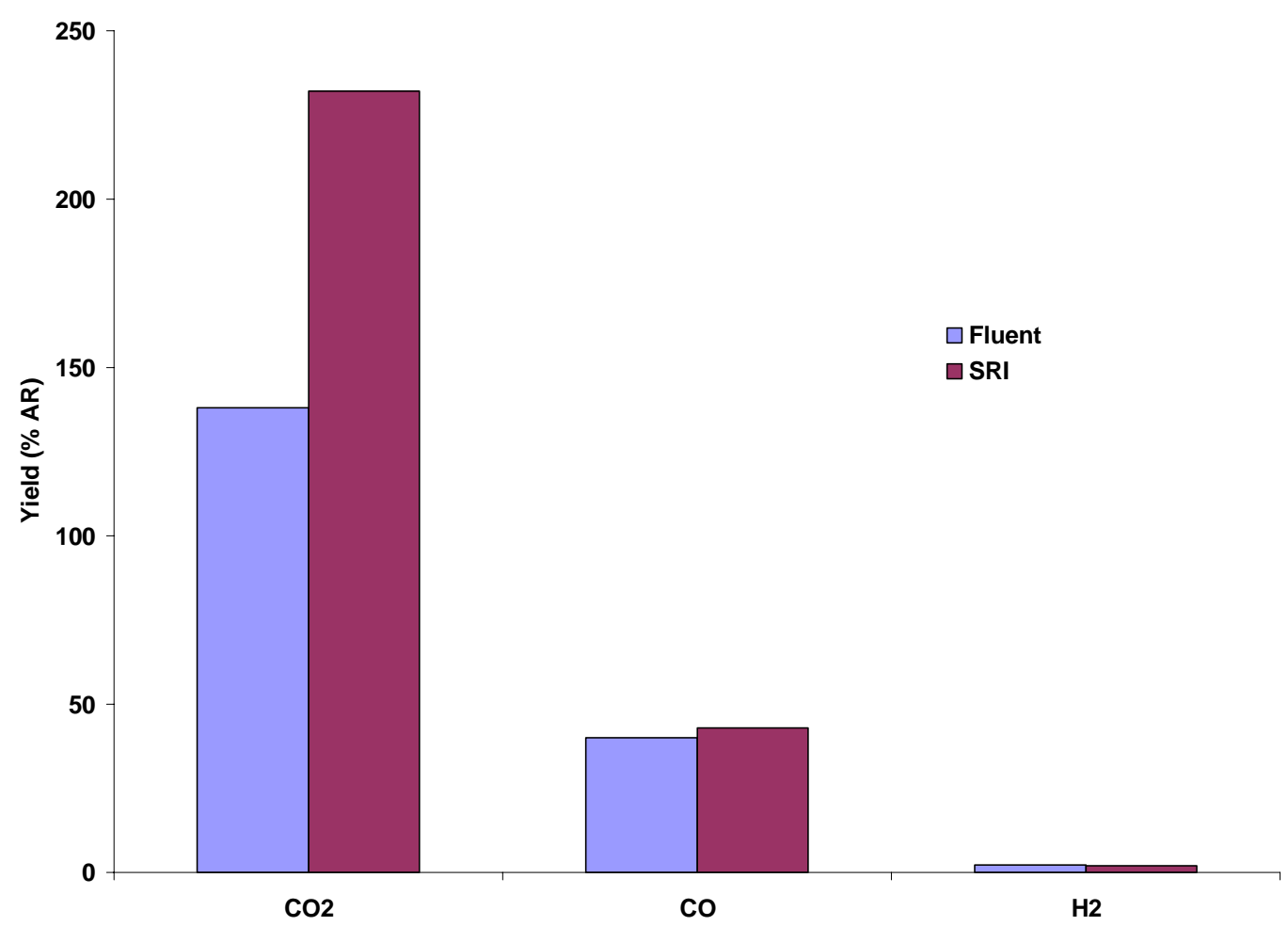

Figure 4.70. Exit gas yields for run 80 . 
Fluent predicts $40 \%$ less $\mathrm{CO}_{2}$ than the amount measured at SRI for run 80 . The $\mathrm{CO}$ and $\mathrm{H}_{2}$ yields are in relatively good agreement. The extent of $\mathrm{CO}_{2}$ gasification predicted in the CFD model could be inaccurate which would account for the discrepancy in Figure 4.70. The fixed carbon conversion predicted by Fluent for run 80 was approximately $72 \%$ compared to $88.3 \%$ measured at SRI. Figure 4.71 displays exit gas yields for run 81. This run has the same $\mathrm{O}_{2}$ :coal ratio as run 80 , but zero steam injected. As with run 80, $\mathrm{CO}_{2}$ levels are under predicted from the Fluent runs. SRI measured $195 \% \mathrm{CO}_{2}$ whereas Fluent predicts 129 ; this is a $34 \%$ under prediction. $\mathrm{CO}$ and $\mathrm{H}_{2}$ are in better agreement between the two. SRI measured $19 \% \mathrm{CO}_{2}$ yield and $0.19 \% \mathrm{H}_{2}$ compared to $21 \%$ and $0.5 \%$ predicted by Fluent. The fixed carbon conversion predicted by Fluent for run 81 was approximately $47 \%$ compared to $72 \%$ measured at SRI.

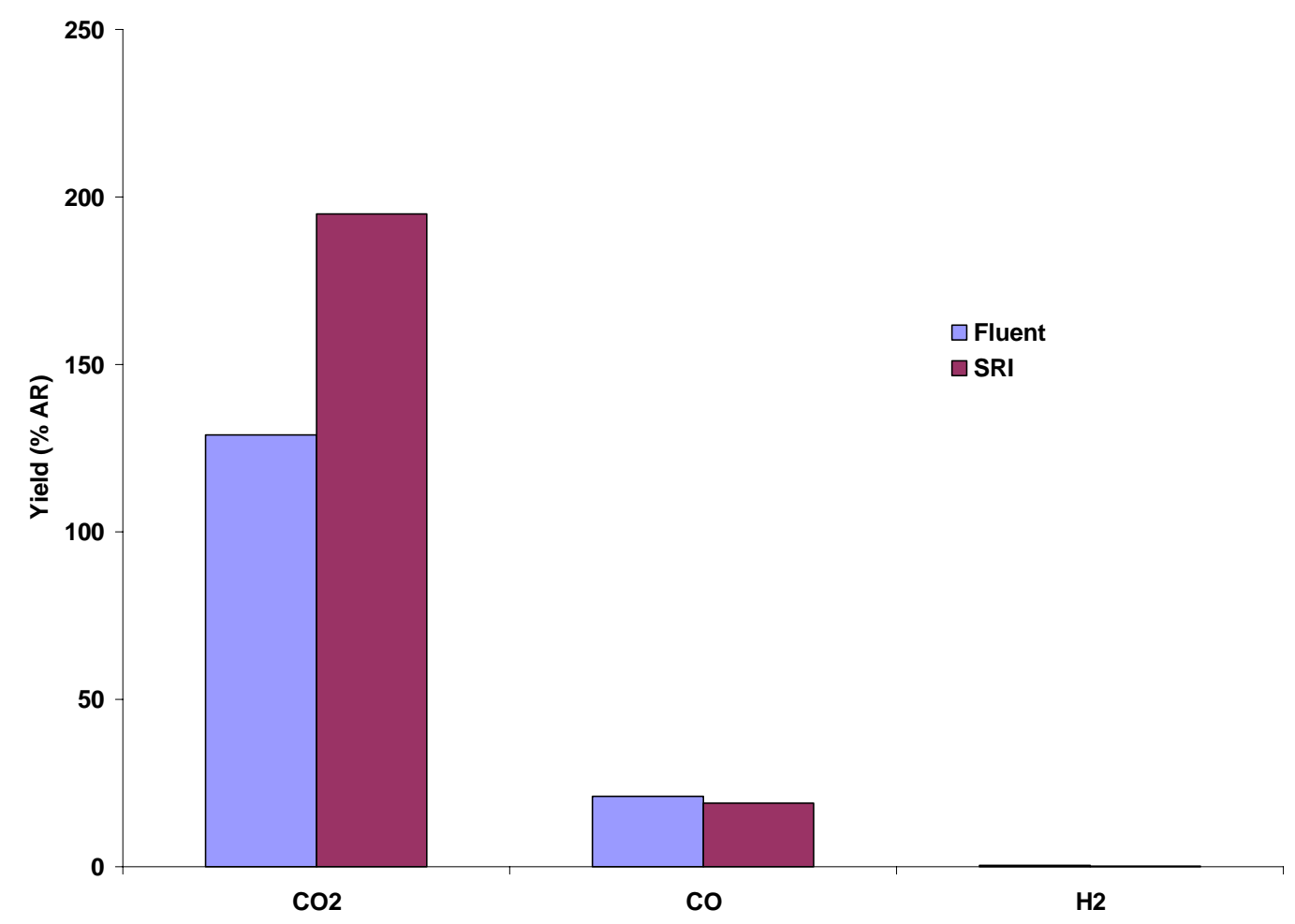

Figure 4.71. Exit gas yields for run 81 . 
The setup for the pyrolysis experiment (run 49) was different than the previous two runs discussed above. The reactor length used at SRI for this run was only $15 \mathrm{~cm}$ and consisted of the graphite heater downstream of the steam injector. Neither oxygen or steam was introduced into the reactor for run 49 . The particles are carried through the heated furnace in a stream of Argon and experience high heating rates which causes the volatile matter to be released. This setup was mimicked in Fluent and the results are compared in Figure 4.72. The results of the CFD simulation show a yield of CO of approximately $2 \%$, whereas the SRI measurements show approximately $18 \%$. Similarly, $\mathrm{H}_{2}$ was under predicted from the CFD model at less than $0.2 \%$, with SRI recording approximately $1.5 \%$. Neither the experimental facility nor the CFD model predicted any $\mathrm{CO}_{2}$ yields, as is expected in a oxygen free reactor.

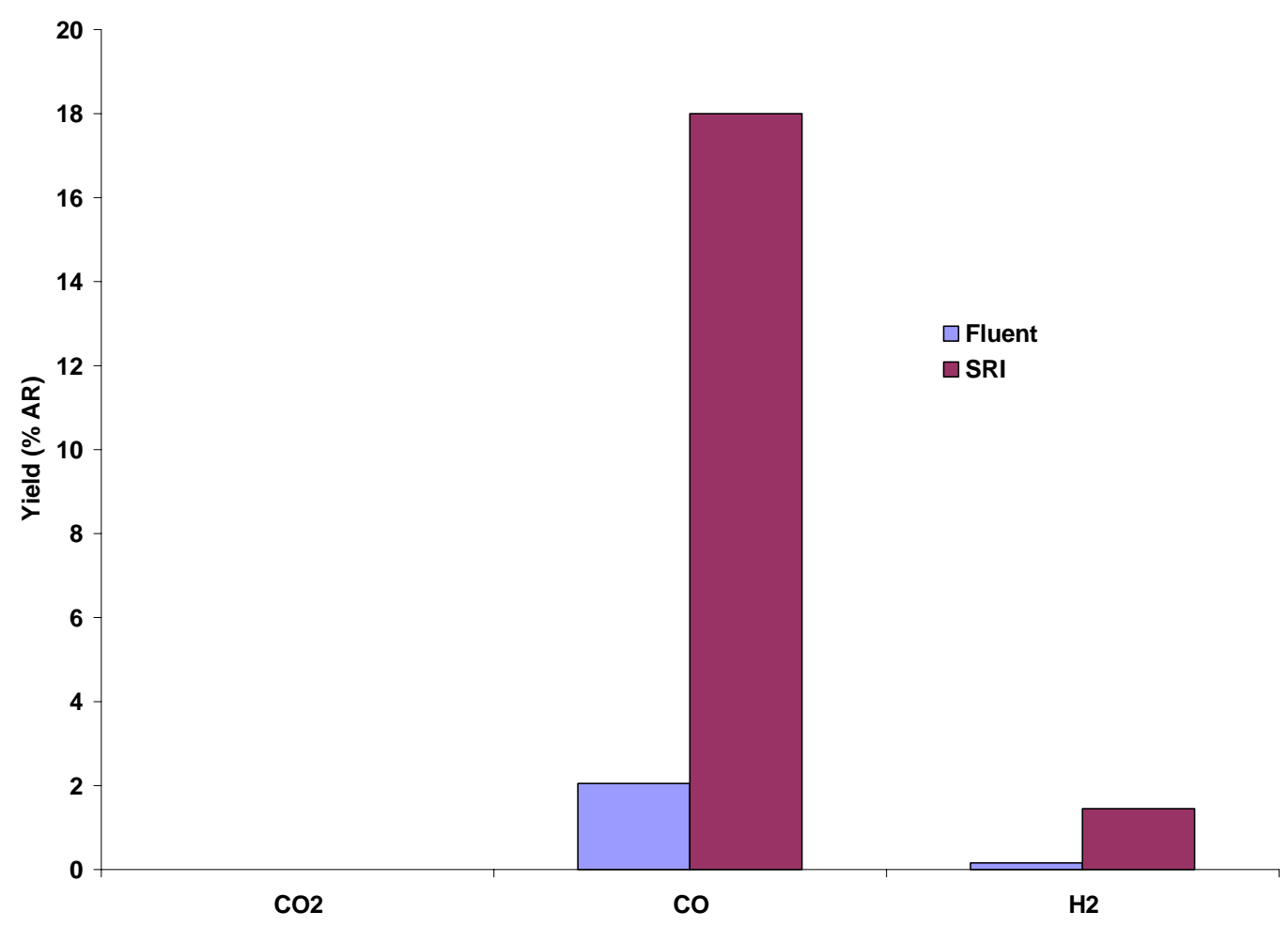

Figure 4.72. Exit gas yields for run 49. 
The discrepancies in Figure 4.72 highlight the need to further tune the devolatilization model used in the CFD code to the experimental data. It should be noted that the volatile distribution predicted in the CFD model assumes that the resultant product gases during pyrolysis will consist mostly of $\mathrm{CH}_{4}$ (Table 3.7) which is not found in the SRI experimental results. 


\section{Chapter 5. Conclusions}

A series of four simulations of a generic commercial two-stage entrained-flow upflow coal gasifier have been presented that explored several different case setups. Cases $1,2,3$, and 4 described flow fields for different laws to govern the gas phase specific heat, thermal conductivity, and viscosity variations with temperature. Results obtained for case 2 were deemed to be unrealistic and are believed to be due to the kinetic theory model used for the gas specific heats. Gas temperature, velocity, and gas compositions did not show a great deal of variability between cases 1,3 , and 4 . Case 3 was chosen as the most representative solution obtained for the current work using an injection of particles with a single density and diameter to describe the Bailey coal sample for comparison with the flow field obtained using 28 simultaneous surface injections (case 4). Gas evolution throughout the second stage was compared for cases 3 and 4 . The $\mathrm{CO}_{2}, \mathrm{CO}, \mathrm{H}_{2}$, and $\mathrm{H}_{2} \mathrm{O}$ levels versus axial distance in stage 2 were compared for the two setups. Slightly higher levels of CO ( $\sim 10 \%$ by volume) were seen for the case 3 results, whereas case 4 predicted more $\mathrm{H}_{2}(\sim 7 \%$ by volume) at the outlet of the gasifier. Reasons for this discrepancy are difficult to identify. One obvious cause is the fact that the case 3 injections only had one coal composition, that of the parent coal sample, whereas case 4 involved 28 separate compositions for each injection port. The elemental makeup of the coal greatly influences the devolatilization specie distributions which, in turn, influence the predicted syngas yield. Particle burnout and temperature versus second stage distance along with average particle impact properties were also compared for cases 3 and 4 . Also, it was determined that the particle-wall impact properties are almost identical for cases 3 and 4. Fixed carbon conversion for SG1 through SG3 fractions follow the same 
trends when injected into flow fields obtained from either case 3 or case 4 . The smaller diameter injections convert all of the fixed carbon, whereas the larger particles convert only around $40 \%$ of their fixed carbon on average when all particles are injected into the steady flow field. Overall fixed carbon conversion was seen to be approximately $90 \%$ for case 4 whereas case 3 predicted approximately $86 \%$ conversion. Particle residence times for each of the 28 size/density fractions are compared for cases 3 and 4 . It was found that the average residence time for each size/density class is around 3 seconds when injected into a flow field described by case 3. More variability in residence time is seen when each fraction was injected into the case 4 flow field, with a maximum average residence time of 10 seconds seen for the SG4PS4 fraction. Trajectories for the larger/heavier injections showed consistent tendencies for the particles to get trapped in the combustion chamber when injected from stage 1 left and right inlets. These heavier particles would most likely escape the reactor through the slag exit from stage 1 . The lighter and smaller particles get entrained with the gas flow and leave mostly at the gasifier exit in the second stage after impacting the reactor walls multiple times. This wall impact behavior was analyzed in detail. It was seen that when all 28 size/density fractions were injected from both stage 1 and stage 2 into the flow field described by case 3 , that only $10 \%$ of the particles would escape when allowed to impact a reactor wall only once. This is in contrast to the case 4 results, where only around $5 \%$ of the particles would escape without ever impacting. Similar results were obtained for the stage 2 injection alone, where it was found that $5 \%$ of the particles would escape for case 3 and only around $2 \%$ for case 4. 
The flow field obtained using the reaction kinetics developed by Shi et al. [3] for the Sauter-mean injections (case 3) was compared to one obtained using a devolatilization model prediction from PC Coal Lab. Exit gas compositions, fixed carbon conversion, gas and wall temperatures, and velocity fields were used as a basis for comparison. It was determined that the results for the two solutions were in agreement for particle burnout versus axial distance in stage 2, but different temperature histories were predicted, with a colder flow field in stage 2 predicted for the PC Coal Lab case. The colder stage 2 flow field obtained from the PC Coal Lab case is believed to be due to the endothermic reaction describing the gasification of soot with steam. Exit $\mathrm{H}_{2}$ and $\mathrm{CO}$ volume fractions were within a few percent and first stage gas temperatures were in agreement.

The grid used for all of the simulations done during the course of this study contained 12,000 hexahedral elements. Three more simulations were performed for the case 3 and case 4 setups using progressively denser grids and it was found that the exit gas composition and wall temperatures did not vary considerably for either solution.

The present study has indicated that the more physically accurate solution that was obtained by accurately modeling the Bailey coal size and density mass fractions during the DPM solution process (case 4) yielded differences in the overall solution, specifically in the values of the average temperatures in the gasifier first and second stages and the exit gas composition. 


\section{References}

1. Wen, C.Y., and Lee, S. E., 1979. Coal Conversion Technology, Addison-Wesley.

2. PC Coal Lab Version 4.0, User's Guide and Tutorial, 2004. Niksa Energy Associates LLC.

3. Shi, S.-P., Zitney, S.E., Shahnam, M., Syamlal, M., and Rogers, W.A., 2006, "Modeling Coal Gasification with CFD and Discrete Phase Method," Journal of the Energy Institute, Vol. 79, No. 4, 217-221.

4. Coal Gasification Guidebook: Status, Applications, and Technologies, EPRI, Project 2221-39, Final Report, December 1993.

5. Skodras, G., Kaldis, S.P., Sakellaropoulos, G.P., Sofialidis, D., and Faltsi, O., 2003. "Simulation of a molten bath gasifier by using a CFD code," Fuel, Vol. 82, n15-17, October-December, pp. 2033-2044.

6. Forstner, M., Hofmeister, G., Joller, M., Dahl, J., Braun, M., Kleditzsch, S., Scharler, R., and Obernberger, I., 2006, "CFD simulation of ash deposit formation in fixed bed biomass furnaces and boilers," Progress in Computational Fluid Dynamics, Vol. 6, Nos. $4 / 5$.

7. Hoppesteyn, P.D.J., Andries, J., and Hein, K.R.G., 1998. "Development and validation of a coal/biomass fuelled gas turbine combustor model, "Proceedings of the 1998 ASME/JSME Joint Pressure Vessels and Piping Conference, San Diego, CA, July 26-30.

8. Hoppesteyn, P.D.J., Andries, J., and Hein, K.R.G., 1998. "Biomass/coal derived gas utilization in a gas turbine combustor," Proceedings of the 1998 ASME International Gas Turbine \& Aeroengine Congress \& Exhibition, Stockholm, Sweden, June 2-5.

9. Bouma, P.H., de Goey, L.P.H., Tummers, M.J., and Kiel, J.H.A., 1999. "Numerical modelling of an entrained-flow gasification simulator," Computational Technologies for Fluid / Thermal / Structural / Chemical Systems with Industrial Applications - 1999 (ASME Pressure Vessels and Piping Conference), Boston, MA, August 1-5.

10. Fletcher, D.F., Haynes, B.S., Christo, F.C., and Joseph, S.D., 2000. "A CFD based combustion model of an entrained flow biomass gasifier," Applied Mathematical Modelling, Vol. 24 , n3, March, pp. 165-182.

11. Liu, H. and Kojima, T., 2004. "Theoretical study of coal gasification in a 50 ton/day HYCOL entrained flow gasifier. II. Effects of operating conditions and comparison with pilot-scale experiments," Energy and Fuels, Vol. 18, n. 4 July/August, pp. 913-917. 
12. Liu, H. and Kojima, T., 2004. "Theoretical study of coal gasification in a 50 ton/day HYCOL entrained flow gasifier. I. Effects of coal properties and implications," Energy and Fuels, Vol. 18, n 4 July/August, pp. 908-912.

13. Liu, G.-S., and Niksa, S., 2005. "Pulverized coal flame structures at elevated pressures. Part 1. Detailed operating conditions," Fuel 84, pp. 1563-1574.

14. Niksa, S. and Liu, G.-S., 2005. "Pulverized coal flame structures at elevated pressures. Part 2. Interpreting $\mathrm{NO}_{\mathrm{x}}$ production with detailed reaction mechanisms," Fuel 84 , pp. $1575-1585$.

15. Fluent 6.3 User's Guide. September, 2006.

16. Shi, S.-P., 2006. "Upgrade the Coal Gasification Model Using DPM," Final Report prepared for Stephen E. Zitney, U.S. Department of Energy, National Energy Technology Laboratory.

17. Wen, C.Y., and Chaung, T.Z., 1979. "Entrainment Coal Gasification Modeling," Ind. Eng. Chem. Process. Dev., Vol. 18, No. 4, 684-695.

18. Wen, C.Y., Chen, H., and Onazaki, M., January, 1982. "User's Manual for Computer Simulation and Design of the Moving Bed Coal Gasifier", Final Report Task Order No. 41 prepared for the United States Department of Energy, Morgantown Energy Technology Center, Morgantown, West Virginia.

19. Soundarrajan, N., Klima M., and Pisupati, S. V., 2007. "Coal Partitioning Project Monthly Progress Report," Project Progress Report, Pennsylvania State University, June.

20. Soundarrajan, N., Klima M., and Pisupati, S. V., 2008. "Coal Partitioning Project Monthly Progress Report," Project Progress Report, Pennsylvania State University, January.

21. McBride, B. J., Heimel, S., Ehlers, J. G., and Gordon, S., 1963. "Thermodynamic Properties to $6000^{\circ} \mathrm{K}$ for 210 Substances Involving the First 18 Elements," NASA SP3001.

22. Kobayashi, H., Howard, J., and Sarofim, A., 1976. "Coal Devolatilization at High Temperatures," Proc. 16 th Int. Symp. on 'Combustion'. University of Pittsburgh, Pittsburgh, PA. The Combustion Institute.

23. Park, C., and Appleton, P., 1973. "Shock-tube Measurements of Soot Oxidation Rates," Combustion and Flame, Vol. 20, 369-379.

24. Niksa, S., 2006. "Coal Gasification Submodels for Transport Gasifier Simulations," Final Project Report, Niksa Energy Associates. 
25. Eckstrom, D., Malhotra, R., 2008. "Coal Partitioning Project Monthly Progress Report," Project Progress Report, SRI International, January. 


\section{Appendix A}

\section{PC Coal Lab Output Reports}




\section{A.1 PC Coal Lab output reports for Stage 1}

DROP TUBE SIMULATION WITH PC COAL LAB

\section{FULL DYNAMICS}

COAL CHARACTERISTICS: Parent Coal

\begin{tabular}{lccc}
\multicolumn{2}{c}{ Ultimate, } & daf wt.\% & \multicolumn{2}{c}{ Proximate, as rec wt.\% } \\
$\% \mathrm{C}$ & 76.8 & Moisture & 1.0 \\
$\% \mathrm{H}$ & 5.5 & Vol. Mat. & 33.5 \\
$\% \mathrm{O}$ & 3.9 & Ash & 7.8 \\
$\% \mathrm{~N}$ & 1.4 & Fixed C & 57.7 \\
$\% \mathrm{~S}$ & 1.5 & &
\end{tabular}

\section{OPERATING CONDITIONS:}

108.4 micron particles at 177. C are entrained in N2 with $0.0 \% \mathrm{O} 2$ at $1974 . \mathrm{C}$ in a furnace at $1964 . \mathrm{C}$ for $.150 \mathrm{E}+00 \mathrm{~s}$. The ambient pressure is $2.80 \mathrm{MPa}$.

**User-specified conditions were implemented during devolatilization.**

\begin{tabular}{lllllllllllllll} 
Thermal History Wt.Loss & \multicolumn{10}{c}{ Secondary Pyrolysis Products, daf wt.\% } \\
Time,s Tmp, & daf wt.\% & Soot & CH4 & C2H2 & H2 & CO & CO2 & H2O & HCN & H2S \\
& & & & & & & & & & & & \\
$.000 \mathrm{E}+00$ & 177. & 0.0 & 0.0 & 0.0 & 0.0 & 0.00 & 0.0 & 0.0 & 0.0 & 0.00 & 0.0 \\
$.265 \mathrm{E}-02$ & 234. & 0.0 & 0.0 & 0.0 & 0.0 & 0.00 & 0.0 & 0.0 & 0.0 & 0.00 & 0.0 \\
$.598 \mathrm{E}-02$ & 314. & 0.0 & 0.0 & 0.0 & 0.0 & 0.00 & 0.0 & 0.0 & 0.0 & 0.00 & 0.0 \\
$.932 \mathrm{E}-02$ & 386. & 0.0 & 0.0 & 0.0 & 0.0 & 0.00 & 0.0 & 0.0 & 0.0 & 0.00 & 0.0 \\
$.127 \mathrm{E}-01$ & 454. & 0.2 & 0.2 & 0.0 & 0.0 & 0.01 & 0.0 & 0.0 & 0.0 & 0.01 & 0.0 \\
$.160 \mathrm{E}-01$ & 517. & 0.6 & 0.5 & 0.0 & 0.0 & 0.04 & 0.0 & 0.0 & 0.0 & 0.02 & 0.0 \\
$.193 \mathrm{E}-01$ & 579. & 1.0 & 0.8 & 0.0 & 0.0 & 0.07 & 0.0 & 0.0 & 0.0 & 0.02 & 0.0 \\
$.226 \mathrm{E}-01$ & 639. & 1.7 & 1.4 & 0.0 & 0.0 & 0.13 & 0.1 & 0.0 & 0.0 & 0.04 & 0.0 \\
$.260 \mathrm{E}-01$ & 699. & 3.2 & 2.1 & 0.0 & 0.2 & 0.23 & 0.2 & 0.2 & 0.1 & 0.05 & 0.1 \\
$.293 \mathrm{E}-01$ & 759. & 5.4 & 3.3 & 0.1 & 0.5 & 0.39 & 0.4 & 0.3 & 0.2 & 0.08 & 0.2 \\
$.326 \mathrm{E}-01$ & 822. & 8.6 & 5.4 & 0.1 & 0.7 & 0.62 & 0.5 & 0.5 & 0.3 & 0.13 & 0.4 \\
$.360 \mathrm{E}-01$ & 891. & 14.0 & 9.0 & 0.1 & 1.1 & 1.02 & 0.7 & 0.8 & 0.4 & 0.21 & 0.6 \\
$.393 \mathrm{E}-01$ & 968. & 21.6 & 14.1 & 0.2 & 1.8 & 1.56 & 1.1 & 1.2 & 0.6 & 0.32 & 0.8 \\
$.426 \mathrm{E}-01$ & 1050. & 30.4 & 19.8 & 0.3 & 2.6 & 2.17 & 1.4 & 1.6 & 0.9 & 0.45 & 1.1 \\
$.460 \mathrm{E}-01$ & 1129. & 37.0 & 23.9 & 0.3 & 3.3 & 2.70 & 1.7 & 2.0 & 1.1 & 0.54 & 1.4 \\
$.495 \mathrm{E}-01$ & 1197. & 40.1 & 25.5 & 0.4 & 3.8 & 3.07 & 1.8 & 2.3 & 1.2 & 0.58 & 1.5 \\
$.534 \mathrm{E}-01$ & 1250. & 41.2 & 25.9 & 0.4 & 3.9 & 3.39 & 1.8 & 2.3 & 1.3 & 0.60 & 1.6 \\
$.687 \mathrm{E}-01$ & 1321. & 42.3 & 25.9 & 0.4 & 4.0 & 4.31 & 1.8 & 2.4 & 1.3 & 0.67 & 1.6
\end{tabular}




$\begin{array}{llllllllllll}.908 \mathrm{E}-01 & 1332 . & 42.5 & 25.9 & 0.4 & 4.0 & 4.38 & 1.8 & 2.4 & 1.3 & 0.84 & 1.6 \\ .124 \mathrm{E}+00 & 1333 . & 43.0 & 25.9 & 0.4 & 4.0 & 4.38 & 1.8 & 2.4 & 1.3 & 1.29 & 1.6 \\ .150 \mathrm{E}+00 & 1333 . & 43.1 & 25.9 & 0.4 & 4.0 & 4.38 & 1.8 & 2.4 & 1.3 & 1.48 & 1.6\end{array}$

DROP TUBE SIMULATION WITH PC COAL LAB

RATE PARAMETER ASSIGNMENTS

COAL CHARACTERISTICS: Parent Coal

\begin{tabular}{cccc}
\multicolumn{2}{c}{ Ultimate, daf wt.\% } & \multicolumn{2}{c}{ Proximate, as rec wt.\% } \\
$\% \mathrm{C}$ & 76.8 & Moisture & 1.0 \\
$\% \mathrm{H}$ & 5.5 & Vol. Mat. & 33.5 \\
$\% \mathrm{O}$ & 3.9 & Ash & 7.8 \\
$\% \mathrm{~N}$ & 1.4 & Fixed C & 57.7 \\
$\% \mathrm{~S}$ & 1.5 & &
\end{tabular}

\section{OPERATING CONDITIONS:}

108.4 micron particles at $177 . \mathrm{C}$ are entrained in N2 with $0.0 \% \mathrm{O} 2$ at 1974 . C in a furnace at $1964 . \mathrm{C}$ for $.150 \mathrm{E}+00 \mathrm{~s}$. The ambient pressure is $2.80 \mathrm{MPa}$.

\section{SFOR RATE PARAMETERS}

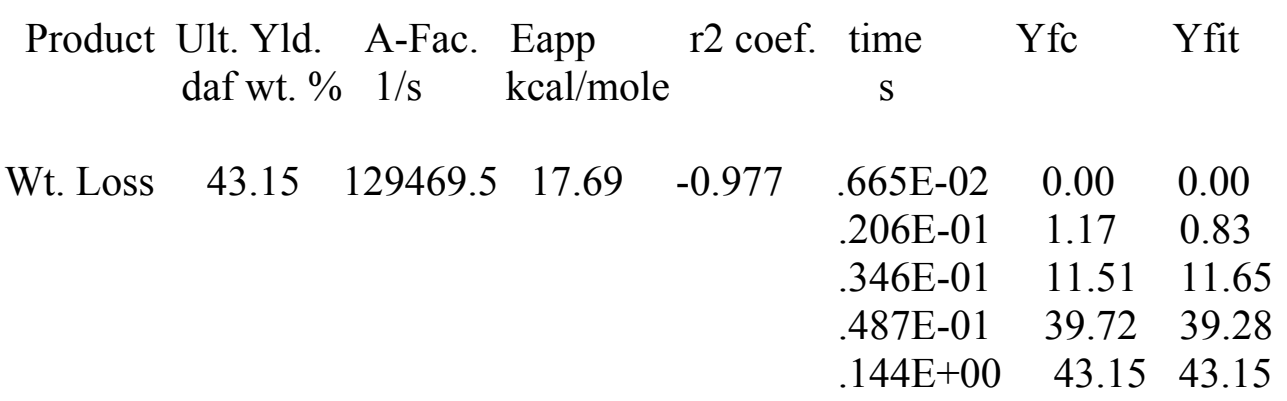


A.2 PC Coal Lab output reports for Stage 2

DROP TUBE SIMULATION WITH PC COAL LAB

FULL DYNAMICS

COAL CHARACTERISTICS: Parent Coal

\begin{tabular}{cccc}
\multicolumn{2}{c}{ Ultimate, daf wt.\% } & \multicolumn{2}{c}{ Proximate, as rec wt.\% } \\
$\% \mathrm{C}$ & 76.8 & Moisture & 1.0 \\
$\% \mathrm{H}$ & 5.5 & Vol. Mat. & 33.5 \\
$\% \mathrm{O}$ & 3.9 & Ash & 7.8 \\
$\% \mathrm{~N}$ & 1.4 & Fixed C & 57.7 \\
$\% \mathrm{~S}$ & 1.5 & &
\end{tabular}

OPERATING CONDITIONS:

108.4 micron particles at 177 . C are entrained in N2 with $0.0 \% \mathrm{O} 2$ at $1227 . \mathrm{C}$ in a furnace at $1210 . \mathrm{C}$ for $.150 \mathrm{E}+00 \mathrm{~s}$. The ambient pressure is $2.80 \mathrm{MPa}$.

**User-specified conditions were implemented during devolatilization.**

\begin{tabular}{|c|c|c|c|c|c|c|c|c|c|c|c|}
\hline \multicolumn{3}{|c|}{ Thermal History Wt.Loss } & \multicolumn{7}{|c|}{ Secondary Pyrolysis Products, daf wt.\% } & \multirow[b]{2}{*}{$\mathrm{HCN}$} & \multirow[b]{2}{*}{$\mathrm{H} 2 \mathrm{~S}$} \\
\hline Time,s & $\mathrm{mp}, \mathrm{C}$ & daf wt. $\%$ & Soot & $\mathrm{CH} 4$ & $\mathrm{C} 2 \mathrm{H} 2$ & $\mathrm{H} 2$ & $\mathrm{CO}$ & $\mathrm{CO} 2$ & $\mathrm{H} 2 \mathrm{O}$ & & \\
\hline $.000 \mathrm{E}+00$ & 177. & 0.0 & 0.0 & 0.0 & 0.0 & 0.00 & 0.0 & 0.0 & 0.0 & 0.00 & 0.0 \\
\hline $265 \mathrm{E}-02$ & 227. & 0.0 & 0.0 & 0.0 & 0.0 & 0.00 & 0.0 & 0.0 & 0.0 & 0.00 & 0.0 \\
\hline $.594 \mathrm{E}-02$ & 299. & 0.0 & 0.0 & 0.0 & 0.0 & 0.00 & 0.0 & 0.0 & 0.0 & 0.00 & 0.0 \\
\hline $.927 \mathrm{E}-02$ & 365. & 0.0 & 0.0 & 0.0 & 0.0 & 0.00 & 0.0 & 0.0 & 0.0 & 0.00 & 0.0 \\
\hline $126 \mathrm{E}-01$ & 426. & 0.0 & 0.0 & 0.0 & 0.0 & 0.00 & 0.0 & 0.0 & 0.0 & 0.00 & 0.0 \\
\hline $.159 \mathrm{E}-01$ & 483. & 0.4 & 0.4 & 0.0 & 0.0 & 0.03 & 0.0 & 0.0 & 0.0 & 0.01 & 0.0 \\
\hline $.192 \mathrm{E}-01$ & 539. & 0.7 & 0.7 & 0.0 & 0.0 & 0.05 & 0.0 & 0.0 & 0.0 & 0.02 & 0.0 \\
\hline $.226 \mathrm{E}-01$ & 592. & 1.1 & 0.9 & 0.0 & 0.0 & 0.08 & 0.0 & 0.0 & 0.0 & 0.03 & 0.0 \\
\hline $.259 \mathrm{E}-01$ & 645. & 1.9 & 1.5 & 0.0 & 0.0 & 0.14 & 0.1 & 0.1 & 0.0 & 0.04 & 0.1 \\
\hline $292 \mathrm{E}-01$ & 697. & 3.3 & 2.2 & 0.0 & 0.2 & 0.24 & 0.2 & 0.2 & 0.1 & 0.06 & 0.1 \\
\hline $.326 \mathrm{E}-01$ & 751. & 5.3 & 3.2 & 0.1 & 0.4 & 0.38 & 0.3 & 0.3 & 0.2 & 0.08 & 0.2 \\
\hline $.359 \mathrm{E}-01$ & 808. & 8.0 & 5.0 & 0.1 & 0.7 & 0.58 & 0.5 & 0.5 & 0.3 & 0.12 & 0.3 \\
\hline $.392 \mathrm{E}-01$ & 867. & 12.6 & 8.1 & 0.1 & 1.0 & 0.92 & 0.7 & 0.7 & 0.4 & 0.19 & 0.5 \\
\hline $.426 \mathrm{E}-01$ & 929. & 19.1 & 12.4 & 0.2 & 1.5 & 1.38 & 1.0 & 1.0 & 0.6 & 0.28 & 0.7 \\
\hline $.459 \mathrm{E}-01$ & 990. & 26.6 & 17.4 & 0.2 & 2.2 & 1.90 & 1.3 & 1.4 & 0.8 & 0.39 & 1.0 \\
\hline $.494 \mathrm{E}-01$ & 1050. & 33.5 & 21.9 & 0.3 & 2.9 & 2.40 & 1.5 & 1.8 & 1.0 & 0.50 & 1.2 \\
\hline $.534 \mathrm{E}-01$ & 1105. & 38.3 & 24.7 & 0.4 & 3.5 & 2.81 & 1.7 & 2.1 & 1.1 & 0.56 & 1.4 \\
\hline $.686 \mathrm{E}-01$ & 1204. & 41.8 & 26.1 & 0.4 & 3.9 & 3.63 & 1.8 & 2.3 & 1.3 & 0.64 & 1.6 \\
\hline
\end{tabular}




$\begin{array}{llllllllllll}.140 \mathrm{E}+00 & 1220 . & 42.6 & 26.1 & 0.4 & 4.0 & 4.36 & 1.9 & 2.3 & 1.3 & 0.72 & 1.6 \\ .150 \mathrm{E}+00 & 1220 . & 42.6 & 26.1 & 0.4 & 4.0 & 4.36 & 1.9 & 2.3 & 1.3 & 0.72 & 1.6\end{array}$

\section{DROP TUBE SIMULATION WITH PC COAL LAB}

RATE PARAMETER ASSIGNMENTS

COAL CHARACTERISTICS: Parent Coal

\begin{tabular}{cccc}
\multicolumn{2}{c}{ Ultimate, daf wt.\% } & \multicolumn{2}{c}{ Proximate, as rec wt.\% } \\
$\% \mathrm{C}$ & 76.8 & Moisture & 1.0 \\
$\% \mathrm{H}$ & 5.5 & Vol. Mat. & 33.5 \\
$\% \mathrm{O}$ & 3.9 & Ash & 7.8 \\
$\% \mathrm{~N}$ & 1.4 & Fixed C & 57.7 \\
$\% \mathrm{~S}$ & 1.5 & &
\end{tabular}

\section{OPERATING CONDITIONS:}

108.4 micron particles at $177 . \mathrm{C}$ are entrained in $\mathrm{N} 2$ with $0.0 \% \mathrm{O} 2$ at $1227 . \mathrm{C}$ in a furnace at $1210 . \mathrm{C}$ for $.150 \mathrm{E}+00 \mathrm{~s}$. The ambient pressure is $2.80 \mathrm{MPa}$.

\section{SFOR RATE PARAMETERS}

\begin{tabular}{|c|c|c|c|c|c|c|c|}
\hline Product & $\begin{array}{l}\text { Ult. Yl } \\
\text { daf wt. }\end{array}$ & $\begin{array}{l}\text { A-Fac. } \\
\% \quad 1 / \mathrm{s}\end{array}$ & $\begin{array}{c}\text { Eapp } \\
\text { kcal/mole }\end{array}$ & r2 coef & $\underset{\mathrm{S}}{\text { time }}$ & Yfc & Y fit \\
\hline Wt. Loss & 42.60 & 335072.8 & 19.80 & -0.993 & $\begin{array}{l}.660 \mathrm{E}-02 \\
.192 \mathrm{E}-01 \\
.319 \mathrm{E}-01 \\
.446 \mathrm{E}-01 \\
.140 \mathrm{E}+00\end{array}$ & $\begin{array}{r}0.00 \\
0.75 \\
4.86 \\
23.58 \\
42.60\end{array}$ & $\begin{array}{c}0.00 \\
0.23 \\
3.96 \\
22.58 \\
42.60\end{array}$ \\
\hline
\end{tabular}


Appendix B

User Defined Function for Particle Wall Interaction 


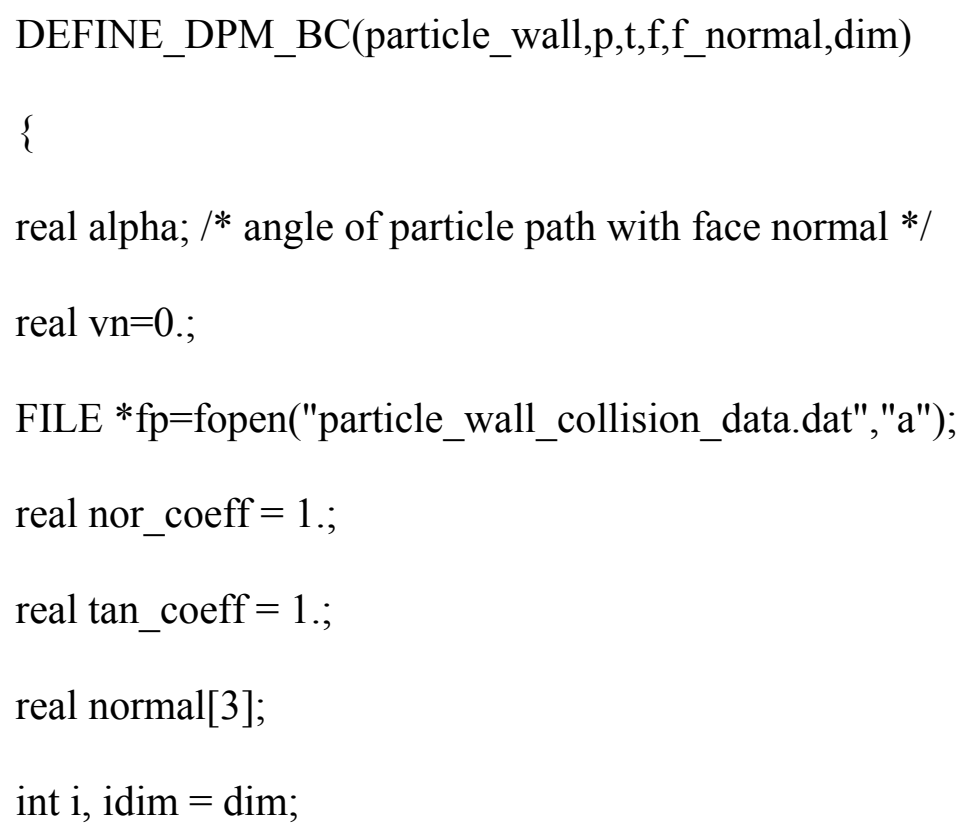




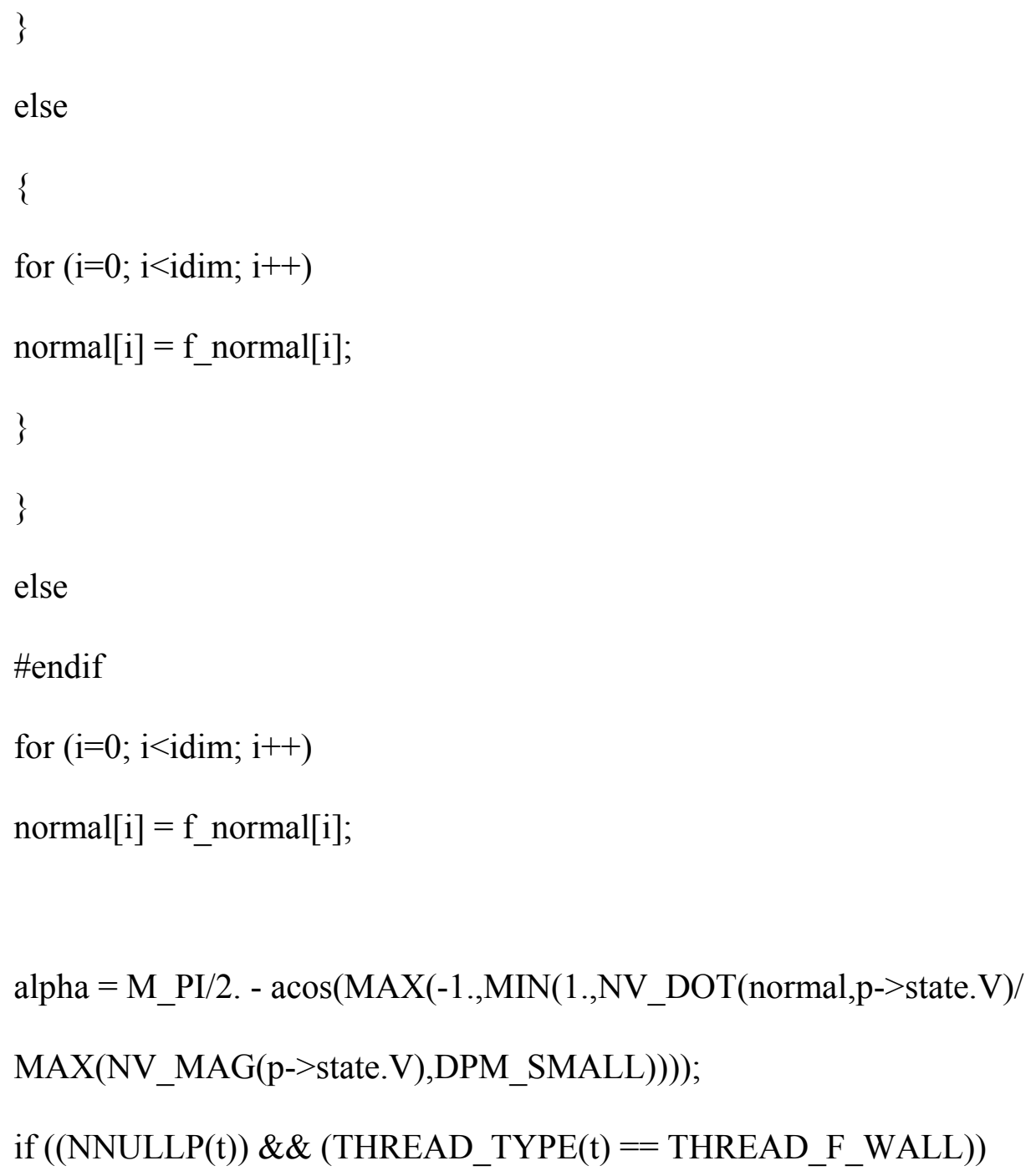

/* Compute normal velocity. */

for $(\mathrm{i}=0 ; \mathrm{i}<\mathrm{idim} ; \mathrm{i}++)$

vn $+=p$ - $>$ state. $V[i] *$ normal $[i]$;

/* Subtract off normal velocity. */

for $(\mathrm{i}=0 ; \mathrm{i}<\mathrm{idim} ; \mathrm{i}++)$

p->state.V[i] -= vn*normal[i];

/* Apply tangential coefficient of restitution. */ 
for $(\mathrm{i}=0 ; \mathrm{i}<\mathrm{idim} ; \mathrm{i}++)$

p->state.V[i] ${ }^{*}=$ tan_coeff;

/* Add reflected normal velocity. */

for $(\mathrm{i}=0 ; \mathrm{i}<\mathrm{idim} ; \mathrm{i}++)$

p->state.V[i] -= nor_coeff*vn*normal[i];

/* Store new velocity in state 0 of particle */

for $(\mathrm{i}=0 ; \mathrm{i}<\mathrm{idim} ; \mathrm{i}++)$

$\mathrm{p}->$ state $0 . V[i]=p->$ state. $V[i]$;

$/ *$ Compute char mass remaining in particle*/

real char_mass $=0$;

real percent_char $=0$;

if $\left(\left(P \_M A S S(p)>\left(\left(1 .-v m \_a r / 100.\right) * P \_I N I T \_M A S S(p)\right)\right) \|\left(P \_M A S S(p)>((1 .-\right.\right.$

moist_ar/100.)*P_INIT_MASS(p))))

char_mass $=f \mathrm{fc}$ ar $/ 100 .{ }^{*}$ P_INIT_MASS(p);

else if(P_MASS $(\mathrm{p})>($ ash_ar/100.*P_INIT_MASS $(\mathrm{p})))$

char_mass=P_MASS(p)-ash_ar/100.*P_INIT_MASS(p);

else

char_mass $=0$;

percent_char=char_mass/P_MASS(p)*100;

$/ *$ Write particle variables to file*/

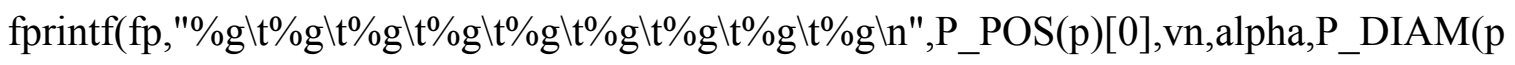

),P_INIT_DIAM(p),P_RHO(p),। 


\section{P INIT_RHO(p),P_T(p),percent_char);}

fclose(fp);

return PATH_END;

\} 


\title{
Appendix C
}

Particle Trajectories for Case 1, Case 2, Case 3, and Case 4

\author{
Solutions
}




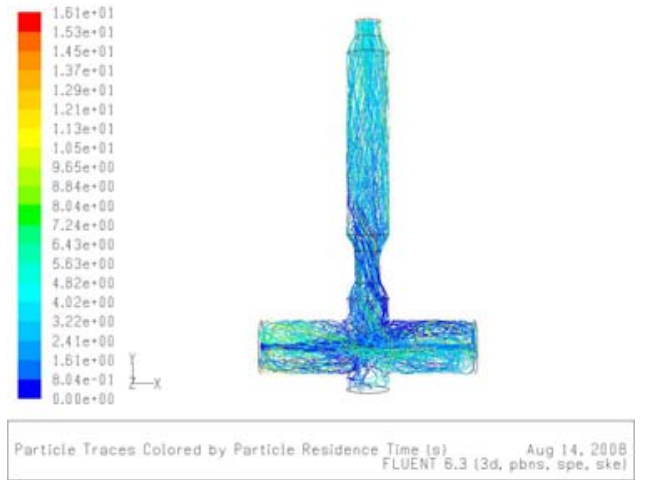

A.) SG1PS7 stage 1
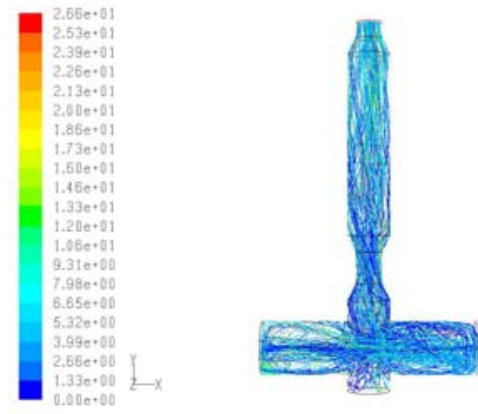

Particle Traces Colored by Particle Residence Time (s)
FLuENT 6,3 (3d, pbos, 14, spe, ske)

C.) SG1PS5 stage 1
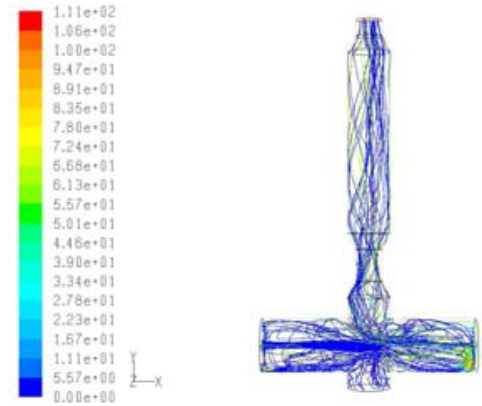

Particle Traces Colored by Particle Residence Time Is) FLUENT 6.3 (3d, pbos, 14, 2008 , ske)

E.) SG1PS3 stage 1

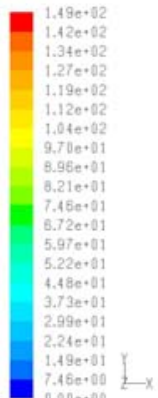

$.460+002$

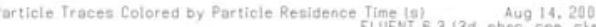

H.) SG1PS1 stage 1

Figure C.1. Case 1 particle tracks for Bailey coal for first stage injection of specific gravity cut \#1 ( $\mathrm{SG}=1.2)$, for particle size cuts \#7 $(50 \mu \mathrm{m})$ through \#1 $(800 \mu \mathrm{m})$. 


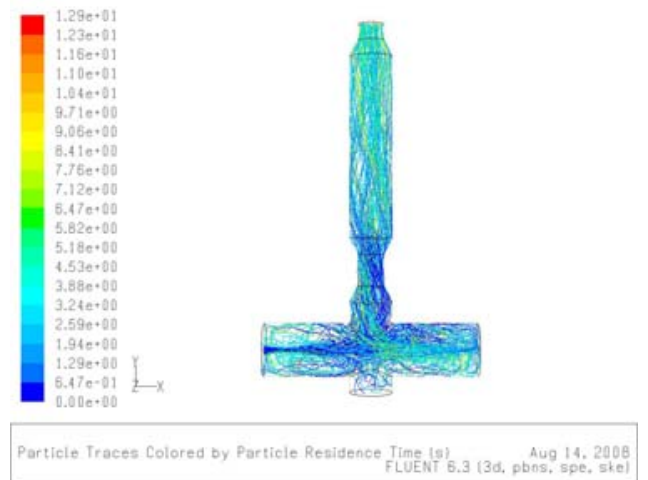

A.) SG2PS7 stage 1
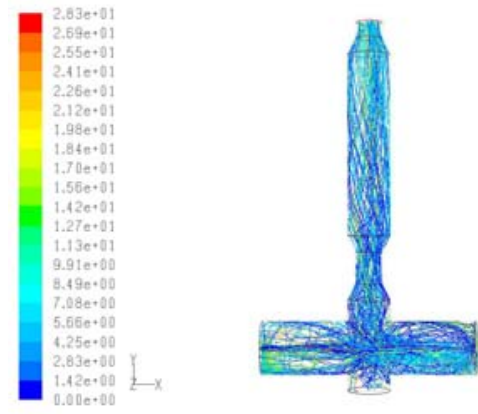

Particle Traces Colored by Particle Residence Time (s)
FLuENT 6,3 (3d, pbos, 14, spe, ske)

C.) SG2PS5 stage 1
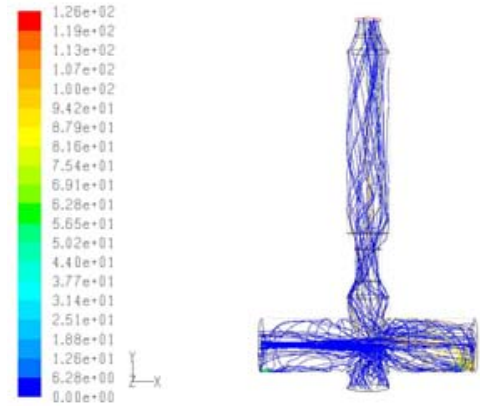

Particle Traces Colored by Particle Renidence Time is) FLUENT 6.3 (3d, pbos, spe, ste)

E.). SG2PS3 stage 1

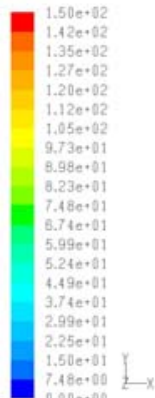

$480+002$

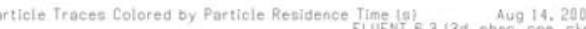

G.) SG2PS1 stage 1

Figure C.2. Case 1 particle tracks for Bailey coal for first stage injection of specific gravity cut \#2 (SG = 1.4), for particle size cuts \#7 $(50 \mu \mathrm{m})$ through \#1 $(800 \mu \mathrm{m})$. 


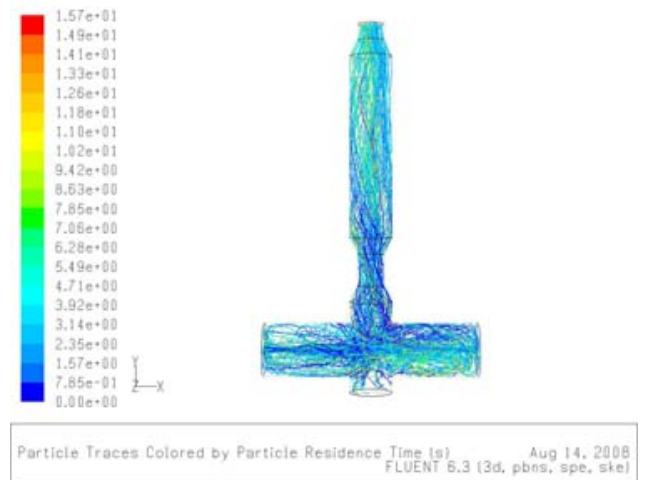

A.) SG3PS7 stage 1
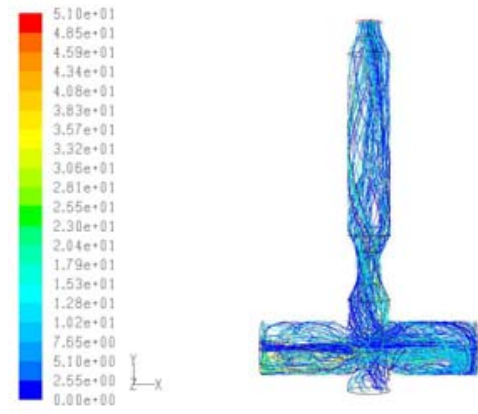

Particle Traces Colored by Particle Residence Time (s)
FLuENT 6,3 (3d, pbos, 14, spe, ske)

C.) SG3PS5 stage 1
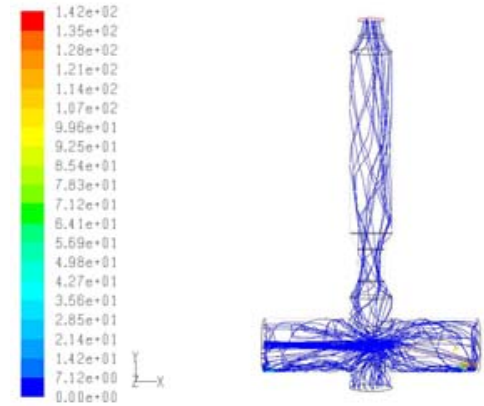

Particle Traces Colored by Particle Renidence Time (s)
FLUENT 6.3 (3d, pbos, spe, ste)

E.) SG3PS3 stage 1

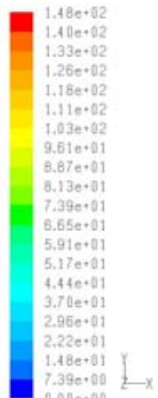

$7.390+002$

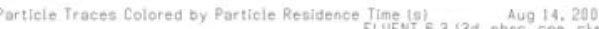

G.) SG3PS1 stage 1

Figure C.3. Case 1 particle tracks for Bailey coal for first stage injection of specific gravity cut \#3 ( $\mathrm{SG}=2.1)$, for particle size cuts \#7 $(50 \mu \mathrm{m})$ through \#1 $(800 \mu \mathrm{m})$. 


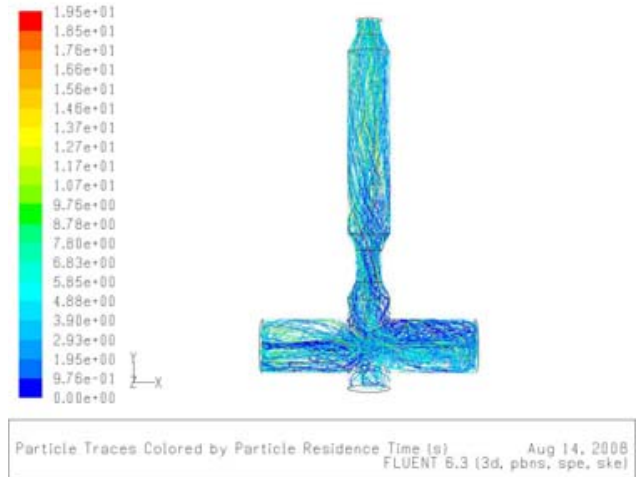

A.) SG4PS7 stage 1
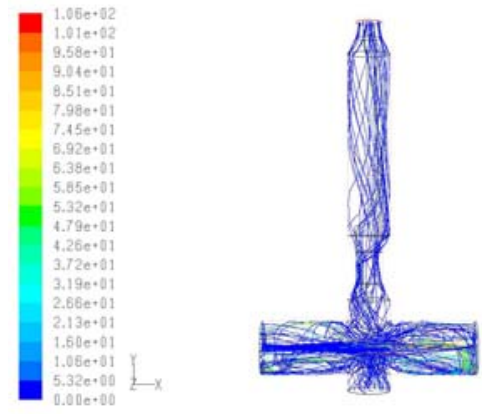

Particle Traces Colored by Particle Residence Time (s)
FLuENT 6,3 (3d, pbogs, 14, spe, ske

C.) SG4PS5 stage 1
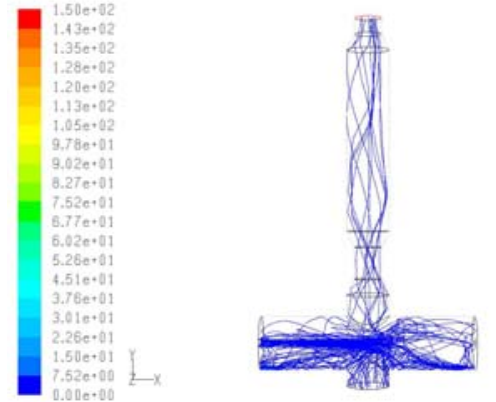

Particle Traces Colored by Particle Renidence Time Is) FLUENT 6.3 (3d, pbos, 14. 2008

E.) SG4PS3 stage 1

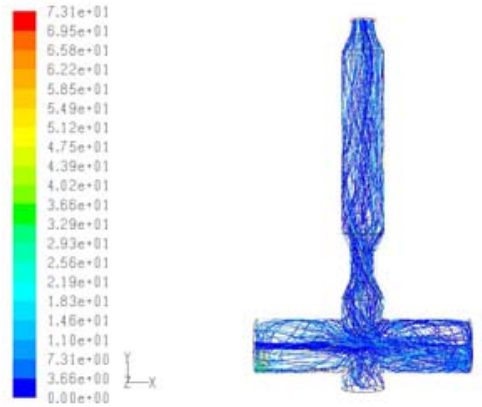

B.) SG4PS6 stage 1

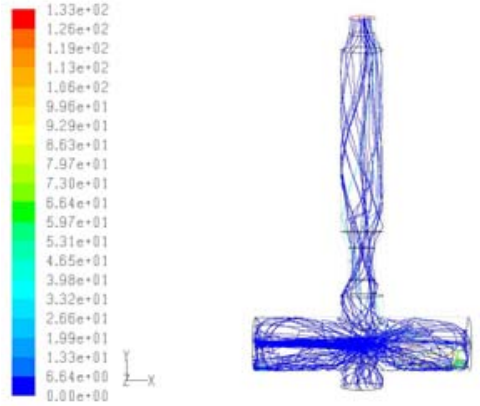

Particle Traces Colored by Particle Renidence Time t9) FLUENT 6.3 (3d, pbns, spe, ske)

D.) SG4PS4 stage 1

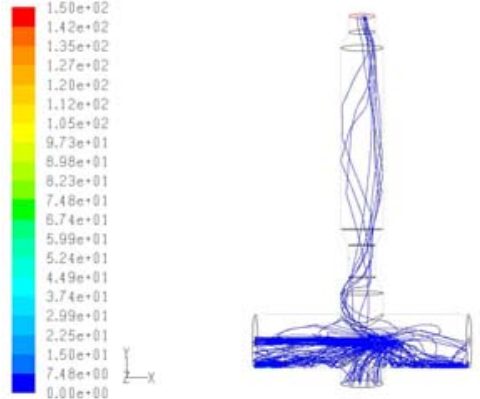

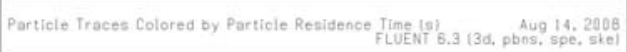

F.) SG4PS2 stage 1

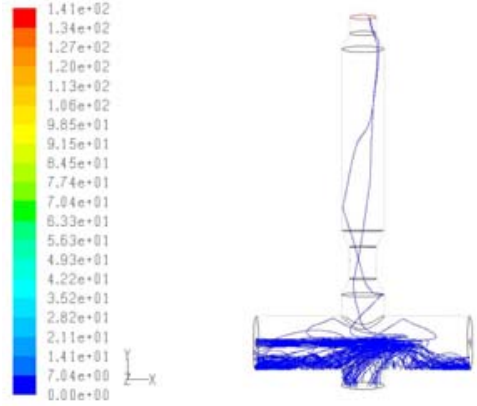

G.) SG4PS1 stage 1

Figure C.4. Case 1 particle tracks for Bailey coal for first stage injection of specific gravity cut \#4 (SG =3.3), for particle size cuts \#7 $(50 \mu \mathrm{m})$ through \#1 $(800 \mu \mathrm{m})$. 


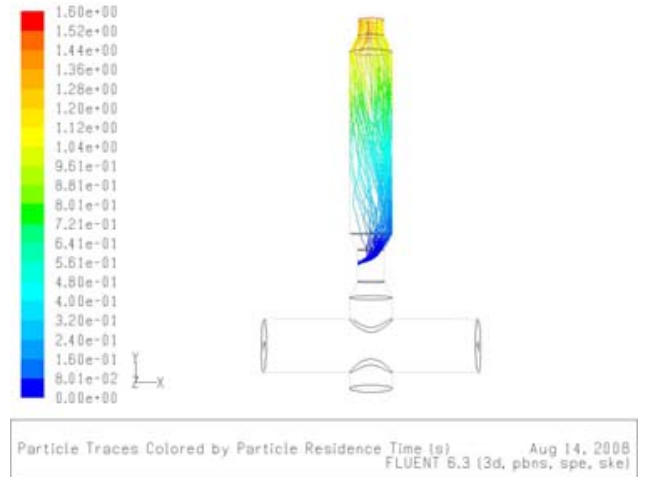

A.) SG1PS7 stage 2

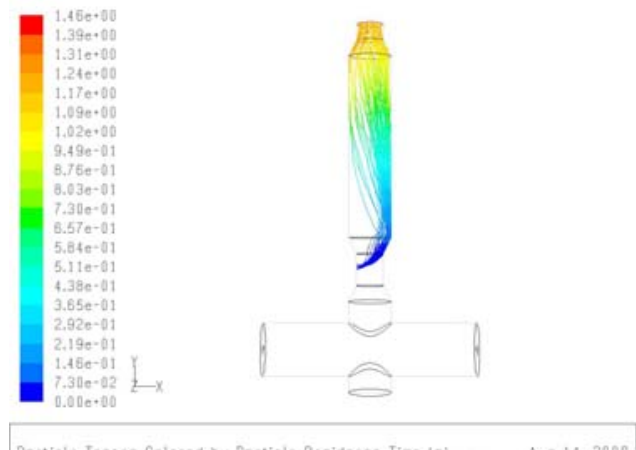

C.) SG1PS5 stage 2

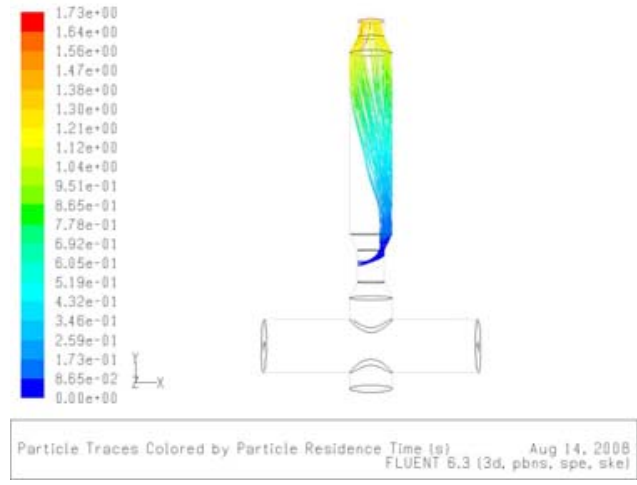

E.) SG1PS3 stage 2

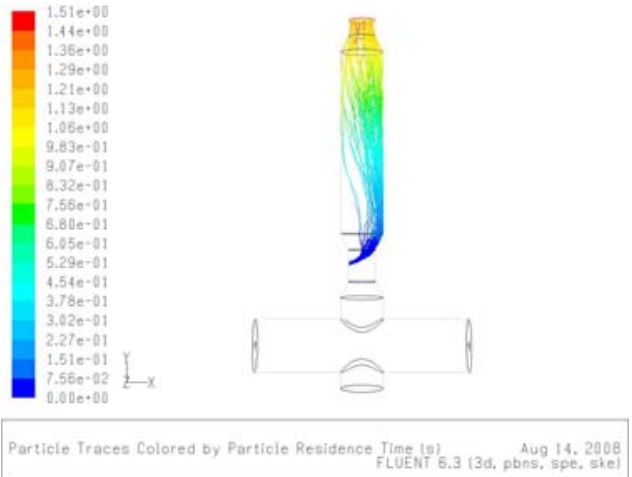

B.) SG1PS6 stage 2

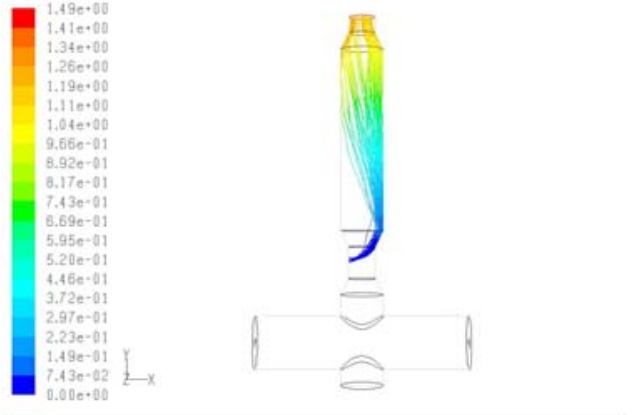

Particle Traces Colored by Particle Renidence Time, (9) FLUEN 6.3 (3d, pbing, 14, 2008

D.) SG1PS4 stage 2

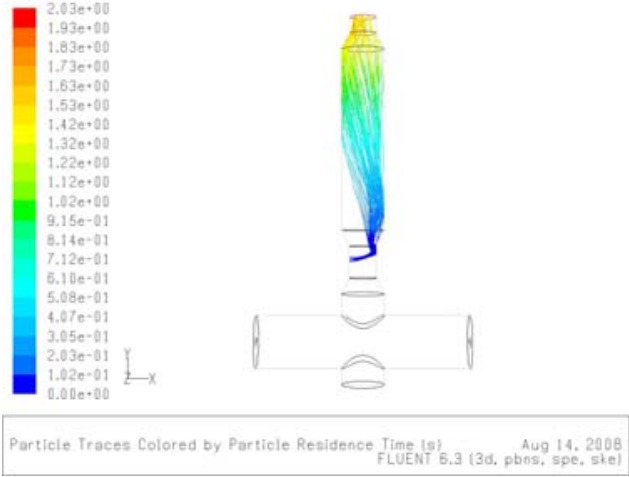

F.) SG1PS2 stage 2

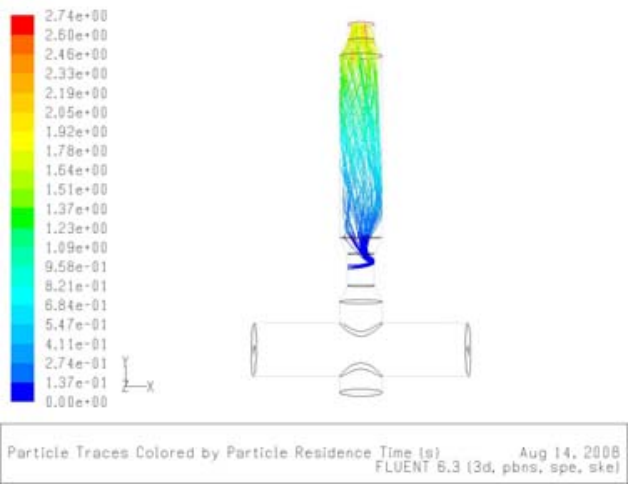

G.) SG1PS1 stage 2

Figure C.5. Case 1 particle tracks for Bailey coal for second stage injection of specific gravity cut \#1 $(\mathrm{SG}=1.2)$, for particle size cuts \#7 $(50 \mu \mathrm{m})$ through \#1 $(800 \mu \mathrm{m})$. 


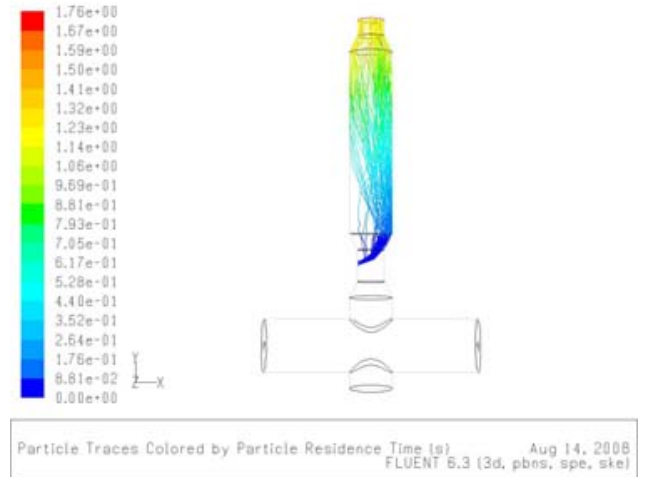

A.) SG2PS7 stage 2

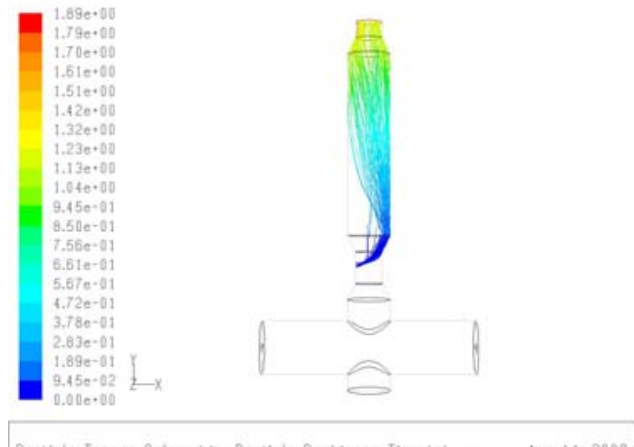

C.) SG2PS5 stage 2

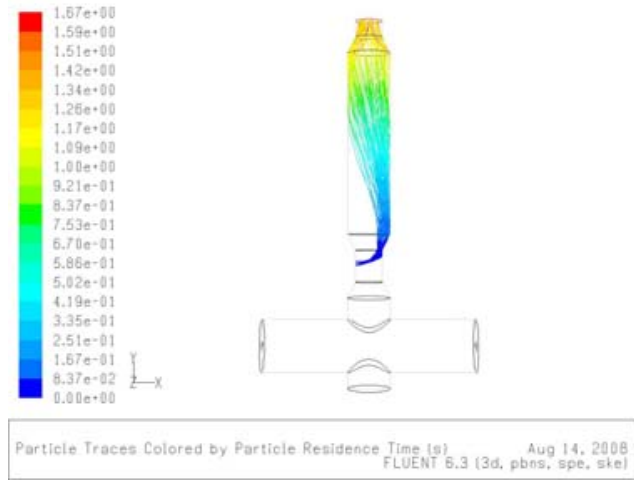

E.) SG2PS3 stage 2

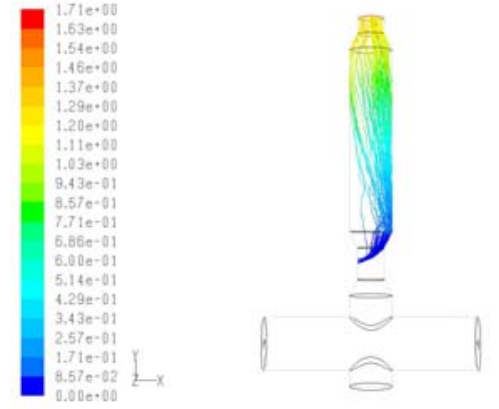

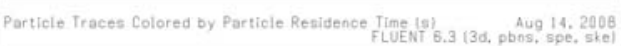

B.) SG2PS6 stage 2
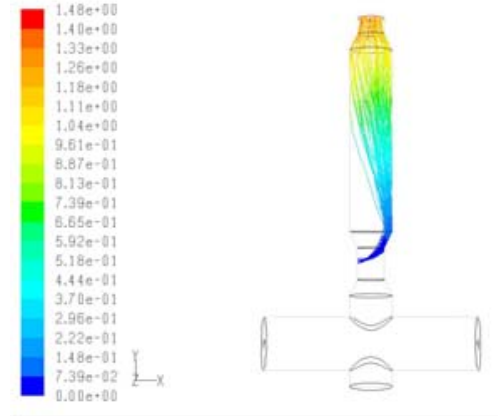

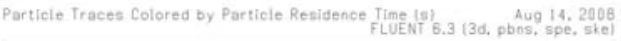

D.) SG2PS4 stage 2

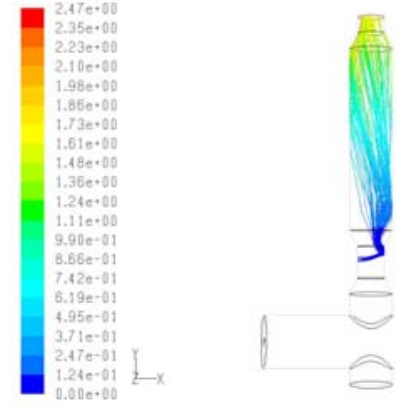

Particle Traces Colored by Particle Rezidence Time, (s)
FLUENT 6.3 (3d, pbos, spe, ske)

F.) SG2PS2 stage 2
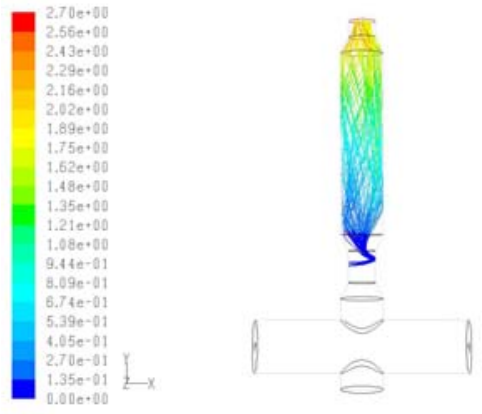

Particle Traces Colored by Particie Residence Time Is) FLUET 6.3 (3d, pbos, spe, ske)

G.) SG2PS1 stage 2

Figure C.6. Case 1 particle tracks for Bailey coal for second stage injection of specific gravity cut \#2 ( $\mathrm{SG}=1.4)$, for particle size cuts \#7 $(50 \mu \mathrm{m})$ through \#1 $(800 \mu \mathrm{m})$. 


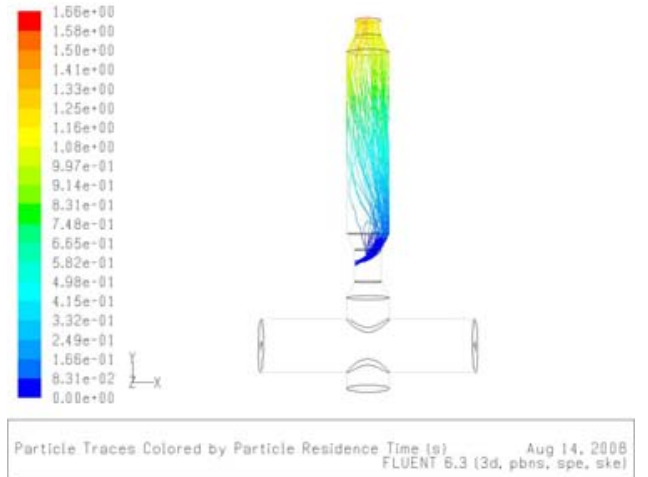

A.) SG3PS7 stage 2

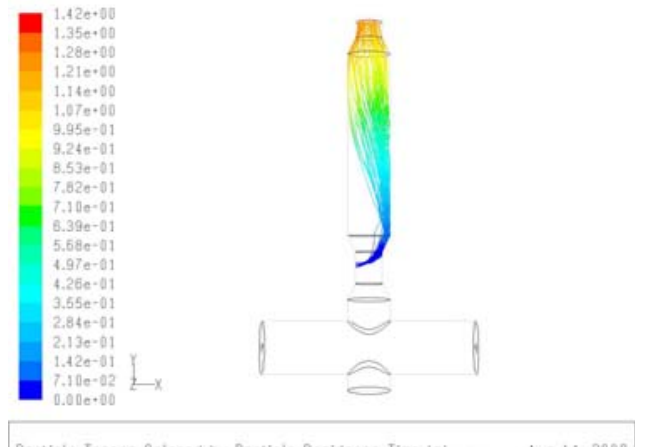

C.) SG3PS5 stage 2

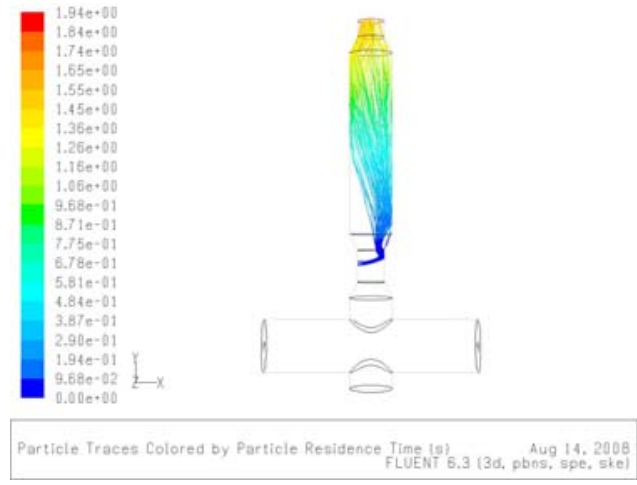

E.) SG3PS3 stage 2

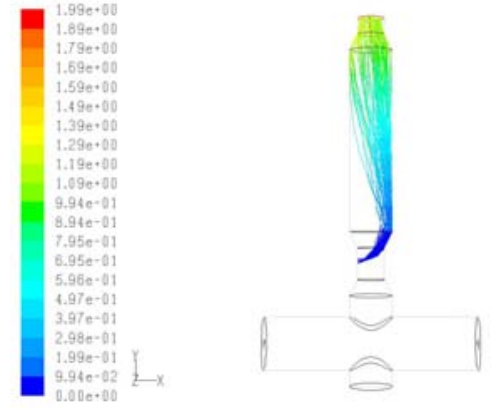

Particle Traces Colored by Particle Residence Time (s) FLENT' B.3 (3d, pbos, spe, ske

B.) SG3PS6 stage 2
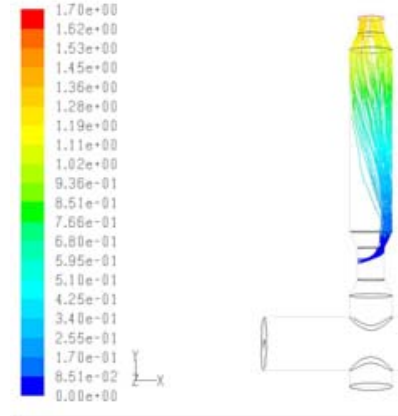

Aug 14, 2008
Particle Traces Colored by Particle Residence Time (9)
FLUENT' 6.3 (3d, pbns, spe., skel

D.) SG3PS4 stage 2

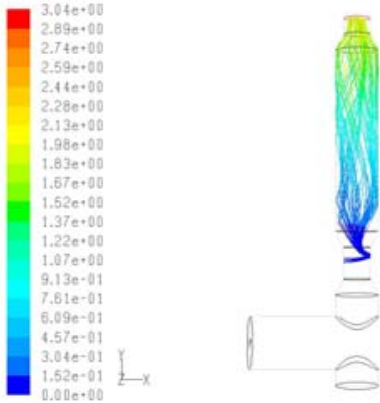

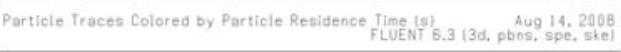

F.) SG3PS2 stage 2
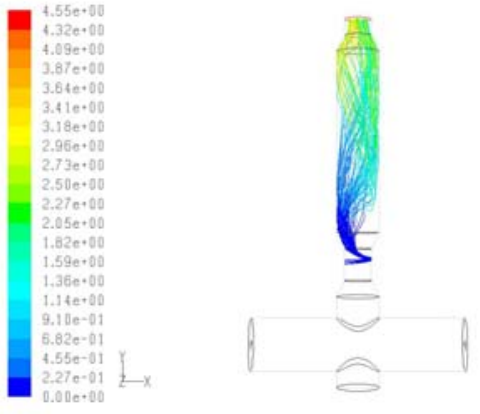

Particle Traces Colored by Particie Residence Time Is) FLUET 6.3 (3d, phos, spe, ske)

G.) SG3PS1 stage 2

Figure C.7. Case 1 particle tracks for Bailey coal for second stage injection of specific gravity cut \#3 $(\mathrm{SG}=2.1)$, for particle size cuts \#7 $(50 \mu \mathrm{m})$ through \#1 $(800 \mu \mathrm{m})$. 


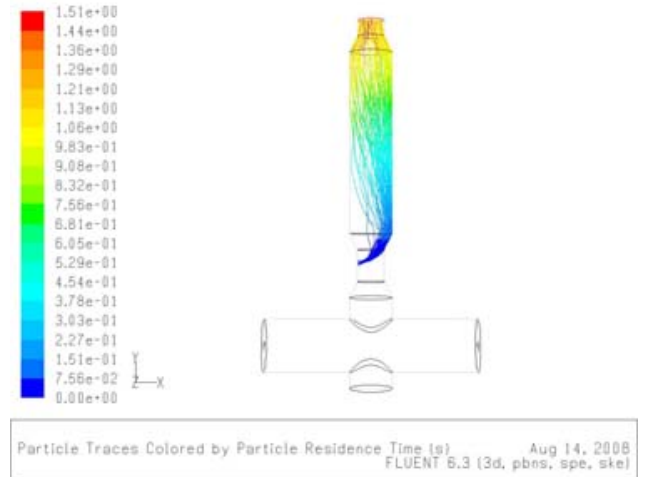

A.) SG4PS7 stage 2

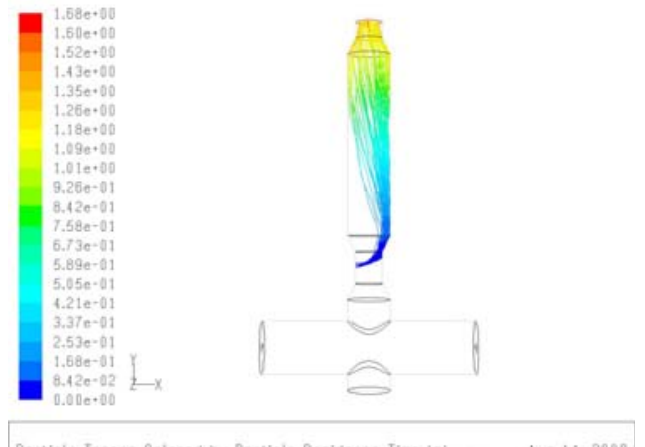

C.) SG4PS5 stage 2

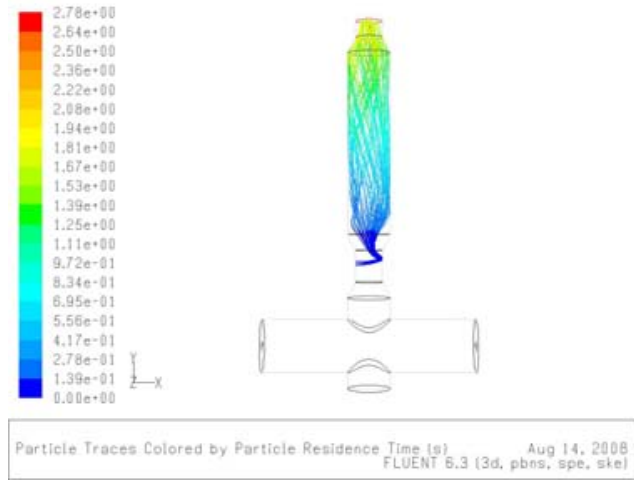

E.) SG4PS3 stage 2

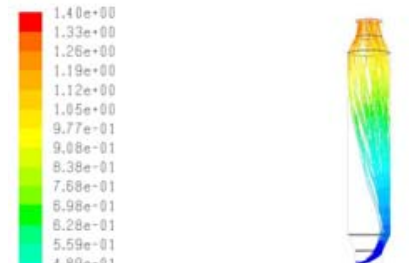

$4.19 \mathrm{e}-0$.

$2,79 e^{-01}$

$2.090-01$
$1.400-01$

$6.980-02 \quad 2$

Particle Traces Colored by Particle Residence Time is) FiUET 6.3 13d, pbns, 14, 2008

B.) SG4PS6 stage 2
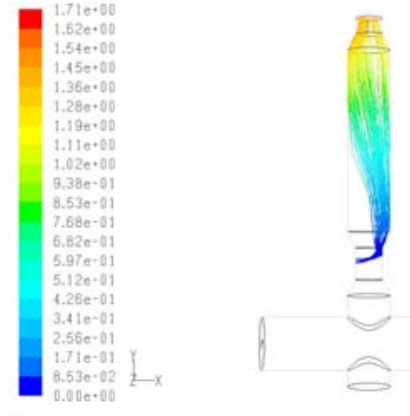

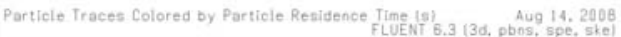

D.) SG4PS4 stage 2

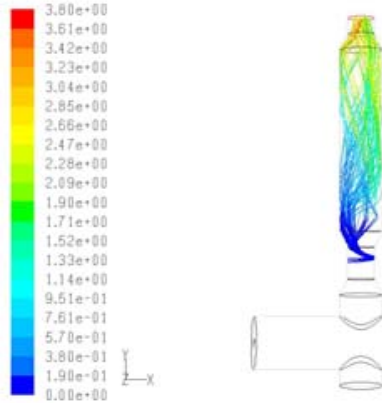

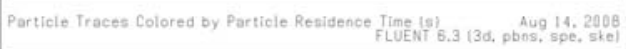

F.) SG4PS2 stage 2
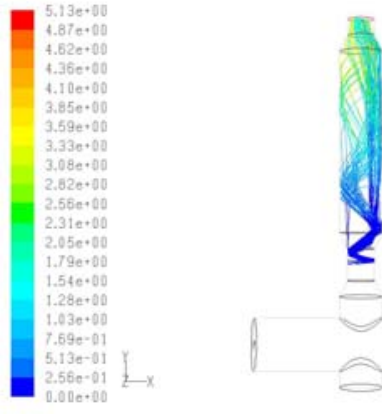

G.) SG4PS1 stage 2

Figure C.8. Case 1 particle tracks for Bailey coal for second stage injection of specific gravity cut \#4 $(\mathrm{SG}=3.3)$, for particle size cuts \#7 $(50 \mu \mathrm{m})$ through \#1 $(800 \mu \mathrm{m})$. 


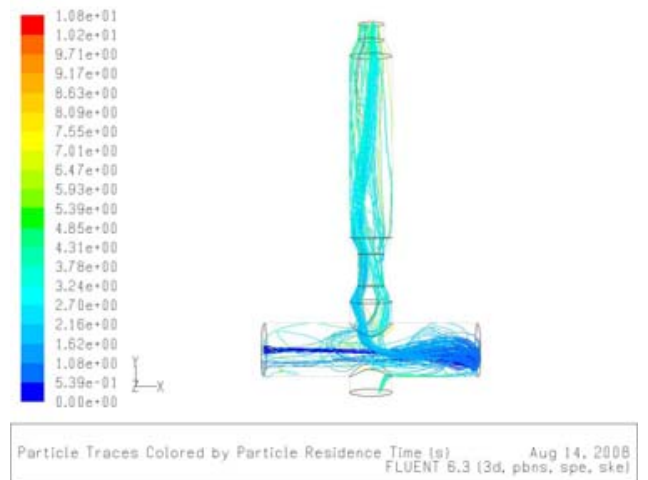

A.) SG1PS7 stage 1

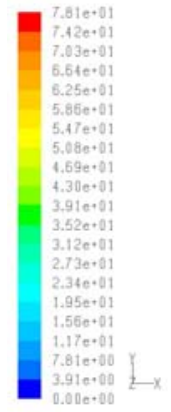

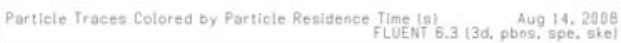

C.) SG1PS5 stage 1
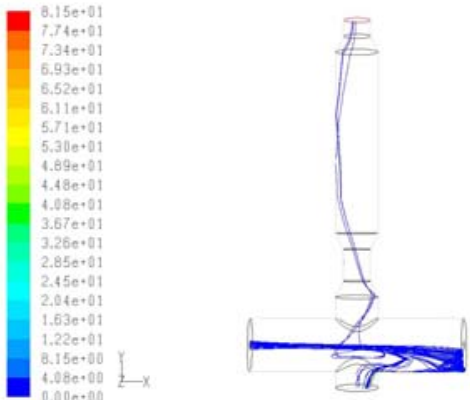

Particle Traces Colored by Particle Renidence Time Is) FLUENT 6.3 (3d, pbos, 14. 2008

E.) SG1PS3 stage 1

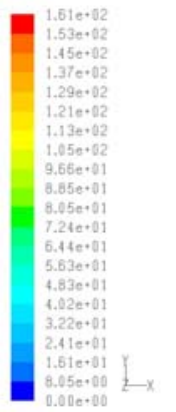

$8.050+00$

Particle Traces Colored by Particie Residence Time (s) a. Aug 14, 2008 f

G.) SG1PS1 stage 1

Figure C.9. Case 2 particle tracks for Bailey coal for first stage injection of specific gravity cut \#1 $(\mathrm{SG}=1.2)$, for particle size cuts \#7 $(50 \mu \mathrm{m})$ through \#1 $(800 \mu \mathrm{m})$. 


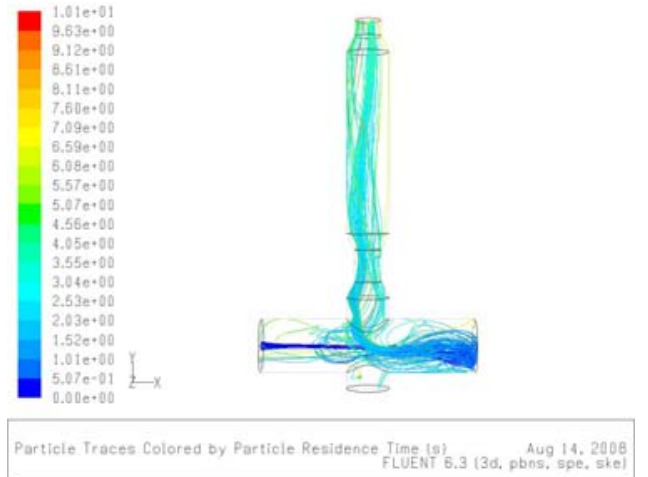

A.) SG2PS7 stage 1

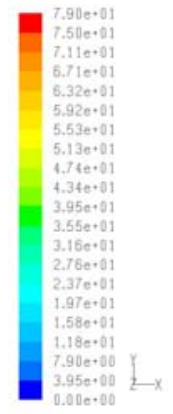

Particle Traces Colored by Particle Residence Time (s)
FLUENT 6,3 (3d, pbng, 14, 2008 , spe, ste)

C.) SG2PS5 stage 1
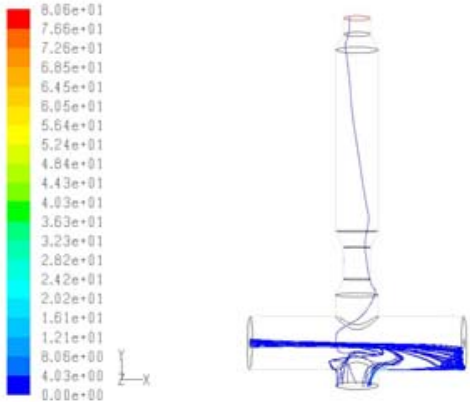

Particle Traces Colored by Particle Renidence Time, Is) FLUEN 6.3 (3d, pbos, 14pe, site)

E.). SG2PS3 stage 1

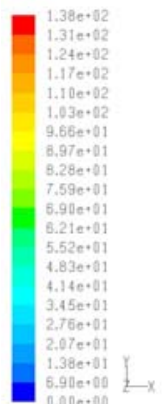

$3.900+002$

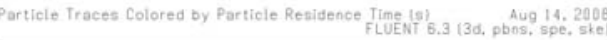

G.) SG2PS1 stage 1

Figure C.10. Case 2 particle tracks for Bailey coal for first stage injection of specific gravity cut \#2 (SG = 1.4), for particle size cuts \#7 $(50 \mu \mathrm{m})$ through \#1 $(800 \mu \mathrm{m})$. 


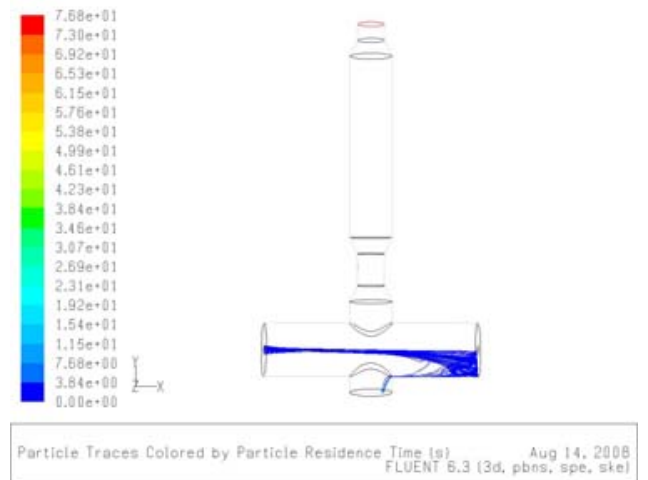

A.) SG3PS7 stage 1

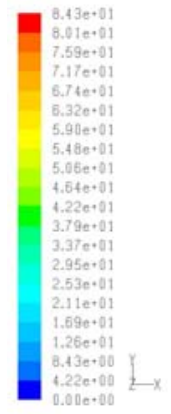

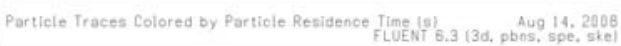

C.) SG3PS5 stage 1
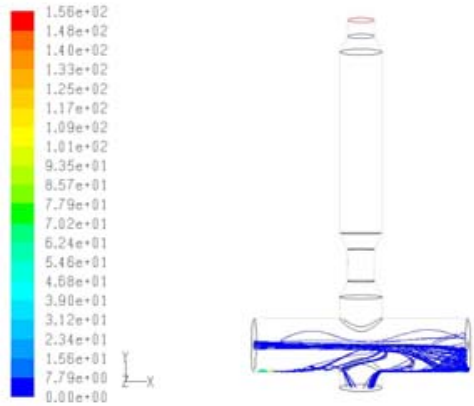

Particle Traces Colored by Particle Renidence Time is) FLUEN' 6.3 (3d, pbos, spe, ske)

E.) SG3PS3 stage 1

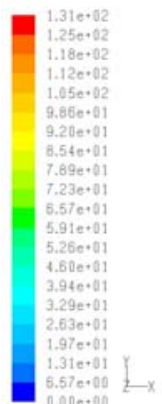

$5.570+00$

Particle Traces Colored by Particle Residence Time (s) FLENT 6.3 (3d, pbos, spe, ske

G.) SG3PS1 stage 1

Figure C.11. Case 2 particle tracks for Bailey coal for first stage injection of specific gravity cut \#3 $(\mathrm{SG}=2.1)$, for particle size cuts \#7 $(50 \mu \mathrm{m})$ through \#1 $(800 \mu \mathrm{m})$. 


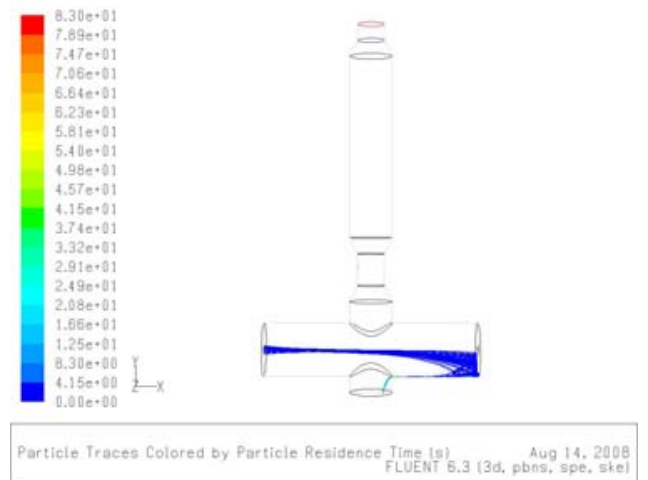

A.) SG4PS7 stage 1

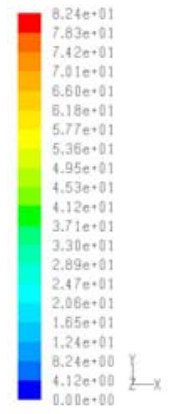

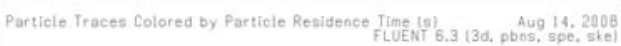

C.) SG4PS5 stage 1
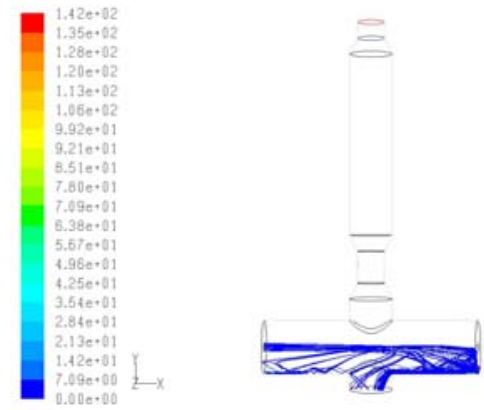

Particle Traces Colored by Particle Renidence Time (s)
FLUENT 6.3 (3d, pbos, spe, ske)

E.) SG4PS3 stage 1

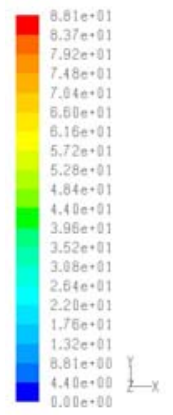

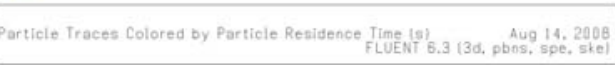

G.) SG4PS1 stage 1

Figure C.12. Case 2 particle tracks for Bailey coal for first stage injection of specific gravity cut \#4 $(\mathrm{SG}=3.3)$, for particle size cuts $\# 7(50 \mu \mathrm{m})$ through \#1 $(800 \mu \mathrm{m})$. 


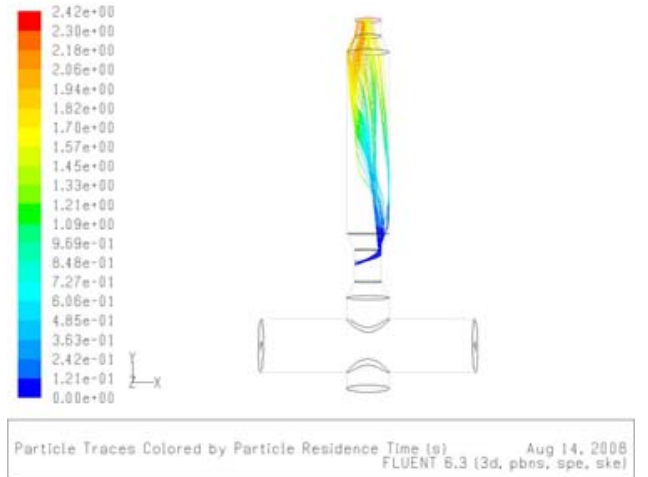

A.) SG1PS7 stage 2

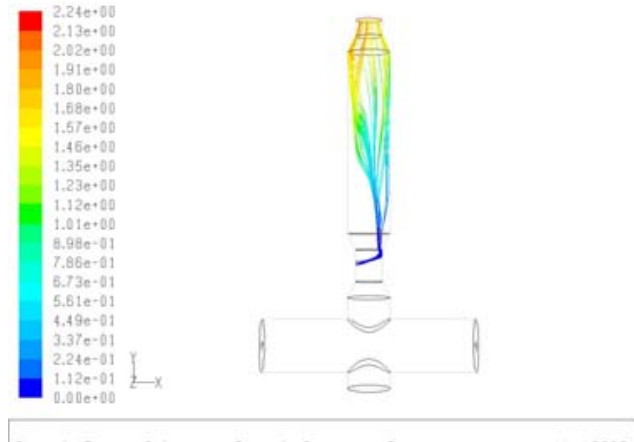

C.) SG1PS5 stage 2

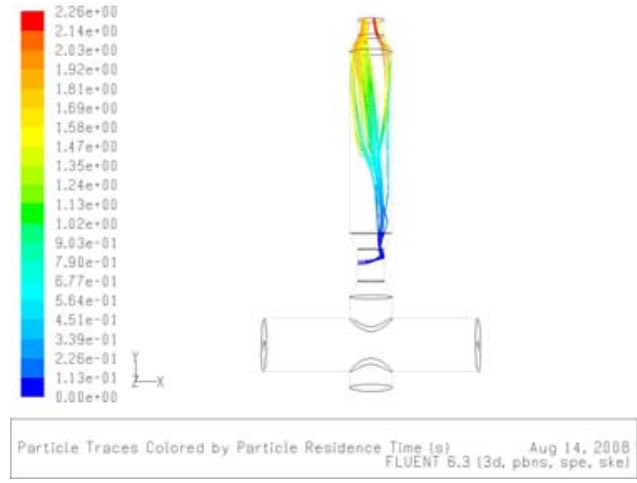

E.) SG1PS3 stage 2

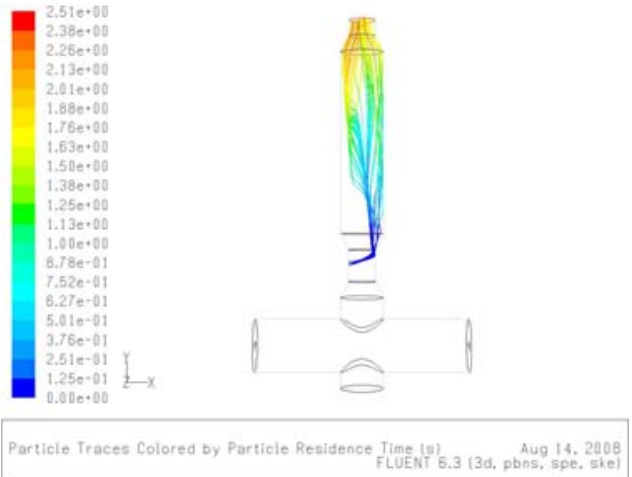

B.) SG1PS6 stage 2

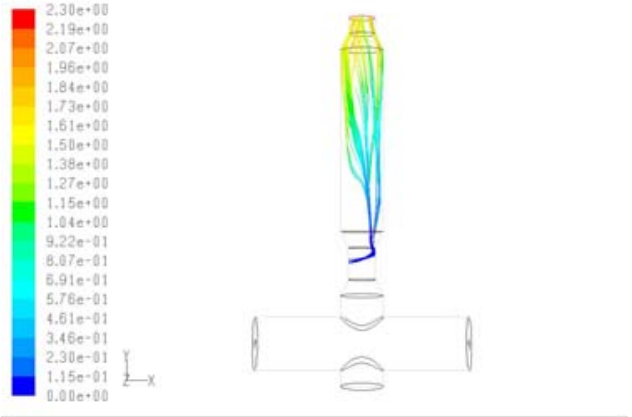

Particle Traces Colored by Particle Renidence Time t9) FLUENT 6.3 (3d, pbos, 14, 2908 spe, ske)

D.) SG1PS4 stage 2

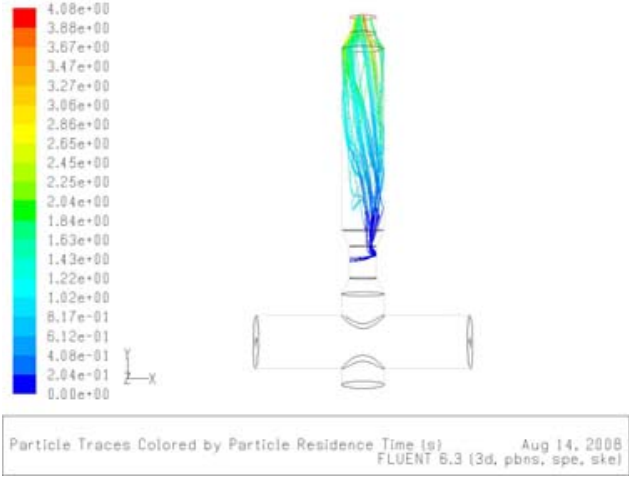

F.) SG1PS2 stage 2
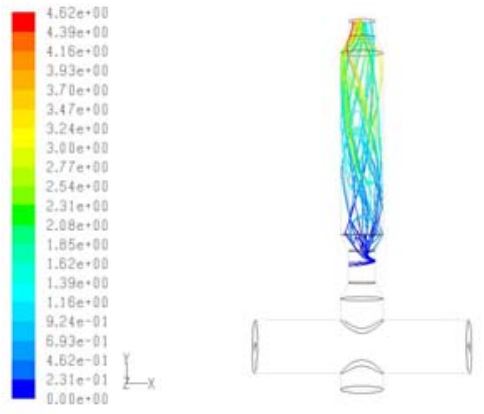

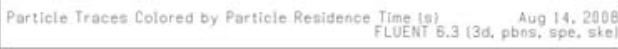

SG1PS1 stage 2

Figure C.13. Case 2 particle tracks for Bailey coal for second stage injection of specific gravity cut \#1 $(\mathrm{SG}=1.2)$, for particle size cuts \#7 $(50 \mu \mathrm{m})$ through \#1 $(800 \mu \mathrm{m})$. 


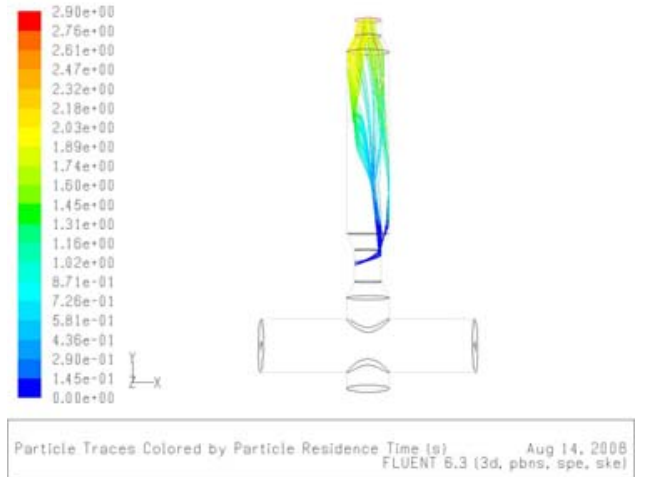

A.) SG2PS7 stage 2

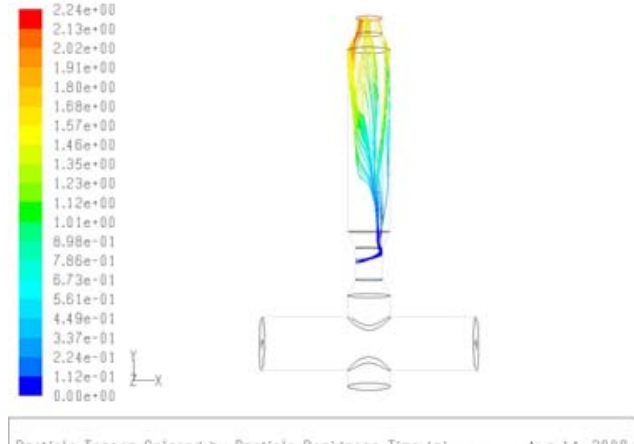

C.) SG2PS5 stage 2

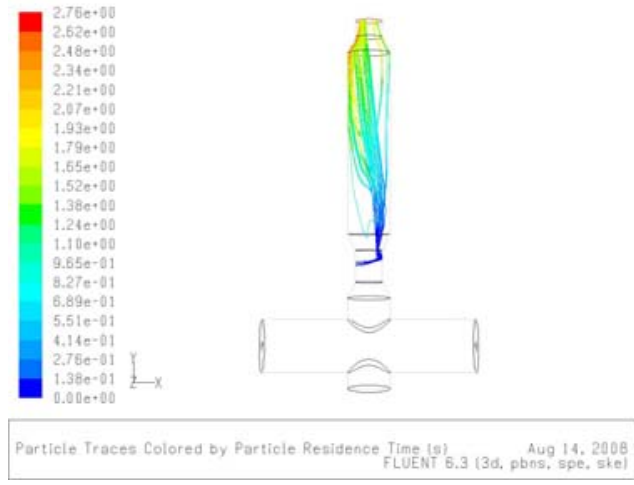

E.) SG2PS3 stage 2
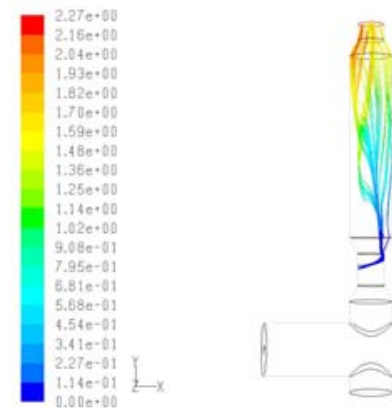

Particle Traces Colored by Particle Residence Time (5) 5 . Aug 14, 2008

B.) SG2PS6 stage 2
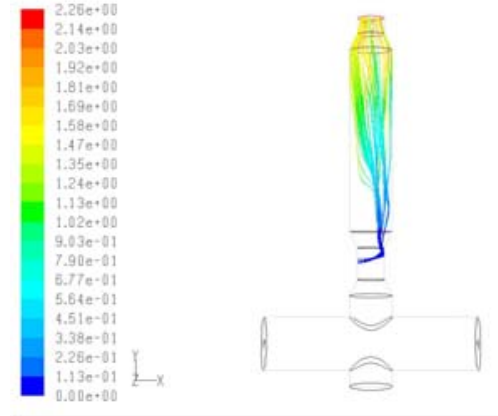

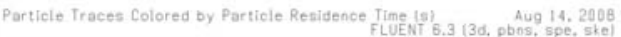

D.) SG2PS4 stage 2

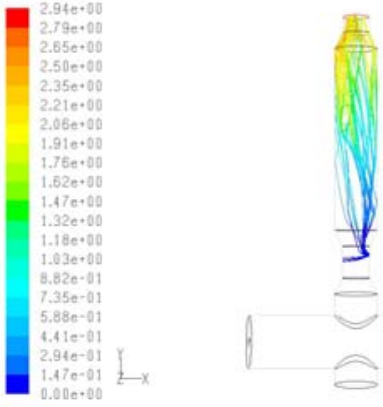

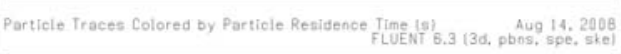

F.) SG2PS2 stage 2
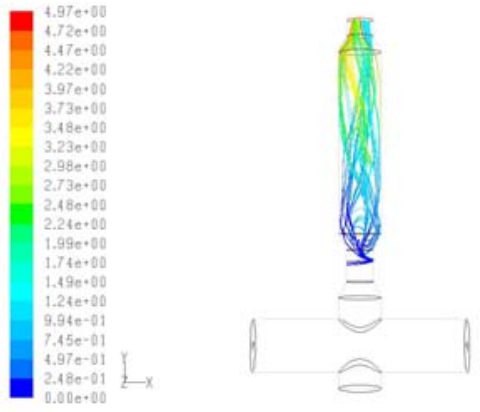

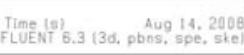

G.) SG2PS1 stage 2

Figure C.14. Case 2 particle tracks for Bailey coal for second stage injection of specific gravity cut \#2 $(\mathrm{SG}=1.4)$, for particle size cuts \#7 $(50 \mu \mathrm{m})$ through \#1 $(800 \mu \mathrm{m})$. 


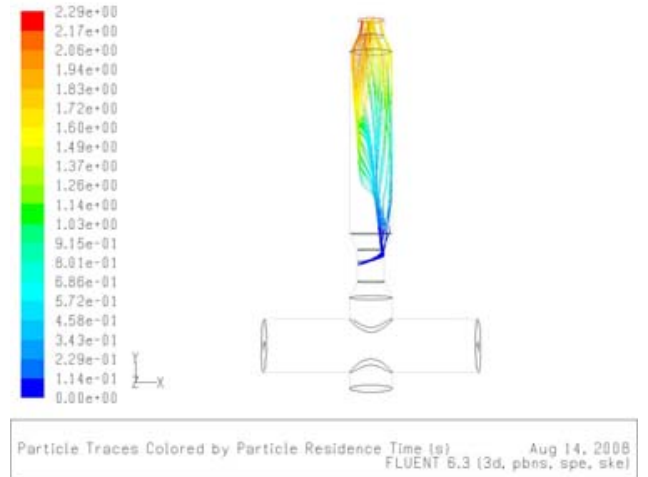

A.) SG3PS7 stage 2

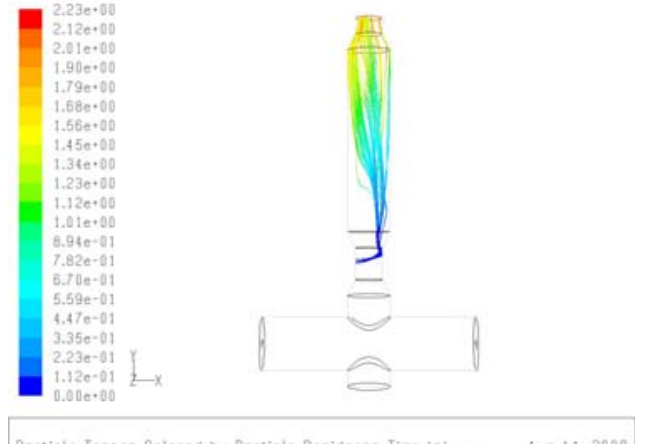

C.) SG3PS5 stage 2

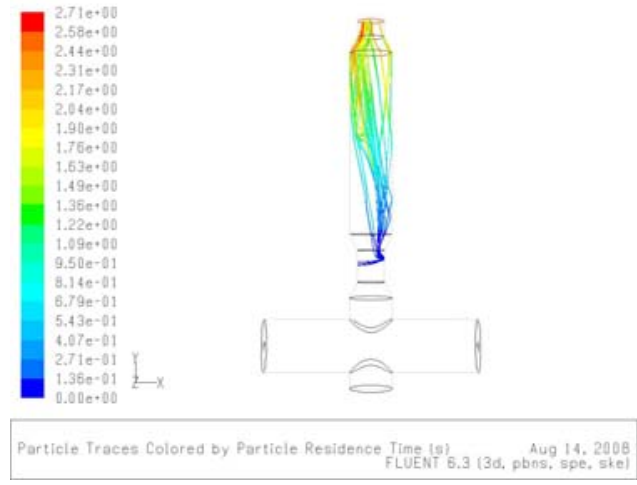

E.) SG3PS3 stage 2

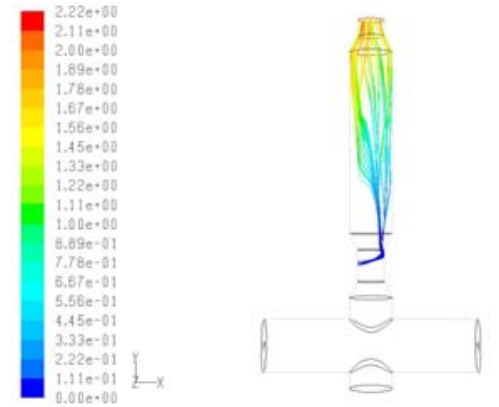

Particle Traces Colored by Particle Residence Time (s) FLENT' B.3 (3d, pbos, spe, ske

B.) SG3PS6 stage 2
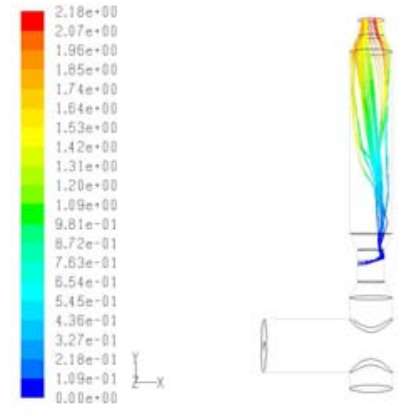

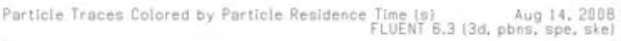

D.) SG3PS4 stage 2

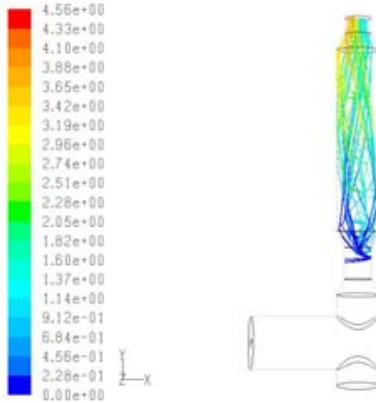

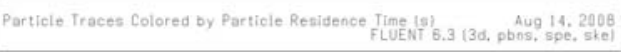

F.) SG3PS2 stage 2
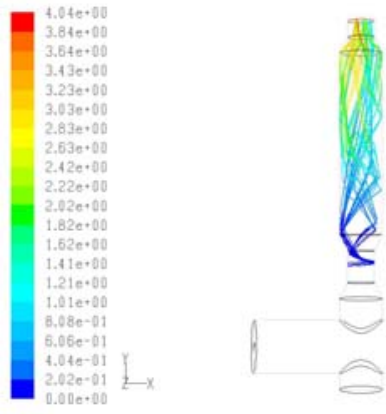

Particle Traces Colored by Particie Residence Time (5) Aug 14. 2008

G.) SG3PS1 stage 2

Figure C.15. Case 2 particle tracks for Bailey coal for second stage injection of specific gravity cut \#3 $(\mathrm{SG}=2.1)$, for particle size cuts \#7 $(50 \mu \mathrm{m})$ through \#1 $(800 \mu \mathrm{m})$. 


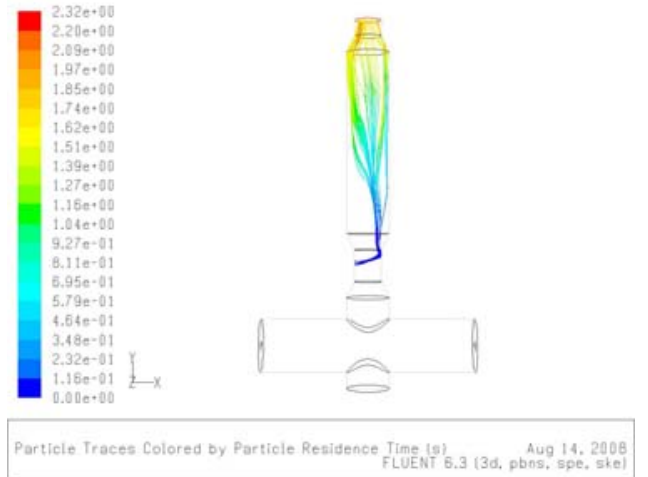

A.) SG4PS7 stage 2

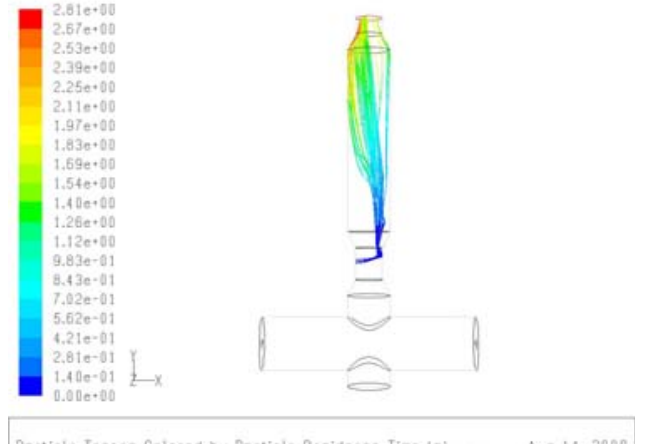

C.) SG4PS5 stage 2

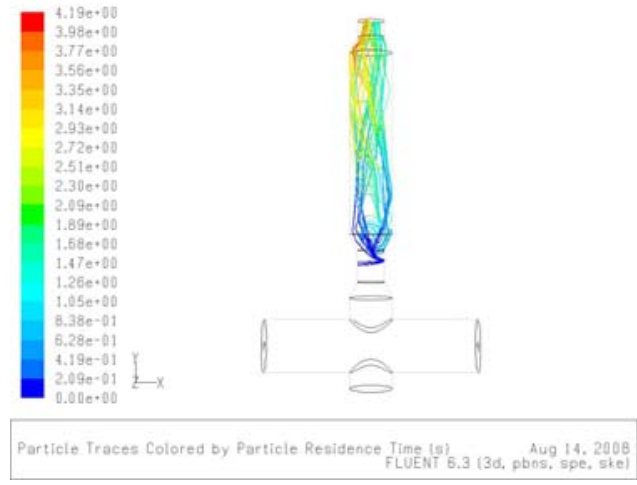

E.) SG4PS3 stage 2
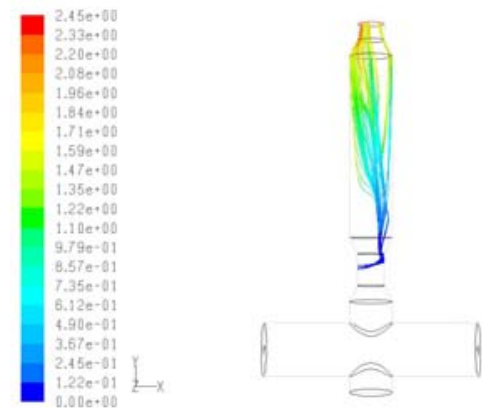

Particle Traces Colored by Particle Residence Time (5) 1 . Aug 14, 2008

B.) SG4PS6 stage 2
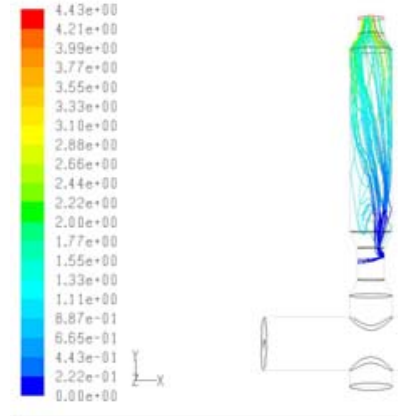

Aug 14, 2008
Particle Traces Colored by Particle Residence Time (9)
FLUENT' 6.3 (3d, pbns, spe., skel

D.) SG4PS4 stage 2

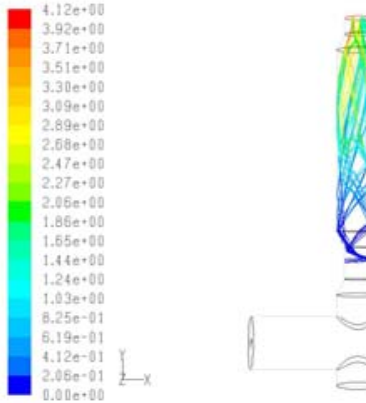

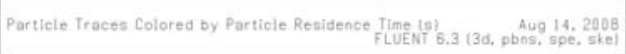

F.) SG4PS2 stage 2
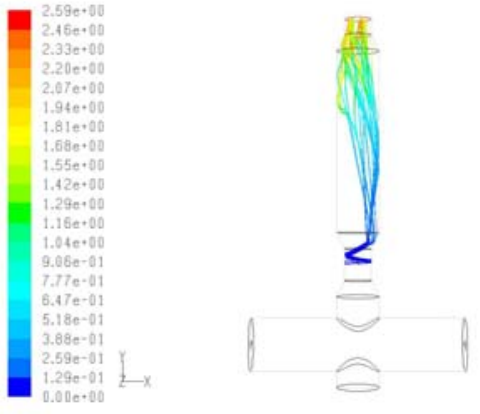

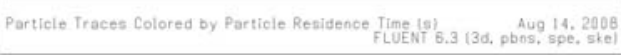

G.) SG4PS1 stage 2

Figure C.16. Case 2 particle tracks for Bailey coal for second stage injection of specific gravity cut \#4 $(\mathrm{SG}=3.3)$, for particle size cuts \#7 $(50 \mu \mathrm{m})$ through \#1 $(800 \mu \mathrm{m})$. 


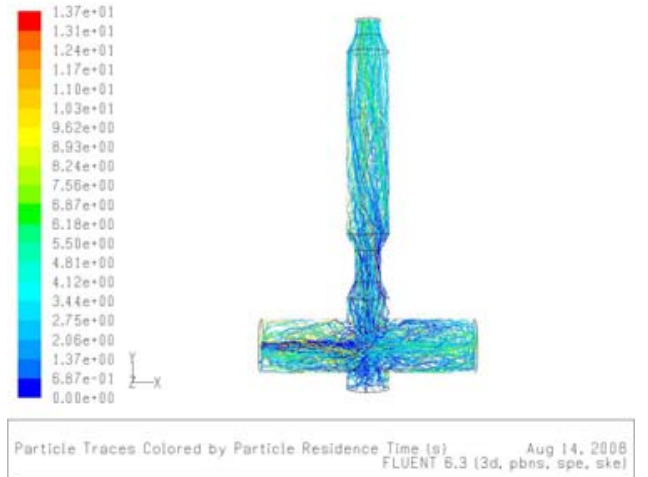

A.) SG1PS7 stage 1
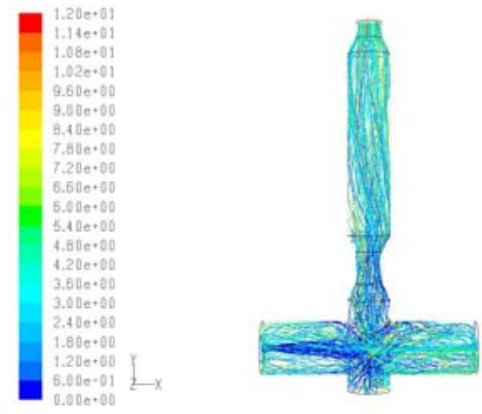

Particle Traces Colored by Particle Residence Time (s)
FLuENT 6,3 (3d, pbos, 14, spe, ske)

C.) SG1PS5 stage 1
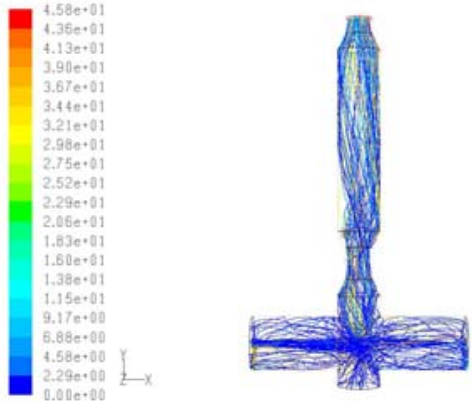

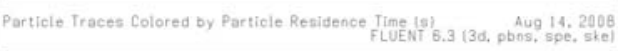

E.) SG1PS3 stage 1

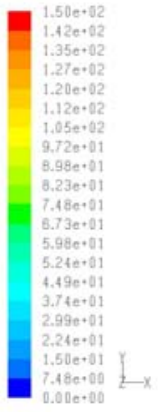

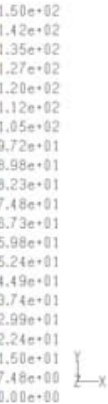

Particle Traces Colored by Particie Residence Time (5)

G.) SG1PS1 stage 1

Figure C.17. Case 3 particle tracks for Bailey coal for first stage injection of specific gravity cut \#1 $(\mathrm{SG}=1.2)$, for particle size cuts \#7 $(50 \mu \mathrm{m})$ through \#1 $(800 \mu \mathrm{m})$. 


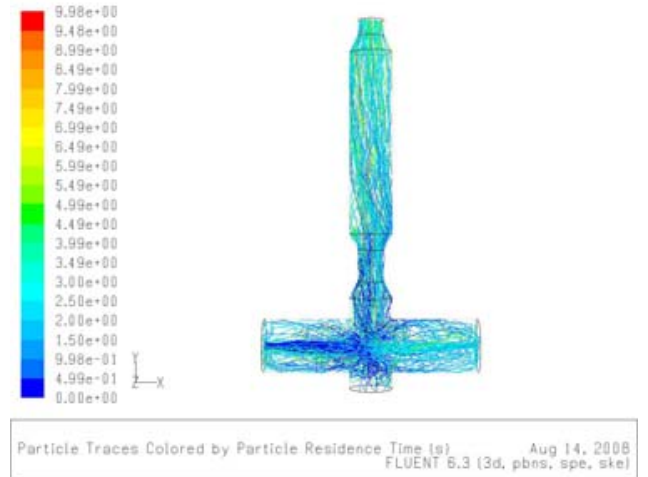

A.) SG2PS7 stage 1
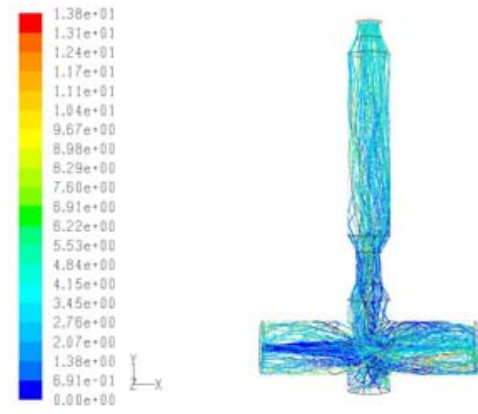

Particle Traces Colored by Particle Residence Time (s)
FLuENT 6,3 (3d, pbos, 14, spe, ske)

C.) SG2PS5 stage 1
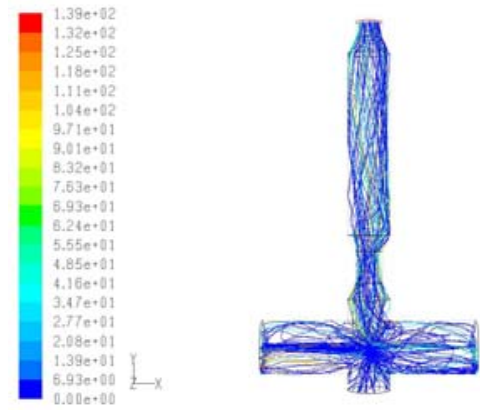

Particle Traces Colored by Particle Renidence Time Is) FLUEN 6.3 (3d, pbos, spe, ste)

E.). SG2PS3 stage 1

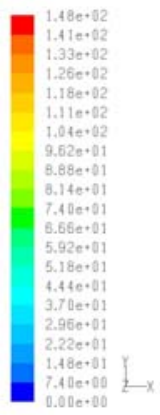

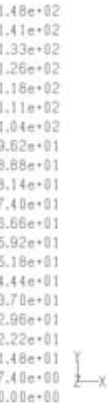

Particle Traces Colored by Particie Residence Time (5)

G.) SG2PS1 stage 1

Figure C.18. Case 3 particle tracks for Bailey coal for first stage injection of specific gravity cut \#2 (SG = 1.4), for particle size cuts \#7 $(50 \mu \mathrm{m})$ through \#1 $(800 \mu \mathrm{m})$. 


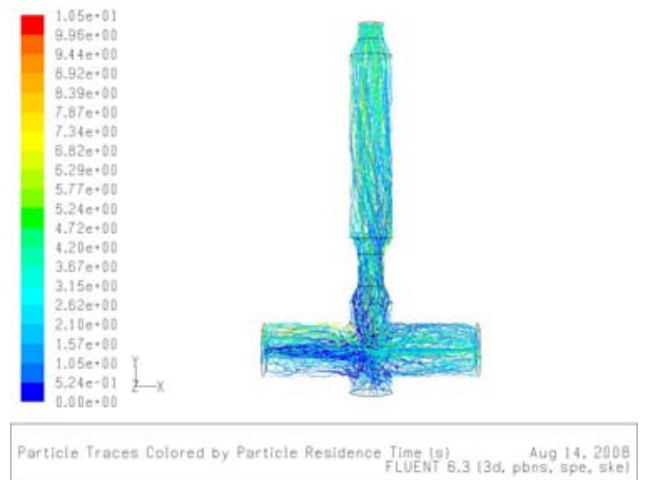

A.) SG3PS7 stage 1
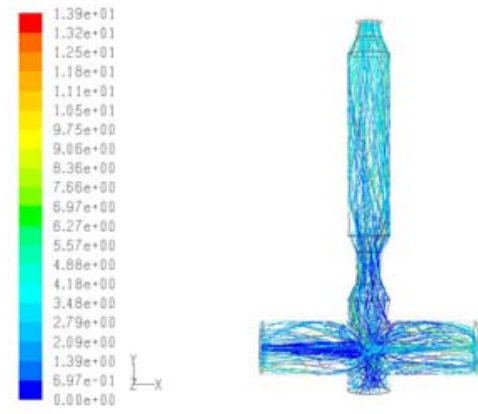

Particle Traces Colored by Particle Residence Time (s)
FLuENT 6,3 (3d, pbos, 14, spe, ske)

C.) SG3PS5 stage 1
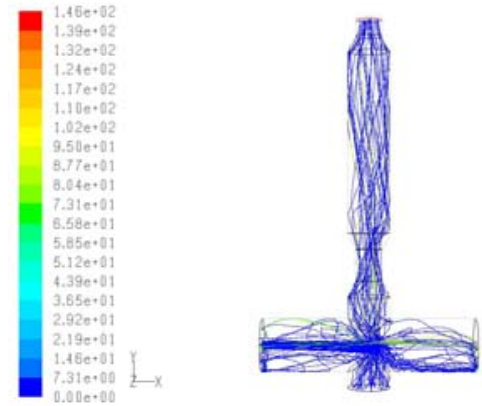

Particle Traces Colored by Particle Renidence Time Is) FLuENT' 6.3 (3d, pbos, spe, ste)

E.) SG3PS3 stage 1

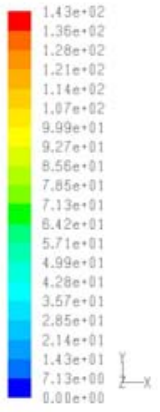

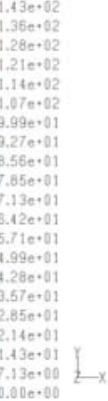

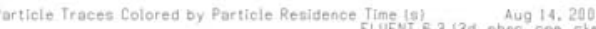

G.) SG3PS1 stage 1

Figure C.19. Case 3 particle tracks for Bailey coal for first stage injection of specific gravity cut \#3 $(\mathrm{SG}=2.1)$, for particle size cuts \#7 $(50 \mu \mathrm{m})$ through \#1 $(800 \mu \mathrm{m})$. 


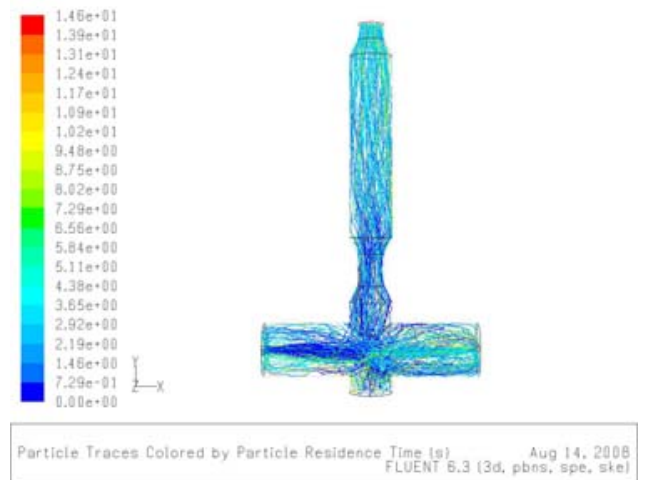

A.) SG4PS7 stage 1
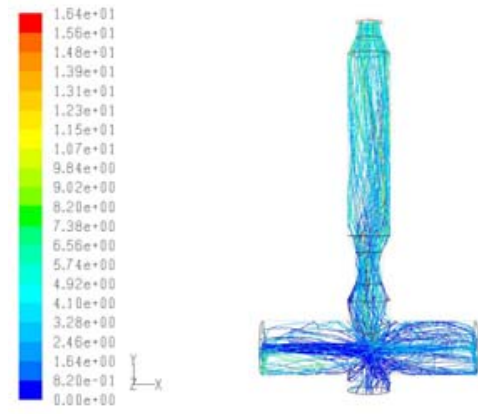

Particle Traces Colored by Particle Residence Time (s)
FLuENT 6,3 (3d, pbos, 14, spe, ske)

C.) SG4PS5 stage 1
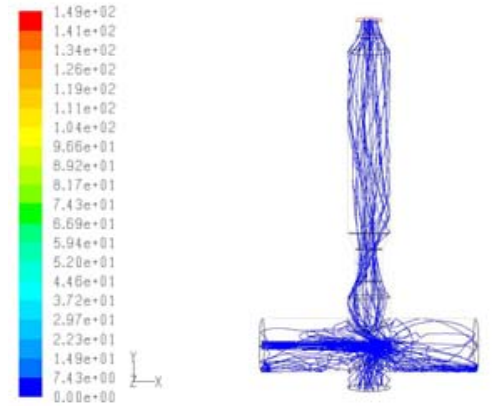

Particle Traces Colored by Particle Residence Time Is) FLUENT 6.3 (3d, pbos, 14, 2008 , ske)

E.) SG4PS3 stage 1

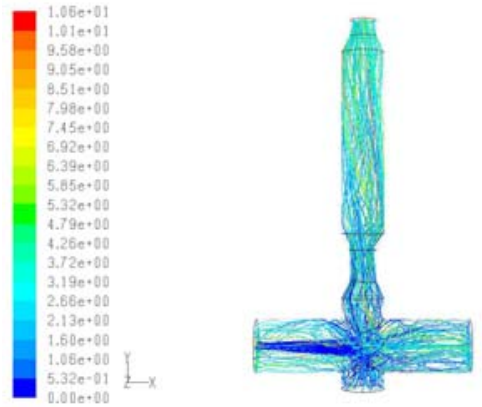

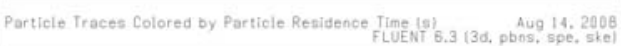

B.) SG4PS6 stage 1

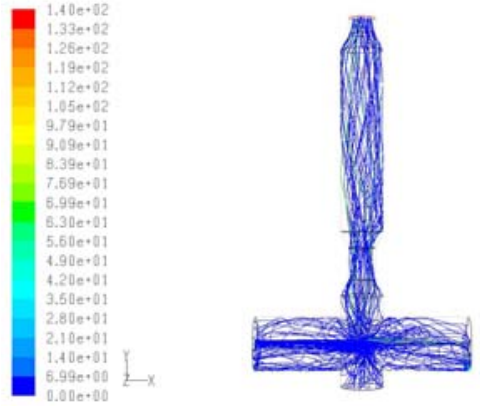

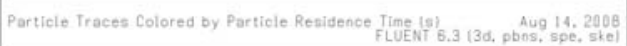

D.) SG4PS4 stage 1

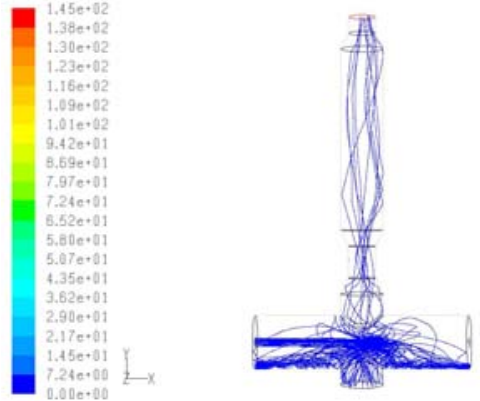

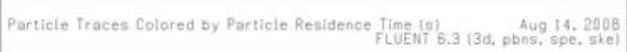

F.) SG4PS2 stage 1

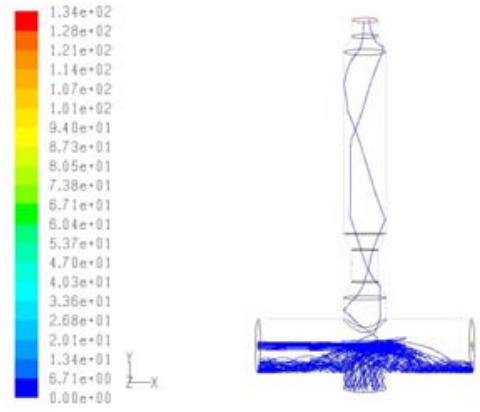

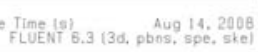

G.) SG4PS1 stage 1

Figure C.20. Case 3 particle tracks for Bailey coal for first stage injection of specific gravity cut \#4 $(\mathrm{SG}=3.3)$, for particle size cuts \#7 $(50 \mu \mathrm{m})$ through \#1 $(800 \mu \mathrm{m})$. 


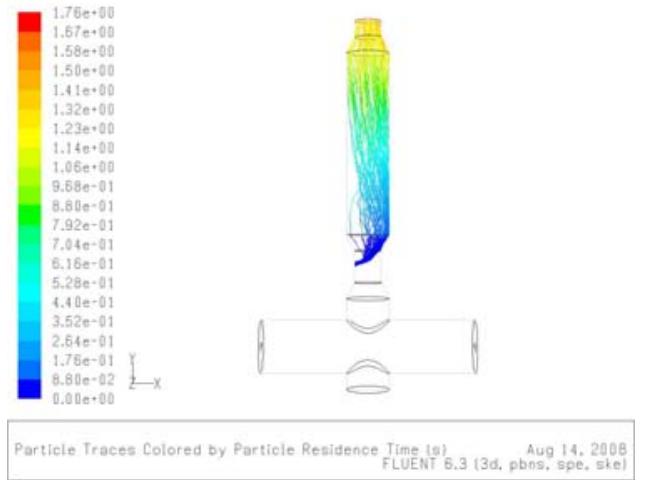

A.) SG1PS7 stage 2

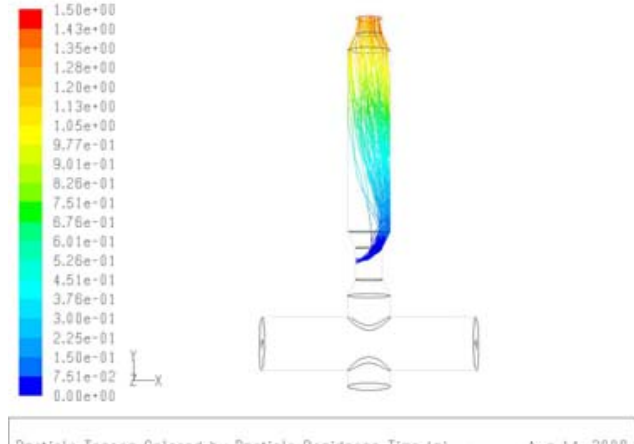

C.) SG1PS5 stage 2

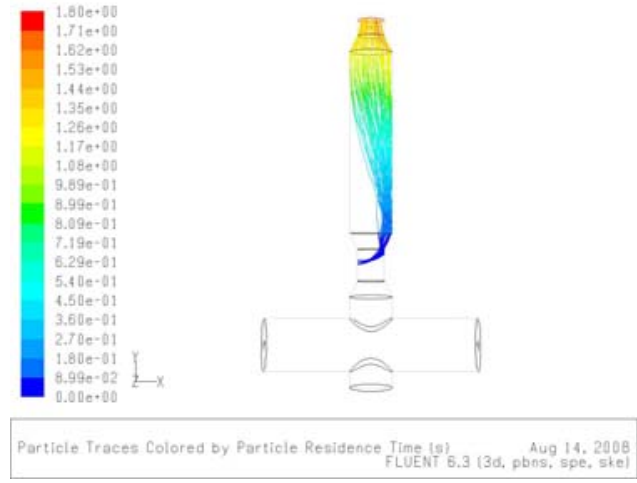

E.) SG1PS3 stage 2

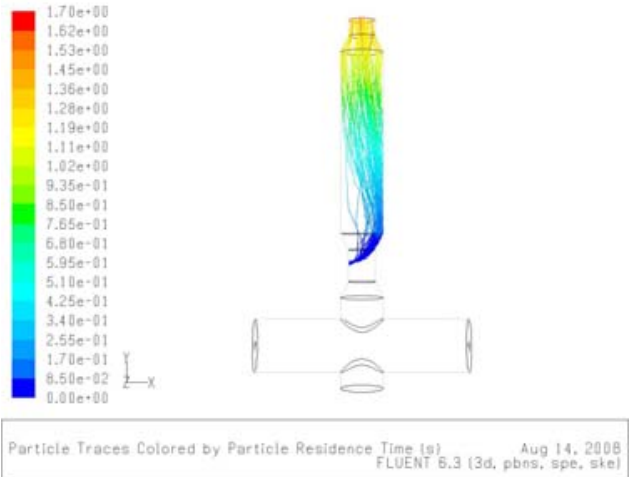

B.) SG1PS6 stage 2

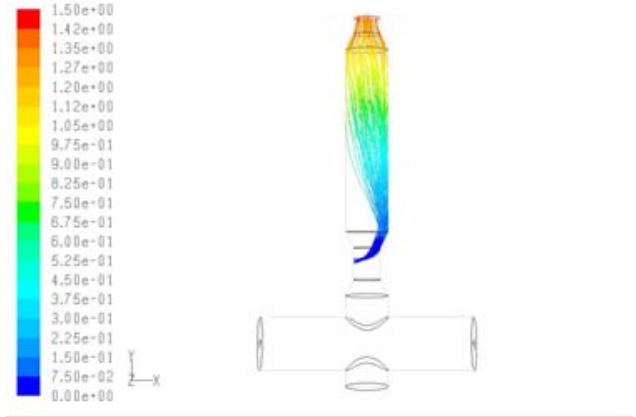

Particle Traces Colored by Particle Renidence Time, (9) FLUEN 6.3 (3d, pbing, 14, 2008

D.) SG1PS4 stage 2

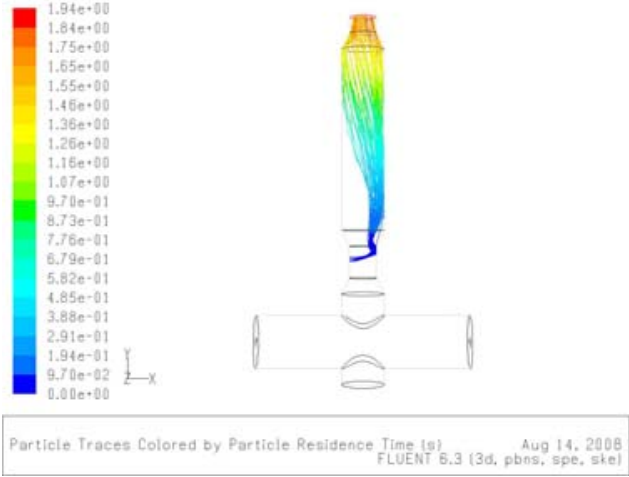

F.) SG1PS2 stage 2

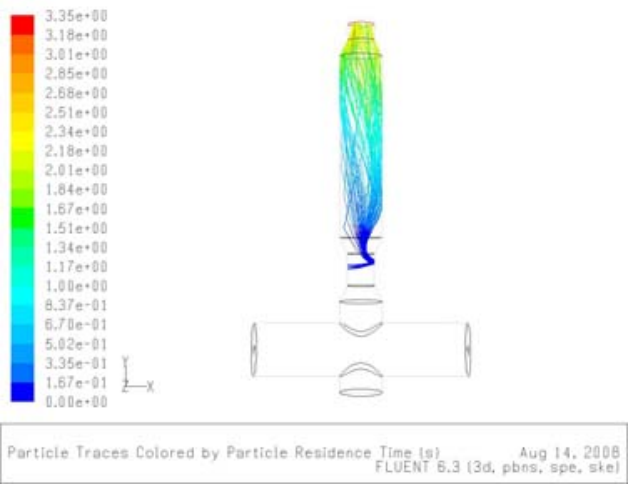

G.) SG1PS1 stage 2

Figure C.21. Case 3 particle tracks for Bailey coal for second stage injection of specific gravity cut \#1 $(\mathrm{SG}=1.2)$, for particle size cuts \#7 $(50 \mu \mathrm{m})$ through \#1 $(800 \mu \mathrm{m})$. 


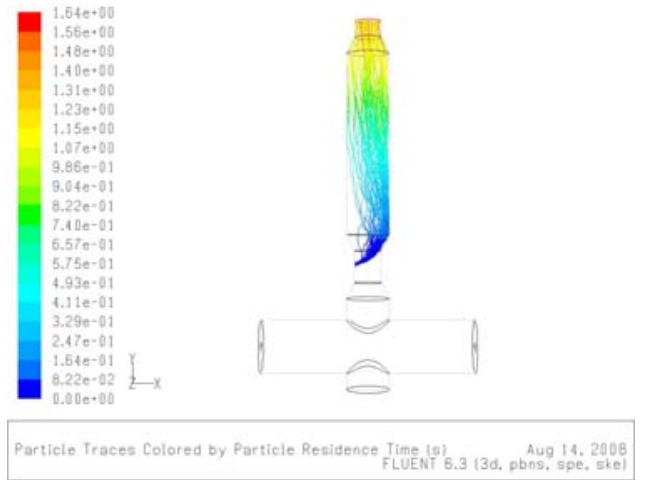

A.) SG2PS7 stage 2

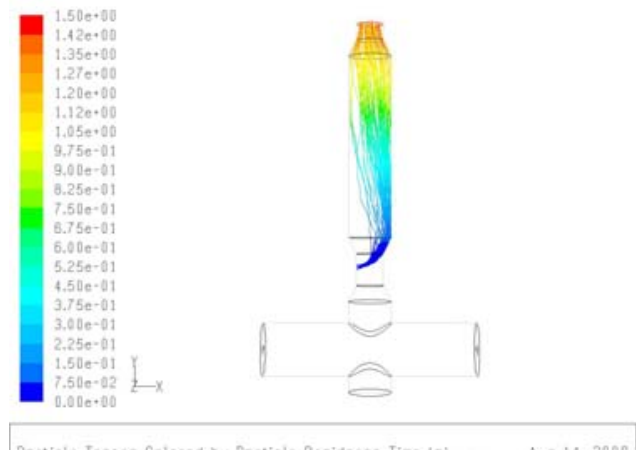

C.) SG2PS5 stage 2

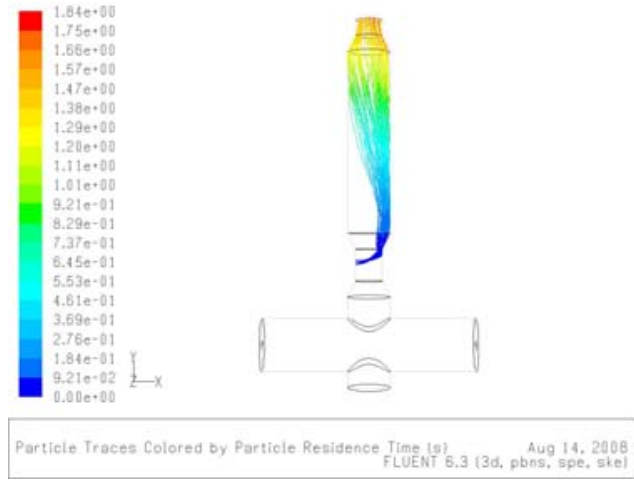

E.) SG2PS3 stage 2

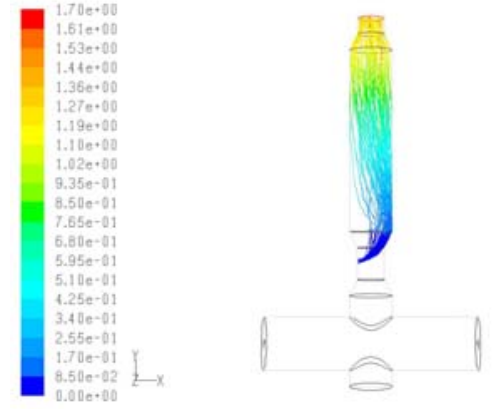

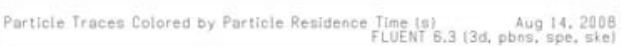

B.) SG2PS6 stage 2
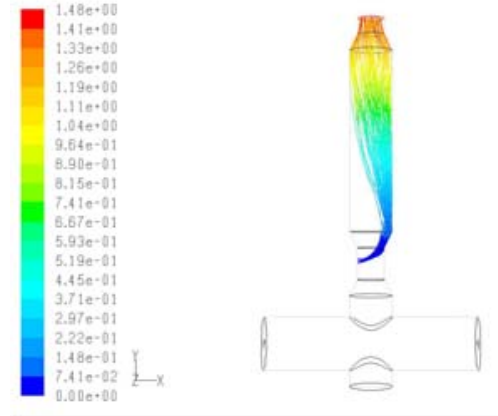

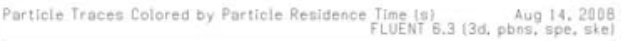

D.) SG2PS4 stage 2

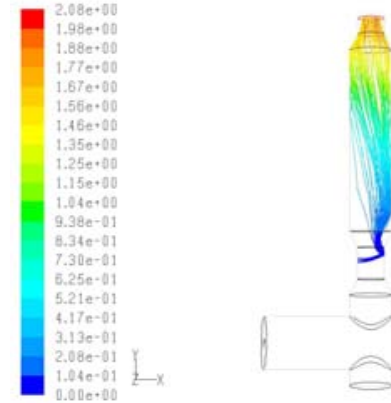

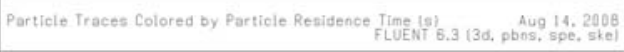

F.) SG2PS2 stage 2
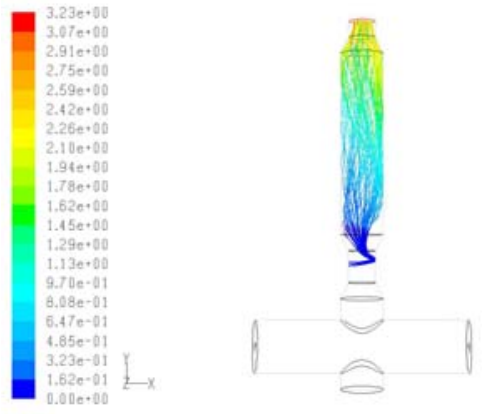

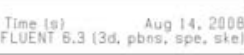

G.) SG2PS1 stage 2

Figure C.22. Case 3 particle tracks for Bailey coal for second stage injection of specific gravity cut \#2 $(\mathrm{SG}=1.4)$, for particle size cuts \#7 $(50 \mu \mathrm{m})$ through \#1 $(800 \mu \mathrm{m})$. 


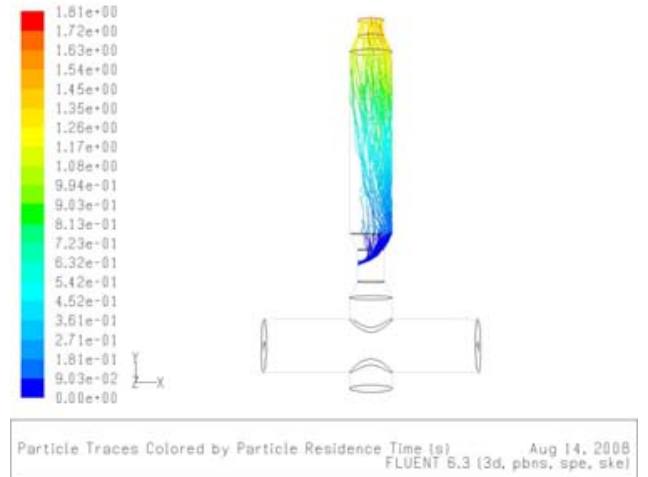

A.) SG3PS7 stage 2

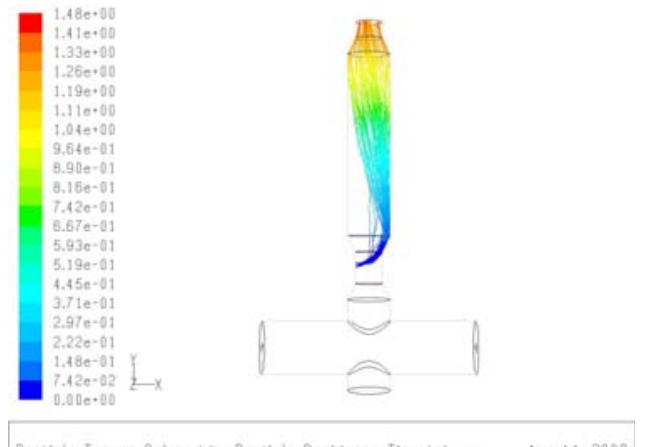

C.) SG3PS5 stage 2

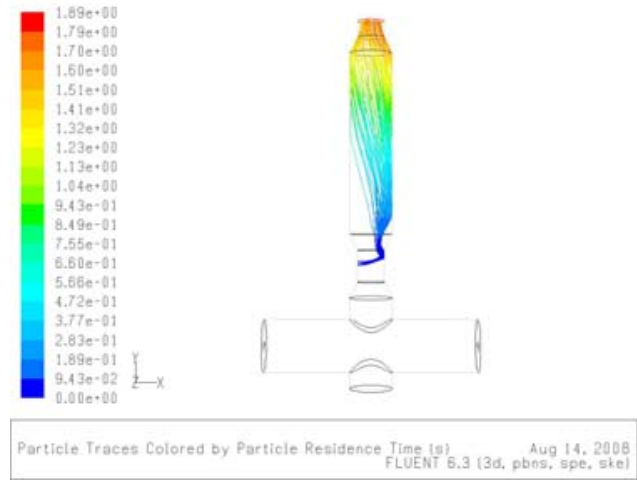

E.) SG3PS3 stage 2

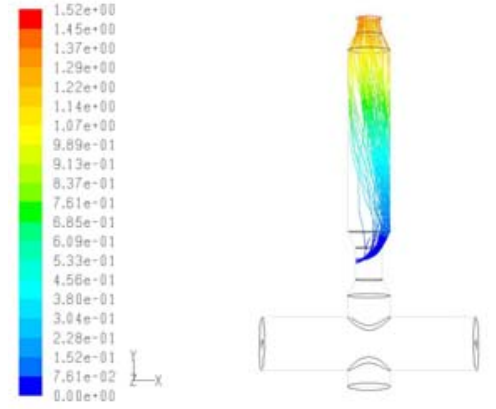

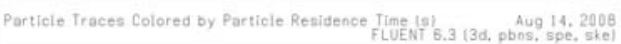

B.) SG3PS6 stage 2
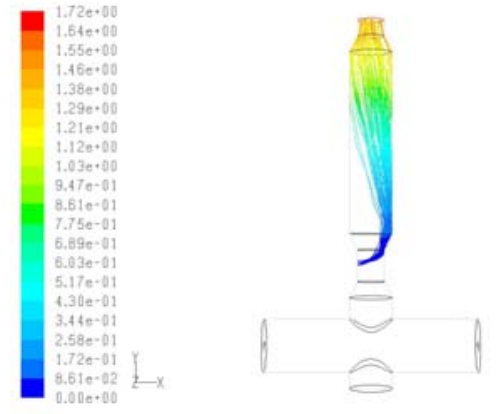

Particle Traces Colored by Particle Residence Time (s) 13.3 (3d, pbos, 14, 2008

D.) SG3PS4 stage 2

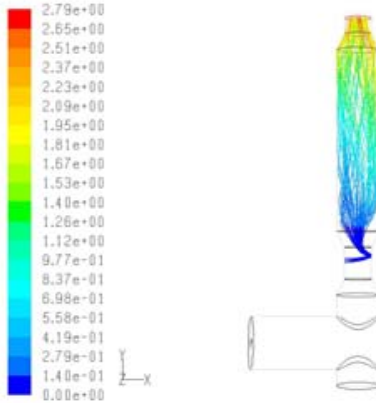

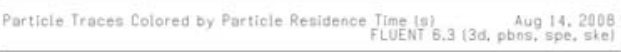

F.) SG3PS2 stage 2
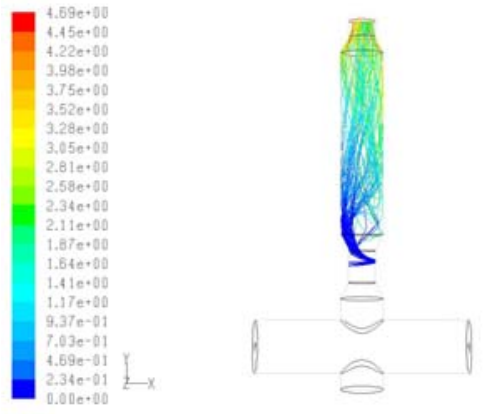

Particle Traces Colored by Particle Residence Time (s) FLUEN 6.3 (3d, pbos, spe, skel

G.) SG3PS1 stage 2

Figure C.23. Case 3 particle tracks for Bailey coal for second stage injection of specific gravity cut \#3 $(\mathrm{SG}=2.1)$, for particle size cuts \#7 $(50 \mu \mathrm{m})$ through \#1 $(800 \mu \mathrm{m})$. 


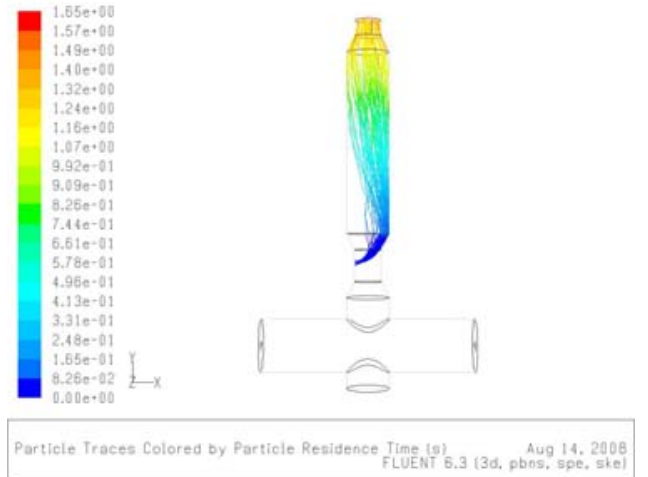

A.) SG4PS7 stage 2

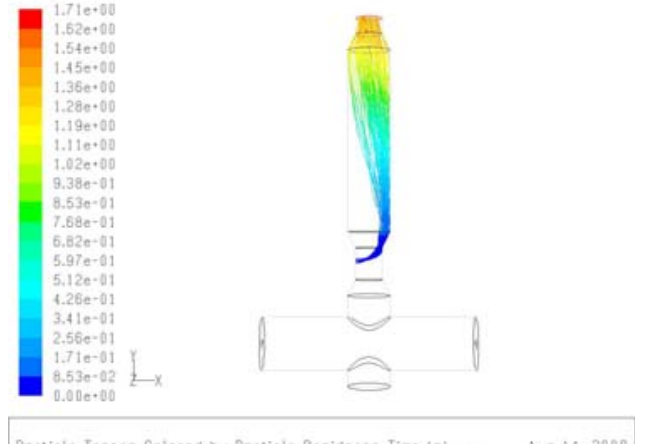

C.) SG4PS5 stage 2

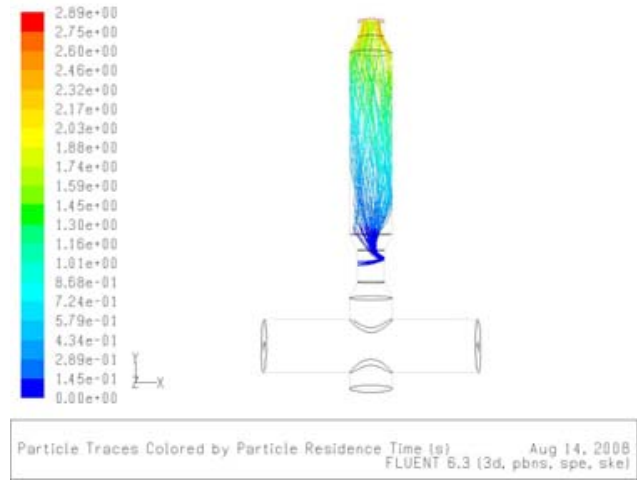

E.) SG4PS3 stage 2

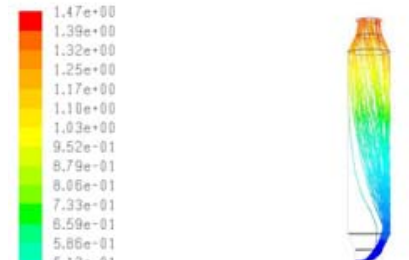

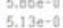

$4.40 \mathrm{e}-0.0$

$3.66 e-01$
$2.93 e-01$
$2.20 e-01$

$2.20 e-01$
$1.47 e-01$

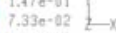

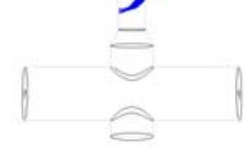

Particle Traces Colored by Particle Residence Time (5) Aug 14, 2008

B.) SG4PS6 stage 2
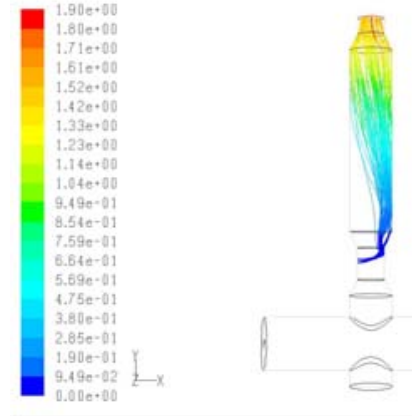

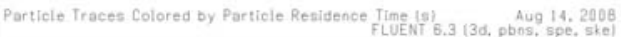

D.) SG4PS4 stage 2

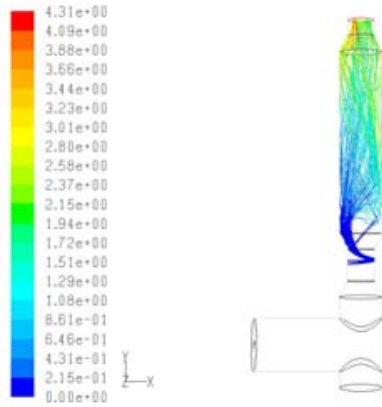

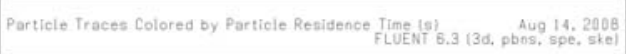

F.) SG4PS2 stage 2
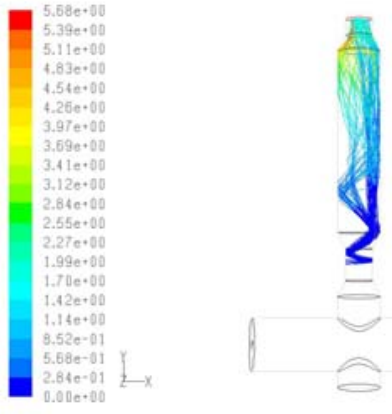

Particle Traces Colored by Particle Renidence Time (19) a 134. Aug 14, 2009

G.) SG4PS1 stage 2

Figure C.24. Case 3 particle tracks for Bailey coal for second stage injection of specific gravity cut \#4 $(\mathrm{SG}=3.3)$, for particle size cuts \#7 $(50 \mu \mathrm{m})$ through \#1 $(800 \mu \mathrm{m})$. 


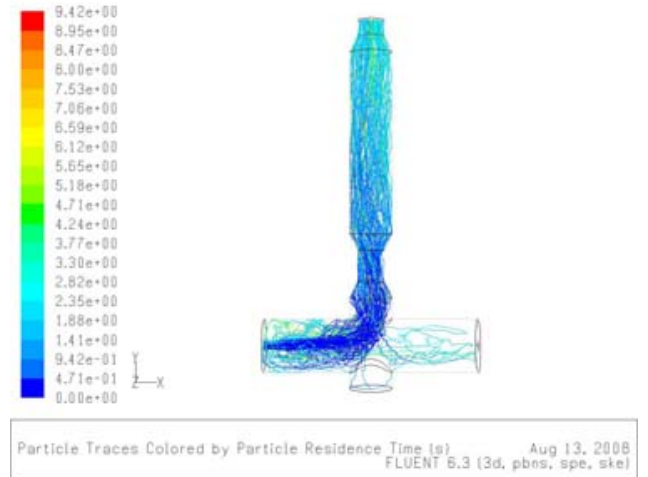

A.) SG1PS7 stage 1

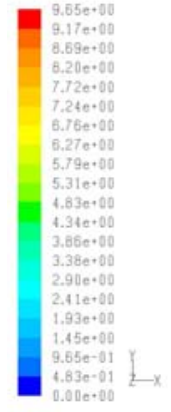

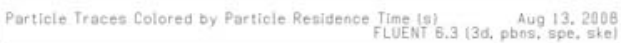

C.) SG1PS5 stage 1
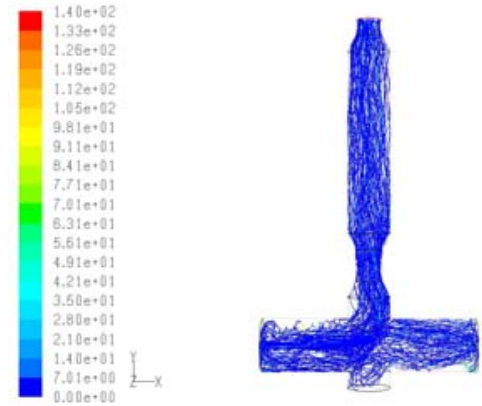

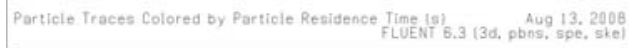

E.) SG1PS3 stage 1

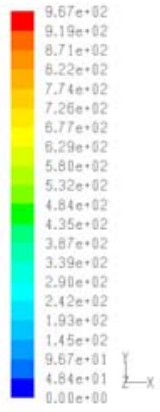

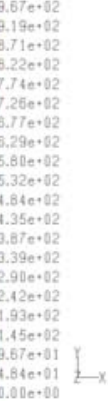

article Traces Colored by Particie Residence Time (5) . Aug 13. 2004

G.) SG1PS1 stage 1

Figure C.25. Case 4 particle tracks for Bailey coal for first stage injection of specific gravity cut \#1 $(\mathrm{SG}=1.2)$, for particle size cuts \#7 $(50 \mu \mathrm{m})$ through \#1 $(800 \mu \mathrm{m})$. 


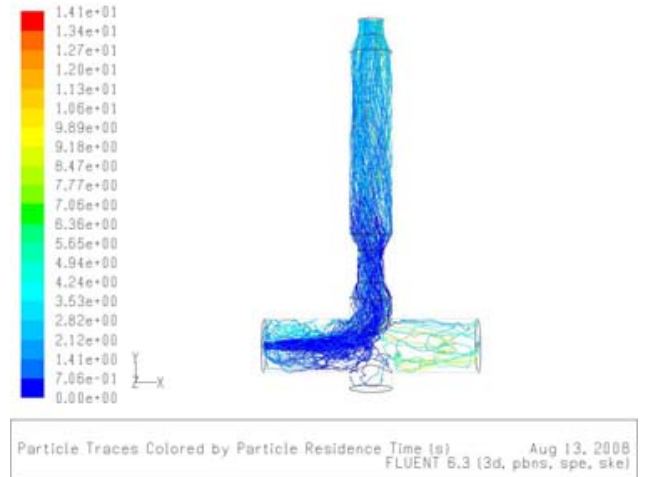

A.) SG2PS7 stage 1
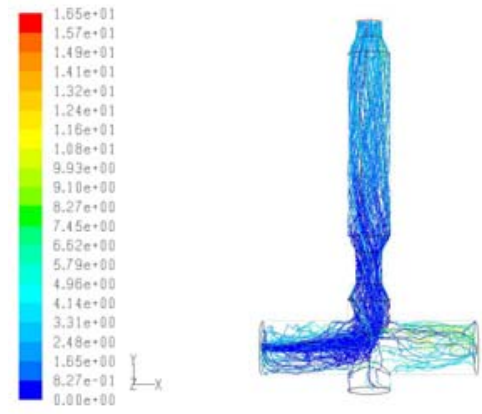

Particle Traces Colored by Particle Residence Time (s)
FLuENT 6,3 (3d, pbos, 13, spe, ske

C.) SG2PS5 stage 1
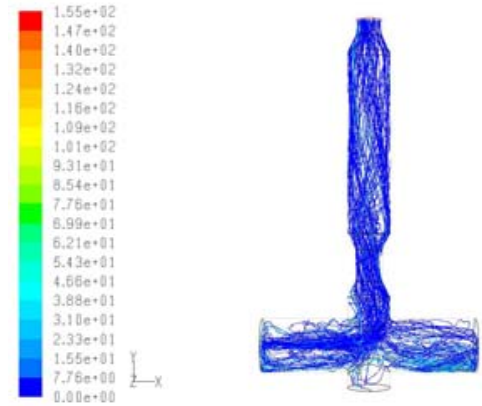

Particle Traces Colored by Particle Renidence Time Is) FLUEN 6.3 (3d, pbos, spe, ste)

E.). SG2PS3 stage 1

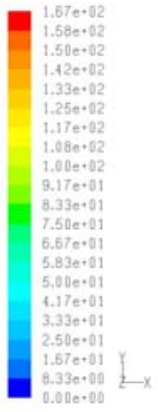

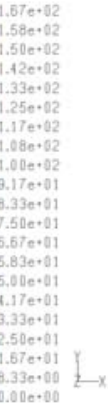

article Traces Colored by Particle Residence Time (S)

G.) SG2PS1 stage 1

Figure C.26. Case 4 particle tracks for Bailey coal for first stage injection of specific gravity cut \#2 (SG = 1.4), for particle size cuts \#7 $(50 \mu \mathrm{m})$ through \#1 $(800 \mu \mathrm{m})$. 


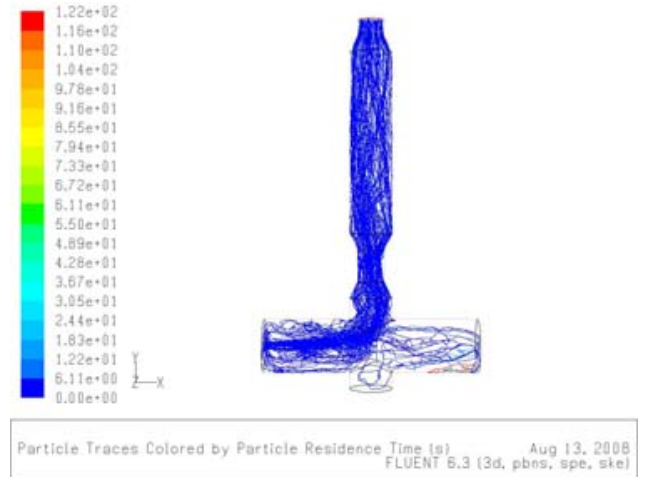

A.) SG3PS7 stage 1
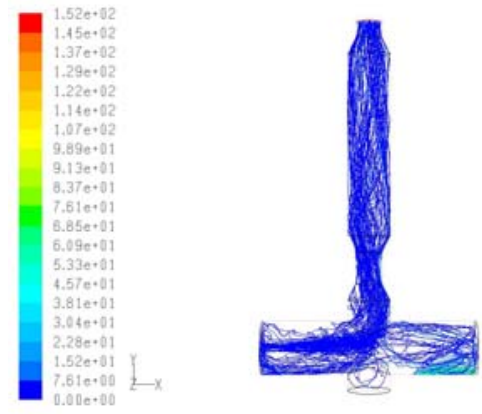

Particle Traces Colored by Particle Residence Time (s)
FLuENT 6,3 (3d, pbos, 13, spe, ske)

C.) SG3PS5 stage 1
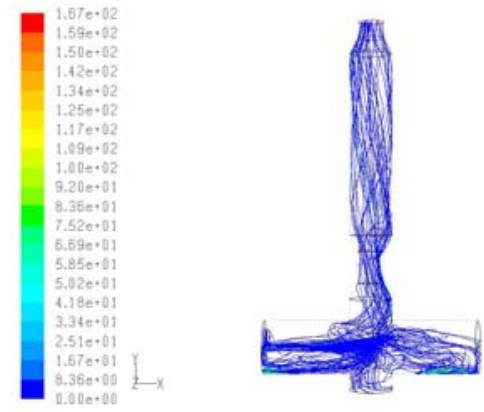

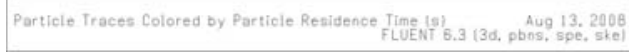

E.) SG3PS3 stage 1

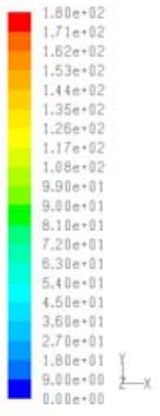

Particle Traces Colored by Particie Residence Time (s) . Aug 13. 2000

G.) SG3PS1 stage 1

Figure C.27. Case 4 particle tracks for Bailey coal for first stage injection of specific gravity cut \#3 $(\mathrm{SG}=2.1)$, for particle size cuts \#7 $(50 \mu \mathrm{m})$ through \#1 $(800 \mu \mathrm{m})$. 


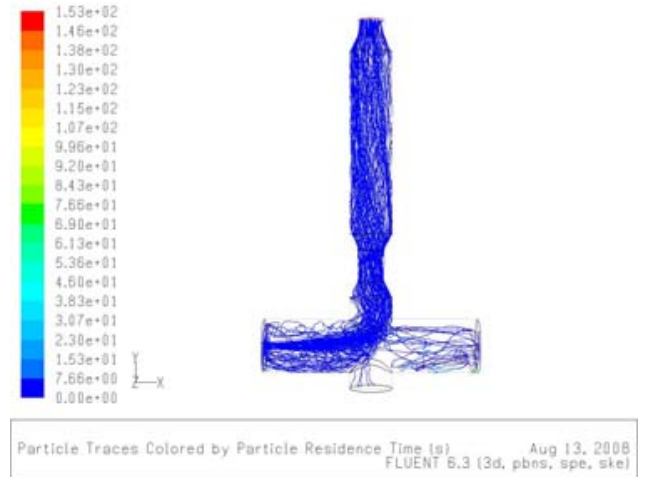

A.) SG4PS7 stage 1
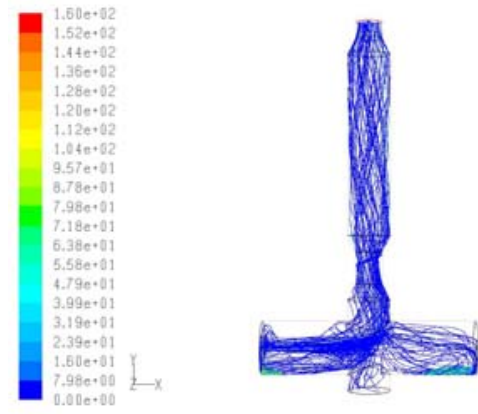

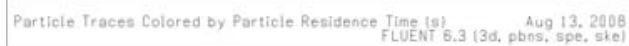

C.) SG4PS5 stage 1

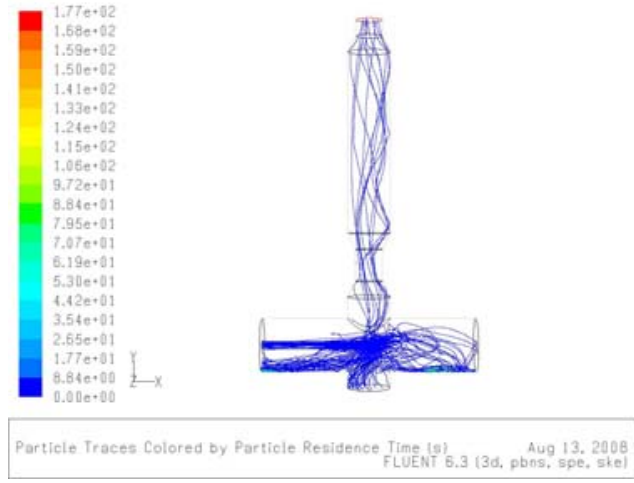

E.) SG4PS3 stage 1

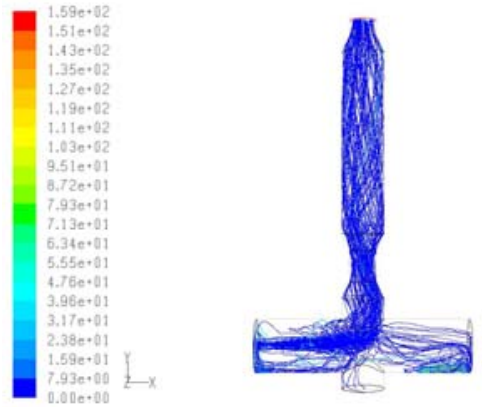

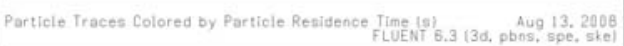

B.) SG4PS6 stage 1

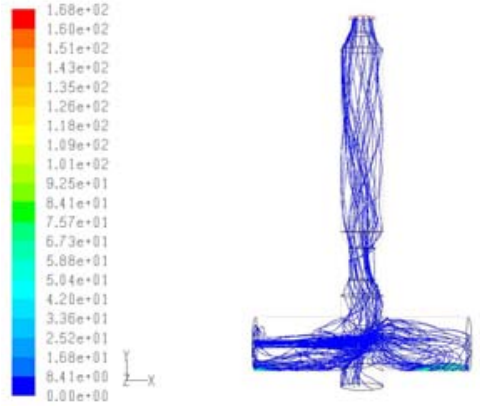

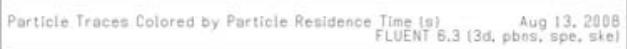

D.) SG4PS4 stage 1

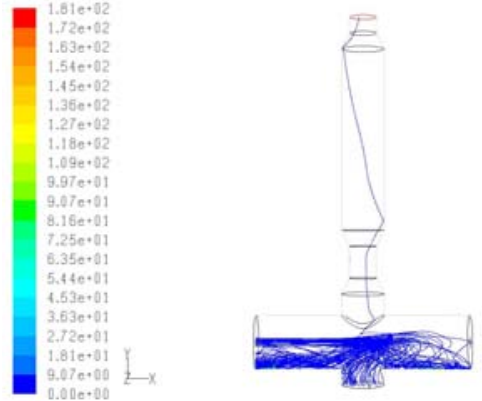

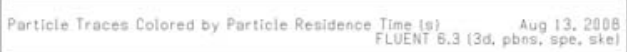

F.) SG4PS2 stage 1

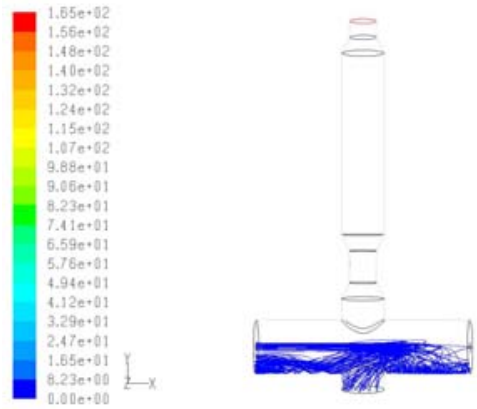

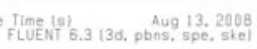

H.) SG4PS1 stage 1

Figure C.28. Case 4 particle tracks for Bailey coal for first stage injection of specific gravity cut \#4 $(\mathrm{SG}=3.3)$, for particle size cuts \#7 $(50 \mu \mathrm{m})$ through \#1 $(800 \mu \mathrm{m})$. 


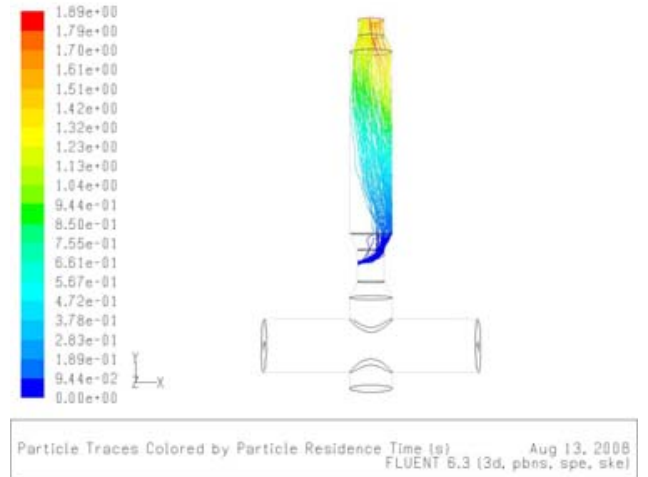

A.) SG1PS7 stage 2

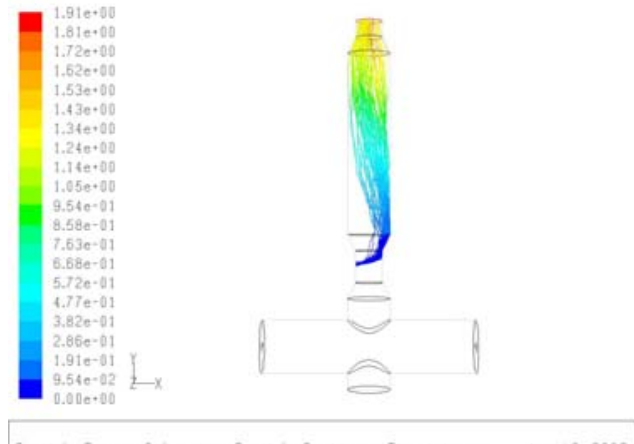

C.) SG1PS5 stage 2

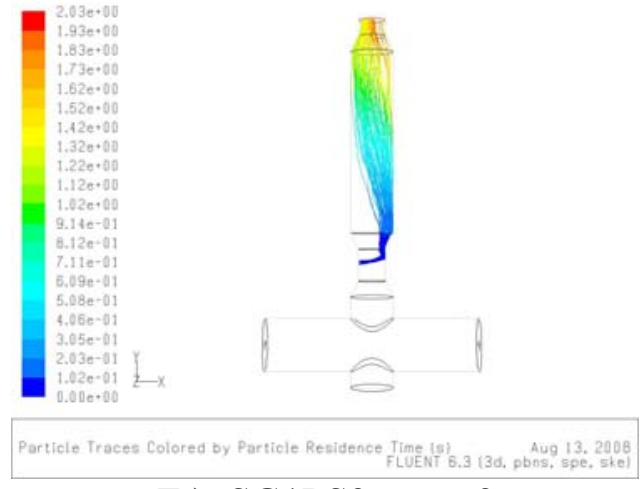

E.) SG1PS3 stage 2

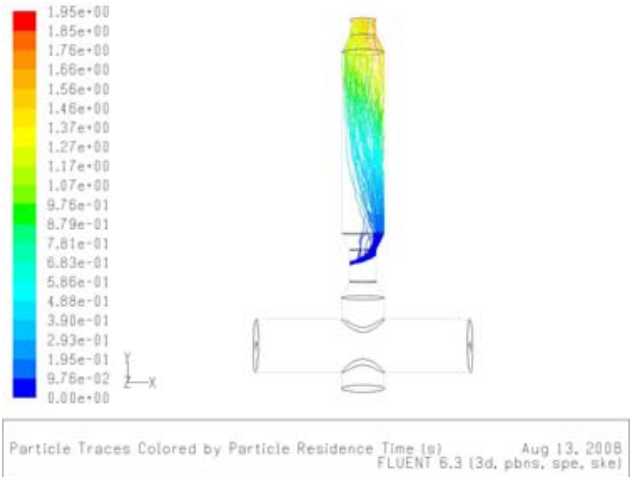

B.) SG1PS6 stage 2

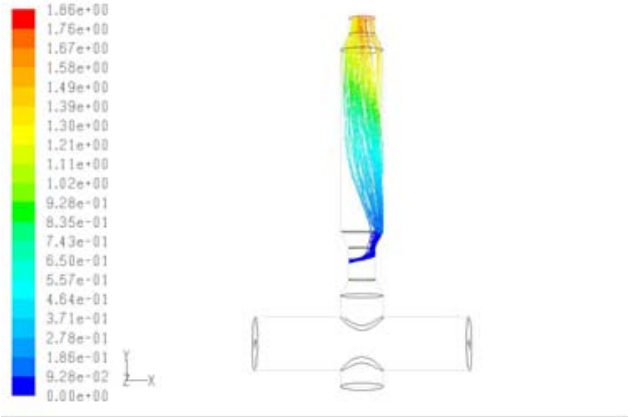

Particle Traces Colored by Particle Reaidence Time Is) FLUENT 6.3 (3d, pbns, spe, ske)

D.) SG1PS4 stage 2

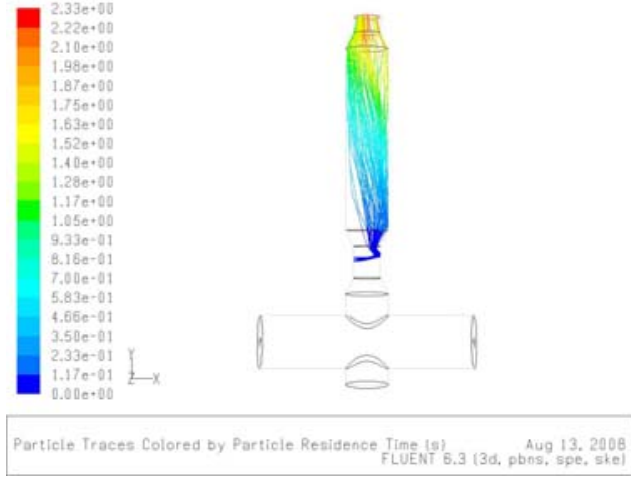

F.) SG1PS2 stage 2

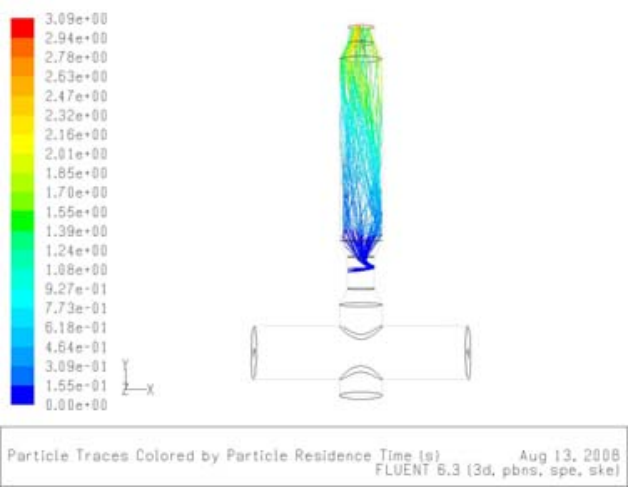

G.) SG1PS1 stage 2

Figure C.29. Case 4 particle tracks for Bailey coal for second stage injection of specific gravity cut \#1 $(\mathrm{SG}=1.2)$, for particle size cuts \#7 $(50 \mu \mathrm{m})$ through \#1 $(800 \mu \mathrm{m})$. 


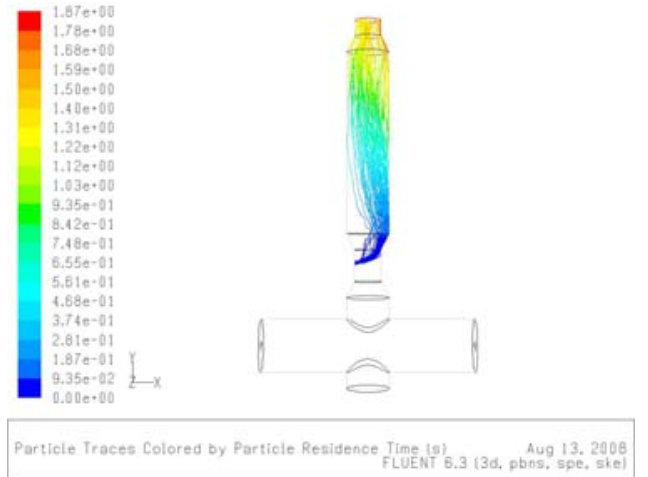

A.) SG2PS7 stage 2

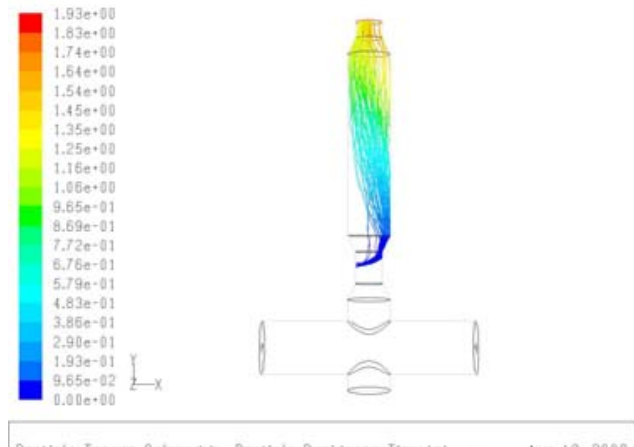

C.) SG2PS5 stage 2

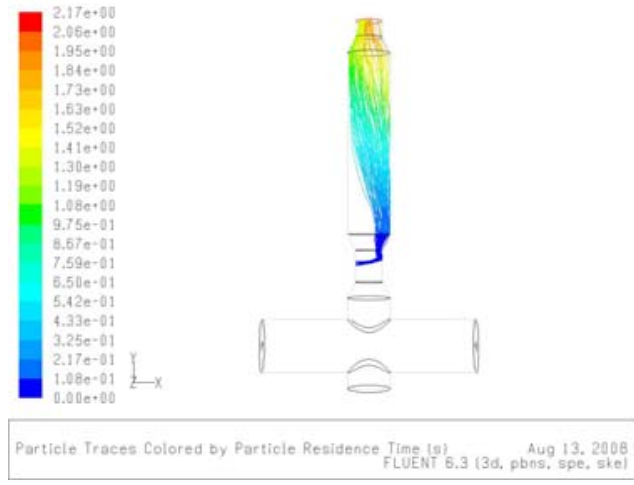

E.) SG2PS3 stage 2

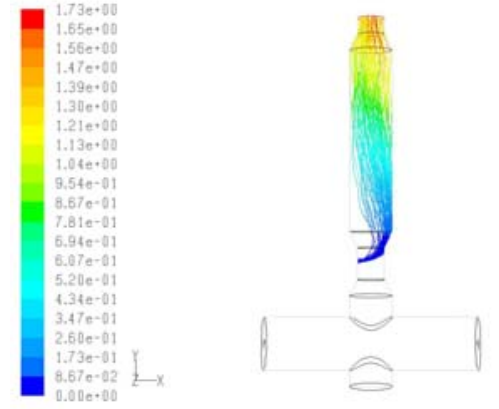

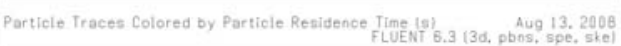

B.) SG2PS6 stage 2

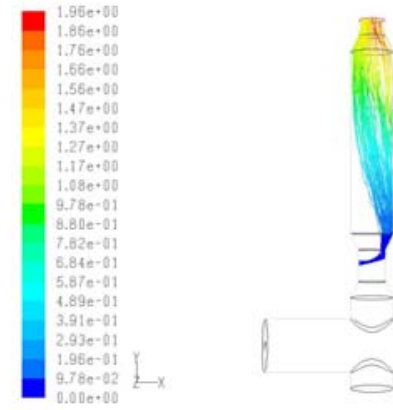

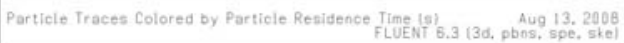

D.) SG2PS4 stage 2
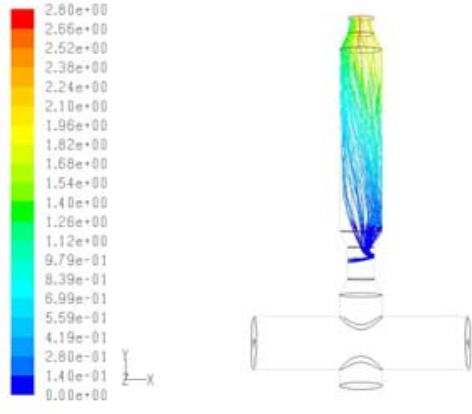

Particle Traces Colored by Particle Residence Time is) FLUET' 6.3 (3d, pbos, 13pe, ske)

F.) SG2PS2 stage 2
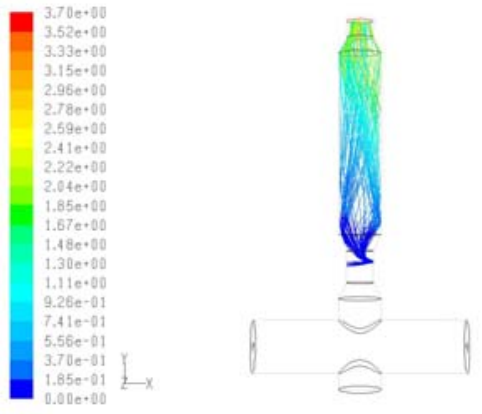

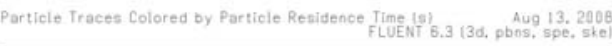

G.) SG2PS1 stage 2

Figure C.30. Case 4 particle tracks for Bailey coal for second stage injection of specific gravity cut \#2 $(\mathrm{SG}=1.4)$, for particle size cuts \#7 $(50 \mu \mathrm{m})$ through \#1 $(800 \mu \mathrm{m})$. 


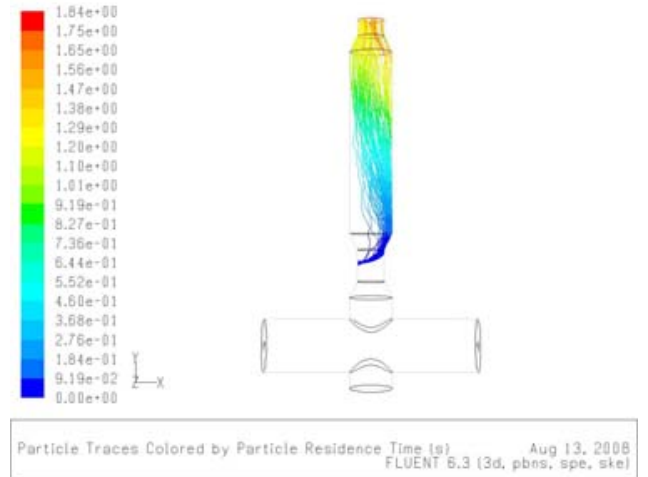

A.) SG3PS7 stage 2

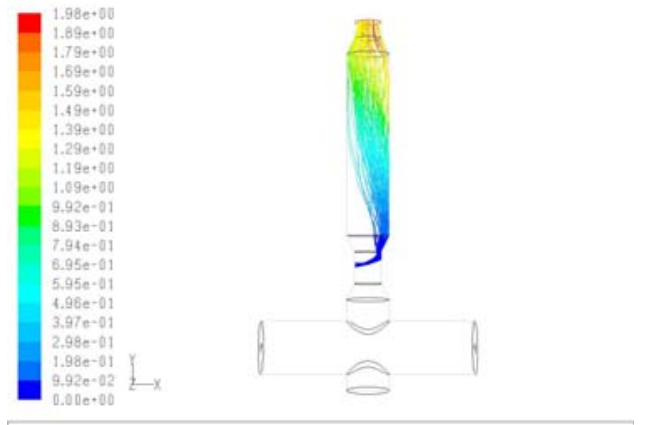

Particle Traces Colored by Particle Residence Time, (s)
FLUENT 6,3 (3d, pbos, 13, spe, ske)

C.) SG3PS5 stage 2

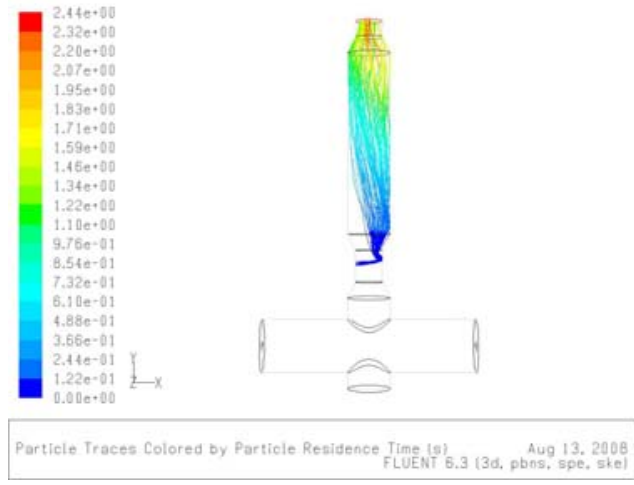

E.) SG3PS3 stage 2

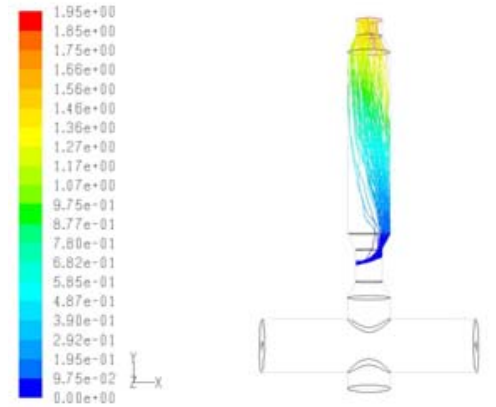

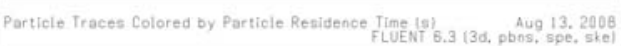

B.) SG3PS6 stage 2
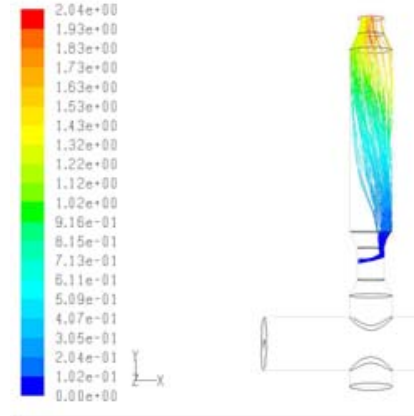

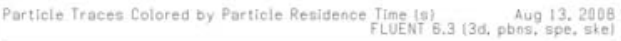

D.) SG3PS4 stage 2

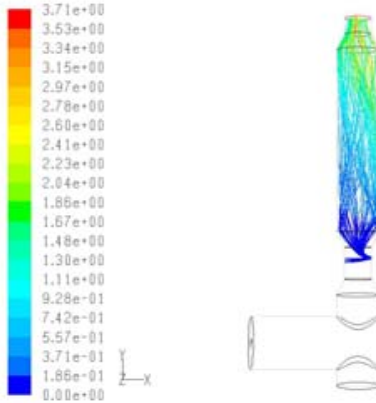

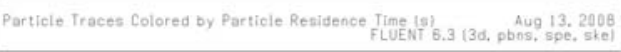

F.) SG3PS2 stage 2
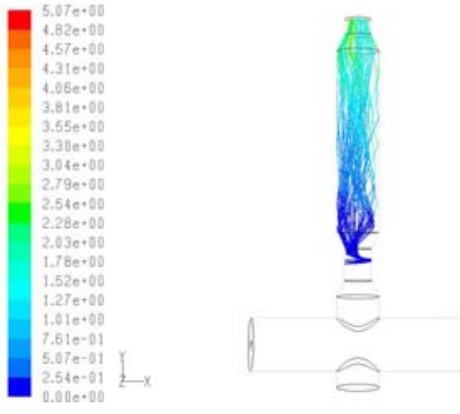

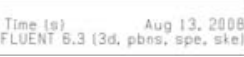

G.) SG3PS1 stage 2

Figure C.31. Case 4 particle tracks for Bailey coal for second stage injection of specific gravity cut \#3 ( $\mathrm{SG}=2.1)$, for particle size cuts \#7 $(50 \mu \mathrm{m})$ through \#1 $(800 \mu \mathrm{m})$. 


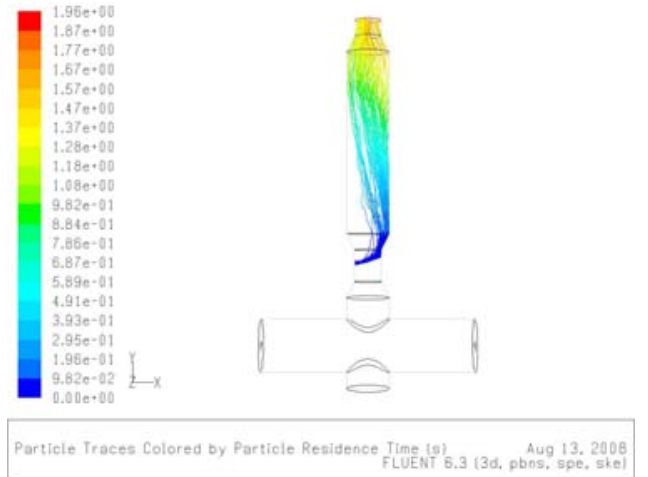

A.) SG4PS7 stage 2

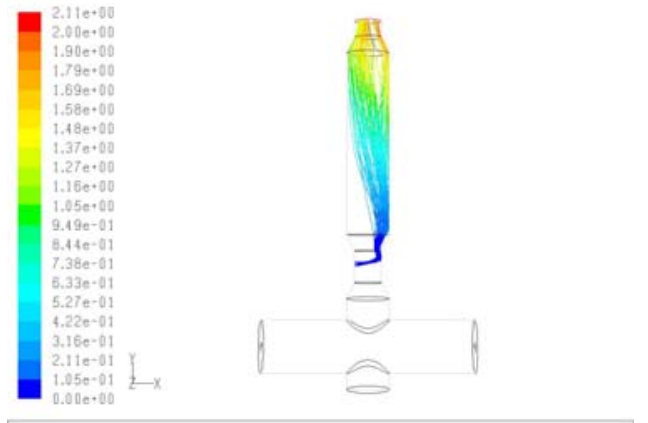

Particle Traces Colored by Particle Residence Time, (s) $\begin{array}{r}\text { Aug 13, } 2008 \\ \text { FLUENT } 6,3 \text { (3d, pbns, spe, ske) }\end{array}$

C.) SG4PS5 stage 2

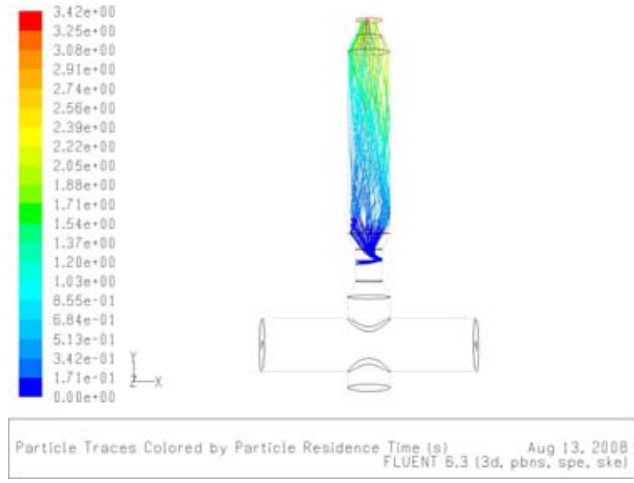

E.) SG4PS3 stage 2

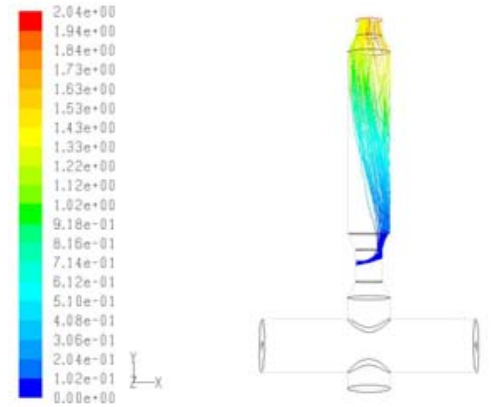

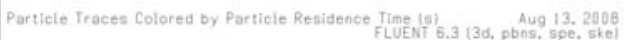

B.) SG4PS6 stage 2
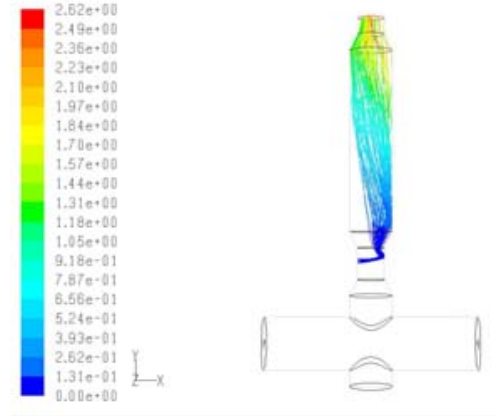

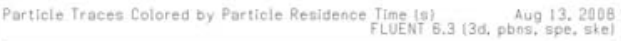

D.) SG4PS4 stage 2

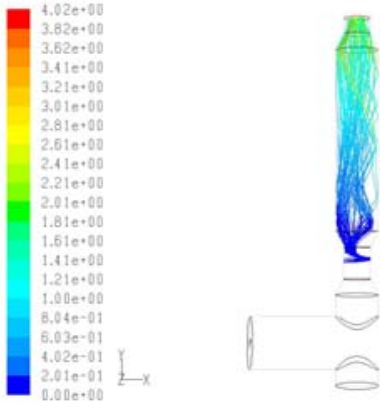

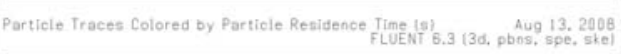

F.) SG4PS2 stage 2
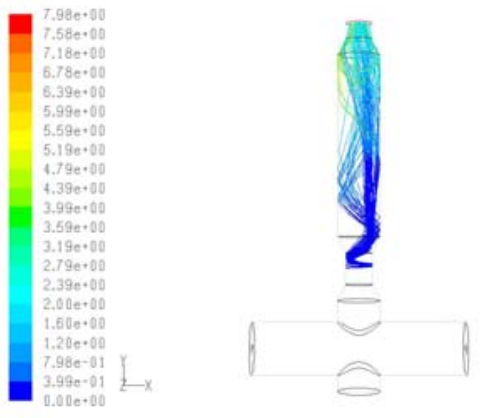

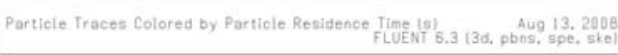

G.) SG4PS1 stage 2

Figure C.32. Case 2 particle tracks for Bailey coal for second stage injection of specific gravity cut \#4 $(\mathrm{SG}=3.3)$, for particle size cuts $\# 7(50 \mu \mathrm{m})$ through \#1 $(800 \mu \mathrm{m})$. 